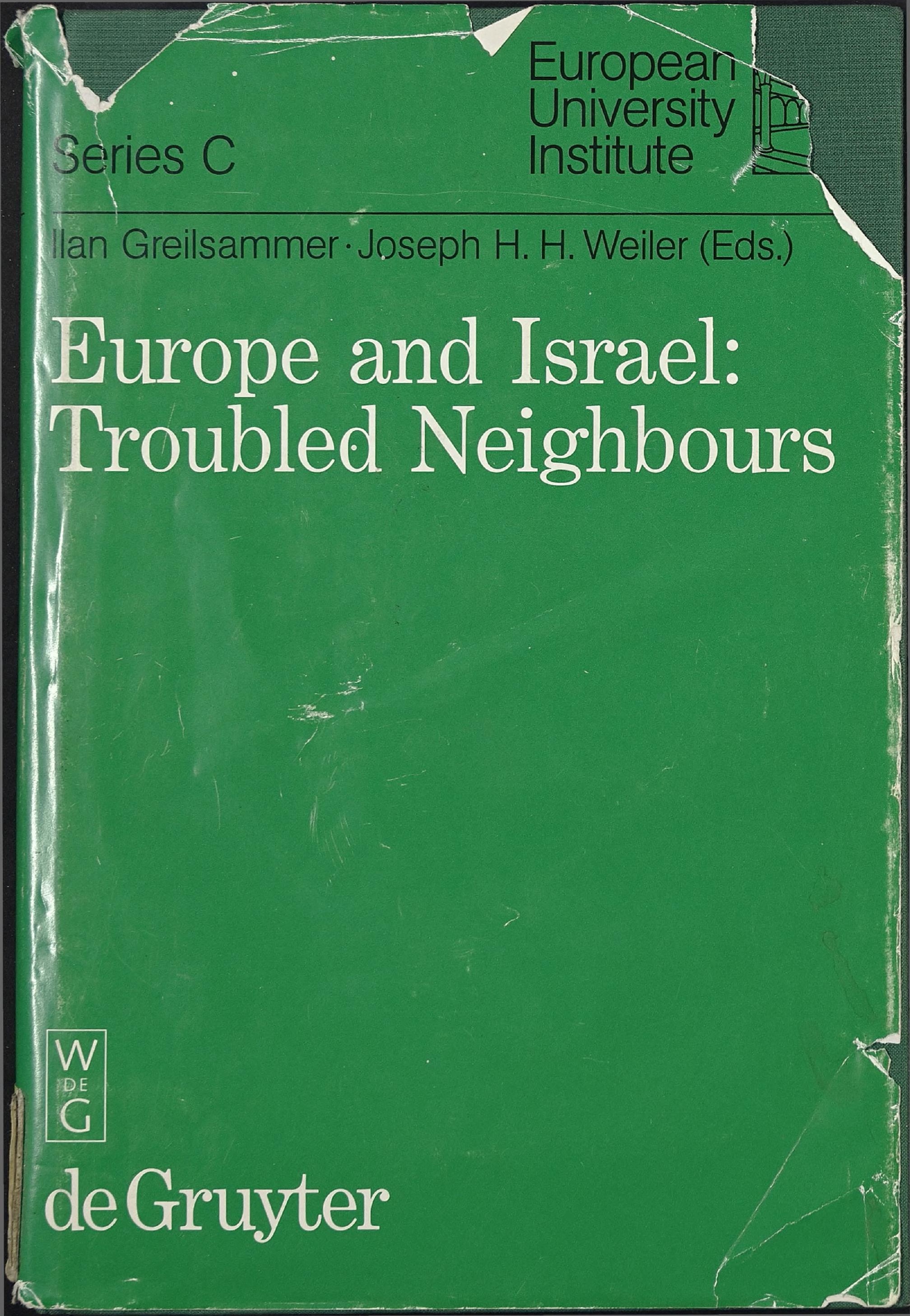


EUI - BIB 
327405694 

EUI - Series C - 9

Greilsammer/Weiler (Eds.),

Europe and Israel: Troubled Neighbours 
European University Institute Institut Universitaire Européen Europäisches Hochschulinstitut Istituto Universitario Europeo

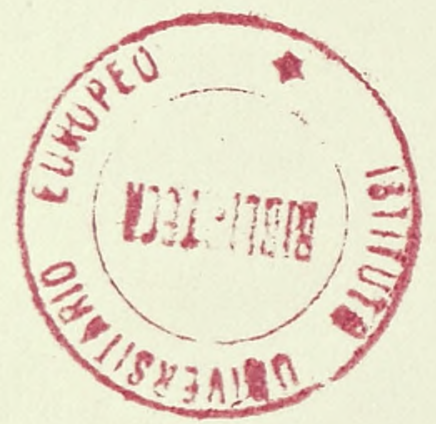

Series C

Political and Social Sciences

Sciences Politiques et Sociales

Politik- und Sozialwissenschaften

Scienze Politiche e Sociali

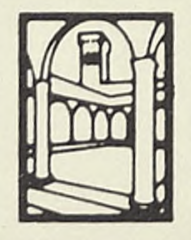

Badia Fiesolana - Firenze 


\title{
Europe and Israel: Troubled Neighbours
}

\author{
Edited by
}

Ilan Greilsammer and Joseph H. H. Weiler

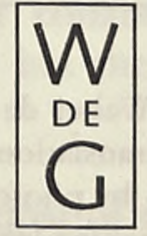

1988

Walter de Gruyter · Berlin · New York 
Europe and Israel : troubled neighbours / edited by Ilan Greilsammer and Joseph H. H. Weiler.

X, 354 p. $15,5 \times 23 \mathrm{~cm}$.-- (Series C--Political and social sciences / European University Institute $=$ Series $\mathrm{C}$--Sciences politiques et sociales / Institut universitaire européen ; 9)

Chiefly revisions of papers presented at an international conference in Ramat-Gan, Israel, organized by the Dept. of Political Science of Bar-Ilan University and the European Policy Unit of the European University Institute, Florence.

Includes index.

ISBN 0-89925-369-5 (U.S.) : $\$ 82.00$ (est.)

1. Europe--Foreign relations--Israel. 2. Israel--Foreign relations--Europe. 3. Europe--Foreign relations--1945-

Greilsammer, Alain, 1948- . II. Weiler, Joseph, $1951-$

III. Universițat Bar-Ilan. Mahlakah le-mada e ha-medinah. IV. European University Institute. European Policy Unit. V. Series: Series C--Political and social sciences ; 9.

D1065.I75E97 1987

87-28404

327.405694--dc 19

\section{CIP-Titelaufnabme der Deutschen Bibliothek}

Europe and Israel: troubled neighbours / ed. by Ilan Greilsammer and Joseph H. H. Weiler. - Berlin ; New York : de Gruyter, 1988

(European University Institute : Ser. C, Political and social sciences ; 9)

ISBN 3-11-009713-3

NE: Greilsammer, Ilan [Hrsg.]; Istituto Universitario Europeo

$\langle$ Fiesole : European University Institute / C

(C) Copyright 1987 by Walter de Gruyter \& Co., Berlin.

All rights reserved, including those of translation into foreign languages. No part of this book may be reproduced in any form - by photoprint, microfilm, or any other means nor transmitted nor translated into a machine language without written permission from the publisher.

Dust Cover Design: Rudolf Hübler, Berlin. - Setting: Arthur Collignon GmbH, Berlin. Printing: K. Gerike, Berlin.

Binding: Verlagsbuchbinderei Dieter Mikolai, Berlin. Printed in Germany. 


\section{Foreword}

With the entry of Greece, Spain and Portugal, the European Community has acquired a more political and cultural character, strengthening the dynamics of its transformation from a simple economic community to a full political union. But with this recent southern enlargement the European Community has also become a truly Mediterranean Community, encompassing almost all the nations on the northern border of this ancient region of "naissance" and "renaissance" of Europe.

These new frontiers of the European Community will charge not only the Mediterranean Member States but also the Community as a whole with new responsibilities for the peaceful development of good neighbourship among all the states bordering on this conflictuals area. The transformation of the European Community within the next few years into a real common market not only for agriculture but also for industry will further intensify the structural problems inherent in the EC's relations with its Mediterranean neighbours from Marocco to Turkey.

Aware of the increasing challenge that these Mediterranean responsibilities represent for the European Community, the European University Institute at Florence in recent years has begun to engage in policy oriented studies on the Miditerranean perspectives of the European Community. It was in this context that in 1984 Professor Weiler, then Director of our European Policy Unit, and Professor Greilsammer of Bar-Ilan University, proposed the organization of a conference, to be co-sponsored by the European University Institute and Bar-Ilan University, to analyse "the Relations between the European Community and the State of Israel in their Economic, Political and Juridical Aspects". Professors Greilsammer and Weiler are to be congratulated on this joint initiative which not only gave rise to the conference which was held in Bar-Ilan in May 1984 and whose proceedings are published in this volume, but which also presented the opportunity for an institutional collaboration with our Mediterranean neighbours which I hope will be but the first of many.

Florence, 1987

Werner Maibofer

Principal of the European University Institute 



\title{
Preface
}

In 1984 the first international conference on the relations between the European Community and the State of Israel took place at Bar-Ilan University. The conference, which was attended by more than 100 scholars from Western Europe and Israel in the fields of political science, law and economics, was successful on two levels. In the first place, it emphasized the need for a strong relationship between the Jewish State and Europe: Western Europe constitutes one of the main poles of attraction for the Israeli political system and economy, and developments in European democratic systems have always been eagerly followed by Israelis who find therein a source of inspiration. In addition, the last thirty years have seen a steady expansion of commercial and technological links between Israel and the Common Market; it is appropriate to remember that Israel was one of the very first countries in the world to apply for a special status within the framework of European Community trade links. The Bar-Ilan Conference set out to assess the progress achieved in these relations and to try to evaluate the potential of present and future developments. We at Bar-Ilan hope that this volume, which includes most of the papers which were presented at the Conference, will contribute towards enhancing this relationship.

On a second level, the Conference, which was organized jointly by Bar-Ilan University and the European University Institute, was a highly successful experiment in cooperation between academic centers in Israel and Europe. In view of Bar-Ilan's continuing interest in and commitment to Western European studies, we certaintly hope that this cooperation will continue and be reinforced in the years to come, and that this book will help to strengthen academic links with our Western European colleagues.

\author{
Professor Ernest Krausz \\ Rector of Bar-Ilan University
}




\section{Acknowledgements}

The Editors would like to thank warmly the following for their help in realizing this projekt:

The Schnitzer Foundation for Research on the Israeli Economy and Society for financial help in all phases of the project.

The European Economic Community, The University of Bar Ilan and the European University Institute for material and infrastructural support in the organization of the conference and eventual publication of this volume. Special thanks also go to Mr. Jack Morris for valuable editorial assistance and to Ms. Brigitte Schwab, Publications Officer of the European University Institute for midwifing this complex interdisciplinary book. 


\section{Table of Contents}

Foreword ...................

Preface ................... VII

Acknowledgements . . . . . . . . . . . . . VIII

Ilan Greilsammer and Joseph H. H. Weiler

Europe and Israel: Troubled Neighbours - An Introduction . . . . 1

\section{Part One \\ Mutual Perceptions}

FrançOIs DuchêNe

Israel in the Eyes of Europeans: A Speculative Essay . . . . . . . 11

SHLOMo Avineri

Europe in the Eyes of Israelis: The Memory of Europe as Heritage

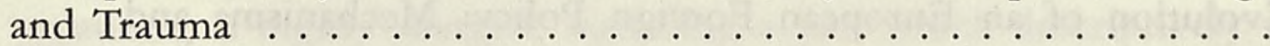

\section{Part Two \\ The Economic Dimension}

WOLFGANG Hager

The Community as Israel's Trading Partner: A Look at the Future

Richard Pomfret

Main Economic Trends in EC-Israel Economic Relations Since the Creation of the Common Market . . . . . . . . . . . . . . .

Yochanan Shachmurove

The Integration of the Israeli Economy into the E.E.C.: Recent Trends and a Forecast $\ldots \ldots \ldots \ldots \ldots \ldots \ldots$

BEnNy Toren

The Impact of the FTA Agreement with the E.E.C. on Israeli Industry: A Follow-up . . . . . . . . . . . . . .

Jacques Silber and Zeev M. Berrebi

The 1975 Free Trade Agreement and its Impact on Israeli Exports to the E.E.C. 


\section{Part Three}

The Second Enlargement of the EEC: Effect on Euro-Israel Relations

Franceso Granell

Spain and the Enlargement of the EEC . . . . . . . . . . 159

Alfred Tovias

The Impact of the Second Enlargement of the EC upon Israel's Balance of Payments . . . . . . . . . . . . . . 173

Rolf J. LANGHAMmer

The EEC Trade Policies in Manufactures, the Mediterranean Market. Access Problems and Israel - Implications of the Second Enlargement

\section{Part Four}

The Institutional Dimension of EEC Israel Relations

Claus Dieter Ehlermann

The Institutional Context of EEC-Israel Economic Relations . . . .

\section{Part Five \\ The Political Dimension}

Joseph H. H. WeILER

The Evolution of an European Foreign Policy: Mechanisms and

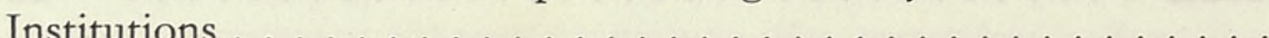

Alain Dieckhoff

Europe and the Arab World: The Difficult Dialogue . . . . . . .

ILAN GREILSAMMER

Reflections on the Capability of the European Community to Play an Active Role in an International Crisis: The Case of the Israeli Action in Lebanon . . . . . . . . . . . . . . . . . . .

Beate LindemanN

Votes of EC Members at the United Nations on Questions Related to Israel . . . . . . . . . . . . . . . . . . . . . . . 303

Noemi GaL-Or

Suppressing Terrorism: Problems of European-Israel Cooperation

Gerald M. Steinberg

The Links Between Israel and the European Community 


\title{
Europe and Israel: Troubled Neighbours
}

\author{
An Introduction
}

Ilan Greilsammer and Joseph H. H. Weiler

There is probably no such thing as "normal" foreign relations between two international actors. Historical factors, economic dependencies and power allegiances apart from the political contingencies of the hour will all contribute in one.way or another to particularize any given international relationship.

The relationship between the European Community and the State of Israel exemplifies this fact, making it particularly complex for the actors and challengingly opaque to the observer and commentator.

The very term "normalization" in the context of current Euro-Israel relations, is highly charged, signalling a past which descriptively was not "normal" and a normative clash in society at large, between public opinion makers and decision takers in the two respective polities about the future of the relations.

In this introduction it is not our purpose to analyse the Euro-Israel relationship in depth. This, after all, will be done in the body of the book. Instead, we propose to glimpse at some of the factors which contribute to the complexity, impede analysis and in effect render the relationship troubled.

The most fascinating of all dimensions is the socio-psychological one even if it is only the remote backdrop against which foreign policy is made.

It is almost banal to mention the Holocaust; it is not a tangible factor in today's foreign policy making. But it is omnipresent in any Euro-Israel encounter at all echelons. In some ways it has become virtually bad manners, even in Israel, to make direct reference to that cataclysmic tragedy when discussing and conducting foreign policy (except perhaps when electoral votes are to be gained). But silence also has a way of registering an impact and no analysis of European-Israeli relations can avoid investigating the current meaning of the Holocaust. Whether one wants it or not, the relationship has a moral dimension - almost a dirty word in foreign policy. If nothing else, the level of public awareness in, say, Europe of the broad issues concerning Israel is relatively high and creates a constraint on policy making which is not altogether common in relation to other issues of foreign policy. 
In Israel the legacy of the Holocaust has created a certain mistrust on the part of many Israelis. Moreover, there is a sense in which Europe is perceived as owing a "moral debt" to Israel. Normalization for many Israelis is an anormal situation. Israel, in this not uncommon attitude, "deserves" a privileged position. It is not surprising that certain circles - including government circles - condemned the Venice Declaration by terming it a "New Munich": Fifty year old memories remain very fresh.

What is instructive in this societal view is how much the European view matters. At one level, Israel and the Israelis have turned their back on Europe; Perfidious Albion is a notion that may extend now to other European States. Politically, Israel's view extends beyond the Atlantic to America. But then, in many ways Israeli attitudes to America replicate European attitudes - a mixture of admiration and contempt bred by a sense of cultural superiority.

It has become apparent that one cannot dismantle the intertwined JewishEuropean history. Although one can doubt whether there had ever been a true Jewish-European symbiosis, the mark of Jews (and the Judaic culture) on European civilization has been profound and for its part the Israeli political class has, overtly or covertly, as their referent European rather than American culture.

European attitudes are even more complex. Although foreign policy finds its expression in political and economic tangibles, the psychological intangibles are omnipresent.

European public opinion - especially as expressed through the media, but also by political parties and other movements - is uncharacteristically judgmental in relation to Israel - a matter of both pride and frustration to Israelis. This judgmental attitude is worth a brief analysis.

In part it is a signal of the affinity (and latent racism) of European public opinion. Israel is regarded as "belonging" to the advanced liberal world of which the highest standards are required. (The latent racism is towards the rest of the world - especially the brown world - which is judged by humiliatingly less exact standards by Europeans).

The judgmental attitude is also a way of dealing with the past. There is almost a sense of glee in which Israeli moral excesses - especially in dealing with Arabs - are greeted in Europe. It is as if a burden is removed when Israel joins the ranks of oppressors. The point does not really need elaboration.

But European judgmental attitude is traceable to an even deeper source - a source brilliantly exposed by Milan Kundera in his address on receiving the Jerusalem Prize for Literature on the Freedom of Man in Society. As Kundera puts it

... the great Jewish figures, exiled from their land of origin and thus lifted above nationalist passions, have always shown an exceptional feeling for a supranational Europe - a Europe conceived not as territory but as culture. Even after Europe so tragically failed them, the Jews 
nonetheless kept faith with that European cosmopolitanism; thus it is that Israel, their little homeland finally regained, strikes me as the true heart of Europe - a strange heart, located outside the body.

What happens in Israel and to Israel matters to Europeans. Israel encapsulates the great conflicts with which European societies have been grappling since the last World War. Integration and immigration, democratic socialism and liberalism, East and West and North and South. The solutions are no better than anywhere else. But the dream and aspiration remain captivating.

In this volume we are interested in institutionalized Europe: The EEC operating through its Common Commercial Policy and through the Framework for Political Cooperation. This is not without significance. In its cooperation and development policy towards the Third World, the European Community has often tried to posit itself as an actor, distinct from its constituent Member States and hence without a debilitating Colonial heritage. A similar temptation could be present in, and part of, the attempt to have a (common) "European" policy towards the Middle East in general and Israel in particular devoid of the shadows of the past. The Holocaust is not, however, the only historical shadow cast on the relationship. The contours of the Arab-Israeli conflict, though not the deep causes, are traceable to European domination over the area in the closing days of the First World War and then in the long British Mandate. The European heritage is felt, on both sides of the battle lines between Arabs and Israelis, in almost every phase of the conflict. A "European" policy cannot, it would seem, really wipe the national slates clean.

Overshadowing all other aspects in the troubled relationship is the ArabIsraeli conflict. The conflict itself has had, and potentially continues to have, a profound effect on European welfare. This may be a trite affirmation, since a similar effect is evident almost everywhere on the globe, but in Europe, as an emergent or potential third power attempting to play a global role, the policy options become horribly messy. Taking clear sides is a tempting (and for most states inevitable) option, but one that is perceived by many as simply not open to Europe. Much of European-Israeli relations is a tug-of-war, within Europe and with her interlocutors in the Middle-East, as to where the centre will be drawn.

Europe's Middle East policy is usually condemned - mostly by Europeans!-as being ineffective. We wish neither to anticipate nor to take issue with the political analyses in this volume but we doubt that evaluation. Europe may not have been effective in influencing events in the Middle East, but has been highly successful in attaining her interests which have been to maintain her trade links with all parties at no political cost. In this respect the applause must be resounding.

Implicit in the previous affirmation is another one: to talk about EuroIsrael relations is inevitably to talk also about Euro-Arab relations, Euro- 
USA relations and Euro-Soviet relations. Europe's attempt to construct a European Initiative, a subject to which much analysis will be devoted in this volume, may on one level be a symbolic expression of European leaders' desperate attempt to shirk away from the interdependence implicit in any policy towards the Middle East.

In mentioning the above issues, all contributing to the double complexity of Euro-Israel relations, we have posited "Europe" as a veritable international actor. It is so, to a considerable extent, in the economic realm. But in discussing High Politics - the politics of war and peace - the fragility of the European construct is daunting.

True, until the Hague Summit of 1969 the members of the European Community maintained essentially different policies regarding the conflict as their reactions to the Six Day War showed. The subsequent process of joint declarations culminating in the Venice Declaration mentioning the right of the Palestinians to Self-Determination and - more touchy for Israel - the possible participation of the PLO in the peace process are all evidence to some success at a unified voice. But the very mixed reactions to the outcome of the Framework for Political Cooperation, especially the Venice Declaration and its aftermath, are testimony to the very fragility of institutionalized Europe in this context. To discuss Euro-Israel relations inevitably becomes, therefore, a discussion of Europe's internal success in projecting its inherent internal power on the international arena.

The economic realm might seem simpler at first sight. After all, we do not have here actor-definition problems, and the Cooperation and Free Trade Area Agreement between the EEC and Israel, like similar agreements between the EEC and EFTA countries, is a functioning reality. The substance of the relations, however, is a different matter from the form. Theories of free trade benefits have not always worked out in practice; the disparity of size has had effects which might have been underestimated and the current economic problems of both Israel and Europe cast a shadow on the optimism of the $70 \mathrm{~s}$.

Moreover, Second Enlargement (by which we mean, Greece, Spain and Portugal) is casting an additional long shadow on future relations, troubling even further an already complex scenario.

This list could have been lengthened further; the case for a fresh look at some of these issues, which "trouble" the relationship, should, however, be evident.

Most papers in this volume are revised versions of contributions to an international conference held in Ramat-Gan, Israel, organized by the Department of Political Science of Bar-Ilan University with the collaboration of the European Policy Unit at the European University Institute, Florence. Participants included government and Community officials, diplomats and academics. In many ways the conference acted out the phenomenon it 
proposed to analyze. Fruitful and detached dialogue mingled with no less instructive tense and even frayed communications.

It is neither possible nor necessary to convey that exciting dimension of the meeting-encounter. We have, instead, selected the most representative academic contributions which can shed light on the various dimensions of the relations of these troubled neighbours. With the exception of the first two introductory papers, we have confined our analyses to institutionalized Europe, embodied in the EEC and the Framework for Political Cooperation. Specific Member State policy is discussed only insofar as it is part of the larger European story.

The precise choice of studies for this volume, and its organization, attempt to reflect the complexity and diversity of the phenomenon.

In Part One, entitled Mutual Perceptions, Shlomo Avineri and François Duchêne touch in two essays on the intangible dimension; Europe in the Eyes of Israelis and Israel in the Eyes of Europeans. Politics, economics and international relations are the material of the discussion, but historical memory, philosophical and moral categories, unashamedly value laden, are taken up both as descriptive elements explaining patterns of behaviour as well as a plank from which to make normative prescriptions. They cannot, of course, abstract "the" view of Europe in the eyes of Israelis and vice versa without resorting to the drudgery of opinion polls or elite studies - methods which no doubt can have a value in sociological exploration of the respective societies. In this type of essay the subjective and personal dimension of analysis, at points taking even a literary complexion, come to the fore. For us as editors, Avineri and Duchêne are authentic expressions of enlightened positions prevalent in Israel and Europe. Given their vitae, their views most likely also reflect the conceptual background against which foreign policy decisions would be taken in both polities.

In the nitty-gritty of EEC-Israel relations, the economic dimension is the most institutionalized and in the formal sense the clearest cut expression of the relationship between the European Community, as an international actor, and the State of Israel.

Parts Two and Three of the volume deal respectively with the two issues which have dominated economic discussion of EEC-Israel relations in the last decade: The operation of the 1975 Cooperation and Free Trade Agreement between Europe and Israel and the likely impact of the Second Enlargement - the accession to the Community of Spain and Portugal.

Part Two commences with two general analyses. One, by Wolfgang Hager - The Community as Israel's Trading Partner - concentrates not only on the structural difficulties of trade relations between Europe - the largest trading bloc in the world - and Israel, but especially on the current internal and international conditions in which Europe now finds itself in terms of its industrial and international trade options. We use Hager's paper as the general scene against which the more specific analyses will take place. 
The three central papers of this Part deal with the actual operation of the Free Trade Area Agreement. In the first - Main Economic Trends in EECIsrael Relations since the Creation of the Common Market-Richard Pomfret takes a long-term temporal-comparative view of the issue. Y. Shachmurove looks at The Integration of the Israelis Economy in the EEC and then Benny Toren - The Impact of the Free Trade Agreement with the EEC on Israeli Industry - gives a clinical insider's view of the impact of the Agreement on Israeli industry: exports, imports, gains from efficiency and direct foreign investments.

We conclude Part Two with contributions by Jacques Silber and Zeev Berrebi, who have compiled the relevant statistical data concerning the integration of the Israeli economy into the EEC and the impact of the agreement on Israeli exports to the EEC, clearly the most sensitive issue of the lot.

Part Three deals with the single most burning economic issue, the political implications of which are also of considerable import: The Second Enlargement. Whereas the accession of Greece has had more impact on the political level, Spanish accession is likely to disturb finely achieved economic balances. We have selected three authors to deal with this topic: An Israeli expert, Alfred Tovias, a Spanish expert, Francesco Granell and a Community expert, Rolf Langhammer. Whereas Granell concentrates primarily on the impact on Spain itself of accession, both Tovias and Langhammer examine the collateral effect on Israeli trade and balance of payment patterns in the EEC. Although much has happened since the conference took place and these papers were written, we believe that the basic analysis of the likely impact of the Second Enlargement has been validated.

Part Four of the volume contains a single paper, by Claus-Dieter Ehlermann, examining the juridical and institutional dimension of the EECIsrael Cooperation and Free Trade Agreement. The relevance of the legal dimension has come to the fore in the context of a recent case before the European Court of Justice concerning, inter alia, the legality under Community law and the EEC-Israel Agreement of a United Kingdom ban on exports of crude oil to Israel. The Court affirmed this legality. But the institutional arrangement is relevant even beyond the direct legal questions. For if the Agreement is to continue as the main economic framework for trade relations between Europe and Israel, the flexibility of the institutional set-up will be tested to the limit.

In the next section of the volume, Part Five, we come to the all-important political dimension of the relationship. This Part's position in the volume is not intended to deny the primacy of politics. It is simply that the notion of "Europe" in this context is somewhat more elusive than in the previous essays. Naturally, our discussion concentrates on collective European action and inaction vis-à-vis Israel in general and the Arab-Israeli conflict in particular. This collectivity finds its expression in the fragile Framework for European Political Cooperation. But to what extent has Europe been able to 
act collectively? and to what effect? Beauty, it is said, is in the eye of the beholder. For some, the so-called European initiative towards the conflict is the apex of EPC activity. For others it is the depressing sign of the limitations of the framework. It is with these issues that this Part of the volume tries to grapple. The answers are as many as the essays presented.

Like the economic sections, Part Five begins with a general introductionThe Evolution of a European Foreign Policy: Mechanism and Institutions - by Joseph Weiler. The purpose of this paper is to explain the evolution of and constraints on the mechanisms which enable one to speak at all about a common European external posture - economic or political. The emphasis is of course on the emergence of the Framework for Political Cooperation in the context of a general discussion of non-unitary actors.

This general introductory piece is followed by three specific analyses: Alain Dieckhoff on Europe and the Arab World: The Difficult Dialogue; Ilan Greilsammer on the Capability of the European Community to Play an Active Role in an International Crisis: the Case of Lebanon; and Beate Lindemann on Votes of the EEC Members at the United Nations on Questions Related to Israel. It will be seen that all three analyses have as their objective not only an examination of the Europe-Israel relationship but also of the very concept of a "European Foreign Policy".

In the final sections of the volume, we treat some miscellaneous aspects. The Europe-Israel relationship is not, after all, only about trade flows or High Politics. We have chosen two discrete areas of European-Israeli areas of cooperation. Suppressing Terrorism: Problems of European Israeli Cooperation by Noemi Gal-Or; and, as a fitting conclusion to an enterprise which linked two institutions of higher learning in Europe and Israel, Science and Politics: The Links Between Israel and the European Community, by Gerald Steinberg.

This volume is testimony to one attempt at such cooperation. 

Part One

Mutual Perceptions 


\title{
Israel in the Eyes of Europeans: A Speculative Essay
}

\author{
FrançOIS DUCHÊNE
}

\section{Values and Images}

Israel can never be wholly foreign to West Europeans any more than to Americans or Russians. Jews are so much part of the fabric of European history and contemporary life that relations with Israel must, in some sense, be an extension of folk memories on both sides. Israel, at least initially, was virtually a transplant of liberal European culture in the Middle East. And yet today Israel is far more foreign to Europe than to the United States. Habit has divested this fact of all power to shock, and it is in any case implicit in the migrations of so many Jews from Europe, and to America. Still, it is sufficiently complex, and important enough to the present theme, to require some elaboration.

Hitler casts such a long shadow over recent experience that he might seem an explanation in himself. In fact, he came so late in the day that he is more of a consequence than a cause. There never seem to have been such large proportions of Jews in Western and Eastern Europe, or as in the United States today. Before Hitler, there were nearly nine million Jews in Eastern Europe, including the lands of the defunct Austro-Hungarian Empire, over four million in North America, and less then 600,000 in Germany, where they were specially eminent. Ashkenazy roots are so shrouded in time that Koestler, eccentrically or not, traced their descent from the converts of the Khazar Empire, contemporary with Byzantium and the Abbasids. But there are no similar doubts about North America, where Jews now number over six million. Eastern Europe, the major reservoir of Jewish people, was also the home of poverty, persecution and recurrent slaughter, and so the great source of migration. Western Europe was rather less intolerant after the French Revolution but out of reach neither of poverty, anti-semitism nor, later, of Hitler. So, like the vast majority of Europe's emigrants, but with even stronger reasons than some of the others, most emigrating Jews headed for America. It might not have been the promised land, but whatever antisemitism reared its head there was of minor significance compared with the hopes and opportunities offered by a new and more open society. 
Though Jews were only modestly present at the creation of the United States (some did, however, figure in the War of Independence and more in the Civil War), they migrated there in force before the national mould had set. They helped in fact to shape that mould. They have thrived in the relatively free competition, and the US, in its present form largely of Victorian make, has provided for individuals and ethnic communities alike. Jews now have an overwhelming presence in the universities and the media; they are in finance and in business a major group, if not the most important minority in a society of minorities. The same openness applies in America to relations between business or the universities and officialdom, so that movement in and out of government has become routine. It is, then, natural that the vigorous presence of Jews in almost every phase of American life should be reflected in American values and policy.

Compared with this, Jewish influence on Western Europe, though older and in many ways profound, seems relatively muted. Of course, this could be ascribed to Hitler. But outside medieval Spain perhaps, the Jews have never enjoyed in Western Europe the degree of influence they wield in the United States today, nor the same degree of acceptance of that influence. Jews form one of the most salient strands in modern European culture, or rather have placed their mark on many strands. It is hard to match the seminal trio of Marx, Freud and Einstein. Darwin and Keynes? - perhaps, but they are only a pair. In the music of the Vienna school, in Socialist thought, in physics and a dozen other major fields, Jewish names spring to the top of the mind. Today, once more, Jews occupy important positions not only in banking and business but government, as in Britain and France. A Jewish Archbishop of Paris is even seen by some as a possible future Pope! - which takes one back to the birth of Christianity. With all that, Jews seem part of the complex European weave rather than determinants of the pattern itself; and this applies a fortiori to official policies.

In Western Europe, the Jews have slowly and painfully emerged from a segregated status to full citizenship and acceptance in the shadow of traditions, institutions and social groups which had crystallized without them and long before emancipation. These imposed pre-existing cultures and priorities on late entrants to citizenship (not only Jews) throughout the long transition from the eighteenth century. The anti-semitism which was more acute in Europe and Russia than in the United States was only one sign of this relative imperviousness. Though it was much the most painful expression of a closed society, it was not perhaps, for present purposes, the most crucial one. The sociology of the state and its attendant establishments has probably been an even greater shaping force. The privileged corps d'état of European governments, which the education systems have been geared to serve, and therefore reflect, are more aloof from society and, from above, have a more pervasive influence over it than they have had (at least until recently) in the United States. In Europe, government tends to make its imprint on society 
whereas in America the influences have traditionally been exerted much more the other way around, by society on government.

In Europe, then, the Jews have not been one of a transforming swarm of immigrant peoples struggling for their place in the sun more or less on equal terms. They have tended, like the working-class, to be outsiders queuing for access to established stations of social and political preferment; and they could only reach them, on the whole, by paying homage to cultural outlooks with a powerful aristocratic pedigree of their own. In practice, European society has always been more mobile than it seemed. That is clear from, say Trollope or Proust. But what is clear also is the snobbery that barred the doors to success. Europe has been nothing near as socially or culturally malleable as the US. Assimilation came first and access to influence after, whereas in America Jews made an impact in their own cultural terms. They have provided much of the intellectual colour in America's polyethnic culture. In Europe, they first had to take on the colour of the existing background.

These differences are reflected in relations with Israel, the balance of which varies greatly from one side of the Atlantic to the other. In the US, relations with Israel are almost like an extension of domestic politics. This is not just a matter of the direct influence of the Jewish community on American policy. There is also the often unquestioning support of a large part of the nonJewish public. In Europe, this is not so, at least not to the same extent. Despite ancient ties and reviving domestic Jewish influences, relations with Israel still seem to be very much ones of foreign policy.

This distinction is reinforced to some extent by the Israelis themselves. They concentrate their efforts at influence on the superpower who is more responsive to their case and more vital to their existence than Europe. Thus, though Israel is in part the offshoot of European Jewry and geographically much closer to Europe, it is strategically, politically and culturally almost symbiotic with the US. There may be a potential for future symbiosis with Europe (an interesting possibility) but there has been precious little sign of it yet.

Of course, to speak of "Europe" presumes too much on the uniformity of the region. Now, as in the past, conditions vary substantially from country to country, and this applies to attitudes about Israel as to everything else. There seem to be three main sets of attitudes to Israel. One group of countries have outlooks dominated by memories of Hitler, though for very different reasons: Germany, on the one hand, and the Netherlands and Denmark on the other. They are specially conscious of, and sensitive to, things Jewish, and to Israel as one of the most obvious of them. Britain and France, or the establishments which dominate foreign policy, though not indifferent to such considerations, are moved much more by their longstanding traditions as former great powers in the Middle East. Their complicated relations with the Arab world play the most important part, and have done so even when they 
courted Israel. The relative ease with which France first adopted a very proIsraeli policy in opposition to Nasser during the Algerian war, and then switched to a pro-Arab one in de Gaulle's last years, is a sign of the subordinate role of relations with Israel in the raison d'état. Finally, the countries of southern Europe, as a millenial fact of geography and history, are much more traditionally aware of the Arabs than are the northern Europeans. The diplomatic attitudes to Israel and the PLO of Greece and Spain are symptoms of this, even though, ironically, it was Israel that refused to recognize Spain in the days when Franco was a pariah. The fact that, on the whole, the record of the southern Europeans towards the Jews during the war was much less shameful than that of most of the northern ones, increases rather than reduces this outlook. They are farther from Hitler and guilt, and a great deal nearer to the Arabs.

\section{Has Anti-Semitism Become Insignificant?}

Behind all this, one particularly important and complex factor is the change in values associated with the steep postwar decline in the amount of domestic anti-semitism visible in Western, as distinct from Eastern, Europe. Is this a mirage? Anti-semitism has revived in such unexpected circumstances in the past that one is bound to be wary. One can argue that the horrors of barely 50 years ago have provided a powerful vaccine for a time but that, predictably, vaccines wear out: many apparently settled features of the postwar scene have been shattered of recent years. There are pockets here and there of angry young machos in jackboots, shooting out Nazi salutes. And if they seem symbols of material and mental underdevelopment rather than of a movement with a future, that was so true at first of the Nazis. Over-optimism is always a possibility and a danger. Yet the fact remains that neo-Nazis remain electorally and culturally insignificant in the Community, most particularly in West Germany. People, even in recession, seem to be looking elsewhere, even though one has to be sixty to have a living memory of what Hitler represented. One must entertain at least the possibility that something lasting may have changed in the culture which sustained anti-semitism in Western Europe.

This something cannot be the disappearance of racism as such. It has duly revived in Western Europe with depression and unemployment. It has, as usual, fastened on recent immigrant proletarians whose manners and ways of life contrast most visibly and uncomfortably with the surrounding society and who compete, or are assumed to compete, for jobs with the native poor. Jews, of course, are no longer prominent among these newcomers. Having moved up the social ladder, they are mainly members of the middle, professional or upper classes and have relatively little contact with disadvantaged groups. They are no longer in obvious competition with a working class haunted by unemployment. Nor are they Muslim, Hindu or Sikh, with different coloured skins and markedly separate cultures. They are also much 
more powerful in society. They have, in short, been largely replaced at the bottom of the economic scale by far more exotic and handy scapegoats. At the simplest level, the social rise of the mass of immigrant Jews (not to speak of Jews as longstanding natives of European countries) has taken them out of the firing line.

However, anti-semitism (like racism generally) has never been purely economic nor working class. It is probable that deeper changes on the European scene have to be sought elsewhere, in political and cultural developments influencing what may broadly be called the establishments. One of the striking characteristics of the present slump in Europe is the lack of the frightening ferocity of the 1930s. The reaction to depression in Europe this time has been conservative (as indeed in Britain between the wars) and not radical (as it was over so much of the continent on the last occasion). Even racism has proved weaker and been slower to appear than between the wars. The only significant political movement to arise on the far right in the Community lately, has been the National Front in France in 1983-1984, ten years after the onset of the depression (that is, in 1939 on an equivalent calendar). One reason for this could be social security, the characteristic achievement of postwar social democracy. It has provided a cushion against the deprivation and despair of the early part of the century. But equally, and perhaps more important, is the decline of the virulent nationalism so typical of Europe's past century and above all of the hysterical period between the wars.

It is often asserted that nationalism has revived in Europe since the war. No doubt, but the question is what such nationalism consists of. Prewar nationalism was a facet of a vicious competition for world hegemony still largely confined, on American sufferance, to the European powers. Certainly in "unsatisfied" states, nationalist parties sought to mobilize the emotional energy necessary to a struggle for domination. Fascist movements, and in Italy a Fascist regime, were born of national frustrations well before the great depression. The deep disturbances the latter produced raised these frustations to a new pitch, but they already existed in their own right. Since the war, however, all the European countries, including Germany, have abdicated from world power. The aggression looking for scapegoats has almost totally disappeared. The result is that racism may arise among the socially deprived or culturally soured, it lacks the breadth of national ambitions looking for fuel to feed larger purposes.

More than that, Europe has exchanged bubris for an American protectorate; and in the short term this has brought unprecedented dividends. The protectorate and the attendant postwar boom have resulted in Europe's wholesale loss of empire being popularly experienced as the greatest period of prosperity and freedom from almost every kind of fear the region has ever known. Europeans who have had to bury so many dead in their struggles for power have so far experienced almost nothing but gain from its loss. The abdication from world power has been felt not as tragedy but as liberation, 
and has been popularly associated with what has seemed a major advance in political civilization. An illustrative analogy might be a medieval people freed from the fear of warring barons by the law and order of a Renaissance monarchy. The rejection of armed force has thus become a positive value. It is felt to be part of the logic of progress of a social democracy whose prime objective is to serve the prosperity and security of the citizen. International anarchy gives way to political process, as in all properly ordered domestic regimes. One need hardly underline that this is not quite the way in which Israelis' views of the world have been shaped since the war.

It is not, of course, the whole story even in Europe. Under the surface, there are resentments and frustrations at the passing of power. The Falkland War evoked armchair chauvinism in the best Victorian manner. Violence has been reviving inside society. There is tinder around and who can say it will never be lit? The fact remains that popular opposition to violence as undemocratic has become a basic precept in European politics and a source of civic pride. There is little or no pressure to sublimate social violence in national drives for domination. There are few large ambitions seeking victims. Racism remains social rather than political, even where it applies, which is no longer primarily to Jews.

Another set of factors which short-circuit the chances of racism being endorsed by establishment opinion is the evolution of cultural values. Again, postwar social democracy seems to have had a lasting effect. Despite trappings of collectivist ideals, its final impact seems to have been very different. Its psychological outlook, as distinct from the official ideological one, can be imagined as a kind of room, the floor of which is constituted by social security and the ceiling by the career open to the talents. This is inherently rather individualistic, as today's Western European politics tend to show, and pays no particular homage to class, race or country. There may therefore be more than a coincidence in the retreat in Europe of recent decades both of collective socialism, enthusiasm for the military and concern with race.

Certainly, one other contributory influence seems not to be a coincidence at all. This is the major postwar extension of the period the young (and increasingly the adult) spend in education, compared with either 1913 or 1938 , before each of the world wars. If one took the primary school population in 1913 as representing 100, the numbers in secondary schools at the time varied, from country to country of the present European Community, between 2 and 10 ; while in universities they were, in all but two cases, below 1. In 1938, attendance at secondary schools, on the same yardstick, has risen somewhat, ranging from 9 to 16; but at university level, there was still no country as high as 2 . Prewar politics were necessarily run by limited governing elites appealing to overwhelming primary-school electorates. Hitler becomes somewhat more easy to understand when one realizes how low the general level of education was. 
By 1979-1980, however, one had moved into another world. Still taking the primary school population in the whole of the European Community that year as 100, the numbers in secondary school (because of ups and downs in the birthrate) were equivalent to 120 ; and those studying at the "tertiary" level, including the universities, had risen above 20. Politics today have to cater to an electorate of secondary school leavers with a large mixture of university graduates.

Of course, more years in education do not of themselves make a self-reliant citizen. But however cynical one may be about the impact of education, it is hard to doubt this constitutes a major change. Whether as cause or effect, the kind of teaching of "facts" almost inevitable in a predominantly primary school system encouraged, or at least did nothing to discourage, a popular outlook preoccupied with a uniform code of social expectations distrusting anything marginal, different, not "respectable" or, in the revealingly absolute French phrase, comme il faut, behaving "as it must be". A longer period of education gradually introduces some relativities of standards and ideas into such attitudes and injects at least glimmerings of diversity. It makes for a more mobile mentality stimulated, at least to some degree, by the "electronic global village" of the media and perhaps, in the future, exercised by the habitual playing with the options of the computer. Conformity never disappears, but it is not altogether surprising that it seems in Europe today more flexible and able to cope with diversity than in the past.

The crise de civilisation, or cultural revolution, of the late 1960 s placed a militant stress on individuals' right to be variously, even experimentally, themselves. The provocative stress on lack of respectability has, predictably, receded since then and economic depression has had its effect. But unemployment means that more young than ever have to live on the margins of society. The stress on individual and collective self-determination, always implicit in Western values, seems to have become more than ever explicit in today's Europe. An adept debater can easily show such assumptions to be full of practical inadequacies and even hidden contradictions. That in no way disposes of their ideological strength in the culture. They correspond to the precepts of daily life by which individuals propose to pursue their personal strategies, assert what they feel as their rights and make the most of their options. These are not values obviously consonant with racism.

It seems then that the postwar decline in anti-semitism in Western Europe is not merely cyclical, a temporary surfacing of tolerance in recoil from the enormities of Hitler. It may well be "structural" in the sense that it corresponds to a logic in the society and culture. It is not that the temptations of racism have disappeared. It is rather that where racism, for historic reasons, was reinforced mutually by reflecting responses at the top and bottom of European society, developments in the dominant and more educated middle class have tended to short-circuit the impulses from the 
vulnerable parts of society; and that even at these levels, it is conceivable that the pressures are somewhat less intense than they were.

Such intimations of confidence are, of course, no more than that and are certainly no warrant for complacency. At the same time, they do seem to accord with what one casually observes in the past three generations. In prewar Europe, anti-semitism was still widespread and even in some influential circles intellectually defended, although it was highly divisive already among non-Jews. (One is speaking here of run-of-the-mill attitudes, not of Nazi extremes.) Postwar, this was replaced by a rejection of racism which was almost too reasonable, and protested almost too much, to be trusted for the long term. In the next generation, however, of the mobile young, the dominant impression is of relative unconcern about people's origins as against their personal qualities, an embryonic indifference to race as well as class or nationality. This seems much more promising because more relaxed and broadly based.

One litmus test of change is attitudes to the Holocaust. The Holocaust has played a significant part in European psychology since the war, but for most people other than the Germans in indirect ways. Most Europeans do not feel the blood guilt many Israelis feel they should bear. There are many reasons for this. For one thing, though anti-semitism was clearly a pan-European phenomenon before the war, it was not at all the same thing as endorsing Hitler. Most non-Germans in Western Europe feel they too (or their parents) were Hitler's prey, even if not to the same degree as the Jews, and that their countries would not spontaneously have produced a government dedicated to genocide. In any case, the majority, even of today's Germans, were not born at the time and cannot bear personal responsibility for what happened then. Last but not least, the vast majority of the more educated probably feel (rightly or wrongly) that they are not personally anti-semitic, and so, in as far as they can, have repudiated the values that led to Hitler as well as the Final Solution.

Looking ahead on the basis of new values is probably the basic Western European response to the Holocaust. It does not involve any pretence to playing it down. There has been no response in Europe to the pseudorevisionism that claims the death camps were a figment of Zionist propaganda. There is no denial that European culture is responsible for Hitler to the extent that anti-semitism, of whatever kind or degree, was so widespread. Instead, the Holocaust is generally seen as an awful warning of just how far collective evil can go when the lust for power runs mad. The young tend to see the Holocaust as the criminal extreme of a self-destructive militaristic Europe they reject virtually all along the line. Those who have never experienced the period have the greatest difficulty understanding the frame of mind behind such behavior. The Holocaust is as alien and repulsive as stories of human sacrifice, and because of its mass scale and parody of bureaucratic conscientiousness, infinitely more threatening. Bureaucratic 
tyranny comes next to the nuclear apocalypse in the nightmares of the modern imagination.

Of course, there is a self-serving element in such responses. To adopt, or think one adopts, values which exclude Hitler also allows to escape vilification for him. Yet it is also true that it is rather dangerous to demand of people that they live too long with a collective guilt which in fact applies in vastly varying degrees to different individuals and generations. For one thing, no one submits gladly to public self-flagellation, and too much enthusiastic self-criticism positively invites a backlash. For another, the role of public prosecutor is not without effects on the prosecutors themselves. Human nature being what it is, a sense of one's own righteousness is a dangerous drug. Israelis, not Europeans, have pointed out the dangers of exploiting the Holocaust for tactical purposes.

Moreover, the change of values is not merely a convenient screen for shame and guilt. Rejection of the Holocaust is strictly paralleled by the domestic burial of blood feuds between Europeans in the European Community and psychologically associated with it. True, the world wars did not kill two-thirds of non-Jews in Europe. They nevertheless slaughtered tens of millions of soldiers and civilians, and brought the European hegemony down literally in ruins. In setting up the European community, the member states had a clear sense of trying to open a better and cleaner chapter in their history. Rejection of the Holocuast is therefore neither unique nor purely self-serving. It is in part of a wider affirmation of news values to replace those of late imperialism.

\section{Images of Israel}

The almost wholly favourable evolution of European culture in the past generation in reducing anti-semitism at home does not necessarily extend to attitudes to Israel as a state. In fact, because of the very different postwar experiences of Western Europe and Israel, the new pattern of European values has had a significant part to play in the increasingly critical European view of Israeli politics.

The main relevant changes in popular values in Europe since the war concern self-determination and suspicion of the use of force. The belief in self-determination is double-edged in its impact on European views of Israel. On the one hand, it lies at the base of an unchallenged commitment to the existence, survival and prosperity of Israel. There is an overwhelming consensus on this point, and it has never been disputed. On the other hand, the same standard is felt to apply just as strongly to the dispossessed Palestinians and has had a great deal to do with the decline of admiration for Israel since 1967.

Belief in Palestinian rights is a mirror-image, not a denial, of support for Israel. A good example of this outlook was provided by the French Socialist President, François Mitterand. On coming to office, he made a special point 
of visiting Israel to stress the break with gaullist Realpolitik; but once there, he seized the opportunity to underline Palestinian rights before the Knesset. The same logic explains why Israeli definitions of Palestinians which exclude the West Bank, or of self-determination which rule out the PLO, fail to carry conviction.

Another sign of such beliefs is that critics of Israel come today from the left rather that the right. Whether these criticisms are a mask for a new kind of anti-semitism is hard to say and impossible to prove, for they are intellectually based on, and can be judged by, a clear political principle. In any case, the extreme left is also an extreme minority, and never more so than when it supports, or refuses to condemn, terrorism. More important is the fact that, in general, Israel which began with the aura of a pragmatic socialist ideal at a time when this ideal enjoyed wider prestige than today, has shifted in most European eyes from the left to the right of the ideological spectrum. The critical transition here was Mr. Begin's tenure of office. Despite the Camp David agreement, his period of power has emphasized the note of strident nationalism and reliance on force at the expense of potential negotiation. Most European are much less aware of the domestic shift in power from the European founding fathers of Israel to the Sephardic Jews. They do sense, however, that there is a greater cultural gap with the new Israeli political forces than there was with the old.

Whereas the belief in self-determination leads Europeans to ambivalent attitudes on the Arab-Israeli conflict, the issue of force, once highly favourable to Israel, has tended with the years to work increasingly against her. Until 1967, Israel was seen as an underdog fighting for life against Arabs who refused her the elementary right to exist. Sympathy was heightened by Israel's epic military performances, and also (it must be added) by the hostility in several European countries to Nasser and his brand of Arab radicalism. But the underlying suspicion of the use of force to settle entrenched disputes tends to re-emerge in public opinion whenever the intensity of crisis abates. Sympathy for Israel has receded since she gained the upper hand in such spectacular way during the Six Day War.

It has been a gradual process of changing perceptions. Israel has no longer needed to persuade anyone of her military superiority. The need instead has been to give signs of putting it to lasting political use. For Europeans, that has meant moving to a compromise peace involving the Palestinians, difficult as that clearly is. Indeed, at one time, Arab rhetoric and PLO terrorism seemed to rule it out of court. But as signs of realism and will to compromise with Israel appeared among Arab governments and even some PLO leaders, Israel herself seemed to invest less and less in the logic of negotiation and more and more in that of force.

Israel gradually gained the image of an occupying power, which is never attractive. She was progressively seen to allow settlements to multiply in the West Bank and to sink roots there. The Likud governments in particular 
seemed openly to aim at the ultimate annexation of "Judea and Samaria". The invasion of Lebanon at a time when threats to Israel from that quarter seemed somewhat less immediate than usual confirmed suspicions that on the balance she preferred to trust her own strength rather than any "process of peace". Though PLO terrorism was repellent, it was also widely felt that Israel was cutting down the options of Palestinian leaders who braved assassination by their own extremists to explore the grounds for negotiation.

This background influenced European reactions to the Christian massacres in the Palestinian camps of East Beirut, tolerated by the Israeli army. European comment has seemed to many Jewish observers a flagrant case of double standards and anti-Israeli bias. It is true that the Hama massacres in Syria killed far more people without receiving anything like the same attention. Similarly, Syria's own occupation of the Lebanon and instigation of civil war in the PLO to defeat the party of negotiation have aroused far less criticism than Israel's invasion of the Lebanon.

Why the European media reacted as they did may warrant research, but for anyone who knows their general responses, there is nothing specially mysterious about their handling of the killings in the Palestinian camps. From a lay European point of view, it was not at all clear what business Israel had to be in Lebanon. This resort to force seemed of a piece with the general rhetoric and intransigence of the Begin administration. And the Israeli army's tolerance of massacres endorsed, or encouraged, behaviour which may have become routine in the Lebanon but is not consonant with the standards on which democracy ultimately rests. It stood for a wider coarsening of Israeli policy as seen from the outside. This may not be supersophisticated nor selfcritical; it may in some individual cases have covered some pleasure at the Israelis being brought down to size; but in general it is near enough to what anyone can recognize as the average response of a contemporary democratic society to the excesses of a quarrel in which it is not directly involved.

As for Syria, double standards are almost inevitable because it would never occur to Europeans to compare the two societies. Syria is known to be ruthless dictatorship based on a minority sect which would be in danger if the Baath lost power; nobody believes human rights mean anything there in a struggle for power; the massacres at Hama, even if massive, are entirely credible and took place at home; and though Syria's presence in the Lebanon is deplorable, both history and communal ties across the border make it much less foreign there than Israel. In all these many senses, Syria is beyond Europe's tribal pale. Israel definitely is not. As a democracy, it is a member of the club. In fact, the publicity the country obtained from the Lebanese war came from the domestic Israeli peace movement which proved just how democratic the system is. For good or ill, news leaks out of Israel, and the country is infinitely closer to European consciousness. It is therefore judged by one's own local standards.

This may seem simply a whip of virtue with which to beat Israelis. But that 
is too partial. The fact is that the sense of identity, which heightens criticism. is also ultimately one of the bases of mass support, in Europe as in America and other democracies, for Israel's right to survive. European opinion is firmly committed to that survival. Only, that support is set in a European and not an Israeli perspective.

Israel is the only non-European country to benefit from a free trade area with the Community virtually on the same terms as Scandinavia, Austria or Switzerland. The treaty was deliberately pushed through in 1975, at the height of OPEC's perceived power, against Arab opposition in the so-called Euro-Arab dialogue. By no stretch of the imagination could it be argued that the treaty was drawn up far from the gaze of the opposition or in a fit of absent-mindedness. It was a significant political act, almost certainly bringing Israel the most effective support the Community, as an economic power, could give her then or is likely to give her now or in the future. It would be quite gratuitous to suspect that European political criticism of Israel represent a covert desire to sidle out of commitments to her. In practice, those are already about as close as they could be.

On the other hand, the European perspective on political issues most definitely is not that of Israel. Some Israelis believe that only their strong right arm stands between them and Armageddon. Accepting the truth of this proposition in so far as Israel is forced on the defensive, Europeans think it is quite inappropriate to Israel as the region's major military power. First, they suspect that force begets force. The standards Israel sets today are the yardstick by which the Arabs, if they have no other prospect, will ultimately built up their riposte. There have been signs of an improvement in Arab and especially Syrian fighting spirit and leadership in 1973 and more recently in the Lebanon. Second, Israelis are simply not numerous enough to reshape the Middle East. The adverse demographic balance will be felt the more the Arabs mobilize their military potential. This is so true that the Arab birthrate inside Israel itself constitutes a weakness. Third, security today is bought by assent and accommodation, not territory. Tel Aviv is certainly frighteningly close to the 1967 borders. But threatening missiles can be massed behind any sustainable borders Israel may care to choose. Security will not come that way, not at least in the common European view.

The conclusion Europeans reach is that there is no alternative to a peace process, however slow and difficult, requiring compromise of both sides and total victory for neither. This may typify an outsider's point of view and be neither welcome nor credible. It may even be felt that for Europeans to express such sentiments, given their responsibility for the conditions which led to the founding of Israel, is little short of an insult. But without admitting that this is something like the common European attitude, it is impossible to make sense of European policy perceptions or relations with Israel. 


\section{Perceptions of Interest}

It is difficult at the best of times to say how popular attitudes interact with official policies. What is spontaneous? What is manipulated? How constrained are governments? These are important questions in many cases, but in practice they come less to the fore in Europe about Israel than about some other issues. True, governments have on occasions set about changing public opinion, as in France after de Gaulle's change of front of 1967. But on the whole there seems to be a fair degree of natural concordance between popular attitudes to "self-determination" and official calculations of interest which (for reasons rehearsed below) lead to the conclusion that peace between Israel and the Arabs is necessary for Western Europe. Public and official attitudes in Europe are not identical, but they seem fairly solidly congruent.

Once again, it is not possible to speak without reservations of "European" interest or perceptions of interest. The larger countries of Western Europe in particular tend to pursue paths of their own. The most obvious involve France - from Iraq to the Maghreb, without forgetting her over-present concern with Black Africa, of which the involvement in Chad against Libya is the latest manifestation. Germany's relations with Turkey have traditionally been close, despite strains in the past decade. The recent controversy over sales of Leopard II tanks to Saudi Arabia is a sign of the economic and political pressures exerted by oil on the policies of all the bigger European states and which bring them into potential conflict with Israel. Italy and Spain, at various times, have made much of their Arab policies and "vocation". For a long time it was hard to see what this meant in concrete terms. But Italy has now joined France and Britain in the policing operations in the Sinai and Lebanon as well as in mine-sweeping in the Red Sea.

To some extent, these national policies are competitive. Each state tries to enhance its relative influence, and such rivalries limit the scope for collective action. It has even been argued that, given the different outlooks of the various European publics, more can be achieved by complementary activities than by unified policies which are bound to be less decisive. French operations in Africa, for instance, would never win the endorsement of all the Community countries, but all are quite willing to pocket the political profits: one rarely hears any protests or even criticisms.

At the same time, there is little doubt that the Europeans do have converging interests, and perceptions of them, in the Mediterranean and the Middle East. It is no accident that their diplomatic cooperation (misleadingly called European "Political" Cooperation) has tended to be more assertive in the area than elsewhere; and that the Community's "global Mediterranean policy" has become the frame for economic ties in the past decade. Four broad European interests can be discerned behind this slow and partial but nonetheless, in evolutionary terms, quite rapid and potentially significant 
convergence - two concerning political, and two economic, aspect of security.

The first of these preoccupations must, of course, be relations with Islam, the dominant geopolitical presence along the whole of the southern face of Europe. It is difficult at any time to gauge the mutual influence across the four and a half thousand miles of Islam from Marocco to Iran, but of the potential for political interactions there is little doubt. Given the immense demographic and social tensions of Islam and the love-hate relationship with Western culture, Europeans must put a high priority on good relations and attempt, as far as possible, to reduce the risks of upheaval in the Arab world which might adversely affect their security. This constant concern conditions European policies, especially in the Mediterranean, more than may appear on the surface.

The Soviet Union is another recurrent presence on the frontiers of the Middle East, through allies in the Arab rejectionist front and as a naval force in the Mediterranean bringing the cold war home to the "southern flank" of Nato. Determination to prevent any shift in the East-West balance in favour of the USSR has been the primary motive behind Germany's increasing involvement in the politics of the Mediterranean since this became obvious with her support to the centre-left against the far-left in the Portuguese revolution of 1974-1976. In many ways, Germany has the most systematic and consistent security policy of any Community state in the Mediterranean, but there are signs that awareness of the region is growing generally in the West European capitals.

The goals of economic policy are complementary with the political ones. The first is to minimize any disturbance to supplies of oil and natural gas. These are less crucial than they were, but still a potential source of crisis and recession worse than those which have already spoiled European prospects (amongst others) in the past decade. The second motive may be less obvious but also runs deep : to expand exports to Islam as much as possible. This is not just a matter of paying for energy imports. The Mediterranean and Gulf have proved two of the most receptive markets for European exports at a time when it is feared that Europe's capacity to compete, especially against Japan, is in decline. Europe had a particularly large and growing surplus with the Mediterranean countries until the second energy crisis undermined their purchasing power.

Beyond all these specifics is the vaguer but crucial fear that the Middle East is the one region of the world from which a world war might plausibly erupt. Since that means war between the superpowers, and the Community sandwiched between them at home, this imports the Middle East as a potential security risk to the Europeans in their own region. Ultimately, their own lives may be at stake in the Middle East. The Suez expedition of 1956 showed how near the surface there is a stratum of panic in European attitudes to oil and the Middle East. Habituation to shocks since then, and survival 
beyond them, may have calmed fears a little. The fact remains that the Middle East is not an area Europeans can consider as observers, calm, aloof and free. They are themselves psychologically close to involvement.

One has only to state these issues to see that they cover nearly all the concerns which are most basic to Western Europe's place in the world. Together, they ensure that the Gulf and Mediterranean constitute the highest policy priorities of the Community states outside their own continent and their relations with the US. The Europeans are not therefore likely to treat their interests in the region, or their perceived interests, with any sense of having great freedom of manoeuvre.

\section{Israel among Europe's Priorities}

Israel, as a vigorous and internally stable country, is an important partner for the Community in the Mediterranean. The Free Trade Area agreement of 1975 reflects this. On the other hand, the Arab-Israeli conflict, like that between Greece and Turkey, sits right astride the divide between the Mediterranean and the Fertile Crescent and Gulf. Together, these two conflicts run a political faultline down the centre of this enormous region. Of the two, the Arab-Israeli conflict seems the more intense and to have the larger potential for disruption. Desire to circumscribe the risks is inevitably at the heart of European policies.

However, these have not been static and have in fact varied substantially over the years. In the phase of decolonization, when both Britain and France were variously at odds with pan-Arab ambitions and nationalism, they welcomed Israel as a tactical ally against Nasser. But that was never the priority for other Europeans, though some were strongly pro-Israeli. Increasingly, good relations with Moslem powers, not only as suppliers of oil but as continental neighbours to the south and east has emerged as the overriding European concern. From this standpoint, an assertive Israel is bound to be a source of uncertainty and risk. There has never been a propensity in Europe, as at times in the US, to regard Israel as a bulwark against Soviet domination of an otherwise permeable and unpredictable area. The ArabIsraeli conflict has been seen rather as an excuse for the Soviet Union to become more and more involved in the region. As a result, from the European point of view, the only lasting way to reconcile the basic commitment to Israel's survival and a stable relationship with Islamic neighbours is through negotiated peace.

The two crucial dates in the gradual definition of these collective European objectives have probably been 1967 and 1973. The significance of the aftermath of the Six Day War in the European perspective has already been discussed. The net effect has been to underline the divergence in goals between Europeans pressing increasingly for peace talks which turn on the Palestinians and the West Bank, and the Israelis who seem less and less 
inclined in the West Bank to accept the risks of a return to the conditions of 1967 and more inclined to press for a Greater Israel.

1973 was significant to European policy perceptions in at least two senses. The first is obvious. It is underlined by the sudden declaration of interest in Palestinian rights in November, as the oil embargo accompanying the Yom Kippur war, began to make a political impact. This has undoubtedly been crucial in the long run in persuading countries like the Netherlands, which at the time resisted the French line of cooperation with Arabs, to shift from their previously strong pro-Israeli line. The second influence is more subtle, but has grown increasingly evident with time. The Feisal-Sadat alliance of 1973 was a rare and sophisticated, almost Clausewitzian, attempt to shift the balance of political bargaining through limited war and the use of the oil weapon. It succeeded in giving a plausible presence to an Arab constituency for relatively pragmatic negotiation. This was further demonstrated both by Camp David and Anwar Sadat's visit of reconciliation to Jerusalem. Even though this cost him his life, the constituency that supported Sadat has grown as a diplomatic factor. The Fez declaration of September 1982 suggested to Europeans that the pro-Western Arab regimes were ready to inch towards recognition of Israel if peace could prevent an Israeli fait accompli on the West Bank. This may be unwelcome to save political forces in Israel even if it is regarded as realistic, but, of course, it chimes in with the European concern to move to a negotiated and ultimately general settlement. There has thus developed a potential convergence between Europeans and pro-Western Arab regimes in favour of talks. Of course, this leaves a host of questions, but as they could not be answered at this stage in any case, the degree of the meeting of minds does not have to be tested.

On balance, the events of recent years have probably reinforced the Europeans' sense of convergence with the pragmatic Arab regimes as the local players most in need of a negotiated peace. One says "on balance" because the factors are complex. On the one hand, the Khomeini revolution has relativised the Arab-Israeli conflict. Iran has shown that even if by some magic the conflict would be waved away, the risks of upheaval in Islam would remain. Khomeini's consequences have also proved less immediately catastrophic than might have been expected. Bad as the recession has proved, it has reduced not heightened the power of OPEC; and the Iraqi-Iranian war has still not spread beyond the two principals. On the other hand, the Iranian revolution has shown once again the socio-political volcano on which the Moslem governments sit so uneasily. And time seems very short once more with Israel settling into the West Bank and the Syrian and Shiite victories in the Lebanon. The relative relaxation from a Western view, of Sadat and Camp David seems a long way off.

The gradually increasing European emphasis on a positive diplomacy of peace has opened up gaps not only with Israel but with the US as well. Of course, there have always been differences, of structure and perspective, 
between the US and Western Europe. At Suez in 1956, the restraining factor was the United States. During the 1960s, and particularly after the mini-oil crisis of 1967, it became usual to contrast the Israeli priority of the US and the European preoccupation with oil. Though true, this was too simple even then. In more recent years, it has been further complicated by general trends in Euro-American relations. A slow change is coming over the continuing close association between the two sides of the Atlantic. There is no prospect of divorce, of the kind once identified (again rather superficially) with gaullism. But there is an increasing European search within the marriage for more bargaining power and freedom for manœuvre vis-à-vis the United States.

There are several areas and levels at which the Europeans feel increasingly uncomfortable with American priorities and, at least as much, with American unilateralism. There are differences between the Europeans' commitment to detente with the Soviet Union in their own continent and the superpower rivalry worldwide, of which the European theatre is only one element. The Germans in particular have been unhappy with the way the United States has tended to use arms control negotiations and economic embargoes as gambits in the superpower struggle rather than pursue policies in key sectors affecting Europe in a constant fashion as ends in themselves. There are also strains within the West over economic policy, most evident with American management of the dollar and in trade, but which potentially extend to some aspects on industrial policy as well. The big difference with the 1960s is that many of the divergences with the US implicate Germany as much or more than France, and increasingly involve the other West European countries as well. The tendency of the Europeans to define their own interests and policies within the West is nowadays the main pressure behind the slow, uncertain but on balance quite marked tendency to build up cooperation in and around the European Community.

Policies towards the Middle East contribute one stream to this growing flow. The Europeans have, on the whole, moved in the direction first promoted by the French, of cooperation with the Arabs. They have not been much tempted by the "carrot and stick" approach to the Arabs sometimes advocated by the Americans, partly because they have always been sceptical about America's ability to apply decisive pressure in the Gulf. They have been more openly sceptical, even critical, of the forward policies of the Likud governments than has the United States. They have also, with American blessing, concentrated increasingly on the Mediterranean, where their power to shape the milieu is relatively high. The German Social Democrats, helped by the European Community's carefully rationed promises of aid, played a significant role in tipping the Portuguese revolution towards Western European norms when the US seemed to have given up; and Germany, with the US, again took the lead in tiding Turkey over the economic chaos of the near-civil war before the military coup of 1980. The Mediterranean emphasis 
will be further accentuated if Portugal and Spain join the Community. By then one-third of the Community's members will be wholly Mediterranean, including two of the five larger states, even if one does not take account of France's interests in the region. All the wholly Mediterranean countries are further from Hitler and nearer to the Arabs than the northern ones in which the Community's centre of gravity has so far lain. This southward shift must influence future European policies.

This is the background to growing European doubts about US "crisis management" in the Middle East. American limitations have been the more glaring because of the relatively favourable conditons since the Egyptians expelled the Soviet Union from its main regional base there in 1972. Developments since the Camp David agreement, which was ambiguous, but creatively so, have increased this scepticism. There were few signs of US pressure on the Begin government to interpret the agreement as a step towards a settlement covering the West Bank. With Haig at the State Department, US policy seemed to see Israel only as a bastion of an anti-Soviet strategy in the region. The Reagan plan revived hopes of a more positive American commitment to negotiation, centering on Israel and Jordan. But the immediate postponement, resembling a hasty burial, of the plan once Israel invaded Lebanon, confirmed the suspicion the US lacked the determination to press seriously and consistently for a long term settlement.

Doubts about American policy have therefore led the Europeans to clarify their own line, not in outright opposition to the US but in sufficient counterpoint to irritate Washington. The Community states' Venice declaration of April 1980 was designed to push the post-Camp David negotiating process towards the Palestinian issue. Similarly, the Community declaration of March 1984 was an attempt to prevent the Reagan plan from sinking without a trace.

The European declarations have made no impact on the two principals. They were opposed by Israel because they raised uncomfortable questions about the West Bank the Likud governments did not wish to consider. They were brushed aside by the Americans who were not prepared to put pressure on Israel and were equally hostile to any encroachments on their monopoly of "crisis management". The Europeans clearly knew that. The implication is that they were concerned to build up their own long term position, both in favour of negotiation and in association with the pro-Western Arab regimes willing, or thought to be willing, to deal with Israel when the moment for action came.

The Europeans have therefore placed themselves in a position between Israel and the US on the one hand and the Arab rejectionists on the other, and in so doing come closer to the pro-Western Arabs. From Israel's point of view, given her present policies, this is necessarily suspect. At the least, it deprives her of what might be useful diplomatic support and relief from excessive reliance on a single patron, however powerful and committed. It 
adds to the weight of those pressing alternative policies on the United States. And at the worst, it looks like incipient opposition. For the US too, it is a tactical nuisance to have the Europeans' sniping at American diplomacy in an already difficult situation. Israel and the US have therefore done all they can to emphasize the Europeans' inability to deliver any short-term results on their initiatives.

Accordingly, the Europeans have muted their line, but they are most unlikely to change it in a basic way. There is, first of all, great unease about Israeli-American priorities, which seem to be seriously awry. From a European vantage-point, Israel has been wasting the opportunity afforded by her period of maximum relative power to cement a lasting and acceptable peace. The failure in the Lebanon opens at least the possibility that Israel's relative power may begin to decline. Second, there is anxiety concerning Israel's ability to drag the United States behind her chariot wheels. The United States seems to have no consistent strategy or leadership to offer. These raise questions about the possibility of major crises in the future and reinforce the European's sense that it is urgent to promote the cause of negotiated peace.

In such a perspective, there are considerable advantages for everyone in the Europeans sticking to their own policy priorities in the Middle East. However faintly, they help to keep alive an alternative option. They also help, a little more substantially perhaps, to cement the pragmatic Arab constituency on which one side at least of a peace process must rely.

There is an ever-present risk that the conservative Arabs, who have been moving towards accommodation with Israel because of the failure of their first policies of force, will, if they despair of negotiation or because regimes are overthrown as a result of the perceived failure of their efforts, move back into the radical front. At that stage, policies of force would no longer be an option for Israel in relatively favourable conditions; they would be forced on her whatever the conditions, favourable or unfavourable. It is therefore not a luxury but crucial that a kind of loyal opposition with some prospects of ultimate success should be kept in being. This is clearly the direction of European policy.

\section{Bilateral Euro-Israeli Relations}

Bilateral relations between the Community or its Member States and Israel have to be seen in this passably complex and difficult environment.

In some ways, it is hard to see how those relations could be improved, not because they are faulty, but because they are quite exceptionally good. The Free Trade Area agreement of 1975 gives Israel, except in agriculture, which is an important but declining consideration, virtually every trading opportunity she could hope for. Israel's access to Community markets is as free as that of any outsider, including the Community's closest European associates. 
They are some limits. It is true that public procurement policies by the governments of the individual member states are an obstacle to Israeli's increasingly significant sales of high technology products. But there is nothing discriminatory in this. The Community countries, to their own ultimate loss, are just as restrictive in this score with each other. In any case where the technology is good enough, there are ways around the barriers. Israel also objects to insufficient European financial aid, which is a criticism made by many others. On balance, the Community accords Israel virtually all it has to offer in the one area where what it has to offer is uniquely valuable. Israel enjoys what most of Europe's other trade partners would dearly like to share. This should not be forgotten in the natural but distorting tendency to concentrate on security issues where Euro-Israeli differences are greatest, and European capacity to deliver, at least in the short term, is least. In practical terms, European-Israeli relations are already very close. There is already a special relationship in being.

If one moves this central though unsung area of relations, there is little doubt that the Europeans and Israelis have so far been moving along divergent courses. On the Arab-Israeli conflict, the whole structure of experience, and of values distilled from experience, since the war, just as much as crude balance sheets of perceived interests, tend to pull them apart. Israelis accuse the Europeans of low "materialism", which seems to be a shorthand for a myopic attention to one's oil, perhaps tinged with antisemitism. Europe has indeed become a cautious region which, seeing how it behaved when it was less cautious, may in itself confer some blessings; and has been made rather more so by its relatively poor performance in the current recession. But, as so often when people discuss their views of one another, they prove to be mirror-images. On the whole, Europeans too regard Israeli policies as short-sighted. No one underrates the difficulties and risks of any approach to a negotiated peace, including some kind of IsraeliJordanian supervision of a Palestinian entity on the West Bank. But the present one, which seems to solve, or not solve, the conflict on Israel's terms, and so exclude local alliances of interest, seems in many Europeans' eyes the most risky one of all. There is in fact only one policy that would have any chance of mobilizing European idealism in the Middle East: a serious search for a negotiated and lasting settlement.

Europeans, such as France's foreign minister, Claude Cheysson, when he was a private citizen, played with ideas for European support of the grandiose Arab-Israeli Jordan Valley schemes. In so doing, they have usually had in mind the European Community's role in burying the hatchet between France and Germany. There would probably be considerable enthusiasm in Europe for joint ventures as one of the prices and rewards of peace. The political investments European governments have agreed to make in peace-keeping operations on the eastern edge of the Mediterranean are tokens of this attitude. One can never tell before the time comes to act, but the signs are that 
Europeans would respond with some zest to any prospect of a settlement and be keen to invest in it.

However, without prospects of peace, there will be no enthusiasm either. There is weariness with a quarrel that threatens to undermine one's own security and which one has apparently no power to stop. If there is no chance of escape by influencing the principals, then one must as far as possible - and even if that means not very far - isolate the danger and seek to move round it to pursue more profitable purposes.

The question therefore arises where the logic of European priorities might lead if there were no settlement. Could this gradually push Europe and Israel into more direct confrontation? There is evidence from the past of points where European policies towards Islam clashed with Israeli interest. Arms sales by European states to the Gulf alarm Israel. France's aid to Iraq's nuclear development (as earlier to Israel's Dimona reactor) led to the famous Israeli air raid on the installations. The Europeans, including the Germans, refused to provide staging posts for America's airlift to Israel in 1973.

Since 1967 , the conflicts have remained of secondary significance because of Israel's immense superiority, with American support, over every Arab combination of forces. European arms sales to the Gulf, often for patently local purposes, stopping short - with the indirect exception of the FrenchIraq connection - of nuclear-capable weapons, have taken place within a concept of maintaining an arms balance in the region. It is, of course, possible to imagine circumstances when this would no longer be the case. How one assesses the potential for European policies then has to be a political, not technical, judgement.

A number of factors suggest great European reluctance to play with fire. First, a major European placation of Arab radical ambitions would come near to a denial of Israel's right to exist. There is no constituency for this in the Member States of the Community. Second, it would create dire tensions with the United States, which could have unpleasant repercussions on the European foreign and domestic policies alike. Third, there is no natural alliance between Europe and Arab radicals. A Drang nach Westen by Moslem fundamentalists would threaten Europe's own interests, close to home, over oil and in the Mediterranean. Last but not least, unless the world economy begins to expand faster than looks likely, Europe's dependence on Gulf oil will remain substantially lower than at any time until the late 1970s.

There is also the question of what Europe could positively do. Military expeditions on a significant scale are clearly excluded. The only conceivable scenario is a wary, minimum support under pressure for the United States in the Gulf. Economic embargoes on Israel such as a reversal of the Free Trade Area agreement are totally implausible. Indeed, the timing of the agreement of 1975 has already shown that the Europeans have far too much economic and political weight for the Arabs or the Israelis to force them into choices they wish to avoid in this field. 
The only significant remaining option would be arms sales. But the dangers of these are so obvious for everyone and not merely Israel that an embargo, as on Khomeini's Iran, is much more likely than a renewed rush to sell. After all, the main purchaser after 1973 was the Shah of Iran, then regarded as a bastion of Western influence in the Gulf.

In these conditions, European policy is likely to remain cautious and evolutionary, an attitude that certainly comes naturally to Community governments in the 1980s. This implies the continuation of the special economic relations with Israel, which will evolve naturally. It will also mean convergence and perhaps tactical alliances with any party or parties to the Arab-Israeli conflict who are trying to promote negotiations. The Community and its members will also be anxious to maintain good, and if possible close, relations with compatible Arab states, the Mediterranean here deserving more weight compared to the Gulf than it is usually given.

This is humdrum, but to be humdrum in the Middle East is to be rather original. If the Western Europeans can become a Western cement of wider coalitions which consolidate the peace process, they may have a rather salutary influence. Their policy amounts to positive abstention rather than passivity; and however suspect that may appear to many Israelis, in European eyes it will seem to conform to general as well as to European interests. If the peace process were to advance, it could turn into something more active. The Europeans would like nothing better, even if experience has made them as sceptical as everyone else. 


\title{
Europe in the Eyes of Israelis: The Memory of Europe as Heritage and Trauma
}

\author{
SHLOMO Avineri \\ We shall remain in the new country what we \\ are here, and we shall never cease to cherish \\ with sadness the memory of the native lands \\ out of which we have been driven.
}

Herzl, Der Judenstaat

Zionism emerged as a political movement out of the convergence of a series of historical developments, some of them complementing, some contradicting, each other. Some of these developments grew out of the general historical context of European history, others came from within the Jewish environment with its many layers of internal contradictions and historical continuity.

Zionism was not only an attempt to realize, through human agency and political action, an ancient Jewish dream, embedded in the perennial quest for Redemption and Return; it was also, basically, a secular phenomenon, integrating into a transformed Jewish community the ideas of Enlightenment. It was an attempt to apply the universalistic norms of selfdetermination, liberty and equality to the specific conditions of Jewish existence in the age of secularization and national self-assertion. It was as much a reaction to the Enlightenment as an attempt to find a refuge from modern, racial anti-semitism. Without the Enlightenment, no Zionism.

This is evident in the language and imagery used by so many of the founders of Zionism - Moses Hess, close friend of Marx, subtitling his Rome and Jerusalem as "The Last National Question"; Leo Pinsker, calling his pamphlet "Auto-Emancipation"; even an orthodox rabbi like Zwi Hirsch Kalischer suggested Jews look to Polish and Hungarian patriotism as a model for what a nation can do for its homeland.

Yet the call for auto-emancipation, expressing as it did the language of the French Revolution, also implied that the conventional wisdom of Jewish emancipation within European society was doomed to failure. It thus carried an ambivalent message about Zionism's relation to the European heritage out 
of which it initially arose. And it is this ambivalence that has accompanied the tortuous relationship of the Israeli attitude towards Europe.

This goes much beyond a simplistic explanation in terms of the Holocaust: the fundamental evil nature of Nazism and the Holocaust can be always explained as an aberration of European history, its dark side, the proof of how thin is the ice on which Western civilization treads. But it was Republican France which proved to Herzl during the Dreyfus Affair how illusory the dream of Jewish integration into a liberal environment may be; it was the emergence of the new nation-states in Eastern Europe in the wake of World War I which brought home to millions of Jews how double-edged the application of Wilsonian principles of self-determination may be to a community which lacked a territorial dimension to its existence; and it was the gradual eradication of any meaningful Jewish existence in the Soviet Union which again suggested that one of the most noble quests for human emancipation and liberty may turn out to be tone deaf to the particular quest of the Jews.

For if Israelis try to relate nowadays to Europe it is these aspects of European history, and not just the Holocaust, which is of course the most shattering of them, that are vivid in their memory. Rabid antisemitism is, in a way, easy to exorcise. What is much more difficult to stomach are perversions of ideas of national self-determination which apply to all - but not to the Jews; indifference coupled with a Realpolitik which loses any shred of a human dimension; and selective criteria of morality sometimes applied to the Middle East conflict by people and nations which are far from ever having practiced these lofty ideals themselves. We have an historical reckoning not only with Nazism but also with democratic, liberal Europe - and it is much more complex and painful.

With the rise of Nazism and the outbreak of World War II, the question of Jewish immigration to Palestine became the major prism through which Zionists - and many Jews generally - began to look at the Western democracies.

When the British mandatory government imposed restrictions on Jewish immigration to Palestine, thus indirectly condemning hundreds of thousands of European Jews to a horrible fate in the gas chambers, this was obviously not done because of any deeply rooted anti-semitic feelings among British colonial officers, though it would be true to say that many of them felt much more comfortable among the oriental, colourful Arabs, who behaved as natives should, than among the pushy and uppity Jews. British policy was dictated by much more reasonable - and defensible - considerations than personal elements of distaste or cultural preference. As an imperial power, Britain had naturally to look for allies in the Middle East, and the idea that British support for Jewish immigration to Palestine might alienate the Arabs from the cause of Britain was evident and understandable.

But a cruel paradox was involved in this dilemma: if the Arab countries 
and their rulers would have been committed to Western democratic ideas, choosing them rather than the Zionists would have been a combination of Realpolitik with a modicum of ideological confraternity. But it was precisely because so many Arab leaders and governments in the late thirties and early forties were leaning towards Nazi Germany which made the imperative of not alienating them so much more compelling. The Mufti of Jerusalem, Hajj Amin el-Husseini, spending the war years in Berlin; the pro-Nazi insurrection of Rashid Ali el-Khailani in Iraq; the pro-German leanings of much of the Egyptian elite (as well as the young army officers like Sadat) during the difficult days for the Allies prior to the battle of El-Alamein: it was precisely the pro-Nazi sympathies in the Arab world which tilted British policies in their favor and against the Jews. The Arabs had other political alternatives, and had therefore to be appeased; the Jews, besides being the victims of Nazism, were after all staunch supporters of western democracy: they had nowhere else to go - so their support did not have to be courted, because they had no choice. Fifty-thousand Palestinian Jews fought in the British Army during World War II at a time when not one Arab soldier from any Arab country stood by Britain in its finest, and most difficult, hour: but the brothers and parents of many of those Jewish soldiers were turned away from the shores of Palestine and condemned to never reach the land of the living at a time when Britain had to make sure that the pro-Nazi sympathies of Arab elites should not become even more virulent. This was surely a cruel dilemma for many British statesmen and civil servants. If a similar structure appears in the present relationship of Common Market countries to Middle Eastern problems, can one blame Israelis who may feel they recognize the phenomenon?

The Jewish community in Palestine had experienced another disappointment in the immediate post-1945 period, and strangely enough this had to do with the victory of the Labour Party in Britain in the summer of 1945 . The Labour platform was traditionally much more supportive of the Jewish right to self-determination, and as the Jewish community in Palestine at that time was led by the Labour Party of Ben-Gurion, Attlee's victory was hailed as the beginning of a new era of relationship with an enlightened, progressive British government which would shed some of the pro-Arab sentiments attached to attitudes expressed by the conventional wisdom of English colonial administrators. That in the wake of Britain's tortuous post-1945 Middle East policy Labour's Ernest Bevin emerged as the most out-spokenly anti-Zionist of British politicians again underscored the ambivalence involved in a relationship to a European world of ideas and interests, where it was much easier for liberal and socialist Zionists to appeal to the ideas shared with the West, yet right-wing Arab governments had easier access to the global and economic self-interest of the same European powers. When a French socialist government brazenly arms a bloody dictatorial and aggressive regime like that of Saddam Hussein in Iraq, many Israelis may feel again 
they can recognize the phenomenon. Joint statements of the Socialist International about disarmament have very little impact on Mitterrand's policies when the French armament industry is involved - and for understandable reasons. But when such Realpolitik is then accompanied by pious preachings to the Israelis about the right of the Palestinians to selfdetermination - a right many Israelis concede themselves - it may not exactly be appreciated as anything else than cheap cant and cynicism couched in the sonorous phrases of the French Revolution.

It has been often said, and it was also mentioned at the opening of the conference, that after 1967, and especially after 1977, Israel lost much of its symbolical stature in the European mind because it was not perceived any more as a beleaguered nation but became more and more identified in the public mind with the role of occupier. This is of course true, and the Lebanon War exacerbated that even more. But I wonder to what degree such a shift in popular perceptions is really an adequate explanation of European policies towards Israel. The socialist government of Ben-Gurion did not receive much support from any European government in 1948, when Israel was attacked by reactionary Arab regimes. And during the October war in 1973 no European NATO country - except Portugal - was ready to allow U.S. aircraft to land on its territory during the American airlift to Israel. Israel was ruled then by a Labour-led coalition headed by Golda Meir, a veteran socialist - not by a right-wing government. European reluctance to be tainted with the Israeli brush had nothing to do with European perceptions of the ideological coloration of Israeli politics: it was an understandable reaction of a frightened continent seeing its prosperity vanish with the newly found assertion of Arab oil power. One can hardly cavil at such behavior; but anyone consorting with the Saudis should at least keep an effective moratorium on left-wing preaching for at least half a generation.

Paradoxically, the only time when Israel ever received full-hearted support from the two major European powers, Britain and France, in any of its wars, occurred during the least defensible and - until Lebanon - the most controversial war Israel ever got involved in. During the Suez-Sinai campaign of 1956 Israel found in Anthony Eden's Britain and Guy Mollet's France staunch supporters and allies in its war against Egypt. Between 1948 and 1956 Israel did not become, suddenly, more liberal and more democratic to warrant such whole-hearted support from two countries which did not care much for Israel's survival in 1948-49. What changed were European interests, with France being locked in a battle against the FLN in Algeria and both Britain and France hit by Nasser's nationalization of the Suez Canal. Again, these are legitimate considerations for policy reversals in the chancelleries of Europe: but Israelis can be understood if after such an alliance cordiale they may continue to be sceptical about the high moral tones employed by some European statesmen and political analysts. And when in 1967 de Gaulle reversed the French position again, and Britain started to 
distance itself once more from Israel, this was not an outcome of any inner shifts in Israeli politics or ideology, but grew out of the changing position of France and Britain in a changing Arab world.

And from war to peace: for many in Israel, as elsewhere, the Camp David accords and the peace treaty with Egypt are far from totally satisfactory. Yet they are until now the only peace arrangements between Israel and any Arab country, and for all their incompleteness, especially on the Palestinian issue, they were an outcome of the imaginative policies of both Sadat and Begin something to be admitted even by people who would not normally be considered admirers of either of these statesmen. Yet when Israel and Egypt did, after 30 years of war, achieve a peace treaty, and regulated to their mutual satisfaction their bilateral relations in a most dramatic way (much more dramatic in its own fashion than the German Ost-Politik) - the European reaction to that was of concern if not outright condemnation. Rather than praise the courage of Sadat, Common Market governments distanced themselves from Camp David, called it a "separate peace" and because they took exception to the unsatisfactory clauses regarding the Palestinian issue, Europe virtually helped the Arab rejection front in its effort to delegitimize Camp David as well as Sadat. Camp David might have been a much more successful agreement, and there might conceivably have been some further follow up, if Common Market countries, rather than distance themselves from it, would have tried to talk the Saudis, and the Jordanians, and the moderate elements in the PLO, into taking up the opportunities opened up by Camp David. Maybe if the Europeans would have done this, there might already be today an autonomous Palestinian entity on the West Bank and Gaza. So again, Europeans should not be that much surprised if some Israelis occasionally ask them: When we made peace with Egypt, when we needed you - where were you?

This raises of course the more fundamental question of how much the Europeans can influence the peace process in the Middle East. Probably very little, but they can help to obstruct it. Camp David was one example: the Venice Declaration was another. Again, the negative reaction of many Israelis to Venice was not limited to the supporters of the policies of Prime Minister Begin, and many of those who were unhappy with Venice in Israel were even unhappier with the language in which Begin's criticism of the declaration was couched. What prompted many moderate Israelis was the following: at a time when moderate Israelis were pinning their hope of accomodation on the West Bank issue on some sort of involvement of the Jordanians, the EEC countries in Venice did not even mention Jordan, the most moderate Arab country, in their declaration, as one of the options to be considered when negotiating the Palestinian issue. At a time when many Palestinians on the West Bank were torn apart between allegiance to the moderation of Hussein and the terrorism involved with the PLO, the Europeans chose the PLO. How could a moderate Palestinian in Nablus or 
Hebron opt for the "Jordanian solution" if the Europeans have categorically and unequivocally opted for the exclusivity of a PLO-related solution? Europe was not helping peace, it was not helping the moderates in the Arab world. It helped to legitimize the extremists and undercut the tenuous hold moderation might have within the Palestinian community.

A related issue in the Israeli perception of European positions has of course been the whole complex of problems connected with the Palestinian aspect of the Arab-Israeli conflict. Whether the Palestinian issue is or is not the center of the conflict or just one of its manifestations may be a moot point: that the broader Arab-Israeli conflict cannot be solved without a solution to the Palestinian problem is, on the other hand, obvious and self-evident. But this still leaves the question of the Palestinian indiscriminate recourse to terrorism an issue about which, to many Israelis, European opinion has not adequately addressed itself on the moral plane.

To many Europeans, PLO terrorism may appear as the desperate last resort of a people under foreign occupation. To the Israelis, there is a different perspective. First, Palestinian terrorism is not a novel, post-1967 phenomenon: it has existed for decades, and expressed itself in murderous attacks against the Jewish community in Palestine in 1921, 1929 and 1936-39, when the Palestinians were neither occupied by the Israelis nor could they conceivably be perceived as the under-dog. Secondly, when one talks about terrorism as the last resort of desperate people, one touches a raw nerve with many Israelis. What people could have been more desperate than the Jews after World War II ? But the mainstream of the Zionist underground at that time, the Hagannah, objected to terrorism against the British as well as against the Palestinian Arabs, and the moral debate which divided the Zionist movement and which isolated the minority led by Begin's Irgun always proved to the Israelis that one can fight for one's independence even under extremely difficult conditions without resorting to the methods of the murderer and the assassin. When many Israelis - perhaps not Mr. Begin and his followers - now condemn PLO terrorism they do not ask of the Palestinians more than they asked of themselves in one of the darkest moments in Jewish history.

I will not reiterate the by now familiar points about the language used in some cases by the European press in its coverage of the Lebanon War: one does not have to agree with either the war aims of the Begin government or with the way in which the war was conducted to realize how utterly repulsive the equation of the Holocaust with the fate of the PLO in Lebanon was. Mr. Begin's equation of the PLO with Nazism and of Arafat with Hitler did, undoubtedly, cheapen the memory of the Holocaust, and this language as used by the former Prime Minister became itself a bone of contention within Israel. But neither this, nor anything else done or said by Israel could provide an adequate explanation to the kind of language used about Israel during the siege of Beirut or after Sabra and Shatila. If there were Israelis who ever felt 
that there was nothing in western society which looks out to get the Jews, the Lebanon war might have convinced them that they were wrong.

The Israeli relationship to Europe is then ambivalent in a multifaceted fashion. It is not only anti-semitism to which Israelis react, nor is it just the feeling, on the other hand, that we belong to the same culture. Everyone here would concede that this dialogue, with all its recriminations and possible misunderstandings, is premised on the commonalty of values shared by Israelis and Europeans. No such common values, and no such common and complex memory, enrich and becloud an Arab-European dialogue when there is hardly any Arab country which practices anything similar to a Western model of a democratic or liberal society. But precisely because of these common shared values, Europeans should be aware of the complexity of the perceptions of their role in the eyes of the Israelis. Israelis respond to the language of idealism, and the harsh realities of historical experience have introduced them, as they have to everyone else, to the recalcitrant facts of Realpolitik. Israelis would recognise both phenomena when they meet them in European politics and culture, and could come to terms with each of them, albeit somewhat reluctantly when the edge of either of them is turned against Israel. But it is when Realpolitik usurps the robes of the preacher that many Israelis may lose their patience and prefer to look inward and withdraw from a community of nations which preaches to others what it does not itself practice.

Such a withdrawal into itself would be calamitous for Israel. Hence the necessity for a frank and honest debate between our two societies is as crucial for the European as it is for the Israel soul. 

Part Two

The Economic Dimension 


\title{
The Community as Israel's Trading Partner: A Look at the Future
}

\author{
WOLFGang Hager
}

When examining the economic implications of linking an import market of $\$ 10$ billion with one of $\$ 300$ billion, attention naturally turns to the welfare implications for the smaller market. All contributions to this section, including the present one, follow this logic. This approach runs the risk, however, that by neglecting to analyse the welfare implications of EC-Israel relations for the Community (which indeed are minute in any aggregate economic perspective) one tends to neglect to analyse it altogether.

An assumption of continuity in the Community's economic policies is often a technical necessity when assessing the future of EC-Israel trade relations on the basis of hard, i.e. historical, data. It may even be close to the mark given the slowness of change in an increasingly hamstrung Community. Yet even the one, albeit major, exception to the expected continuation of the status quo, i. e. the Iberian accession, must with this approach be conceived in fairly mechanistic terms as a geographical extension of present agricultural and industrial trade regimes. Thus, in a more speculative mode, this introductory chapter will attempt to identify possible changes in Community affairs, and their effect on Israel.

In the perception of the European Commission and key governmental and private decision-makers, economic Europe is in the midst of a profound crisis. This throws a question mark over the stability of its economic behaviour, its internal regime and its commercial policy. The main elements of the perceived crisis are

- Europe's competitive backwardness in the race towards the "third industrial revolution"; and

- the seemingly inexorable rise of unemployment, in the medium term, towards the $15-20 \%$ level.

In addition, in a narrow Community context, there is the crisis of agricultural policy, the political impact of which is quite out of proportion to its economic significance.

To change a familiar phrase: will Europe catch a cold and if so, will Israel catch pneumonia? 


\section{Reform of the CAP?}

One crucial, and some ways quite open question in Europe's future - and for Israeli interests - concerns agriculture. Although a declining share of total Israeli exports to the EC (about one quarter), the Community provides twothirds of the outlet for Israeli agricultural surpluses.

These surpluses are not, of course a mere economic phenomenon to be corrected, if necessary, by automatic adjustment processes. Like most things in Israel, they are linked to existential questions: In order to consolidate and indeed control its territory, Israel must be physically present in the countryside. Giving spectacular lie to Ricardian notions of comparative advantage, Israeli determination and technological ingenuity have created a highly productive agriculture and (partially) rural processing industry. Steady advances in productivity and a much lower growth in home demand makes further dependence on exports inevitable.

There is unanimous agreement, reflected also in the papers in this volume, that (notably Spanish) enlargement will reduce the scope for Israeli agricultural exports. Possible reactions on the Israeli side include diversification of markets and products, and further upgrading of quality. In all this, the continuation of the present agricultural policy of the $\mathrm{EC}$ is taken for granted. This may be a fair assumption, but it is not the only possibility.

At present, the CAP exercises control over one factor determining output: prices. It exercises no control whatsoever over investment policy, i.e. the generous subsidies to machinery and other inputs granted by the Member States. It is the combination of high prices and investment subsidies which lead to overproduction, not least by accelerating productivity-enhancing technological change.

When overproduction became a serious charge on the budget (costly storage, de-naturation, or export subsidies) the Community's first response was to moderate price rises, and/or to introduce quotas on price-supported quantities. But if total production costs are kept low enough by national subsidies to inputs, it remains profitable to produce even at the lower price and, for marginal quantities, even at free market prices. Control over subsidies to investment thus becomes a necessity, with the implicit threat to farm incomes made up by some form of direct income support.

The possibility of some drastic action of this kind - despite the enormous political obstacles - stems from the threat to the Community's political survival posed by budgetary strains associated with the status quo. The stagnation of the Community in the early eighties precisely for this reason is only a taste of what would happen to the system after enlargement.

The precise consequences for Israel cannot be calculated. But it is obvious that any EC policy change which solves the farm-income problem less by subsidies to production, and hence reduces the incentive to produce, would be good news. 


\section{A neo-mercantilist Community?}

Broader issues of Community development are raised by the general crisis of the European economy, and some would say, society. To an Israeli, speaking of an economic crisis in the Community may seem like mockery. With an inflation rate which reached $1,300 \%$ in 1984 , a deficit in visible trade of almost $2: 1$, key manpower and budgetary resources committed to the military, and the need to integrate immigrants with culturally diverse backgrounds in a modern economy, Israelis might well say to Europeans: We wish we had your problems. In fact, they probably do not. There is a basic optimism in Israel, a can-do attitude, which contrasts with the pessimism and angst characteristic of Western Europe today.

For analytical purposes one can distinguish an internal and an external dimension of Euro-pessimism. The internal one stems from the co-incidence of low growth with relatively high productivity increases in the secondary and tertiary sectors, which with arithmetic fatality produces unemployment. Since increases in productivity are considered essential for the external reasons to be discussed below, attention focuses on the reasons for low growth. Among the many explanations possible, public consensus has chosen one which concerns the quintessential European contribution to recent economic history, inadequately summarised by the term "welfare state".

Many of the policy implications of this questioning of the extensive regulation, by private and public contracts, of distributional and social security issues need not concern us here. Suffice it to say that the tempering of market forces and micro-economic efficiency, which is the essence of the welfare state, was suddenly seen to have prohibitive cumulative costs by causing economic rigidity and misallocation of scarce resources. A symptom of both these ills is inflation, attributed to mistaken distributional bargains (high wages, deficit-financed public expenditure); and to sluggish responses in the economy to market shifts. Investment, in this context, becomes the policy variable.

It implies a shift from private and public consumption to private and public investment; and it implies a loosening of regulatory and other constraints on the mobility and efficient use of resources, including labour. One important means to combat inflation and to free savings for investment is the reduction of public deficits. In practice, all this adds up to a mediumterm strategy of austerity, which has become public policy in virtually every Western European country. One first consequence to note for Israel is a medium-term prospect of slow growth of its main export market.

The bias towards supply-side solutions is strongly reinforced by an almost existential preoccupation in Europe with the threat of technological backwardness, i.e. the fear of failing to seize fast enough the opportunities offered by the "third industrial revolution". The introduction of informatics in industry and services, and, in a somewhat longer perspective, the new 
production possibilities offered by bio-technologies potentially touch every area of economic activity, however humble and low-tech at present. While proprietary control of key technologies is a goal of the larger Community states - and spurring a revival of industrial policy - all states seek at the minimum to raise the level of investment. For it is through the rejuvenation of capital stock that the new technologies become an operational part of the economy.

The urgency with which the modernisation goal is tackled stems from its link to international trade. As a number of recent episodes seem to indicatecomputers, micro-chips, and video-recorders for example - there is a high penalty in being slightly behind in the commercial introduction of new products. Others take over the world market (including the "domestic" European one), reap economies of scale, lower cost - and invest the proceeds in yet newer and better versions. A cumulative process of falling behind is thus set in motion. This is not the place to discuss whether these fears are exaggerated. The point is that it creates a peculiarly delicate situation for the Community, where centrifugal and centripetal effects are finely balanced.

The centrifugal effects stem from the fact that technological mercantilism becomes first of all a national objective, pursued by a reinforced national trade and industrial policy instrumentarium which threatens to balkanise the Common Market. Large national soi-disant pre-commercial R\&D programmes, reinforced national procurement policies (used not just for protectionist purposes, but also to make advantageous technology-transfer deals with foreigners); the use of technical standards as non-tariff barriers these are some of the micro-economic instruments used. The accompanying macro policies, export-led growth (which imply slow growth of domestic demand relative to output, and hence a loss of market opportunities for trading partners) reinforce the competitive, zero-sum character of the new game.

The Commission of the European Communities has attempted to neutralise the dangers of intra-European mercantilism by seeking to direct it at the outside world. Its "Communications", in the 1980s, have taken on a consistent tone of economic nationalism, where the EEC becomes a kind of economic defense community. This has a macro-economic and microeconomic component.

The former is important more for what it does not do, i.e., warn the Member States of the incompatibility of conducting austerity policies simultaneously while hoping for export-led growth. Instead each member state is exhorted to cut wages and government spending so as to free resources for modernising investment. In time, this will improve Europe's competitiveness both in cost and quality terms, leading to increased exports.

This is a strategy for a small country. It does not make sense for a continent. Three-quarters of Member States' exports are destined for other Western European markets, all of which (including the EFTA countries) are 
pursuing austerity policies, and to Eastern Europe whose imports depend on market growth in Western Europe.

The rest of Western Europe's exports - some $8 \%$ of GNP - would thus have to grow spectacularly to make up for the restraint of domestic demand prescribed by the EC's macro-structural modernisation policy. Ironically, this is what happened with the US market, where EC exports increased by $45 \%$ in 1984 . While even this was not enough to spark vigorous growth in Europe, it made the first year of concerted austerity policies tolerable and helped to disguise the medium-term dangers.

The micro-economic components of the strategy comprise a number of measures which are not of direct concern to Israel's export prospects. They range from investment- and innovation-promoting reforms of the fiscal system, patent law, (venture) capital markets, etc. ; changes in the EEC's own loan, regional fund, and social fund priorities; the creation of improved infrastructure in transport, information networks, etc. Of greatest interest, however, are direct industrial policy measures and trade measures.

As regards industrial policy, one distinguish with efforts to cope with contracting industries on the one hand, and the promotion of "sunrise industries" on the other. The greatest priority for structurally depressed industries is to combine a reduction of excess capacity with the modernisation of capital stock. Since these industries generally benefit from a high level of national subsidies, the Commission increasingly seeks to impose conditionality on such subsidies, calling for a reduction of total capacity, and spending on improved capital stock, before allowing subsidies. Steel, shipbuilding and textiles are familiar examples, but the principles are applicable in general. This establishes a de facto Community responsibility for such industries, and hence a responsibility to safeguard the "external flank" of such efforts.

As regards modernisation as such, two instruments stand out. The first is a reform of competition policy which allows even large firms to "collude" in advanced product development (by setting up joint subsidiaries for such purposes). The second, in some sense complementary to the former, is a series of programmes of so-called pre-commercial R\&D on advanced technologies, planned by industry, national research establishments and governments; financed half by the Commission and half by private industry, and undertaken by ad hoc groups of firms from different Member States. ESPRIT (European Strategic Programme on Information Technologies) is the best known of these efforts, but similar programmes are being developed in bio-technology, new materials and other areas. In the telecommunications sector, R\&D cooperation is complemented by short-term efforts to create a common infrastructure, common standards, and the restructuring of European industry around a reduced number of basic systems.

This brings us to the question of trade which, in the high-technology field, is intimately linked with questions of international cooperation among firms. The first priority is the "completion of the internal market", which at present 
is fragmented by different VAT regimes requiring cumbersome border controls, different standards, and differing regulatory regimes in tradesupporting services like banking, insurance, transport and date transmission. (These services are, of course, also "tradeables" in their own right).

The creation of a continental industrial space is part and parcel of the modernisation strategy. The idea is not only to reap economies of scale and provide incentives for bold innovative investments, but also to bring together, via the market, the best available combination of scientific knowhow, engineering capacity, organisational and marketing skills, and finance. The present fragmentation of the Common Market - reinforced by rigidly national procurement practices - prevents the emergence of world-class, commercially viable technology.

One of the draw-backs of pure liberalisation is that it provides incentives for European firms to cooperate with firms outside Europe, e. g. via licensing agreements, joint ventures, cross-investments, or a combination of these.

These incentives for extra-European technological cooperation increase, if the notion of "Community preference" is extended to non-tariff barriers, (e.g. on mutual recognition of standards), the development of new "Eurostandards", or the opening of national procurement markets. For the higher the degree of joint Community protectionism, the greater the willingness of a foreign partner to market his technology directly rather than through exports. For Community firms, on the other hand, increased competition in a genuinely liberalised internal market forces them to adopt rapidly the best technology available, which for commercial and technological reasons may mean taking on a Japanese or US partner.

Such an outcome has many attractions for the Community. The technological level is at once raised and equalised at a fraction of the cost of publicly sponsored R\&D and regional policies. It does not solve, however, the problem of "technological independence". While some would argue that this is an atavistic concept in the emerging global economy, others assign both an economic and a security value to such independence.

Economically, there is the fear that European firms would not be getting the latest technology from their partners, losing out in export markets to the leaders. Their bargaining position in technology trade would weaken to the extent that first-rate, home-produced technology is not available.

In security terms, technological dependence has two drawbacks. One is the inability to conduct an independent trade policy with the East which, apart form its economic attractions, is Europe's way to give concrete expression to detente. The second drawback is losing the option, in the medium term, to conduct an independent defense policy. Military technology will increasingly advance in the interface between telematics and space technology.

Today's Community, bogged down in the minutiae of haggling over budgets or standards, unable to agree on the terms for enlargement or the completion of the EMS, seems a poor vessel for some of the new challenges. 
Yet in national chancelleries, notably in France and Germany, among leading business men, and in the Commission itself the intellectual and political basis for a new European techno-economic nationalism is being laid.

However, as pointed out earlier, many of the forces creating the new dynamics, and notably the competitive, technology-based mercantilism, contain the seeds of an economic balkanisation of Europe. Other models are conceivable: a la carte cooperation bypassing the Community; between two countries; within Western European consortia; or with a cross-Atlantic link (space shuttle). The point remains that for the first time since the nineteenfifties the Community is developing a rationale for its existence which appeals not to idealism but to hard political and economic interests.

\section{A protectionist Community?}

The new constellation of economic interests stemming from technological competition with, above all, the United States and Japan, has arisen within a longer term context of world-wide competition to which we must now turn. It is only by placing it in a global and long term context that a "non-status quo" scenario for Community trade policy can be developed and its impact on Israel assessed.

To do so, we must at first understand the fundamental shift in the Community's commercial position in the world which has occurred since the 1960s when the basic liberal lines of policy, which are formally still valid today, were being laid.

In the sixties, Eastern Europe enjoyed, collectively, a virtual monopoly in its own and third markets for the bulk of manufactures. This monopoly rested on:

- an overvalued dollar, leading US firms to prefer direct investment over exports. (This overvaluation has again reappeared in the eighties, providing a temporary shield against a now strongly export-oriented US economy);

- the initial Japanese concentration on the US market, and on very few product ranges. Not least in response to US protectionism from the late sixties onward (in textiles since 1961), Japan diversified its export products and its markets;

- Eastern Europe's antiquated capital stock, and the poor design and quality of its manufactures. The modernisation drive with Western equipment and often direct participation of multinationals, plus the creativity released through economic reforms, have made Eastern Europe competitive in a growing number of areas; and

- the development countries (LDCs), having been seemingly permanently constrained by lack of education, infrastructure and capital, from making effective use of modern production techniques. Some are still in this position. 
Other LDCs have managed to combine a newly educated workforce with greatly eased flows of technology and capital, and easier market access, much of it supplied by multinational producers and traders. Relying on domestic underconsumption for economic growth, LDCs are rapidly becoming the most disturbing element in world trade. All signs point to a rapid mastery of production in all but a handful of industrial activities. The quasi-racist notion that brown people will specialise in a few simple, labour-intensive lines, leaving sophisticated production to the smarter whites, is a dangerous fallacy. Of course, the bulk of the initial export successes follow this "comparative advantage" logic. But as happened earlier in Japan, voluntarist industrial strategies are transforming the LDCs collectively into competitors across the whole range of manufactures.

As regards the supposedly "natural" shelters, the goals of a dynamic adjustment strategy, these are generally becoming crowded, low-profit activities, as most Western European countries, Japan, and the United States try to occupy the same space. That space is limited by the composition of final demand, i. e. the continuing need of consumers for routine goods rather than those requiring the most advanced technology. And the micro-chip in tomorrow's washing machine facilitates low-skill production rather than reestablishing a technological shelter.

The problem with the familiar adjustment prescription - from lowtechnology, routine goods to sophisticated goods - is that it works very well for a time. Those two most quickly follow this road (German special steels, Italian high-fashion clothing, French and German specialised cargo ships, etc.) become the success stories - for a few years. Then imitators start crowding the market place, and low profits (losses) re-appear. In the meantime, production capacity at the lower end of the market has been reduced or abandoned. Since the structure of final consumption remains essentially stable, imports make up the difference.

What changes in public attitude - and policies - can we expect from this constellation? First, the goal of achieving a maximum "division of labour" which never had to be tested as long as structurally similar countries exchanged versions of similar products (intra-industry trade) will be called into question. The geography of protectionism will tend to favour partners whose production and export patterns do not require costly adjustment in the form of specialisation at the sector or product-line level; or else partners with whom complementary trade (raw materials) remains important (this includes the superpowers, much of the "white" Commonwealth, OPEC, and Brazil, for example). Israel, for manufactures, belongs in the first category.

Secondly, the economic implications of high-cost labour will have to be faced squarely. As long as the conviction persists that this question can be solved by propelling Europe's (by world market standards) grossly overpaid workforce toward activities with natural monopoly shelters, the problem 
does not have to be faced. As reality becomes apparent, a number of income and equity issues arise.

Thus, there is a seeming conflict of interests between those in the sheltered part of the economy and those exposed to external competition. The former have an immediate interest in raising their real incomes through cheap imports, and in not paying taxes to finance industrial policies. But this conflict is more apparent than real. Public and private services derive only part of their income from mutual exchanges. An important part is derived via exchanges with the exposed economy, through the taxes and markets it provides. Moreover, in a modern welfare state, idled resources not only fail to contribute to national wealth; but they have to be paid as if they did.

To that extent, whether one likes it or not, the exposed part of the economy is part and parcel of the general pattern in our civilisation with its contractual (rather than purely market-determined) forms of exchange. This does have real economic consequences; it also establishes the practical necessity of introducing a contractual element in the exchanges between one universe of contractual payments (Western Europe) and others.

Since these other universes - socio-industrial cultures - differ among themselves and thus impinge to varying degrees on the autonomously developed patterns of contractual payments in the Western European welfare states, such external forms of management by contract must be differentiated. This is part of the logic determining the geography of protectionism.

The socio-economic and structural case for differentiated trade regimes is best summed up by an (overdrawn) bi-polar view of the world. On the one hand there are

- free societies, with unfree labour markets and still relatively free capital markets; and on the other

- largely unfree societies with free labour markets and unfree capital markets.

By free labour markets we understand those societies, including Eastern Europe, where trade unions do not exist or are essentially instruments of management. The description "unfree capital market" does not refer to money capital as such, but to the centrally directed allocation (investment of national savings and/or borrowed capital), usually toward specific (industrial) development purposes. The use of entrepreneurs as agents of such centrally directed investment makes no difference, other than to raise the effectiveness of centrally directed development (as in South Korea).

Europe, Israel, and to an extent North America are characterised by unfree labour markets (wages and disposition of the production factor labour circumscribed by contracts). While the pluralistic allocation of capital means a much wider spread of investment, it also results in investment in social infrastructure capital, services, homebuilding, and other purposes which do not necessarily raise productivity in the tradeables sector.

It is within this double context of wage levels (and other socio-political 
production costs), and the strategic allocation of investment, that the pattern of differentiated trade management, or of the geography of protectionism, will emerge.

A third variable is the institutional capacity for trade management of the various partners. Thus Eastern Europe, which as an extreme case of nonmarket factor pricing and allocation, could be expected to pose difficult problems of co-existence, is quite easy to live with. The central trading authorities "voluntarily" observe what amounts to oligopolistic price discipline in Western markets. One major exception is the shipping market which, being largely non-territorial, makes retaliation difficult.

Japan, too, observes voluntary price-disciplines, as well as negotiated quantity disciplines (VERs and OMAs) once it has gained a substantial market share and/or is faced with the threat of EEC-administered protectionism. While for a long time these were arrangements with national governments and industry federations, they are now increasingly negotiated by Brussels. If the EEC does not assert itself more strongly, this is due not to Japan's inability to cóoperate in trade management, but to divergent views among the Member States on how to deal with Japan. There is, however, a trend to common and more restrictive policies, notably in "infant-industry" high technology areas like video-recorders.

Problems of management are particularly difficult as regards developing countries, not least because of their numbers and the mixture of motives with which the Community approaches them - in a spirit of trade as aid; as promising markets; and as uncomfortable competitors. A look at the different categories of countries shows that regional and functional differentiation of trade regimes can go a long way toward harmonising the different objectives.

The most difficult problem is posed by developing countries who combine low-cost production with industrial targeting, and which are too numerous to be partners in the sort of mutual accommodation and semi-negotiated moderation which is emerging as an alternative to (or flexible version of) unilateral protectionism. Potential exceptions to this are India and China, who together form half the Third World's population (and two-thirds of the low-income population). Both these giants have recently engaged on an export-oriented or -dependent growth strategy which, if successful, would blow away the remnants of a liberal world trading system. Both are conscious of the problem and are said to have discussed ways of avoiding self-exploiting price competition.

The major Newly Industrializing Country (NIC) producers are sufficiently few in number, and present such a large share of potential problems that bilateral approaches are possible, complemented by a general NIC policy (reciprocity!) and existing and future international sectoral understandings (in addition to textiles: ships, steel, perhaps automobiles). More forceful representations as regards exchange-rate policies, social policies, and export 
subsidies of all kinds, if successful, would greatly help to defuse productrelated trade disputes.

For yet another group of developing countries, numerically by far the largest one, the old rather than the new logic of North-South relations prevails : their industrialisation is to be encouraged by aid and trade. For these pre-take-off countries to be able to take advantage of the potential dynamic effects of Western export markets they urgently need an "infant-industry import preference" vis-à-vis their more industrialised LDC competitors. They are thus among the potential beneficiaries of managed trade toward those with greater ability to take advantage of, indeed to shape, their international market opportunities.

By and large, a lessening of trade pressure from the most dynamic and/or large countries would allow a traditional free-market approach to be adopted toward these and similar countries. Trade management, except in sectors such as textiles, would be too cumbersome and inefficient in both administrative and economic terms. Efforts by UNIDO and the World Bank to aid industrial decision-making in these countries through medium-term market forecasts would be worth pushing for, however.

The United States, by contrast, belongs to the high-cost oligopoly of the old industrialised countries. Conflicts arise typically where the state is involved on either side: agriculture for both; European steel exports; US chemicals produced with artificial energy prices; civil/military hightechnology goods. Provided politicians on both sides learn to accept tough bargaining among the two as a normal fact of life, mutual interests are large enough and well enough balanced that the Atlantic Community can stand a fair amount of conflict - normal in civilian politics - without crumbling.

\section{The implications for Israel}

Israel's position in a Community system of differentiated trade relations is determined both by its economic status in the terms of the earlier analysis, and by its political status. A third element, the legal framework formed by the 1975 Free Trade Agreement, gives some medium-term stability to relations. But it may be as important as a defense against political pressures as against the economic ones sketched out above.

In economic terms, unhindered access to the Community market depends among other things on what one might call the "nuisance value" of imports, which is a function of their amount, multiplied by their growth rate, and of their composition. In a world where bargaining would play a greater part than in the past in trade matters, the power of retaliation, i. e. the value of the import market would also count.

Israel's low nuisance value, and its low priority as a Community export market were both reflected in the lop-sided terms of the 1975 Free Trade Agreement under which Israel gained almost immediate access for its 
manufactured exports while being granted a transition period, lasting to 1989, for liberalizing its imports.

What are the reasons for this generosity on the Community's part? The simplest explanation lies in the size of Israel's exports relative to the EC economies: about $0.6 \%$ of the EC's "third country" imports come from Israel. In the protectionist ' 80 s, this may not, however, be small enough. The free-trade agreement between the US and Israel was opposed by the generally pro-Israel AFL-CIO and faced opposition in Congress. And it is worth remembering that in the EC-Israel Preferential Agreement of 1970, which reduced the Community's tariffs by $50 \%$, fully one third of Israel's industrial exports were excluded due to pressures from, inter alia, textiles and chemical interests.

A second reason for the imbalance in mutual obligations lies in the ambiguous status of Israel as an ex-developing country, which as such has a right to favourable treatment. At the same time it is not really a NIC (Newly Industrializing Country), which might be seen as a threat. Not only was the share of industrial exports in national output in 1975 a modest $15.5 \%$ (albeit rising to $20 \%$ in the 1980 s), but the degree of diversification of these exports is high - a sign both of economic maturity and the absence of industrial targeting typical of some of the NICs (cf. Table VII in the contribution by Y. Shachmurove).

Perhaps the clearest expression of Israel's non-NIC status, in the eyes of the $\mathrm{EEC}$, is that it is not subjected to the worldwide protectionist regime of the Multifibre Arrangement (MFA) on textiles. On the other hand, the 1977 Protocols (notably the one on financial cooperation), which form an integral part of the free-trade area agreement, are predicated on granting Israel developing country status. A similar status was granted by the US by including Israel in its Generalised System of Preferences (now superseded by the new US-Israel Free Trade Agreement). On the other hand, Shachmurove gives figures on per capita GNP and other economic indicators which place Israel firmly in the ranks of "normal" European countries.

Thus, Israel's place in this heterogeneous universe of trading partners increasingly resembles that of the EFTA countries. Israel's exclusion from MFA restrictions proves that it is considered a high-cost producer. Similarly, it is the only country among those linked to the EC by Mediterranean freetrade agreements which grants reciprocity.

A more serious problem is raised by the mixed-economy character of Israel's manufacturing sector. About one third of industrial investment is undertaken by the state. While this is not substantially different from Italian or French patterns, not to speak of Spain, the institutional means for coping with this problem (e.g. intra-Community subsidy control) differ.

The problem is made worse by the fact that Israel's public and private industry, the latter heavily supported by public R\&D, is moving strongly into the electronics and telecommunications sector, as well as aerospace, 
which in the Community provide hope of technological regeneration and apt to benefit from de facto infant-industry status. Israel may follow a similar logic against the EEC. If so, it might be vulnerable to a newly proposed flexible Community protectionist instrument, which facilitates tit for tat retaliation to any partner's unfair trading practice.

In practice, three considerations argue against protectionist tensions in the high-tech field. First, in most cases Israel will not produce finished products for final consumption, but highly specialised items for use in other high-tech industries. Secondly, where this is not the case, as in aerospace, marketing will concentrate outside the Community. Thirdly, the small amounts involved, product diversification, and market diversification (US) all militate against EC protections.

The Free Trade Agreement does, of course, provide some security, especially since the Cooperation Council (set up in 1977) needs to be informed before any protectionist measures are taken. On the other hand, Articles in the Agreement concerning the respect of "normal competition" (subsidies!) and the avoidance of "serious disturbances" leave loopholes that can be exploited.

Thus the greatest value of the Agreement may lie in the protection it offers against political pressures aimed at isolating Israel economically and politically. The scope for such pressures has of course diminished dramatically owing to the weakness of the oil market. Thus the future political benefit may be more subtle: forcing the countries of the southern littoral of the Mediterranean to take account of Israel when dealing with the Community in the context of its global Mediterranean policy. Cooperation in common infrastructure projects, and in joint (agricultural) trade management, are a distant possibility at this stage, but may become necessary in a world of shrinking options. 


\title{
Main Economic Trends in EC-Israel Economic Relations Since the Creation of the Common Market
}

\author{
Richard POMFRET
}

The focus of this paper is on merchandise trade, and specifically that part of EC-Israel trade affected by commercial agreements. Trade is not the only economic aspect of EC-Israel relations, but it is in my view the most important. The first section of the paper gives a brief history of EC-Israel commercial diplomacy. The overall picture is one of Israel initially suffering from trade diversion due to EC policies, but this is reversed in the 1970s by the mutual lowering of tariff barriers on a preferential basis. By 1977 the EC had removed all duties on Israeli manufactured exports and reduced barriers to agricultural exports, while Israel's duties on EC manufactured goods are being removed at a slower pace (with a final deadline of 1989). How much has Israel gained from the preferential trade agreement? I have previously estimated, on an $e x$ ante basis, the annual welfare gain from free trade in manufactured goods to be around $2 \%$ of Israeli domestic consumption of these goods, which is a substantial amount. The bulk of the present paper is addressed to the question of whether this prediction can be checked ex post. In the second section the conceptual problems of expost analysis are discussed, while the third section reports an attempt to shed light on this question by econometric methods. The analysis in these two sections is perhaps more forceful in illustrating the difficulties of separating out the impact of commercial agreements from the many other determinants of EC-Israel trade flows during the last turbulent decade, but some conclusions do emerge and these are assessed in the final section.

\section{EC-Israel Commercial Diplomacy}

Western Europe is in several respects Israel's natural trading partner, considering the restricted commercial relations with her geographical neighbors, the climatic differences favoring primary product trade with northern Europe, and the high living standards which provide demand for the type of manufactured goods in which Israel possesses a comparative 
advantage. Not surprisingly, Israeli policy-makers have monitored commercial policy development in Western Europe, seeking to avoid negative economic impacts on Israel and to promote closer trade relations. This has occurred against the background of continual liberalization of Israel's own trade policies, which has eased negotiations by permitting reciprocal "concessions" in the form of improved access to Israeli markets for European exports ${ }^{1}$.

In the year that the Rome Treaty took effect, 1958, Israel submitted a memorandum to the EC Commission about the need for a comprehensive EC-Israel agreement and established a mission to the Commission in Brussels (the third country to do so, after the USA and Greece). In 1960 Prime Minister David Ben Gurion, at a meeting with Commission President Walter Hallstein, expressed Israel's desire to become an associated member of the Community. Despite these early steps, special trade relations were slow to evolve. The first commercial agreement signed in 1964 was non-preferential, with reductions in the Community's MFN tariff on some goods of special interest to Israel. When in 1967 the Commission recommended negotiation of a preferential trade agreement with Israel, this was vetoed by France. In the absence of a major ag reement, the net effect of the creation of the EC customs union and its preferential trade agreements with other countries was to hurt Israeli exports: one estimate is that Israel manufactured exports (excluding diamonds) were reduced by around five percent ${ }^{2}$.

The situation began to change at the end of the 1960s as the Community moved more actively towards preferential agreements with Mediterranean countries and the French veto on an Israel-EC agreement was dropped. In June 1970 a preferential agreement was signed, allowing for $50 \%$ reductions in EC tariffs on Israeli manufactured exports and $40 \%$ reduction for some agricultural exports. There was, however, an exceptions list for sensitive industrial products (covering one third of Israeli industrial exports to the EC) which were liable to full duties, and most agricultural products were not covered by the agreement. Some reciprocity existed, but the tariff reductions promised to Israel were limited.

The actual impact of the 1970 agreement is difficult to evaluate because Israel's competitive position was affected by other events. The EC signed

1 For more detail and further references on the history of EC-Israel trade negotiations see Y. Cohen, "Israel and the EEC, 1958-1978: Economic and Political Relations", in The Economic Integration of Israel in the EEC 13 (H. Giersch ed. 1980); and R. Pomfret and B. Toren, Israel and the European Common Market. An Appraisal of the 1975 Free Trade Agreement (1980). On Israeli trade policies see M. Michaely, Foreign Trade Regimes and Economic Development: Israel (1975); R. Pomfret, Trade Policies and Industrialization in a Small Country: The Case of Israel (1976); and Z. Sussman, "Israel" in Development Strategies in Semi-Industrial Countries (B. Balassa ed. 1982).

2 M. E. Kreinin, "Israel and the European Economic Community", 83 Q.J. Econ. 297 (May 1968). 
preferential agreements almost simultaneously (i.e. over 1969-1971) with most of the other Mediterranean countries, and introduced its GSP scheme for developing countries' exports in 1971. Even more important for Israel was the first enlargement of the Community, as the UK was Israel's largest European export market and UK duties on Israel's major exports were significantly lower than EC duties. Requests for renegotiation by Israel and other Mediterranean preference recipients led the EC in 1972 to adopt a global Mediterranean policy, envisaging free trade in manufactures and substantial agreements on agricultural trade with all Mediterranean countries. Negotiations with Israel (and Spain) should have been relatively easy, but were delayed by the protracted Maghreb negotiations and the EC's unwillingness to appear to be favoring Israel and Spain over its Arab partners. Eventually a free trade agreement (FTA) was signed between the EC and Israel in May 1975.

Under FTA the EC abolished all trade barriers on Israeli manufactured exports by July 1977, subject only to ceilings on a limited number of goods which were removed by the end of 1979. Israeli tariffs on EC manufactured exports were to be removed according to two timetables, with the latest date for removal of tariffs on the most sensitive imports set at 1989. Liberalization of agricultural trade was more limited, with EC tariffs on some $85 \%$ of Israeli exports being reduced by an average $40-50 \%$ and Israeli tariffs on selected agricultural imports from the EC being cut by $15-25 \%$. The FTA also contained safeguard clauses and statement of origin rules.

An important reason why Israel was able to conclude such a far-reaching trade agreement with the EC was that it fitted naturally into a continuous trend towards liberalization in Israeli commercial policy. After the founding of the state Israel had adopted interventionist economic policies favoring import substitution, with high protective tariffs and fixed (multiple) exchange rates. From the late 1950s onwards trade barriers were reduced and increased reliance was placed on the market mechanism. This was done unilaterally through the 1960 s, but there were advantages to taking bilateral steps such as the EC agreements of 1970 and 1975. First and foremost, these agreements by liberalizing imports from such a large supplier could be expected to yield all the gains from unilateral tariff elimination plus Israel gained preferential access to her major market. A secondary advantage of the bilateral approach was that the contractual nature of the EC agreements and the enhanced market access gave Israeli policymakers greater leverage in making import liberalization acceptable to domestic vested interests who had to bear the adjustment costs, Israel's positive attitude towards imports also made it far easier to reach agreement with the EC.

In the long-run there is little doubt that Israel's movement away from the 1950's import substitution policy has been beneficial. One of the strongest conclusions of international trade theory is the optimality of free trade for a small economy. This is borne out by many studies pointing out the costs of 
the distortionary elements in Israeli trade policy ${ }^{3}$. There is a corresponding presumption of benefit from freer EC-Israel trade. Preferential import liberalization could lead to trade diversion if Israel were induced to purchase imports from the EC instead of from the least-cost supplier, but it is unlikely that in a bloc the size of the EC the lowest-cost supplier would be selling at a price much above the global least-cost. Thus Israel can expect to reap the benefits from unilateral tariff elimination plus the benefits from liberalized exports. The next section will consider the magnitude of these benefits.

The main potential drawback of the bilateral approach is the possibility of retaliation by trading partners who find their exports to Israel discriminated against vis-à-vis EC exports. The principal danger here was, of course, with respect to the USA, which was not only the largest single country purchaser of Israeli manufactured exports but also represented a key political and military ally and was the main defender of the principle of non-discrimination in world trade. The specific threat lay in the US Trade Act of 1974, which made equitable treatment of American exports a condition for GSP eligibility. The majority of US exports to Israel consisted of products on the FTA's second timetable, i.e. for which reduction of Israeli duties on EC exports only began in July 1977, and by that date Israel had agreed to reduce her MFN tariffs on 123 goods of special interest to the USA. Partly by taking such steps to specifically avoid discrimination against US exports Israel gained inclusion in the American GSP scheme. Moreover, in April 1978 an US-Israel trade understanding was signed, reducing US duties on thirty items of which Israel is a substantial supplier and which constitute most of the dutiable Israeli exports to the USA. In sum, Israel's access to the American market has not suffered ${ }^{4}$.

The denouement of US-Israel trade relations seems likely to follow the ECIsrael path. Although Israel has been a major beneficiary of the American GSP scheme, this is a non-contractual arrangement and the discretionary graduation clauses introduced in March 1981 pose a serious threat to higher income beneficiaries such as Israel ${ }^{5}$. At the end of 1983 President Reagan and

3 See Michaely, supra note 1; Pomfret (1976) supra note 1.

4 The Israel Economist (December 1983, p. 4) estimates 55\% of Israeli exports to the USA face zero MFN duties and 39\% are covered by the GSP, which in combination with the American position as principal purchaser of Israeli exports suggests a high degree of unimpeded market access. This does not, of course, deny the possibility that with complete elimination of US tariffs exports of those goods currently facing non-zero duties might grow significantly.

5 Some Israeli goods have already been affected by discretionary graduation. Before 1981 there were few restrictions on Israeli GSP-eligible exports to the USA and her average preference margin of $8 \%$ was one of the highest among beneficiary countries. On the basis of the margin A. Sapir and L. Lundberg (The US GSP and its Impacts, mimeo, Universite Libre de Bruxelles, 1983) estimated the GSP-induced portion of the value of 1979 Israeli exports to the USA at $\$ 24$ million, which was placed sixth in rank among all beneficiaries. 
Prime Minister Shamir proposed a US-Israel free trade area, which could make GSP status redundant. Now that the agreement has become operational, by having FTAs with both the EC and the USA, Israel has in effect moved to a free trade policy on imports while gaining free access to her two major exports markets.

\section{The conceptual problems of ex post analysis}

Have the agreements with the EC had a significant impact on Israeli trade flows, and what are the welfare implications of the changes? Three approaches to this of question have been pursued ${ }^{6}$. The simplest is the oracular approach of surveying affected or informed parties (e.g. exporters, importers, policymakers) for their opinion on the agreement's impact. Before the agreement takes effect this approach can indicate intentions and later it reveals whether an impact was perceived, but it gives little idea of magnitudes ${ }^{7}$. The ex ante analytical approach estimates the trade and welfare effects from an explicit economic model, normally partial equilibrium import and export markets models whose parameter estimation requirements are relatively modest. As the 1975 agreement was coming into effect I made such estimates for Israel ${ }^{8}$, which will be summarized in the next paragraph. Finally, expost approaches compare post-agreement trade flows with the flows which would have occurred in the agreement's absence; most of the remainder of the paper will be devoted to such an analysis.

My earlier studies combined estimates of Israeli manufactured export supply and import demand elasticities with the "small country" assumptions of perfectly elastic demand for exports and supply of imports, to estimate that removal of tariffs on Israeli imports from and exports to the EC would have increased these flows by circa $15 \%$ and $14-18 \%$ respectively. The welfare effects associated with these changes in trade flows (i.e. the gain to consumers minus the loss of import-substitute producers and the lost Israeli tariffs revenue in the former case, and the gain to exporters in the latter case) were each estimated at around one percent of Israeli consumption of manufactured goods. As a recurring benefit these are substantial welfare gains. Moreover,

6 P. J. Verdoorn and C. A. van Bochove, "Measuring Integration Effects: A Survey", 3 Eur. Econ. Rev. 337 (1972); D. G. Mayes, "The Effects of Economic Integration on Trade", 17 J. Common Mkt. Stud. 1 (1978).

7 For an application of this approach to the EC-Israel Free Trade Area see B. Toren, "The Competitive Position of Israeli Industrial Branches", in The Economic Integration of Israel in the EEC (H. Giersch ed. 1980).

8 R. Pomfret, "The Economic Consequences for Israel of Free Trade in Manufactured Goods with the EEC", 114 Weltwirtschaftliches Archiv 526 (1978); Pomfret and Toren (1980) supra note 1. 
since the estimates are based on the assumptions of static upward-sloping supply curves, they have a conservative bias insofar as any induced factor inflows, increased technical efficiency or scale economies would increase the effects of EC-Israel free trade?

From the vantage-point of the mid-1980s can we verify whether Israeli trade flows have responded in the predicted manner? One difficulty is that the movement towards free trade is still incomplete. Although EC tariffs on Israeli manufactured exports were removed in 1977, Israeli tariffs are being reduced at a slower rate so that in 1983 she still applied duties (at roughly half of the old rate) on two-fifths of her imports from the EC. For this reason the remaining analysis will be restricted to Israeli exports.

The main problem with expost analysis lies in specifying the counterfactual situation which would have existed in the absence of free access to EC markets. The estimates of increased exports quoted above were based on the assumption that nothing else changed (in order to isolate the preferences' impact), but in fact much changed after the first preferential agreement came into effect in 1970. Therefore simple before-and-after comparisons are inadequate, because they would fail to separate the impact of free access to EC markets from the impact of Bretton Woods breakdown, war and peace in the Middle East, serious recessions in the industrialized countries, and so forth. One way around this dilemma is to examine market shares rather than export volumes or values. In its simplest form this approach assumes that all nontrade-agreement forces affect Israeli exports to each market equally and shifts in the market share of each purchasing country can be ascribed to such agreements.

The export market share approach was adopted by Fishelson, Hillman and Hirsch (1980) in their study of seventy-one Israeli industries' exports to the EC and the USA in 1971 and 1975. They found some support for the hypothesis that the 1970 agreement had an impact insofar as the EC share increased between 1971 and 1975, although the change was concentrated in a few chemical and textiles and clothing industries ${ }^{10}$. The authors were cautious not to overstate their case and emphasized the short time period then available for analysis and the possible role of other forces (e.g. shorter distance may have been important as transport costs rose) in luring Israeli exporters from American to European markets. In discussion of this paper,

9 All of these "dynamic" effects are investigated, and considered possible consequences of the FTA, by Benny Toren in part III of Pomfret and Toren (1980), supra note 1.

10 The dominance of textiles and clothing reflects the high EC effective rates of protection on these goods, so that the tariff preferences were most valuable here. The preferential edge became even more pronounced when the EC tightened quantitative restrictions on non-preferred countries' textile and clothing exports after 1976-1977. See R. Pomfret, "Trade Effects of European Community Preferences to Mediterranean Countries", 10 World Dev. 857 (1982). 
Weinblatt ${ }^{11}$ argued for income effects and Syrquin ${ }^{12}$ for relative price changes as additional influences on export shares.

Table I presents data on the destination of Israeli manufactured exports (excluding diamonds); the listed countries are the nine largest buyers in 1982 plus Japan, which had been a relatively important market for these goods in the early 1970s. With respect to trade agreements these aggregate data can be used to support almost any conclusion. As reported in the previous paragraph the share of Israeli exports going to the original six EC members increased between 1971 and 1975 (from 18\% to 23\%), but if three-year averages before and after the agreement are compared then this share falls from $21 \%(1967-1969)$ to $19 \%(1970-1972)$ ! The share of the Six plus the U.K. was $33 \%$ when the FTA was signed in 1975 and then fell steadily over the next three years $(32 \%, 31 \%, 30 \%)$, but it recovered to $35 \%$ in 1979 and $39 \%$ in 1980 - clearly any before-and-after comparison would depend critically on the selection of years. The post-1975 drop in EC share does not appear to be attributable to the American GSP, which took effect in 1976 when the US share of Israeli manufactured exports was $17 \%$-a share larger than any in the rest of the 1970s.

The fluctuations in the share data suggest that other forces were at work during the period covered by table I. The shift in the world purchasing power in favor of oil producers and newly industrializing countries helps to explain the rapid increase in the share of exports going from "other" countries in table I from $40 \%$ in 1973 to $51 \%$ in 1978 , and its collapse in the early $1980 \mathrm{~s}^{13}$. These trends are independent of Israel's trade agreements, but since all shares sum to $100 \%$, they will affect the EC shares. Thus in examining the agreement's impact I will focus on the distribution of Israeli manufactured exports among the ten more-developed non-OPEC countries of Table I. Even among these ten markets, account should be taken of variations in

11 Weinblatt, "Discussion" of Fishelson, Gideon, A. L. Hillman and S. Hirsch, "Comparative Performance of Israeli Exports in EEC and US markets", in The Economic Integration of Israel in the EEC 173 (H. Giersch ed. 1980).

12 M. Syrquin, "Discussion" of Fishelson et. al. supra note 11.

13 Complete explanation of Israeli manufactured exports to other markets is impossible, because the sources for table I identify only about thirty countries and most of the $1973-1978$ change occurred in the unclassified category, whose share averaged $15 \%$ in $1973-1975$ and over $30 \%$ in $1978-1980$. Among the listed countries the most dramatic changes were with respect to Iran, whose purchases increased from \$34 million in 1973 to a peak of $\$ 115$ million in 1975 and then flattened out in the $\$ 85-92$ million range over the next three years before collapsing to less than $\$ 3$ million in 1980; the Iranian market shares from 1973 to 1980 were $5.2 \%, 6.1 \%, 11.3 \%$, (i. e. second only to the USA in 1975 !), $7.2 \%, 5.4 \%, 4.3 \%$ and $0.1 \%$ - in subsequent years Iran doesn't even merit a separate listing. The shares of nearby semi-industrialized trading partners are volatile in this period; each of Greece, Spain and Turkey accounted for over 2\% of Israeli manufactured exports at some time in the mid and late seventies, but their cumulative share was only $3 \%$ in 1980. 
Table 1: Distribution of Israeli Manufactured Exports ${ }^{\mathrm{a}}$ Among Ten Major Markets, 1967-80

\begin{tabular}{|c|c|c|c|c|c|c|c|c|c|c|c|c|}
\hline \multirow{2}{*}{\multicolumn{2}{|c|}{$\begin{array}{c}\text { Total } \\
\text { (million } \\
\text { US \$) }\end{array}$}} & \multicolumn{11}{|c|}{ Percentage going to ${ }^{\mathrm{b}}$ : } \\
\hline & & USA & UK & BRD & $\mathrm{F}$ & I & NL & B & RSA & SW & JP & Other \\
\hline 1967 & 254 & 12.7 & 14.4 & 11.4 & 1.7 & 2.4 & 2.5 & 4.5 & 1.5 & 1.5 & 1.2 & 46.2 \\
\hline 1968 & 297 & 15.1 & 14.1 & 7.6 & 3.9 & 1.9 & 3.1 & 4.5 & 1.3 & 1.6 & 0.8 & 46.1 \\
\hline 1969 & 358 & 16.4 & 11.9 & 7.4 & 4.6 & 2.1 & 3.1 & 2.8 & 2.2 & 1.6 & 1.7 & 46.3 \\
\hline 1970 & 405 & 20.5 & 11.5 & 6.3 & 4.4 & 2.5 & 4.6 & 1.3 & 2.6 & 1.4 & 1.8 & 43.2 \\
\hline 1971 & 498 & 21.9 & 11.4 & 6.8 & 4.1 & 2.6 & 3.6 & 1.1 & 1.7 & 1.4 & 2.5 & 42.8 \\
\hline 1972 & 561 & 20.3 & 11.8 & 8.0 & 5.2 & 2.4 & 3.2 & 1.3 & 1.4 & 2.3 & 1.3 & 42.7 \\
\hline 1973 & 672 & 19.6 & 13.0 & 10.0 & 4.7 & 3.1 & 3.2 & 1.4 & 1.6 & 2.0 & 1.4 & 40.1 \\
\hline 1974 & 992 & 15.8 & 10.8 & 6.8 & 5.1 & 5.4 & 5.8 & 3.0 & 2.7 & 1.8 & 1.1 & 41.8 \\
\hline 1975 & 1022 & 14.9 & 9.7 & 8.1 & 5.0 & 4.0 & 3.9 & 2.1 & 3.0 & 1.9 & 1.3 & 46.2 \\
\hline $1976^{\circ}$ & 1291 & 16.7 & 9.0 & 7.7 & 5.3 & 4.0 & 3.9 & 2.1 & 2.0 & 1.6 & 0.6 & 47.2 \\
\hline 1977 & 1598 & 15.1 & 9.0 & 8.4 & 4.6 & 3.0 & 3.9 & 2.1 & 1.4 & 1.6 & 0.6 & 50.3 \\
\hline 1978 & 1989 & 15.3 & 9.0 & 7.8 & 3.9 & 3.2 & 4.1 & 1.7 & 1.8 & 1.6 & 0.7 & 51.0 \\
\hline 1979 & 2572 & 15.6 & 10.5 & 9.0 & 4.2 & 5.6 & 4.2 & 1.4 & 1.8 & 1.9 & 0.9 & 44.8 \\
\hline 1980 & 3367 & 12.7 & 10.9 & 10.7 & 4.5 & 7.0 & 4.6 & 1.4 & 2.3 & 2.2 & 1.1 & 42.8 \\
\hline 1981 & 3673 & 19.3 & 9.7 & 7.6 & 5.3 & 4.5 & 3.4 & 1.0 & 2.6 & 2.0 & 0.9 & 43.8 \\
\hline 1982 & 3571 & 19.4 & 8.9 & 7.2 & 4.6 & 4.4 & 3.6 & 1.3 & 2.1 & 1.5 & 1.1 & 45.9 \\
\hline
\end{tabular}

Notes: (a) excluding diamonds.

(b) $\mathrm{BRD}=$ West Germany, $\mathrm{F}=$ France, $\mathrm{I}=\mathrm{Italy}, \quad \mathrm{NL}=$ Netherlands, $\mathrm{B}=$ Belgium and Luxembourg, RSA = South Africa, $\mathrm{SW}=$ Switzerland, $\mathrm{JP}=\mathrm{Japan}$; Other includes unclassified. Percentages may not add to 100 because of rounding.

Source: Calculated from Statistical Abstract of Israel:

1969, pp. 210-11; 1971, pp. 232-33; 1973, pp. 210-11; 1975, pp. 202-03; 1977, pp. $198-99 ; 1979$, pp. 224-25; 1981, pp. 218-19; 1983, pp. 203-31. 
income growth and price changes. The first point is straightforward; exports will tend to increase most rapidly to the fastest growing markets. The second point is more complex and has not been addressed rigorously in the economics literature ${ }^{14}$.

The mechanism by which trade preferences encourage increased trade lies in the higher prices accruing to exporters. In the case of the EC-Israel FTA, assuming Israeli goods to have a small part of the EC market and individual $\mathrm{EC}$ importers to have no monopoly power, all of the EC tariff could now accrue to the Israeli exporțer - a percentage of the price varying from $4 \%$ for transport equipment to $14 \%$ for clothing (the range would be greater if more disaggregated products were included). The ex ante estimates discussed earlier are derived by multiplying these changes by Israeli export supply elasticities. In the post-Bretton Woods world, however, such changes in the relative attractiveness of exports to the $\mathrm{EC}$ could be swamped by the much larger percentage changes in the EC-non-EC exchange rates. Reaction to these two sources of export price changes will not be identical, because while the FTA price changes are permanent shifts the exchange rate changes are not and some exporters will not respond to the latter. If exports can easily be shifted from one market to another, then the profit-maximizing reaction to exchange rate changes large enough to alter the short-run relative profitability is to shift markets, but if exports depend on personal contacts, reputation, etc., then the superior strategy may be to select the export market with the best long-term prospects and stick to it regardless of exchange rate fluctuations ${ }^{15}$. The balance between these two behavior patterns will

14 I suspect this is due to wishful thinking about the empirical validity of the law of one price, which is often assumed in economic theory because in its absence commodity arbitrage would be profitable. With perfect arbitrage an Israeli exporter would receive the same dollar price for a given product in all countries with convertible currencies, and there would be no incentive to shift markets. There is, however, strong evidence of systematic and persistent changes in relative common currency prices at detailed commodity aggregation levels. See e.g. P. Isard, "How Far Can We Push the Law of One Price?", 67 Amer. Econ. Rev. 942 (May 1977); I. B. Kravis and R. E. Lipsey, "Export Prices and the Transmission of Inflation", 67 Amer. Econ. Rev. 155 (May 1977); Kravis and Lipsey, "Price Behavior in the Light of Balance of Payments Theories", 8 J. Int'l. Econ. 193 (May 1978); J. D. Richardson, "Some Empirical Evidence on Commodity Arbitrage and the Law of One Price", 8 J. Int'l. Econ. 341 (May 1978). These studies do not deny the existence of commodity arbitrage, but suggest it to be slow and imperfect. The following paragraph indicates some reasons, from the seller's perspective, why adjustment costs in changing export markets inhibit the arbitrage response to temporary profit opportunities.

15 In 1981 the Israeli government provided compensation for exporters to Europe to compensate for the falling profitability of such sales and introduced an exchange rate insurance facility for the same purpose (Bank of Israel Annual Report 1982, p. 135). Such measures tilt the balance in favor of taking a long view by cutting the opportunity cost of not arbitraging. 
determine the extent to which aggregate export shares respond to exchange rate changes.

In the next section I will try to separate out the above considerations within a multiple regression framework, but I will close this section by describing some of the salient examples. The slowest growing of the ten countries, the UK, also experienced the largest drop in share of Israeli manufactured exports, although the trend was temporarily reversed in $1971-1973$ and $1977-1980$ when the pound appreciated against the dollar. The share of Israeli exports going to the fastest growing country, Japan, increased rapidly between 1968 and 1971 but then fell back again despite the yen's rapid appreciation in 1971-1973 and 1976-1978. The next fastest growing countries, France and the Netherlands, show a pronounced positive relationship between real output growth and their export share, particularly up to 1975 . The role of exchange rates seems most apparent in the behaviour of the US export share, which fell after 1971 and again in the late 1970s but picked up dramatically in 1981-1982, mirroring the dollar's performance in currency markets. These examples suggest that income and price changes do affect export shares and their impact must be recognized before such data can reveal anything about the agreements' economic effects. Such analysis must, however, be based on more sophisticated techniques than simply eyeing the data to find preconceived patterns. For example, the fall in exports to Japan despite a rapidly growing market and appreciating yen may plausibly be interpreted as a consequence of more favorable access to EC markets, but can the same be said of the more or less trendless Swiss export share when slow real income growth and an appreciating currency are pulling in opposite directions. In the Swiss case we need to know something about the relative magnitude of price and income effects, and this applies in varying degrees to the other cases.

\section{An Econometric Model}

This section reports an attempt to model the market distribution of Israeli manufactured exports. The hypothesis is that market shares are determined by the prices and income forces just described:

$$
\mathrm{XS}_{1}=\mathrm{F}\left(\mathrm{P}_{1}, \mathrm{Y}_{1}\right)
$$

although the relationship may be shifted by preferential trade agreements. The dependent variable, $\mathrm{XS}_{1}$, is the share of total Israeli manufactured exports (excluding diamonds) to the ten countries which goes to the ith country. The real income variable, $Y_{1}$, is GNP or GDP in constant local currency prices. The price variable, $\mathrm{P}_{1}$, is the product of the dollar exchange rate and wholesale prices in the ith country; Israeli exporters are assumed to be price-takers whose price varies with the local currency wholesale price 
index, and the value to them of these local currency receipts depends upon the exchange rate. Both independent variables are calculated as percentages of the weighted average of all ten observations for each year; the reasoning is that attractiveness relative to other possible markets is the relevant determinant of export market shares.

The data, techniques and estimates are described in the appendix. The regression results varied greatly in quality and in their characteristics. The results are best for Britain, Italy and the USA, and not bad for South Africa. On econometric criteria the Japanese, Belgian and Dutch equations are good, but each contains a (from an economic perspective) wrong sign. For Germany and Switzerland the hypothesis does not appear to explain the behavior of Israeli export shares at all adequately.

The price coefficient is positive and statistically significant for the United States and for the United Kingdom. The American and British markets appear to have been the most suitable for market shifting in response to shortrun profit opportunities. They are Israel's largest export markets, which presumably permits greater room for manœuvre. Also their price changes were among the three largest ${ }^{16}$ and probably the best publicized. In six other cases the price coefficient has the expected positive sign but is statistically insignificant ${ }^{17}$. Unfortunately my data set is only complete up to 1980 ; inclusion of 1981 and 1982 figures should make the results more robust, because the American share increased as the dollar strengthened.

The income coefficient has the expected positive sign and is statistically significant for Britain, France, Italy, Japan, the Netherlands and South Africa ${ }^{18}$. For the other four countries, the income coefficient is negative, but this may reflect a specification problem ${ }^{19}$.

To test whether the functional relationships were changed by the EC-Israel free trade agreement a dummy variable was introduced for 1975 and later years. The dummy's coefficient is expected to be postitive for EC members and negative for non-members. These expectations were borne out of all cases except the U.K., but only the Italian and Japanese coefficients were significantly different from zero ${ }^{20}$. Only in the latter two cases and Germany did the dummy improve the regression equation's explanatory power (as measured by the adjusted $\mathrm{R}^{2}$ ). The size of the EC effect is best suggested by

16 Only Switzerland had as large price changes, but it has the smallest domestic market of the ten countries.

17 It is negative for Japan and the Netherlands.

18 For Italy and Japan it is only significant after the EEC dummy is introduced.

19 In each case introduction of a lagged variable reduced the negative income coefficient to levels not significantly different from zero. These results are reported for the USA und Belgium in Appendix equations (1a) and (7a). For Switzerland and Germany the adjusted $R^{2}$ is very low.

20 The sign of the French and Belgian coefficients depended on the particular specification used (i. e. linear or loglinear form or whether a lagged dependent variable was included). 
the linear regressions in which the dummy's coefficient is simply the percentage points change in XS ; for Italy and Germany the FTA adds 2.6 and 2.1 points respectively while for Japan it knocks off one percentage point, which are all large percentages of these countries' shares (see table A1).

Despite the defects of the regression results and of the EC test ${ }^{22}$, they do shed some light on our subject. Firstly real exchange rate changes do affect the share of Israeli manufactured exports going to the USA and the UK, her two largest markets accounting for between a quarter and a third of her total manufactured exports during the period studied. In these two cases other prices effects appear to swamp EC preferences as a determinant of their market share of Israeli exports. Secondly, the Italian, Dutch, South African and French shares are all significantly related to real income. This suggests that in these smaller markets Israeli manufactured exports face some demand constraints and the price-taker assumption is unjustified. Thirdly, the results for the other four countries are not totally consistent with my hypotheses. This may be related to market size insofar as Belgium and Switzerland have the smallest domestic markets and Japan is the least important Israeli market in the sample, but the German result is puzzling. Finally, the EC test does indicate that the FTA increased EC members' shares of Israeli manufactured exports and reduced non-members' shares in almost all cases. The magnitude of these changes is proportionately very large for Italy, Germany and Japan, but not significantly different from zero in other cases. Overall, I interpret these results as indicating that forces other than the free trade agreement were strong determinants of the direction of Israeli trade in the seventies, but are difficult to model in a general fashion. Even a relatively crude accounting for other price and income effects allows us to perceive an FTA effect from the export data share, albeit more pronounced in markets than others.

21 The full equations are:

$$
\begin{aligned}
& \mathrm{XS}_{\mathrm{I}}=-86.27+0.18 \mathrm{P}_{\mathrm{I}}+0.74 \mathrm{Y}_{\mathrm{I}}+2.60 \mathrm{EEC} \\
& (-4.07)^{* *} \quad(0.77) \quad(2.70)^{* *}(3.44)^{* *} \\
& \mathrm{R}^{2}=0.81 \quad \text { Adj. } \mathrm{R}^{2}=0.75 \quad \mathrm{~d}=1.22 \\
& \mathrm{XS}_{\mathbf{J}}=6.63-0.08 \mathrm{P}_{\mathbf{J}}+0.05 \mathrm{Y}_{\mathbf{J}}-0.99 \mathrm{EEC} \\
& (2.10)^{*}(-2.61)^{* *}(1.61) \quad(-1.91)^{*} \\
& \mathrm{R}^{2}=0.62 \quad \text { Adj. } \mathrm{R}^{2}=0.50 \quad \mathrm{~d}=2.72 \\
& \mathrm{XS}_{\mathrm{G}}=98.55-0.01 \mathrm{P}_{\mathrm{G}}-0.83 \mathrm{Y}_{\mathrm{G}}+2.12 \mathrm{EEC} \\
& (2.65)^{* *} \quad(0.04) \quad(-2.07)^{* *} \quad(1.14) \\
& \mathrm{R}^{2}=0.43 \quad \text { Adj. } \mathrm{R}^{2}=0.26 \mathrm{~d}=1.67
\end{aligned}
$$

22 The main defect of this test is that EC preferences were gradually introduced over most of the period rather than as a one-shot event in 1975. Nevertheless the 1975 agreement was more far-reaching and its open time horizon and lack of restrictions promised more definitive improved access to EC markets than previous agreements. Also, the EC tariff reductions were scheduled to take effect rapidly. 


\section{Conclusions}

What conclusions can be drawn about the impact of preferential trading agreements on Israeli exports to the European Community? I have said nothing about agricultural exports, which are subject to product-specific terms, and diamonds, which are not affected by customs duties. As far as other manufactured exports are concerned, it is difficult to disentangle empirically a causal relationship, but there are three sets of evidence to support a substantial positive impact.

Logically, it is difficult to imagine that the price incentive given to Israeli exporters by free access to EC markets has not encouraged increased exports. Studies of Israeli manufactured export supply have estimated significant positive price elasticities ${ }^{23}$. There is no reason to believe that these elasticities are not relevant to measuring the response to EC preferences, and on this basis I have previously made $e x$ ante estimates pointing to substantial positive trade and welfare effects for Israel.

It is difficult to test these predictions ex post because other things have changed apart from EC tariffs. The clearest evidence is at the sectoral level. Israeli textiles and clothing exports seem to have responded noticeably in the predicted direction to the 1970 preferential agreement and the FTA24. Fishelson et al also find supporting evidence from some chemical industries. These are precisely the sectors in which my ex ante predictions estimated the largest trade effects -about $60 \%$ of the total export effects were in clothing, textiles and chemicals ${ }^{26}$.

The macroeconomic data are more difficult to interpret. Simple before/after comparisons of export volume are clearly inappropriate, but the second section showed that even using export shares as a control device can be misleading. The analysis of the third section improves over these simple $e x$ post procedures, but is far from conclusive and any conclusions drawn from it must be tentative. With this caveat in mind, these new results do add extra piece of support for the hypothesis that the preferential agreements have stimulated additional Israeli exports to the European Community.

23 See e.g. N. Halevi, "Effective Devaluation and Exports: Some Issues in Empirical Analysis, with Illustrations from Israel", 39 Economica n. s. 292 (1972); R. Pomfret (1976) supra note 1.

24 Fishelson et. al. at 141-143, supra note 11; Pomfret (1982), supra note 10.

25 Fishelson et. al., supra note 11.

26 Pomfret and Toren, supra note 1. 


\section{Appendix}

Table A1 presents the data for the regression analysis. XS is calculated from the source to Table 1. The price variable is the product of the wholesale (or closest similar) price index and an index of the dollar exchange rate (both 1975=100 from International Financial Statistics (IFS) lines 63 and $\mathrm{ahx}$ ) divided by the weighted average of all ten observations for that year (weights are $1975 \mathrm{XS}$ values). The income variable is GDP or GNP in local currency at 1975 prices (IFS line 99) divided by a similar weighted average. The dummy variable, EEC, has a value of zero before 1975 and one in other years.

All equations are estimated by ordinary least squares. The OLS estimates are unbiased but may be inefficient, because the equations are not unrelated (the ten XS sum to 100); for a discussion of the econometric aspects of this type of problem see Resnick and Truman (1975). Both linear and logarithmic forms were run, although the constant elasticity property makes the latter preferable. Results for the basic equation system are reported in Table A2.

I also experimented with a lagged dependent variable to capture delayed adjustment. This is successful for the USA and Belgium:

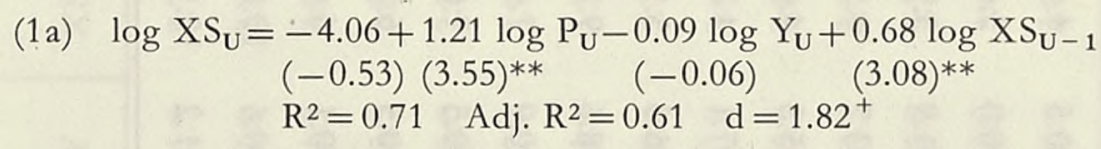

(7a) $\log \mathrm{XS}_{\mathbf{B}}=-8.93+3.23 \log \mathrm{P}_{\mathbf{B}}-1.19 \log \mathrm{Y}_{\mathbf{B}}+0.59 \log \mathrm{XS}_{\mathrm{B}-1}$

$$
\begin{array}{ll}
(-0.51) & (1.23) \\
\mathrm{R}^{2}=0.55 \quad \text { Adj. } \mathrm{R}^{2}=0.39 \quad \mathrm{~d}=2.17^{+}
\end{array}
$$

In both cases the fit is improved and the perverse income coefficient becomes not significant. For the other eight countries, however, the lagged dependent variable had an insignificant coefficient and lowered the adjusted $\mathrm{R}^{2}$.

Introducing the EEC dummy into the basic equation improved the adjusted $\mathrm{R}^{2}$ in only three cases: Italy, Japan and Germany. In each of these cases the sign was as expected and in the first two the coefficient was significant at the $5 \%$ level. However, since both the Japanese and German equations had a significant wrongly signed coefficient for one of the other variables, only the Italian equation is really satisfactory:

$$
\text { (5a) } \begin{aligned}
\log \mathrm{XS}_{\mathrm{I}}= & -56.45 \quad+4.15 \log \mathrm{P}_{\mathrm{I}}+8.49 \log \mathrm{Y}_{\mathrm{I}}+0.42 \mathrm{EEC} \\
& (-4.10)^{* *} \quad(1.27) \quad(2.19)^{*} \quad(3.93)^{* *} \\
& \mathrm{R}^{2}=0.82 \quad \text { Adj. } \mathrm{R}^{2}=0.77 \quad \mathrm{~d}=1.57
\end{aligned}
$$

For the other seven countries the EEC coefficient was not significant, and for the UK and France it had the wrong sign. 


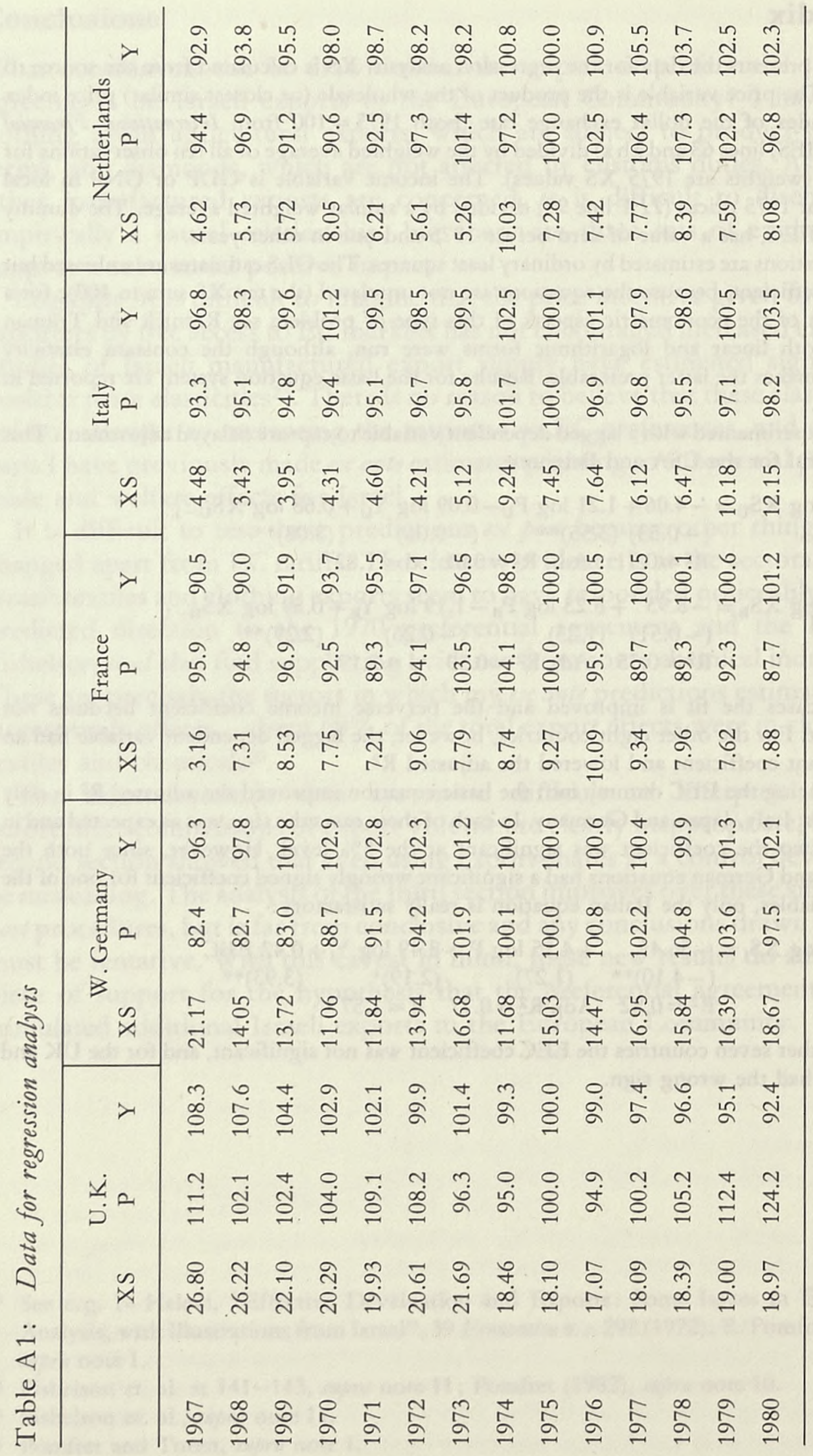




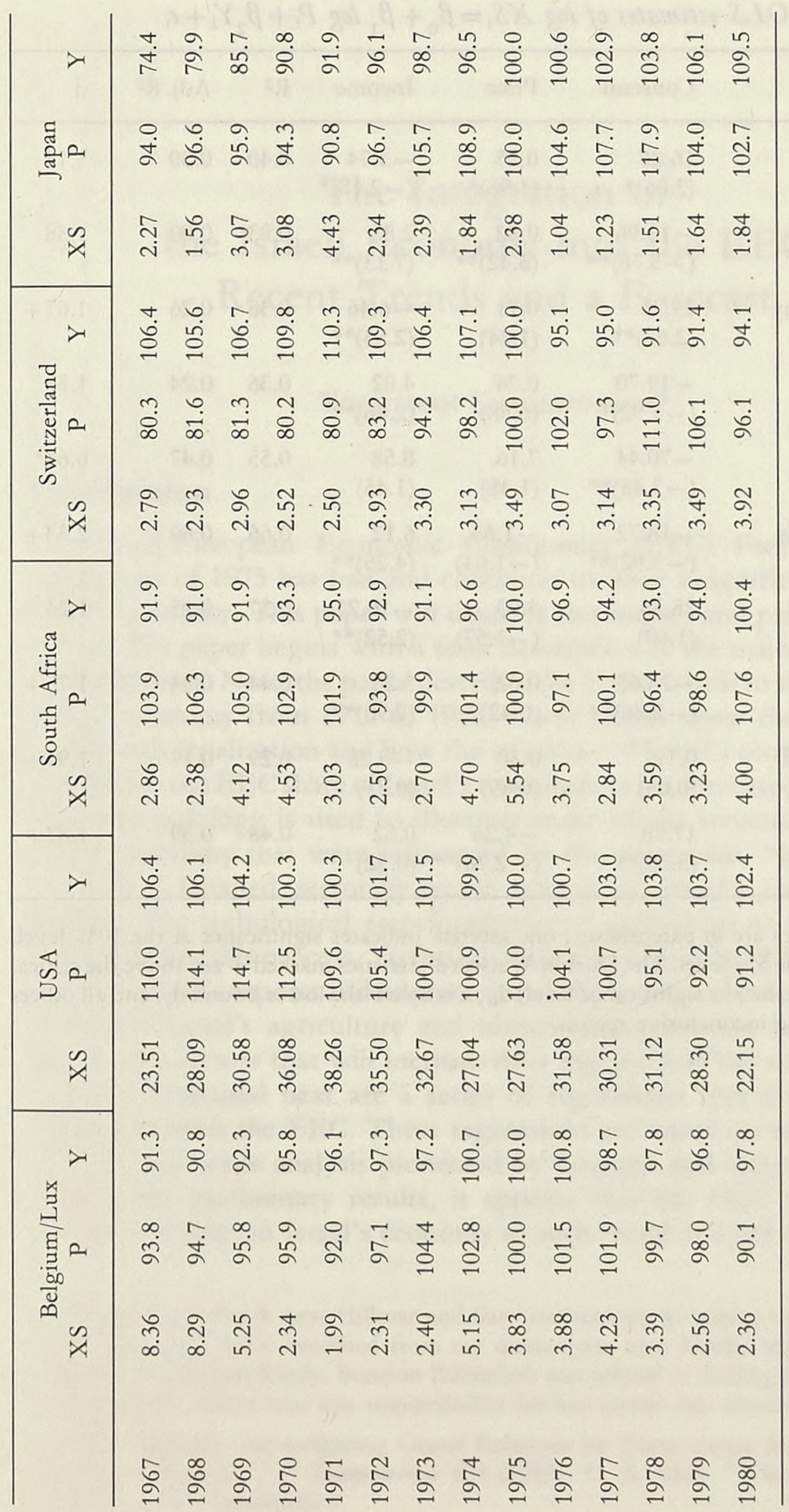


Table A2: OLS estimates of $\log X S_{\mathrm{i}}=\beta_{0}+\beta_{1} \log P_{\mathrm{i}}+\beta_{2} Y_{\mathrm{i}}+e_{\mathrm{i}}$

\begin{tabular}{|c|c|c|c|c|c|c|c|}
\hline \multicolumn{2}{|c|}{ No. Country } & \multirow{2}{*}{$\begin{array}{l}\text { Constant } \\
16.26 \\
(2.06)^{*}\end{array}$} & \multirow{2}{*}{$\begin{array}{l}\text { Price } \\
0.95 \\
(1.98)^{*}\end{array}$} & \multirow{2}{*}{$\begin{array}{l}\text { Income } \\
\begin{array}{c}-3.74 \\
(-2.18)^{*}\end{array}\end{array}$} & \multirow{2}{*}{$\frac{\mathrm{R}^{2}}{0.40}$} & \multirow{2}{*}{$\frac{\text { Adj. } R^{2}}{0.30}$} & \multirow{2}{*}{$\frac{d}{1.13}$} \\
\hline 1 & USA & & & & & & \\
\hline 2 & UK & $\begin{array}{l}-13.96 \\
(-5.76) * *\end{array}$ & $\begin{array}{l}0.82 \\
(3.42)^{* *}\end{array}$ & $\begin{array}{l}2.86 \\
(7.13) * *\end{array}$ & 0.83 & 0.80 & 1.38 \\
\hline 3 & W. Germany & $\begin{array}{l}29.25 \\
(2.63)^{* *}\end{array}$ & $\begin{array}{l}0.71 \\
(1.34)\end{array}$ & $\begin{array}{l}-6.46 \\
(2.53)^{* *}\end{array}$ & 0.38 & 0.26 & $1.67+$ \\
\hline 4 & France & $\begin{array}{l}-19.70 \\
(-1.92)^{*}\end{array}$ & $\begin{array}{l}0.74 \\
(0.58)\end{array}$ & $\begin{array}{l}4.02 \\
(2.46)^{* *}\end{array}$ & 0.36 & 0.24 & 1.38 \\
\hline 5 & Italy & $\begin{array}{l}-70.44 \\
(-3.48)^{* *}\end{array}$ & $\begin{array}{l}7.16 \\
(1.48)\end{array}$ & $\begin{array}{l}8.58 \\
(1.45)\end{array}$ & 0.55 & 0.47 & $0.64 *$ \\
\hline 6 & Netherlands & $\begin{array}{l}-18.72 \\
(-3.92)^{* *}\end{array}$ & $\begin{array}{l}-1.63 \\
(-1.64)\end{array}$ & $\begin{array}{l}6.12 \\
(4.25)^{* *}\end{array}$ & 0.66 & 0.60 & $2.33+$ \\
\hline 7 & Belgium & $\begin{array}{l}25.38 \\
(1.60)\end{array}$ & $\begin{array}{l}4.93 \\
(-1.57)\end{array}$ & $\begin{array}{l}-10.21 \\
(2.52)^{* *}\end{array}$ & 0.37 & 0.25 & 1.24 \\
\hline 8 & S. Africa & $\begin{array}{l}-25.65 \\
(-2.46)^{* *}\end{array}$ & $\begin{array}{l}0.62 \\
(0.42)\end{array}$ & $\begin{array}{l}5.28 \\
(2.90)^{* *}\end{array}$ & 0.44 & 0.34 & $1.75+$ \\
\hline 9 & Switzerland & $\begin{array}{l}0.19 \\
(0.03)\end{array}$ & $\begin{array}{l}0.50 \\
(0.89)\end{array}$ & $\begin{array}{l}-0.28 \\
(0.31)\end{array}$ & 0.29 & 0.17 & $1.94+$ \\
\hline 10 & Japan & $\begin{array}{l}17.98 \\
(3.30)^{* *}\end{array}$ & $\begin{array}{l}-4.26 \\
(-2.76)^{* *}\end{array}$ & $\begin{array}{l}0.52 \\
(0.52)\end{array}$ & 0.48 & 0.39 & $1.87+$ \\
\hline
\end{tabular}

Note: t-statistics are in parentheses; one asterisk indicates significance at the $10 \%$ level, two at the $5 \%$ level. The Durbin-Watson d-statistics marked + are above the critical value (at the $5 \%$ significance level) $d_{u}, x$ is below the lower bound $d_{1}$, and all others are in the inconclusive region. 


\title{
The Integration of the Israeli Economy into the EEC: Recent Trends and a Forecast
}

\author{
Yochanan Shachmurove*
}

\section{Introduction}

The Israel-European Economic Community (EEC) Free Trade Area Agreement of 1975 has had and continues to have a significant impact on Israel's economy. This paper will describe this impact and predict its future course. The paper begins with a brief description of the main provisions of this agreement. Next, the paper describes the broad trends in the structure of Israel's economy from 1970 to 1980 . These trends show the evolution of Israel's industrialization and how the structure of Israel's economy has been modified as the EEC share of Israel's total exports has increased. Chenery and Syrquin's typology is used to illustrate some of the structural changes in Israel's economy that were influenced by the agreement. Next, the paper provides a detailed sector-by-sector review of Israel's industrialization process. The techological transformation of agriculture is considered an integral part of this process. To further clarify the role of the EEC agreement, trends in Israel's exports and imports since 1980 are described so that one may see where Israel's agriculture and industrial exports are headed; i.e. to identify the sectors that will increase their exports and the sectors that will contract. Presented next are a series of regressions that describe Israel's integration with the EEC. These regressions are based on recent development in time series analysis pioneered by Granger and Sims ${ }^{1}$.

From the preliminary results, it appears that the EEC influences key national variables in Israel's economy as such: total and per capita national

* I would like to thank Arye Hillman and Ilan Greilsammer for encouraging me to pursue this research. I have benefited from my discussions with Moshe Mandelbaum, Zeev Hirsch and Robert Sandy. Benzion Zilberfarb was helpful in finding financial support. None of the above bear any responsibility for any errors that remain.

1 C. W. Granger, "Investigating Causal Relations by Econometric Models and CrossSpectral Methods", 37 Econometrica 424 (1969); C. A. Sims, "Macroeconomics and Reality", 48 Econometrica 1. 
income, disposable income, total and per capita gross domestic product, expenditure on government consumption, exports of goods and services and wages in manufacturing. The EEC countries that have the greatest impact on the above key national variables are, in declining order, West Germany, Denmark, Italy, the Netherlands, and a newcomer to the EEC, Spain. Finally these trends and regressions are used to make some predictions and offer some reflections of the future of Israel's industrialization and its trade with the EEC.

\section{The 1975 Free Trade Agreement}

Two fundamental considerations have shaped Israel's policy toward the EEC: first, Israel's dependence on foreign trade for economic growth and survival, and second, Israel's geopolitical conditions such as the trade barriers posed by the Arab boycott of Israel. These considerations caused Israel to seek a comprehensive agreement with the EEC. Accordingly, there was no public disagreement within Israel concerning the signing of a Free Trade Area Agreement with the EEC. It was widely viewed as a diplomatic success even though it favored the EEC countries by, for example, protecting the European agricultural sector while most of Israel's exports to the EEC are agricultural and by sharply lowering Israel's tariffs on the EEC's industrial goods which are Israel's main import from the EEC. Further details of the economic and political considerations influencing the policies adopted by Israel's government, the history of the negotiations and their outcomes are discussed in Cohen ${ }^{2}$.

The 1975 agreement includes two main components:

a) The formal content of the agreement, which concentrates on the gradual reduction of tariffs on both sides. This component enabled the export of Israel's industrial goods under conditions of equal competition (at least in terms of tariffs) with goods of the member states of the EEC itself and with other countries which are linked to the EEC by similar agreements. The EEC tariff reductions should not be considered the main reason for Israel's interest in the agreement because the reductions were not substantial. The Preferential Agreement of 1970 already enabled Israel to enjoy considerable tariff concessions and the external tariff level of the EEC against industrial goods was not high. In addition, the number of countries which enjoy preferences similar to those of Israel is constantly growing. However, if Israel had not made its agreement with the EEC, its trading position would have worsened as more countries joined the Common Market or negotiated preferences with the EEC. The advantage of the agreement in the short run arises mainly from avoiding discrimination against Israel's exports to the EEC in favour of other

2 Y. Cohen, "Israel and the EEC 1958-1977: A Short Historical, Political and Economic Review", David Horowitz Institute (Nov. 1977). 
competitors in Europe, the Mediterranean, in the Caribbean and the Pacific islands (The Lomé Agreement). In the long run the advantage of the Israel$\mathrm{EEC}$ agreement lies in integrating Israel's economy into the EEC by forcing structural changes in Israel's economy.

b) The Supplementary Protocol on Industrial, Scientific and Economic Cooperation between Israel and the EEC, and the Financial Protocol, which were attached as codicils to the Free Trade Area Agreement. The Supplementary Protocol was intended to equalize the conditions granted to Israel with those of other countries in the Mediterranean basin. Through the Supplementary Protocol the EEC made a commitment to help Israel's industrial development by encouraging purchases of Israel's manufactured goods, organizing meetings of industrialists, abolishing non-tariff barriers, and facilitating the transfer of technology and patents. The Financial Protocol enables Israel to draw from the funds of the European Bank for Investment. To date Israel has not made any extensive use of these funds.

\section{Broad Trends}

The Chenery and Syrquin classification system can be used to show the status of Israel's industrialization ${ }^{3}$. They classified industrial countries in a range starting with "early stage" to "mature". At the time of signing the agreement with the EEC, Israel was in the process of transition from a developing economy in the early stages of industrialization to a developed WestEuropean-type industrial economy. In the mature industrialized countries the importance of manufacturing expressed as a share of output and employment is on the decline while in the countries which are in the process of rapid industrialization the share of manufacturing in output and employment is growing.

Using pre-1970 data, Chenery and Syrquin used per capita national income, population and ten other criteria, to classify the economies of 101 noncommunist countries. Chenery and Syrquin methods are an extension of the pioneering work of Kuznets ${ }^{4}$. Israel was classified among the countries oriented towards small industry which had a relatively high per capita income. Among the twenty countries with these characteristics Israel was further classified in the sub-group of countries with the smallest populations (up to five million) that did not rely primarily on one industry. Other similar countries among the twenty were Ireland, Denmark, Norway and Finland. As for the capita income among the twenty countries, Israel was comparable with Austria and Italy. From the criteria of ratio of imports to gross domestic product (GDP) among the twenty countries, Israel could be compared to Switzerland, Denmark and Portugal. Within this group, the share of Israel's

3 H. Chenery and M. Syrquin, Patterns of Development 1950-1970 (1975).

4 S. Kuznets, Modern Economic Growth (1966). 
industry total output was low, comparable to Finland, Italy and Norway. The share of industry in employment was similar to that of Denmark, Norway, Spain and France. Also within the twenty countries, the share of industrial export in output was low in Israel as it was in Ireland and Spain.

Development through the 1970s has shown some changes. In 1975, for example, Israel's per capita income was higher than that of Austria and Italy and even higher than the per capita income of England. It approached the capita income of Belgium, Holland and Finland. Chenery and Syrquin's typology was used to re-classify the twenty small-industry-high-income countries that they previously identified using the 1965 data. The twenty countries were divided into three groups according to their per capita income. Group one included the countries with the highest per capita income. In these countries (Denmark, Norway, Sweden and Switzerland) the importance of industry in output as well as in employment has decreased over time. This trend has been observed by Chenery and Syrquin in their 1950 to 1970 data. The second group of countries shows a decrease or no change in the importance of industry in employment while there is a continuation in the growth of its importance in output, i.e., an increase in efficiency and/or transfer to capital intensive goods or goods with a higher per unit value. Israel, Austria, Belgium, Holland and New Zealand are included in the second group. The third group, in which the two weights increase dramatically, includes Finland, Greece, Ireland, Portugal and Puerto Rico, i.e., all the countries which started their main industrialization during the 1970 s and in which great progress in industrialization took place. Israel is on the border between the two last mentioned groups. Table I contains selected statistics that profile the development of fourteen of the small-populationhigh-income countries from 1965 to 1980. Economic indicators for the period 1963-1982 for the industrial world are given in table II.

Tables I and II show that the agreement with the EEC forced internal adjustments in order to achieve a structure which is better adapted to competitive conditions and more integrated with world markets. In the next section of the paper, a sector-by-sector review of changes in Israel's economy will show how the Israel-EEC agreement brought increased efficiency to Israel's agricultural and industrial spheres and how the Agreement helped concentrate Israel's production on goods which will continue to have a comparative advantage under the Agreement.

\section{Detailed Trends}

A sector-by-sector analysis of recent economic developments in Israel can provide a clearer picture of the changes caused by the EEC Agreement. This review is limited to the agricultural and manufacturing spheres of Israel's economy. The agricultural sphere will be reviewed first.

The agricultural sphere of Israel's economy constituted 6 to 8 percent of 
the national product in 1982 and 1983 and it continues to increase its share both in terms of national product and employment. The rate of growth of productivity has been positive and has increased during the last decade. The agricultural sphere is characterized as "intensive" as far as research and development ( $R \& D)$ is concerned. The capital-labor ratio of the agricultural sector is second only to the electrical sector because numerous investment projects were made in agricultural research, both applied and basic. This substantial investment in agriculture in the recent past is a continuation of a policy that has been followed since the founding of Israel. However, Israel's agricultural sector has always been hampered by the small size of the local market. Various private and state planning agencies clearly saw that the agricultural terms of trade would worsen if external markets were not found. Without access to external markets the prices of agricultural products relative to the consumer price index would fall. Since the income elasticity of agricultural products is less than one, the agricultural share in the national income would diminish as Israel's income would increase. However, this scenario did not materialize since the export markets were discovered, mainly in Western Europe.

Between 1948 and 1981 Israel had a policy of subsidizing and regulating a broad range of agricultural products, both those intended for domestic consumption and for export. Farmers knew well in advance their input prices and production quotas and their profits were virtually guaranteed. Agricultural organizations exercise their power through marketing boards. The system of subsidies was used not only to lower prices but also served as a means to enforce production limits upon the farmer. The policy of subsidizing the production of agricultural exports had the consequence of subsidizing EEC consumers. As agricultural exports to the EEC increased the real burden of these agricultural subsidies also increased.

As part of a general move towards a more market-oriented economy the export subsidies on agricultural products were substantially reduced in 1981. The result of this action was a severe dislocation within Israel's agricultural sphere. One example of the new policy is the reduction of the subsidy for water. The profitability of water-intensive agricultural products has decreased sharply. A second example is the reduction in the subsidy for energy. The farm sectors which are energy intensive such as flowers grown in hothouses became unprofitable when the subsidies were reduced. The impact of these dislocations within agricultural cannot, as yet, be shown on the macroeconomic level because, overall, agriculture remains prosperous. It is not clear that this prosperity can be maintained, particularly with regard to exports. Available data for the first four months of 1984 already show an increase in industrial exports but a $30 \%$ reduction in agricultural exports compared to the same period in 1983.

Even though there were substantial gains in farm productivity and an increase in the overall farm income, farmers of some commodities have 
suffered greatly. Evidence of this distress can be seen in the recent protests by Israeli farmers. The already powerful Kibbutzim movement gained because this group had the resources to shift their product mixture towards the products which have had increased exports. The Moshavim movement was severely hurt because the new export products such as avocados, kiwis, pecans, and nectarines required more capital, labor, gestation time, and research than these relatively small farms could provide.

One can note the irony of a political regime, the Likud, strengthening an agricultural movement which had always opposed it while the independent farmers and Moshavim who had shown more support for Likud were weakened. The abandoned agricultural planning had given security to the independent farmer, "the Moshavnik", who had enjoyed moderate success in the Upper Galilee, the Mountain Region or in the Jerusalem Corridor. As a result of the Likud policy, the Moshavim have exhibited profound sociological disturbances. At this point more thorough research is required if one wishes to know the implications of reduced planning in the different sectors.

A sector difficulty facing Israel's agriculture is the weakening of the European currencies vis-à-vis the American dollar. The weakening of these currencies has caused difficulties because most of Israel's fresh products are shipped to Europe. The most affected sector is the citrus which began to have trouble in covering its costs in 1980 and since 1982 has not been able to cover $30 \%$ of its costs. The Jaffa orange, which had been for many years an important source of hard currency and a famous Israeli trademark, may disappear from the European market unless substantial technological changes are applied to its cultivation.

A third difficulty is that other countries have increased and will continue to increase their competition against Israel's agricultural products. In part, the increased competition is caused by other countries adopting technology developed in Israel. Israel's transportation and product processing methods are gradually being copied all over Europe. This competition became keener when Greece entered the EEC and it will be keener still when Spain and Portugal become full members of the EEC.

Table III summarizes the development of the agricultural exports from 1977 to 1983 and table IV describes the distribution of agricultural output over the years 1979 through 1983.

The increase in the output of the agricultural sector which was accompanied by a decline in inputs shows that there was an increase in the productivity of agriculture. Output per unit of labor increased, on the average, by 8.4 percent per year from 1979 to 1983 and the output per unit of capital and labor (total productivity) increased by $6.2 \%$ per annum over the same years ${ }^{5}$.

5 See Bank of Israel Annual Report, 1983, at 116. 
Table $\mathrm{V}$ describes the annual increase (in percent) in Israel's direct agricultural exports from 1973-1982. Greece in 1979 becomes the 10th member of the EEC. Spain and Portugal are now in the process of joining the EEC. These three countries compete against Israel in winter oranges, tangerines and lemons, but not yet in the grapefruit and blood orange markets. Avocados and melons are not yet seriously affected. However, competition is growing in flowers, strawberries and peaches. Even greater competition exists with vegetables as well as cotton where Spain has tried to substantially increase its production.

A crucial factor related to agriculture and its export is the processing of agricultural products. Food processing, which involves cooking and packaging food so that it will be more convenient for the consumer, has grown in importance in both the domestic and the export market. For example, the Israeli company, Sunfrost, claims that its products are "more fresh than fresh" because of its processing techniques. The processed product represented $50 \%$ of the total agricultural output at the beginning of the last decade but $75 \%$ in 1983. In comparison, in the United States, the processed agricultural product represents $95 \%$ of total agricultural output. The industrial processing of agricultural products will help solve the problems related to expanding export markets. Indeed, it is easier to market citrus juices in Canada and in the USA than to market fresh fruit in Western Europe. Processing will deeply affect the agricultural sphere because the prices of processed foods are less sensitive to surpluses or shortages than fresh products and will provide an impetus for organizational reforms in Israel's agriculture. As agriculture becomes more industrialized, surpluses will fall and agricultural boards will lose their influence because industry can offer fixed contracts to the farmers. In 1983, agricultural exports declined but agricultural processed products did not follow the same trend. Nevertheless, this trend towards processed products does not represent a panacea for the problem of low agricultural incomes because processed food is relatively cheaper at the wholesale level than fresh food. For example, a "processed" orange brings the farmer one-third the revenue of a fresh orange.

Next is a discussion of the effect of the EEC agreement on the industrial sphere. Industry, like the agricultural sphere, has developed export markets. About 50 percent of the industrial output is exported including exports of military equipment. Industry constitutes $34 \%$ of the national product in 1983 , and $24 \%$ of employment. This gap between the share of industry in output and employment is widening. The export industry in Israel enjoys more fixed capital and higher daily wages than total industry as can be seen in table VI.

The industrial sector in Israel has undergone a process of substantial technological development. This technological development began later in the industrial sphere than the agricultural sphere. The industrial sphere has become research intensive as can be measured by the weight of expenditures 
on research and development and its share of university-trained personnel. Yet, the number of employees with some university training is lower (about $6 \%)$ in the industrial sphere than in the entire labor force $(28 \%)$. This low figure suggests that industrial firms will not be able to press ahead with the technological changes needed to keep Israel competitive in foreign markets. However, the number of university-trained employees in the industrial sphere has doubled since 1967.

Through the 1970 s dramatic changes occurred in the scope and structure of the industrial export sector. From $\$ 394$ million in 1970 , (excluding diamonds) the nominal value of these exports rose to $\$ 3,264$ million in 1980 , a real annual growth of 11.4 percent. In 1981 overseas sales of industrial goods (excluding diamonds) grew twice as fast as sales to the domestic market. Export value added (direct and indirect) averaged 28 percent of the sector's product in 1968-1972, but rose to fully half of the product in 1980-1983. Basic changes also occurred with regard to the structure of exports. The sectors whose exports grew most rapidly were transportation equipment, electronics, miscellaneous manufacturing, basic metals, metal products, machinery, and chemicals. These trends are apparent in table VII where significant changes are present in the ranking of sectors according to their export share, relative to total industrial exports. The five sectors with the highest export shares in 1970 were, in declining order, food, clothing, chemicals, textiles, and mining. However in 1980 they were chemicals, transportation equipment, metal products, clothing, and food. The electronics and miscellaneous manufacturing sectors jumped from the 9th and 10 th place respectively to the 6 th and 7 th place, while textiles and mining dropped from the 5 th and the 6 th (in 1970) place to the 10th and 9th place in 1980. The share of total output exported increased (see table VIII). Miscellaneous manufacturing, which include scientific instruments, optical and photographic equipment, clothing, mining, chemicals, transportation equipment and machinery have the highest share of output exported in 1980 . Most of the sectors with rapid export growth and the highest export related increases in output are the sophisticated equipment fields. In these fields one finds many qualified scientists, engineers, programmers and the existence of research and development programs. On the basis of table VII and VIII one can infer that Israel's comparative advantage has been shifted during the 1970 s and the early 1980s. The human capital intensive industrial sectors in 1980 were: electronics, transportation equipment, miscellaneous manufacturing, chemicals, machinery, metal product and rubber and plastics.

The changes in the structure and value of Israel's industrial exports necessitated production in bigger series. Many local plants have enlarged their production lines and marketing networks. Thus, export production has become increasingly concentrated in the hands of a relatively small group of enterprises (see table IX - Concentration of Industrial Export. 1977-1981).

This trend is extremely important and is still one of the problematic aspects 
of the organizational structure of industrial firms in Israel. In 1975, approximately 11,250 industrial plants and workshops employing salaried workers, 5,150 employed less than 5 workers and another 2,500 or so employed up to 10 workers. The ongoing trend in the growth of the size of the firm is still weak, even in comparison with the units in the small developed countries abroad. This is a critical obstacle from the point of view of economies of scale for attaining efficiency, adopting new technologies, employing high levels of human capital, etc. Table X in the last two columns compares the centralization of industrial sectors according to the percentage of export of the three biggest companies in that sector.

The increase in exports of sophisticated products developed locally was accompanied by a steady increase in government research and development grants, which went mostly to the large firms - those which have enough resources and managerial skills to use highly skilled labor and to implement large-scale experiments and tests. In 1977-1980 these grants increased annually by a real average of 7 percent and by 15 percent in 1981 . However, the total amount (e.g. $\$ 5.6$ million in 1981) is still low. In addition, the present system of grants, which in many cases are given after long delays (and without indexation), is apparently failing to achieve its purpose. Such aid is often too small to be a decisive factor.

Table XI gives Israel's trade balance since 1979 by geographical area. One can note that consumer goods exported once by Israel, such as textiles and leather goods have been largely replaced by science-based and metal equipment including electronic components, transport equipment, medical machinery and telecommunication systems.

Depending on how Israel reacted to the opportunity, the 1975 EEC-Israel Agreement has the potential for either expanding the exports of Israel's industrial goods to the EEC or to replacing much of Israel's industrial production with EEC-made goods. The results to date are that Israel's industrial sphere has expanded. Overall industrial exports to the EEC have risen by about 10 percent per year. The persistence of this trend in 1981-1983 stands out in view of the developments, both internal and external to Israel's economy, which could have harmed Israel's exports. Internally, increases in domestic demand increased competition on the part of the home market for export products and externally, international trade has been reduced because of a world wide recession. Furthermore, the weakening of the major European currencies against the dollar has limited the ability of the EEC, Israel's major trading partner, to purchase Israel's goods.

Three main strategies can be identified as causes of this expansion.

1. Israel has been successful in industrial sectors which are research and development oriented. As the percentage of a firm's total expenditures devoted to research and development increases across firms the percent of output that is exported increases. The data on R\&D expenditures can be supplemented with data on the fraction of employees with university 
training. Firms with a high fraction of university-trained employees had the greatest gains in exports. Thus, those firms in Israel which are export leaders are the ones which started research and development projects of new or modified products and only later moved to the stage of actually producing the products. An insight that merits wider recognition is that Israel's comparative advantage is not in assembly or completion of industrial products but rather in the research and development of new products. Such research and development usually takes place in the home country of a multinational firm but Israel has become a research center for foreign firms. For example, Intel's investment of $\$ 150$ million that started the development of a new software. The modification of existing ideas or the redesign of a product will do better than assembly projects. Highly capital intensive products or brand new technologies may be a poor strategy for Israel's development. For example, sending a man to the moon is not within the scope of Israel's resources but a laser beam to be used in the space program can be developed by Israeli scientists.

2. Israel has done better in products for which the marketing outlays and penetration costs are relatively low. For example, a successful area for Israel's industry is medical equipment. The reason that the marketing costs are low is that these products are sold to small groups of professionals who are well informed about the technical qualities of the product. The Arava business jet and sophisticated weapons are other examples. Israel has not been successful when it has tried to penetrate the mass consumer market which requires extensive advertising and distribution networks. A possible exception is women's high-fashion clothing. Israel also has had difficulty in marketing products which are characterized by increasing returns to scale. For example, in 1982 overall exports increased moderately while small firms suffered the most in terms of contraction of their exports. The barrier of a lack of a distribution network can be circumvented by manufacturing for a foreign company that has an established distribution network, but this solution can only work if the scale economies are not too high. Further, private label manufacturing tends to offer lower profits than selling a product under a company's own name.

3. Israel's exports have done better when the transportation costs for a product were low relative to the product's price. Generally, Israel imports raw materials and sends abroad completed products. Thus, Israel will have higher profits in gold and diamonds than in iron or steel.

The EEC-Israel Agreement also affected Israel's imports. Table XII gives the goods and services account in 1977-1981. The decline in the relative price of the imported goods and the economic situation in Europe can explain the increase in imports. In 1981-1982 the annual average rise of import and export prices in Israeli currency terms (at the effective rates of exchange) trailed behind the domestic inflation rate (see table XIII). 
Table XIV divides the factors affecting exports into the level of world trade and the change in relative prices. Table XV gives the geographical distribution of Israel's export according to sectors for the years 1980-1981.

\section{A Regression Analysis}

In order to ascertain the extent of the integration of Israel's economy with the EEC, annual data was collected on such key variables as: per capita disposable income, gross domestic product in purchaser's value, per capita gross domestic product in dollars, expenditure on government final consumption, export of goods and services, earnings in manufacturing, rates of discount of central banks, consumption of primary energy, and production of energy. Each variable was brought to a common denominator of $1977=100$ and regressions were run using data from the following states: Israel, Denmark, France, West Germany, Ireland, Italy, the Netherlands, Spain, Luxembourg, the UK and Belgium.

The objective of this procedure is to find regularities in the data. This approach is in the spirit of the vector auto regression time series analysis developed by Granger and Sims ${ }^{6}$. One way to test if integration between Istael and the EEC is taking place is to see how variables from EEC countries help predict (or cause in Granger sense) Israeli variables, in particular the same Israeli variables. Data problems prevented the division of the sample to pre- and post-1975. Moreover, the year 1975 may not be a good dividing line because Israel has had a Tariff Preference Agreement with the EEC since October 1958, the Free Trade Area Agreement was anticipated before 1975, and for some sectors the Agreement was not implemented until July 1977.

In the following regressions the Israeli variable is the dependent variable. The first and second lagged value of the Israeli variable as well as the concurrent, first and second lagged values of the same variable for various EEC countries are the independent variables. The equations presented are those which gave reasonable $t$-values for a given $\mathrm{R}^{2}$. The equations are presented in the following order: per capita disposable income, gross domestic product, per capita gross domestic product, exports of goods and services, earnings in manufacturing, discount rates of central banks, primary energy consumption, energy production. For each variable a stepwise regression procedure was utilized as well as a maximum $\mathrm{R}^{2}$ procedure. Generally these two procedures selected the same independent variables as having the most influence on the Israeli variable. When these two procedures selected different variables both equations are reported. The stepwise procedure adds variable one at a time to the model and the $\mathrm{F}$ statistic for the larger model compared to the previous model must have a probability of .15 or less for the variable to be retained in the model. After a variable is added,

6 Granger and Sims, supra note 1. 
the stepwise procedure searches across all of the included variables at the .15 level. Only after this check does the stepwise procedure go on to add new variables to the model. In contrast, the maximum $\mathrm{R}^{2}$ procedure does not settle on a single model. Instead it tries to find the one-variable model with the highest $\mathrm{R}^{2}$. Then it finds the two-variable model with the highest $\mathrm{R}^{2}$, and so forth. The difference between the stepwise procedure and the maximum $\mathrm{R}^{2}$ procedure is that all switches are evaluated before any switch is made in the maximum $\mathrm{R}^{2}$ procedure. In the stepwise procedure the variable that adds the least to the $\mathrm{R}^{2}$ can be removed before a check is made to see if adding the best excluded variable improves the model. The maximum $\mathrm{R}^{2}$ and the stepwise procedures were both used to test if either made a difference in terms of the $t$ statistics for the independent variables.

For the estimate of per capita disposable income in million dollars the best equation is:

$$
\mathrm{X} 1=-2074-0.786 \mathrm{X} 1 \mathrm{~L} 2-1.658 \mathrm{X} 2 \mathrm{~L} 2+3.070 \mathrm{X} 4 \mathrm{~L} 2-2.66 \mathrm{X} 8 \mathrm{~L} 1+2.01 \mathrm{X} 10 \mathrm{~L} 1
$$

Standard error are in parenthesis $\mathrm{R}^{2}=0.987$ where

$\begin{array}{llll}\mathrm{X} 1=\text { Israel } & \mathrm{X} 4=\text { West Germany } & \mathrm{X} 7=\text { the Netherlands } & \mathrm{X} 10=\text { UK } \\ \mathrm{X} 2=\text { Denmark } & \mathrm{X} 5=\text { Ireland } & \mathrm{X} 8=\text { Spain } & \mathrm{X} 11=\text { Belgium } \\ \mathrm{X} 3=\text { France } & \mathrm{X} 6=\text { Italy } & \mathrm{X} 9=\text { Luxembourg } & \mathrm{X} 12=\text { Greece }\end{array}$

and where $\mathrm{L} 1$ indicates that a variable is lagged once

and where $\mathrm{L} 2$ indicates that a variable is lagged twice.

The regressors are Israel, Denmark, West Germany (lagged twice) and Spain and the UK (lagged once) with $\mathrm{R}^{2}=0.98$. Denmark and Spain affected Israel's per capita disposable income negatively while West Germany and the UK affected it positively. All of the regressors are statistically significant. The "best" model in the stepwise regression of one independent variable model is the UK (lagged once). Among the two independent variable models the best regressors were the $\mathrm{UK}$ and West Germany with $\mathrm{R}^{2}=0.92$. With three variable models the best regressors were Spain, Ireland and France (all lagged once). All the coefficients are statistically significant.

The equation for Gross Domestic Product at purchaser's prices is:

$$
\begin{aligned}
& \mathrm{X} 1=4160+0.095 \mathrm{X} 4 \mathrm{~L} 1-0.093 \mathrm{X} 4 \mathrm{~L} 2-0.373 \mathrm{X} 8 \mathrm{~L} 2-0.022 \mathrm{X} 6 \mathrm{~L} 2 \\
& \begin{array}{llll}
(0.017) & (0.019) \quad(0.194) \quad(0.0086)
\end{array} \\
& \begin{array}{l}
R^{2}=0.934 \\
14 \text { observations. }
\end{array}
\end{aligned}
$$

In the maximum $\mathrm{R}^{2}$ regression France, the Netherlands, Spain and Denmark reached an $\mathrm{R}^{2}=0.989$ and all variables were significant at the five percent level.

The next equation is for per capita gross domestic product in dollars using stepwise procedure.

$$
\mathrm{X} 1=585.98+1.29 \mathrm{X} 4 \mathrm{~L} 1-1.845 \mathrm{X} 7 \mathrm{~L} 1+2.041 \mathrm{X} 8 \mathrm{~L} 1
$$

$$
\begin{array}{lll}
(0.408) & (0.53) \quad(0.75)
\end{array}
$$

$\mathrm{R}^{2}=0.951$

14 observations. 
According to maximum $\mathrm{R}^{2}$ procedure the estimated equation is:

$$
\begin{aligned}
& \mathrm{X} 1=290+199 \mathrm{X} 4 \mathrm{~L} 1-1.73 \mathrm{X} 4 \mathrm{~L} 2-3.106 \mathrm{X} 7 \mathrm{~L} 1+3.65 \mathrm{X} 8 \mathrm{~L} 1+1.52 \mathrm{X} 2 \mathrm{~L} 2 \\
& \begin{array}{llllll}
(0.47) & (0.58) & (0.37) & (0.28) & (0.43) & \mathrm{R}^{2}=0.987 .
\end{array}
\end{aligned}
$$

Thus Denmark is included in addition to West Germany and the Netherlands. The equation for expenditure on government final consumption according stepwise and maximum $\mathrm{R}^{2}$ procedures are:

$$
\begin{array}{lllll}
\mathrm{X} 1=33.65+0.53 \mathrm{X} 1 \mathrm{~L} 1+0.44 \mathrm{X} 1 \mathrm{~L} 2-1.71 \mathrm{X} 4 \mathrm{~L} 2+0.378 \times 6 \mathrm{~L} 2-0.618 \mathrm{X} 8 \mathrm{~L} 2 \\
(0.03) & (0.027) & (0.07) & (0.166) & (0.105) \\
& & & \mathrm{R}^{2}=0.998 .
\end{array}
$$

Note that Germany and Spain enter negatively while Israel's lagged government expenditures are very important.

The equation for the export of goods and services is:

$$
\begin{aligned}
& \mathrm{X} 1=-6.4-0.679 \mathrm{X} 1 \mathrm{~L} 2-3.088 \mathrm{X} 4 \mathrm{~L} 1+1.21 \mathrm{X} 5 \mathrm{~L} 1+2.46 \mathrm{X} 10 \mathrm{~L} 1+1.19 \mathrm{X} 11 \mathrm{~L} 1 \\
& \begin{array}{llll}
(0.09) & \left(\begin{array}{lll}
.41) & (0.24) & (0.29)
\end{array}\right)(0.34)
\end{array} \\
& \begin{array}{l}
\mathrm{R}^{2}=0.981 \\
14 \text { observations. }
\end{array}
\end{aligned}
$$

Israel's exports seem to have a close negative relationship to the exports of West Germany and a close positive relationship to the exports of the UK, Ireland and Belgium.

The following equation is for daily wage earnings in manufacturing for Israel, Denmark, France, West Germany, Ireland, Luxembourg and Italy.

$$
\begin{aligned}
& \mathrm{X} 1=13.192+1.72 \mathrm{X} 1 \mathrm{~L} 1-0.165 \mathrm{X} 3 \mathrm{~L} 2+15.11 \mathrm{X} 4 \mathrm{~L} 1-1.814 \mathrm{X} 5 \mathrm{~L} 1-0.491 \mathrm{X} 9 \mathrm{~L} 2 \\
& \begin{array}{llll}
(0.409) \quad(0.034) \quad(2.63) \quad(0.32) \quad(0.09)
\end{array} \\
& \mathrm{R}^{2}=0.997 \\
& 27 \text { observations. }
\end{aligned}
$$

The following equation is for the rates of discount of central banks using the stepwise procedure.

$$
\begin{array}{llllcl}
\mathrm{X} 1=44.48-0.33 \mathrm{X} 11 \mathrm{~L} 1-0.39 \mathrm{X} 3 \mathrm{~L} 2-1.473 \mathrm{X} 4 \mathrm{~L} 1+ & +2.033 \mathrm{X} 4 \mathrm{~L} 2+1.18 \mathrm{X} 6 \mathrm{~L} \\
2 & (0.13) & (0.07) & (0.08) & (0.22) & (0.08) \\
& & & \mathrm{R}^{2}=0.998 \\
& & & 14 \text { observations. }
\end{array}
$$

The rate of discount of central banks using the maximum $\mathrm{R}^{2}$ procedure with a three-variable model is:

$$
\begin{aligned}
& \mathrm{X} 1=41.27-1.45 \mathrm{X} 4 \mathrm{~L} 1+1.37 \mathrm{X} 4 \mathrm{~L} 2+1.57 \mathrm{X} 6 \mathrm{~L} 2 \\
& \begin{array}{llll}
(0.24) & (0.40) \quad(0.13) & \mathrm{R}^{2}=0.979
\end{array} \\
& 14 \text { observations. }
\end{aligned}
$$

The equation for primary energy consumed expressed in million metric tons of coal using the stepwise procedure is :

$$
\mathrm{X} 1=-1.39+0.25 \mathrm{X} 1 \mathrm{~L} 1+0.171 \mathrm{X} 8 \mathrm{~L} 1+0.33 \mathrm{X} 8 \mathrm{~L} 2-8.44 \mathrm{X} 2 \mathrm{~L} 2
$$$$
\mathrm{R}^{2}=0.984
$$

20 observations. 
The equation for the production of energy using the maximum $R^{2}$ procedure is:

$$
\begin{aligned}
& \mathrm{X} 1=7272.72-1768 \mathrm{X} 1 \mathrm{~L} 1+16.88 \mathrm{X} 4 \mathrm{~L} 1+1772.81 \mathrm{X} 2 \mathrm{~L} 1+210.61 \mathrm{X} 5 \mathrm{~L} 1
\end{aligned}
$$

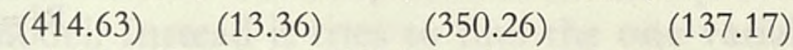

$$
\begin{aligned}
& -30.98 \mathrm{X} 10 \mathrm{~L} 1-400.55 \mathrm{X} 7 \mathrm{~L} 1+504.87 \mathrm{X} 2 \mathrm{~L} 1 \\
& \text { (11.6) (137.57) (134.89) } \\
& \mathrm{R}^{2}=0.943
\end{aligned}
$$

To summarize the above regressions, the West German data are present in all of the regressions except for energy consumption and production. Denmark, Italy, the Netherlands and Spain appear to be the second most important group of countries in terms of how closely changes in these countries are associated with changes in the same variables in Israel. Except for the export and energy equations, the UK's and Belgium's variables have less in common with the counterpart variables in Israel than those of the above countries.

These regressions should be interpreted with caution. One cannot assume, for example, that if the West German government increased its expenditures that Israel's government will respond by changing its expenditures in the amount indicated by the equation. Rather, over the long run, one would expect to observe similar regularities because of the statistically significant relationship that can be traced in the past data of their economies shows that these countries are interrelated.

This research is limited in scope. Elsewhere it is demonstrated, in a more elaborate vector auto regression model for a particular state in the USA, that the vector auto regression technique in particular, and time series analysis in general can provide improved predictions compared to a structural economic model (SEM) for key state variables ${ }^{7}$. These methods are based only on regularities in the data and on statistical inference. The claim of improved predictions is supported by such measures as the mean squares error and Theil's U. Structural econometric models were originally designed to serve two purposes : forecasting and analysis of the impact of a structural change in the economy, such as the effects of new types of taxes or rising energy prices. Given the weak forecasting performance of the SEM's, worldwide as well as in Israel, the policy function of SEM's has become their raison d'être. However, as Lucas (1976) has convincingly argued SEM's do not allow for changes in behavior in response to changes in government policies ${ }^{8}$.

Vector auto regression models are not a panacea, they can not be used to analyze the impacts of fundamental changes, i.e., conditional forecasting. What is required for this analysis is the development of structural models that

7 See Y. Shachmurove, "A Comparison of the Performance of a Vector Autoregressive Econometric Model of the Indiana Economy with the I. U. School of Business Structural Model", Indiana Acad. Soc. Sci. (1983).

8 R. E. Lucas, Jr., "Econometric Policy Evaluation: A Critique", in The Phillips Curve and Labor Markets (K. Brunner and A. Meltzer eds. 1976). 
are based on the deep parameters of economic agents utility maximization and firm profit maximization. Such rational expectations models should allow agent's behavior to respond to changes in policy rules?

The present paper is only the first step. The one equation models presented above are one of the most limited applications of vector auto regression. The next step is to use richer vector auto regression models. Once economists and policy makers realize the power of vector auto regression models they will favor these models over the SEM's. By letting the data speak for itself, economic forecasts can be greatly improved.

\section{Predictions}

A discussion of the likely course of Israel's trade and development over the near future will provide an overview of the effects of the Israel-EEC Agreement. The Israel-EEC Agreement is only one piece of a broad mosaic that includes the general level of world trade, currency fluctuations, and a possible free trade agreement between Israel and the United States. Any predictions must be preceded by a warning that it is extremely difficult to predict trends in Israel's economy. A country with one of the highest rates of inflation in the world facing a possible change of government and a new set of economic policies whether or not the government changes represents a formidable problem for making accurate predictions. Nevertheless some major trends which seem likely to continue are discernible.

These predictions for Israel's economy are predicated on the following changes in the world economy. The world economy is likely to come out the current recession. In the United States, the recovery is in its second year but the recovery in Europe is just beginning. Worldwide inflation will be reduced and the real price of petroleum will decline. Finally, lower nominal interest rates will be available because of the lower world inflation.

The recovery in Europe and in the United States should help Israel's exports, particularly if the government does not artificially halt the depreciation of Israel's currency. There is some danger that Israel's government will try to halt the decline of Israel's currency for political reasons, i.e. to allow Israel's consumers to import goods more cheaply. This policy would limit Israel's industrial and agricultural exports and would increase Israel's imports. However, the low level of foreign reserves will prevent any government in Israel from pursuing a policy of overvaluing Israel's currency for any length of time. Another policy that could limit the expansion of Israel's exports in the long run is the retroactive compensation which the government grants to exporters. This policy is consistent with the objective of a short-term increase in exports but it prevents the optimal

9 See Y. Shachmurove, A Rational Expectations Equilibrium Model of Capital Accumulation under Uncertainty, Ph. D. Thesis, University of Minnesota, 1983. 
development of the economy, and in the long run it will adversely affect both economic growth and the balance of payments.

The EEC currencies have been falling relative to the US dollar and given the slow recovery of the EEC compared to the United States, it appears that this decline will persist. Thus, it is likely that Israel's exports will be redirected towards the United States. This redirection will be even stronger now that the United States and Israel have signed a free trade agreement.

The following trends in the agricultural sphere appear likely. Israel will maintain its relative advantage in agricultural exports by continuing to invest in agricultural research. This investment will enable Israel to develop and market new agricultural products. Such a program has been advocated by what has been called the "square tomato" school of thought. For example, Israel may market the "industrial" orange that can be harvested mechanically with a special equipment from a tree no higher than a human being. Such methods are beneficial both to the grower and the food processor. But they require heavy capital investments which may be beyond Israel's resources given the capital that will be required in the industrial sphere. The reason that the capital requirements for the new agricultural products are so heavy is that the new products can be easily copied and a continuous stream of low costly new products is required to maintain Israel's competitive position.

Another trend that can be identified for the near future is an increase in the amount of food that will be processed as the marketing and processing methods are improved. This trend will continue in spite of the fact that the Israeli consumer has a definite preference for fresh agricultural products and is quite conservative when it comes to adopting new processed products. As the proportion of food that is processed increases, the gap between farmer's receipts and consumer spending on agricultural products will be reduced. This intermediation gap is very large in Israel, amounting to about sixty percent of all agricultural sales. In contrast, in the United States, the intermediation gap in agricultural goods is about seventeen percent.

Finally, some structural changes in Israel's agriculture are imminent. The distribution system in which an agricultural product from the northern part of Israel must be shipped to the Tel Aviv wholesale market in the center of Israel even when it will ultimately be retailed in the northern part of Israel places an absurd burden on Israel's consumers and farmers. Another change that can be expected is an increase in the size of farms to a more efficient scale. All of these changes are necessary for Israel to be able to survive the fierce competition for the EEC market.

The following predictions can be made for the industrial sphere. The weight of industry in employment and output is expected to rise. The ongoing trend towards growth in the size of the firm is expected to continue. The sectors that will grow most rapidly are sophisticated equipment, clothing, chemicals, electronic equipment, and communications systems. Israel's exports may be redirected towards the United States and Canada for 
two reasons. The first reason is the rise of the US dollar relative to EEC currencies. The second reason is the relative freedom from non-tariff barriers in the US and Canadian markets compared to the EEC. Again, this trend will be accelerated if the United States signs a free trade agreement with Israel.

The entry of Greece, Spain and Portugal into the EEC as full members has implications for both Israel's agriculture and industrial development. As far as agriculture is concerned, Israel will face stiff competition from these countries because they export the same agricultural products with lower shipping costs. Israel will have to rely on the development of new agricultural products and new technology. By studying the patterns of specialization in these countries it is apparent that the entry of these countries should provide important trade creation effects and few trade diversion effects. According to the standard theory of customs unions, free trade between Israel, Spain, Portugal and Greece will increase the volume of trade. Since the economies of these countries are closer to Israel as far as domestic qualities, brands and designs are concerned they could become customers of Israel's footwear, floor tiles, irrigations materials, summer clothing, etc. Israel in return may become a good customer of those nations, for example, by purchasing Spanish cars. In this context, it should be noted that Spain, Greece and Portugal are gradually developing some industries which are different than the industries being developed in Israel such as steel and iron industries, shipbuilding, automatic industries, and non-metallic mineral products. The chemical industry is an exception.

One development which will have to be postponed, at least through the end of this decade, is Israel's entry into consumer markets for manufactured goods with its own brand names. Penetration of the final consumer markets is difficult because of the high costs of setting up foreign distribution networks with service centers, local representatives, and spare parts stocks and the costs of advertising Israeli brand names. In contrast, Japan has been successful in establishing marketing companies in different countries with new methods suited to the special requirements of each market. Japan's experience is an example of a marketing policy overcoming cultural barriers by investing a large amount of money in advertisements and distribution networks.

To summarize the main impacts of the Israel-EEC Agreement, EEC trade has been the most important engine pulling Israel towards industrialization. The EEC represents a stable market for Israel's exports (compared to the African or South American markets) that is unlikely to be closed by changes in the political climate. It also represents one of the most competitive markets for manufactured goods. Israeli manufacturers that can offer the quality, services and prices needed to compete in the EEC will be able to compete in other markets world wide. The most important long-term benefit of the Israel-EEC Agreement to Israel is that it forced Israel's manufacturers to meet these standards and thus assure Israel's long-term competitive posidioln. 
Table I: Profiles of Patterns of Development for 14 Small Countries During 1965-1975

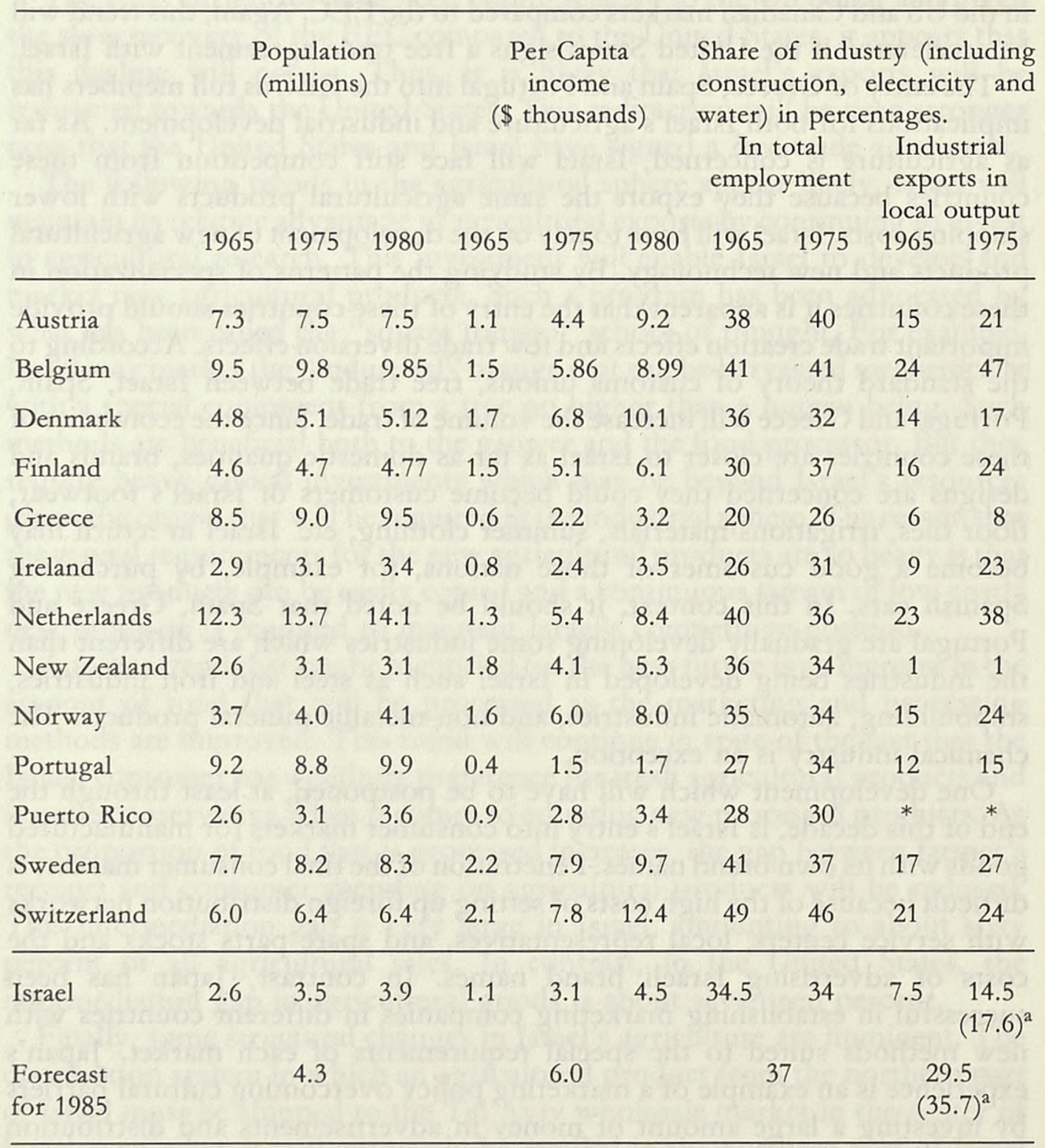


Percentage of urban

Population

$1965 \quad 1975 \quad 1979$

\begin{tabular}{lccc}
\hline Austria & 52 & $*$ & $*$ \\
Belgium & 68 & 94.6 & 94.6 \\
Denmark & 78 & 82.6 & $*$ \\
Finland & 57 & 58.8 & 59.8 \\
Greece & 46 & $*$ & $*$ \\
Ireland & 45 & 54.7 & $*$ \\
Netherlands & 69 & 76.8 & 88.1 \\
New Zealand & 77 & 83.0 & $*$ \\
Norway & 51 & 44.6 & 43.7 \\
Portugal & 35 & $*$ & $*$ \\
Puerto Rico & 59 & $*$ & $*$ \\
Sweden & 77 & 82.7 & $*$ \\
Switzerland & 80 & $*$ & $*$ \\
\hline Israel & 78 & 85.3 & 87.9 \\
Forecast & & & \\
for 1985 & & 90.0 & \\
\hline & & & \\
\hline
\end{tabular}


Table I (continued)

\begin{tabular}{lcccccccccc}
\hline & \multicolumn{2}{c}{$\begin{array}{c}\text { Share of man- } \\
\text { ufactured goods } \\
\text { in total export }\end{array}$} & \multicolumn{3}{c}{$\begin{array}{c}\text { Ratio of exports } \\
\text { to imports } \\
\text { (percent) }\end{array}$} & \multicolumn{3}{c}{$\begin{array}{c}\text { Ratio of exports } \\
\text { to GDP } \\
\text { (percent) }\end{array}$} \\
& 1970 & 1975 & 1981 & 1970 & 1975 & 1981 & 1970 & 1975 & 1981 \\
\hline Austria & 82.8 & 86.7 & 86.1 & 80.5 & 80.0 & 75.4 & 20.0 & 19.9 & 23.8 \\
Belgium & 82.8 & 79.4 & 72.5 & 101.6 & 95.3 & 89.9 & 93.4 & 44.0 & 58.4 \\
Denmark & 54.5 & 56.5 & 56.7 & 76.2 & 83.9 & 89.6 & 21.1 & 23.0 & 28.0 \\
Finland & 69.6 & 80.1 & 74.8 & 87.5 & 72.2 & 98.7 & 21.6 & 19.9 & 28.4 \\
Greece & 40.9 & 47.9 & 57.1 & 32.8 & 42.8 & 48.4 & 6.4 & 11.1 & 11.7 \\
Ireland & 36.9 & 42.4 & 58.3 & 66.1 & 84.3 & 73.5 & 26.7 & 39.4 & 46.2 \\
Netherlands & 57.7 & 55.3 & 49.9 & 87.7 & 101.6 & 104.0 & 37.2 & 42.2 & 48.7 \\
New Zealand & 12.7 & 17.0 & 24.1 & 98.4 & 65.4 & 93.4 & 19.5 & 17.6 & 22.4 \\
Norway & 74.1 & 70.4 & 38.4 & 66.4 & 74.3 & 114.9 & 22.0 & 25.5 & 31.8 \\
Portugal & 62.7 & 70.1 & 69.9 & 60.0 & 50.2 & 42.4 & 15.4 & 13.1 & 17.4 \\
Puerto Rico & $*$ & $*$ & $*$ & $*$ & $*$ & $*$ & $*$ & $*$ & $*$ \\
Sweden & 77.0 & 79.4 & 80.8 & 97.0 & 96.5 & 98.8 & 20.6 & 24.2 & 25.4 \\
Switzerland & 90.9 & 93.4 & 94.8 & 79.4 & 97.6 & 89.6 & 24.4 & 23.8 & $*$ \\
Israel & 72.1 & 75.7 & 81.7 & 53.5 & 46.5 & 71.8 & 13.1 & 16.6 & 24.3 \\
\hline & & & & & & & & \\
\hline
\end{tabular}




\begin{tabular}{|c|c|c|c|c|c|c|c|c|c|c|}
\hline \multirow{2}{*}{ 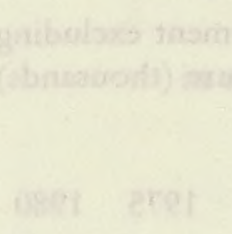 } & \multicolumn{6}{|c|}{$\begin{array}{l}\text { Per capita imports } \\
\text { (\$) }\end{array}$} & \multicolumn{4}{|c|}{$\begin{array}{c}\text { Ratio of import } \\
\text { to gross domestic } \\
\text { product }\end{array}$} \\
\hline & 1970 & 1975 & 1981 & 1970 & 1975 & 1981 & 1965 & 1970 & 1975 & 1980 \\
\hline Austria & 478 & 1249 & 2798 & 384 & 1000 & 2109 & 27 & 31 & 33 & 41 \\
\hline Belgium & 1141 & 2972 & 6009 & 1160 & 2830 & & 36 & 42 & 46 & 63 \\
\hline Denmark & 894 & 2041 & 3422 & 681 & 1712 & 3066 & 31 & 31 & 31 & 34 \\
\hline Finland & 572 & 1614 & 2956 & 500 & 1165 & 2918 & 23 & 27 & 30 & 35 \\
\hline Greece & 223 & 588 & 904 & 73 & & 438 & 22 & 18 & 27 & 28 \\
\hline Ireland & 535 & 1185 & 3080 & 354 & 1000 & 2263 & 41 & 45 & 49 & 71 \\
\hline Netherlands & 1030 & 2520 & 4642 & 904 & 2561 & 4829 & 46 & 49 & 49 & 53 \\
\hline New Zealand & 443 & 1037 & 1824 & 436 & 678 & 1703 & 24 & 25 & 30 & 30 \\
\hline Norway : & 954 & 2420 & 3814 & 633 & 1797 & 4382 & 40 & 43 & 49 & 42 \\
\hline Portugal & 175 & 416 & 986 & 105 & 206 & 418 & 31 & 30 & 32 & 30 \\
\hline Puerto Rico & $*$ & $*$ & * & * & * & $*$ & 65 & 63 & 73 & 73 \\
\hline Sweden & 871 & 2206 & 3467 & 845 & 2129 & 3425 & 24 & 25 & 28 & 32 \\
\hline Switzerland & 1048 & 2064 & $*$ & 832 & 2014 & * & 31 & 34 & 29 & 40 \\
\hline Israel & 489 & 1206 & 1971 & 261 & 561 & 1371 & 32 & 44 & 54 & 58 \\
\hline
\end{tabular}


Table I (continued)

\begin{tabular}{|c|c|c|c|c|c|c|c|c|c|c|}
\hline \multirow[b]{2}{*}{$x^{2}$} & \multicolumn{3}{|c|}{$\begin{array}{c}\text { Share of Agriculture } \\
\text { in gross domestic } \\
\text { product }\end{array}$} & \multicolumn{4}{|c|}{$\begin{array}{c}\text { Share of total } \\
\text { industrial activity } \\
\text { in GDP }\end{array}$} & \multicolumn{3}{|c|}{$\begin{array}{l}\text { Employment excluding } \\
\text { agriculture (thousands) }\end{array}$} \\
\hline & 1970 & 1975 & 1980 & 1965 & 1970 & 1975 & 1980 & 1970 & 1975 & 1980 \\
\hline Austria & 7 & 5 & 4 & 49 & 37 & 33 & 32 & 2418 & 2598 & 2781 \\
\hline Belgium & 4 & 3 & 2 & 33 & 35 & 31 & 29 & 3492 & 3608 & 3634 \\
\hline Denmark & 6 & 5 & 5 & 38 & 21 & 21 & 21 & 2158 & 2105 & 2293 \\
\hline Finland & 11 & 10 & 8 & 35 & 27 & 28 & 29 & 1645 & 1892 & 1593 \\
\hline Greece & 16 & 17 & 16 & 23 & 19 & 20 & 20 & $*$ & $*$ & * \\
\hline reland & 14 & 17 & 17 & * & 24 & 25 & 33 & 762 & 791 & 829 \\
\hline Netherlands & 6 & 5 & 4 & 38 & 32 & 30 & 29 & 4225 & 4224 & 4309 \\
\hline New Zealand & * & 11 & 13 & 31 & * & 25 & 27 & 764 & 852 & 860 \\
\hline Norway & 6 & 6 & 5 & 34 & 26 & 28 & 34 & 1465 & 1548 & 1752 \\
\hline Portugal & 16 & 14 & 13 & 38 & 33 & 33 & 34 & 2406 & 2461 & 2804 \\
\hline Puerto Rico & 3 & 3 & 3 & 31 & 27 & 36 & 38 & 625 & 665 & 789 \\
\hline Sweden & 4 & 4 & 3 & 43 & 28 & 29 & 25 & 3540 & 3801 & 3995 \\
\hline Switzerland & * & $*$ & * & 48 & * & $*$ & * & 2856 & 2780 & 2741 \\
\hline Israel & 7 & 6 & 5 & 35 & 28 & 26 & 28 & 787 & 949 & 1110 \\
\hline
\end{tabular}




\begin{tabular}{|c|c|c|c|c|c|c|c|c|c|}
\hline \multicolumn{7}{|c|}{$\begin{array}{cc}\text { Employment } & \text { Unemployment } \\
\text { in manufacturing (thousands) } & \text { (percentage) }\end{array}$} & \multicolumn{3}{|c|}{$\begin{array}{c}\text { Hours of work } \\
\text { per manufacturing } \\
\text { per week }\end{array}$} \\
\hline & 1970 & 1975 & 1980 & 1970 & 1975 & 1980 & 1970 & 1975 & 1980 \\
\hline Austria & 629 & 640 & 627 & 2.4 & 2.0 & 1.9 & 39.7 & 38.7 & 39.3 \\
\hline Belgium & 1087 & 1033 & 870 & 5.0 & 6.8 & 9.4 & 39.9 & 34.8 & 33.4 \\
\hline Denmark & 419 & 375 & 371 & 1.1 & 6.0 & 6.9 & 36.2 & 33.1 & 32.9 \\
\hline Finland & 541 & 593 & 594 & 1.9 & 2.2 & 4.8 & 38.3 & 38.4 & 40.4 \\
\hline Greece & $*$ & * & * & $*$ & $*$ & * & 44.6 & 42.7 & 40.7 \\
\hline Ireland & 4594 & 5127 & 5857 & 7.2 & 12.2 & 10.3 & 42.7 & 41.5 & 41.1 \\
\hline Netherlands & 1203 & 1088 & 973 & 1.1 & 5.0 & 5.8 & 44.2 & 41.2 & 41.1 \\
\hline New Zealand & 257 & 261 & 258 & $*$ & $*$ & * & 40.4 & 39.3 & 39.3 \\
\hline Norway & 389 & 395 & 375 & 1.5 & 2.3 & 1.7 & 35.3 & 33.5 & 31.0 \\
\hline Portugal & 856 & 829 & 921 & 1.8 & 4.5 & 7.8 & 44.8 & 41.8 & 36.5 \\
\hline Puerto Rico & $*$ & * & $*$ & 10.8 & 18.1 & 17.1 & 36.7 & 37.0 & 38.0 \\
\hline Sweden & 664 & 669 & 607 & 1.5 & 1.6 & 2.0 & 33.6 & 29.6 & 29.3 \\
\hline Switzerland & 5 & 9 & 9 & 1.0 & $*$ & * & 44.9 & 44.5 & 43.8 \\
\hline Israel & 192 & 231 & 250 & 3.8 & 3.1 & 4.8 & 42.1 & 40.3 & 38.3 \\
\hline
\end{tabular}


Table I (continued)

Index number of per capita

product at constant prices

$1975=100$

1970

1979

Austria

84

117

Belgium

85

112

Denmark

92

114

Finland

84

109

Greece

81

117

Ireland

89

111

Netherlands

90

110

New Zealand

Norway

82

118

Portugal

84

104

Puerto Rico

98

110

Sweden

89

103

Switzerland

99

105

Israel

82

105

* not available

a The figures in brackets are according to the effective exchange rate.

b 1970

Sources: 1965 - Chenery-Syrquin, "Patterns of Development 1950-1970”, (1975), Tables 2 and S2.

1975 - Statistical Monthly of the United Nations, August 1977, Eurostat Basic Statistics, 1977; 1 Israel Yearbooks, Statistical Abstract of Israel, No. 28; Plan for the Development of Industry in Israel, 1975-1985, Ministry of Industry, Trade and Tourism, Jerusalem, September 1977.

1980 - United Nations Statistical Yearbook, 1981.

1985 - Plan for the National Economy 1977-1981, Ministry of Finance, Economic Planning Authority; Eurostat Basic Statistics, 1977; Plan for Development of Industry in Israel 1975-1985, Ministry of Industry, Trade and Tourism (Jerusalem, 1977). 


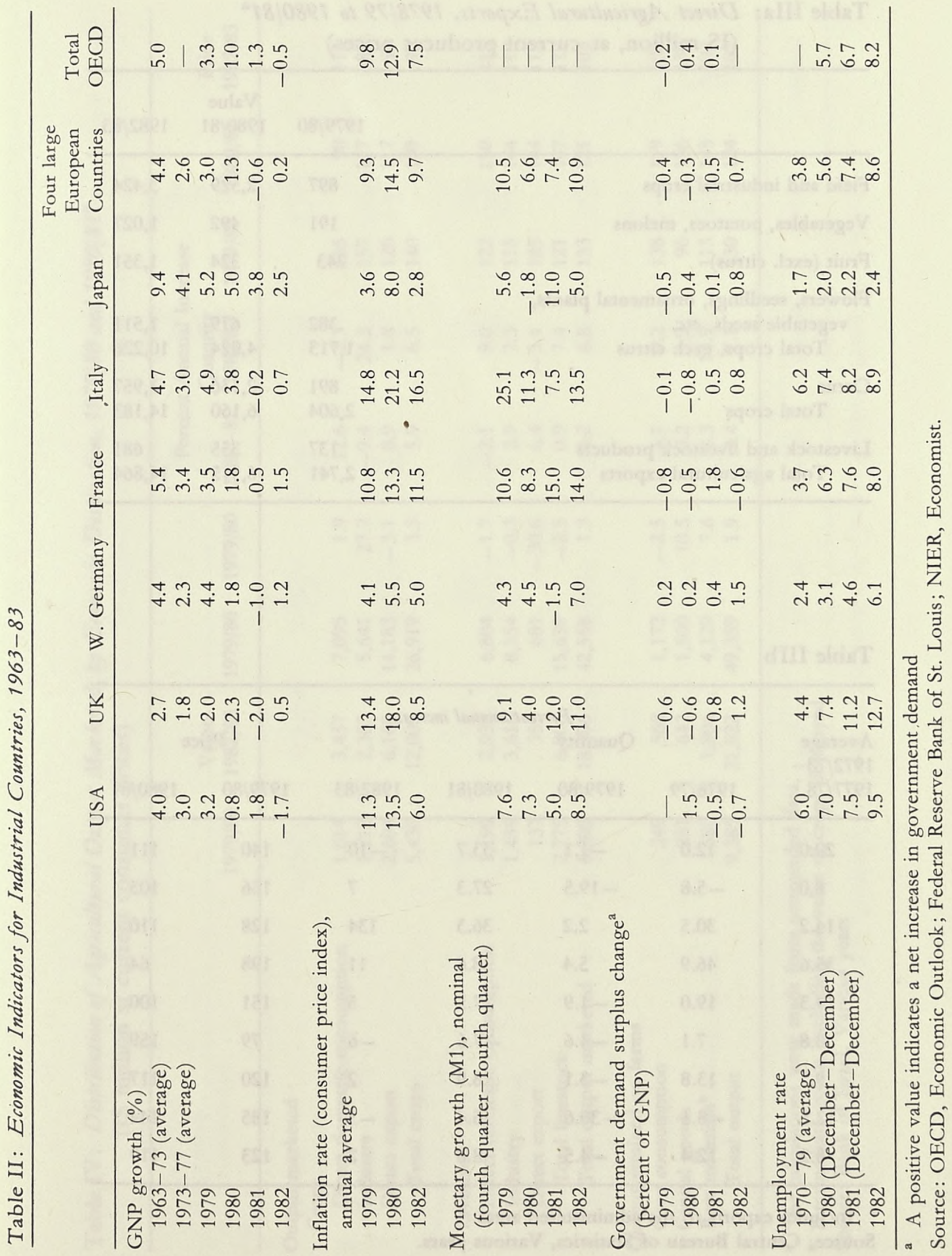


Table IIIa: Direct Agricultural Exports, $1978 / 79$ to $1980 / 81^{\mathrm{a}}$

(IS million, at current producer prices)

\begin{tabular}{lrrr}
\hline & \multicolumn{3}{c}{ Value } \\
& $1979 / 80$ & $1980 / 81$ & $1982 / 83$ \\
\hline Field and industrial crops & 897 & 2,529 & 3,424 \\
Vegetables, potatoes, melons & 191 & 492 & 1,027 \\
Fruit (excl. citrus) & 243 & 324 & 1,351 \\
Flowers, seedlings, ornamental plants, & & & \\
$\quad$ vegetable seeds, etc. & 382 & 679 & 1,511 \\
$\quad$ Total crops, excl. citrus & 1,713 & 4,024 & 10,226 \\
Citrus & 891 & 2,136 & 3,957 \\
$\quad$ Total crops & 2,604 & 6,160 & 14,183 \\
Livestock and livestock products & 137 & 355 & 681 \\
$\quad$ Total agricultural exports & 2,741 & 6,515 & 14,864 \\
\hline
\end{tabular}

Table IIIb

\begin{tabular}{rrrrrrr}
\hline $\begin{array}{l}\text { Average } \\
1972 / 73-\end{array}$ & \multicolumn{3}{c}{$\begin{array}{c}\text { Percent annual increase } \\
\text { Quantity }\end{array}$} \\
$1977 / 78$ & $1978 / 79$ & $1979 / 80$ & $1980 / 81$ & $1982 / 83$ & $1979 / 80$ & $1980 / 81$ \\
\hline 20.0 & 12.0 & -1.1 & 33.7 & -10 & 140 & 111 \\
8.0 & -5.8 & -19.5 & 27.3 & 7 & 156 & 103 \\
14.2 & 30.5 & 2.2 & 36.3 & 134 & 128 & 110 \\
35.6 & 46.9 & 5.4 & 8.6 & 11 & 198 & 64 \\
19.3 & 19.0 & -1.9 & 17.5 & 5 & 151 & 100 \\
0.8 & 7.1 & -4.6 & -7.6 & -6 & 79 & 159 \\
9.7 & 13.8 & -3.1 & 8.9 & 2 & 120 & 117 \\
12.5 & -8.1 & -30.6 & 6.4 & -3 & 185 & 144 \\
8.2 & 12.4 & -4.5 & 8.8 & 2 & 123 & 119 \\
\hline
\end{tabular}

a Includes exports to the administered areas.

Source: Central Bureau of Statistics, Various years. 
The Integration of the Israeli Economy into the EEC

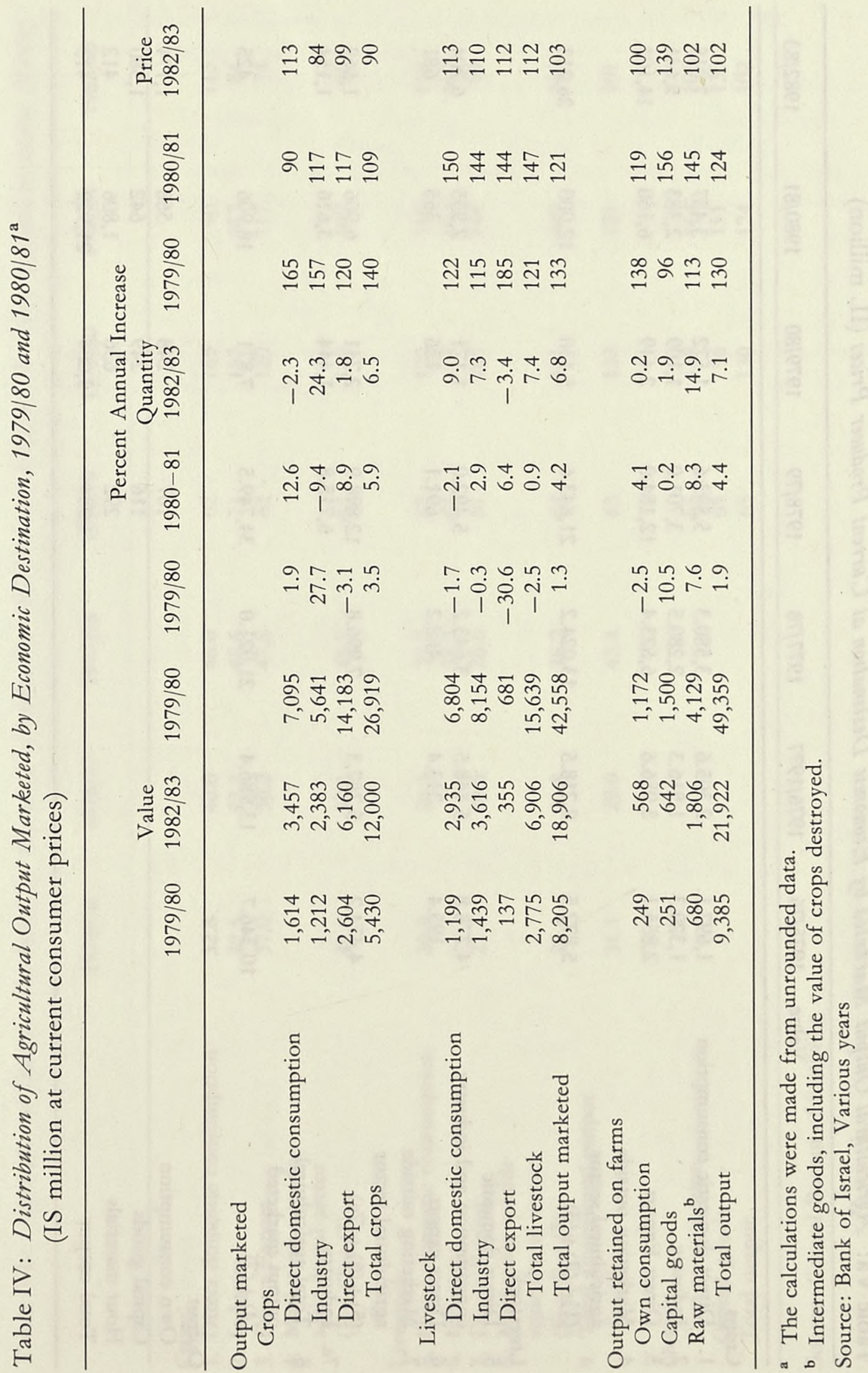




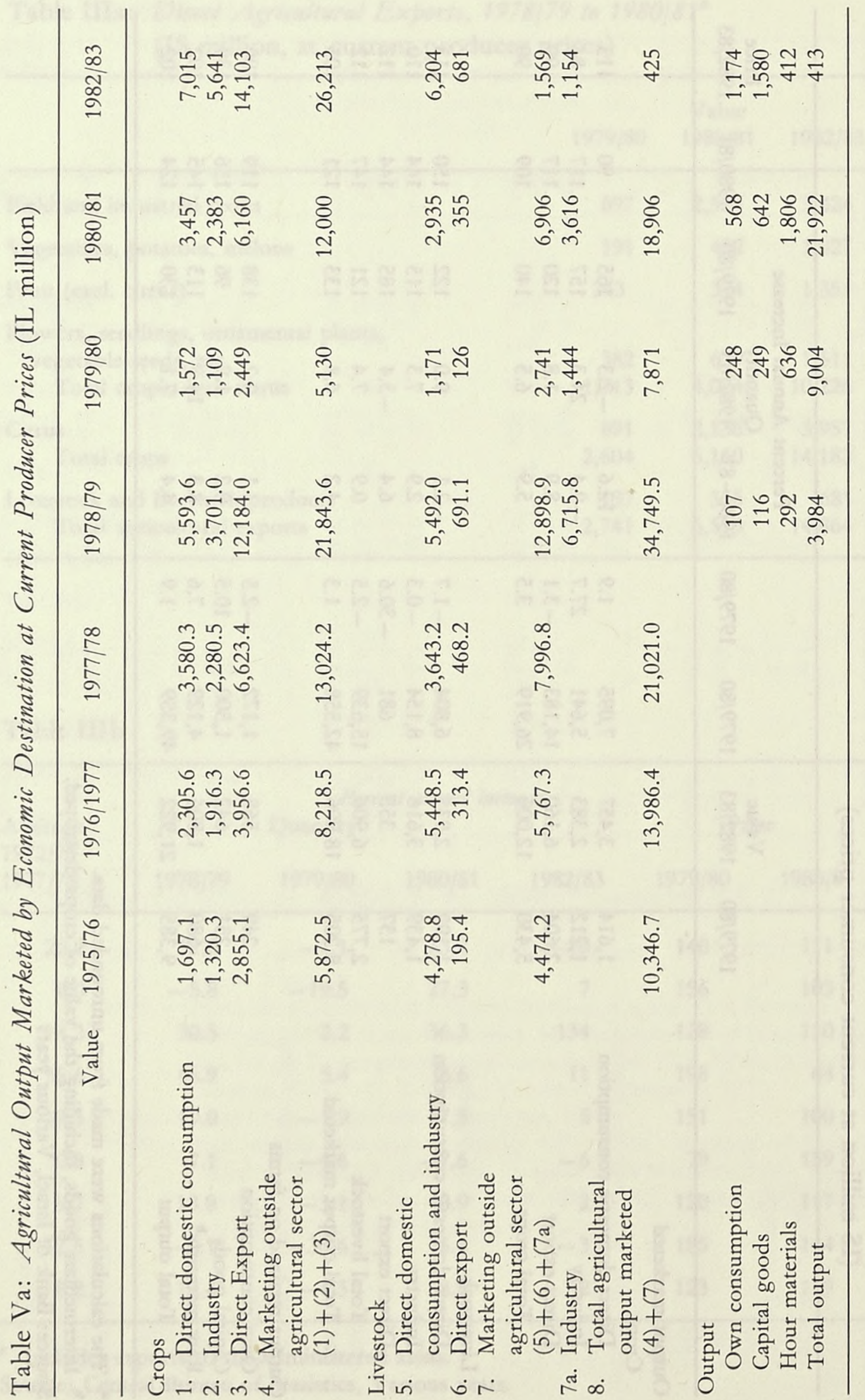


The Integration of the Israeli Economv into the EEC

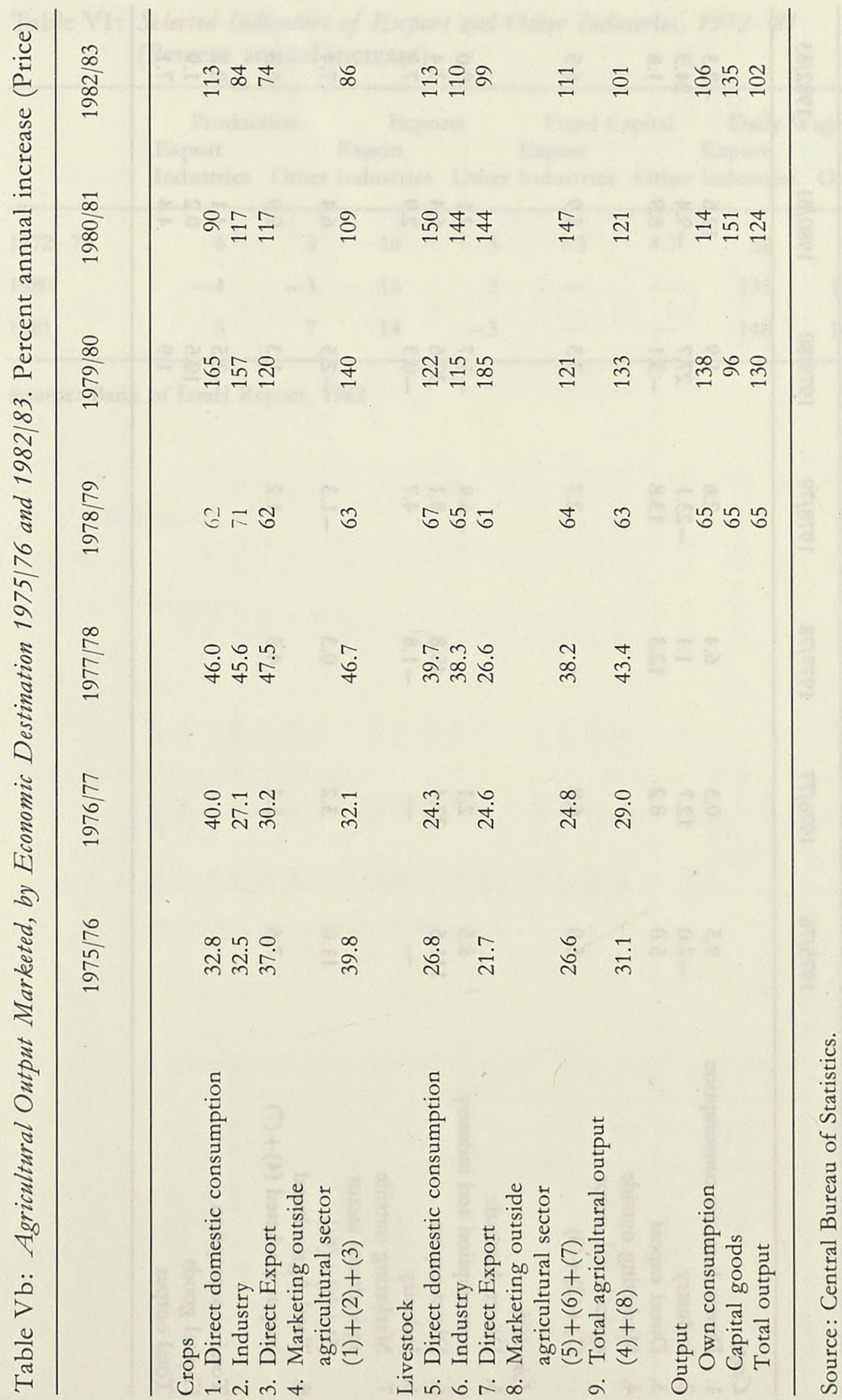




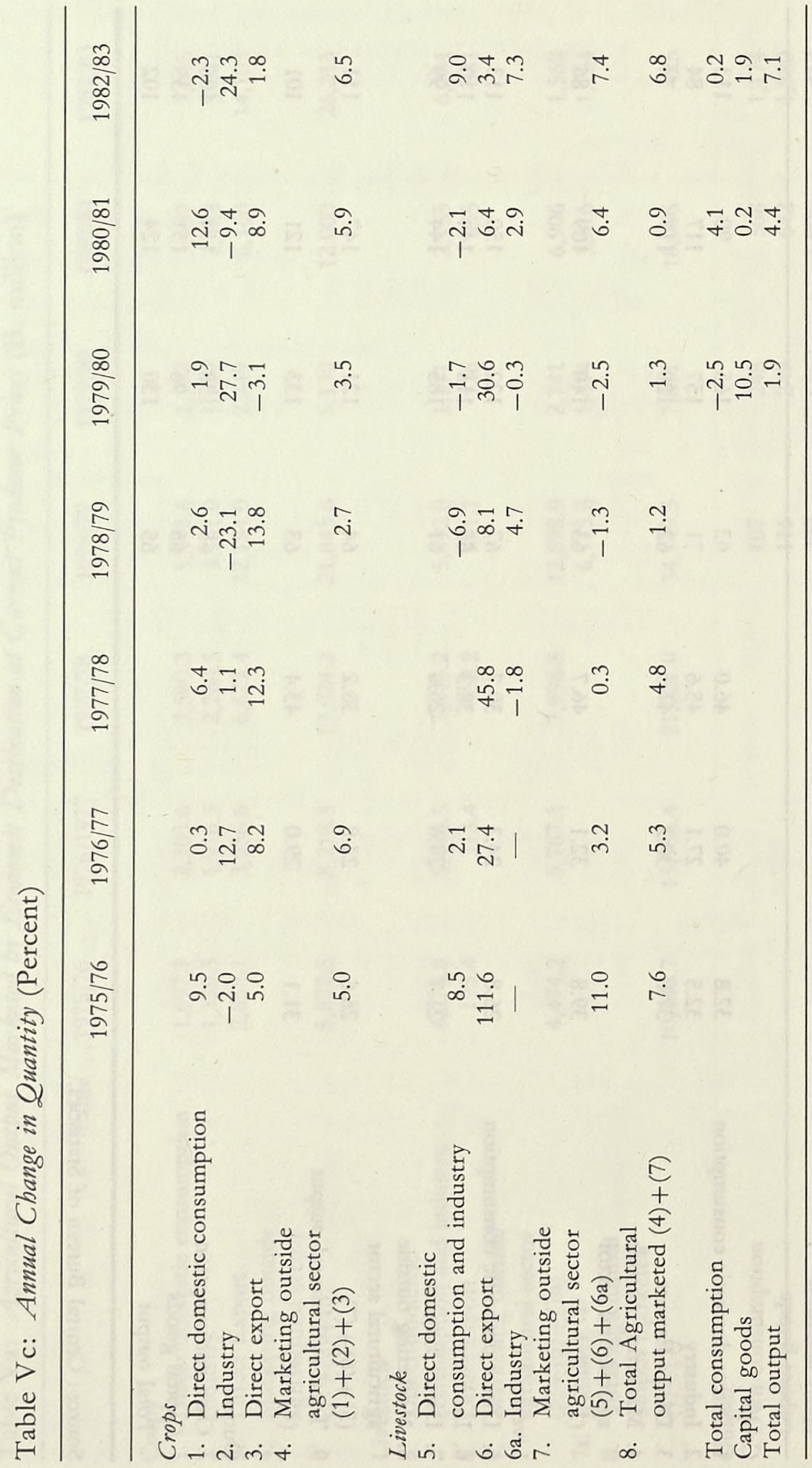


The Integration of the Israeli Economy into the EEC

Table VI: Selected Indicators of Export and Other Industries, 1972-81 (Percent annual increase)

\begin{tabular}{lrrrrrrrr}
\hline & \multicolumn{2}{c}{$\begin{array}{c}\text { Production } \\
\text { Export } \\
\text { Industries }\end{array}$} & $\begin{array}{c}\text { Exports } \\
\text { Oxport }\end{array}$ & $\begin{array}{c}\text { Fixed Capital } \\
\text { Export }\end{array}$ & \multicolumn{2}{c}{$\begin{array}{c}\text { Daily Wages } \\
\text { Export }\end{array}$} \\
\hline $1972-79$ & 6 & 3 & 16 & 3 & 7.5 & 4.7 & 52 & 43 \\
1980 & -4 & -3 & 16 & 3 & - & - & 135 & 132 \\
1981 & 5 & 7 & 14 & -3 & - & - & 148 & 147 \\
\hline
\end{tabular}

Source: Bank of Israel Report, 1982 


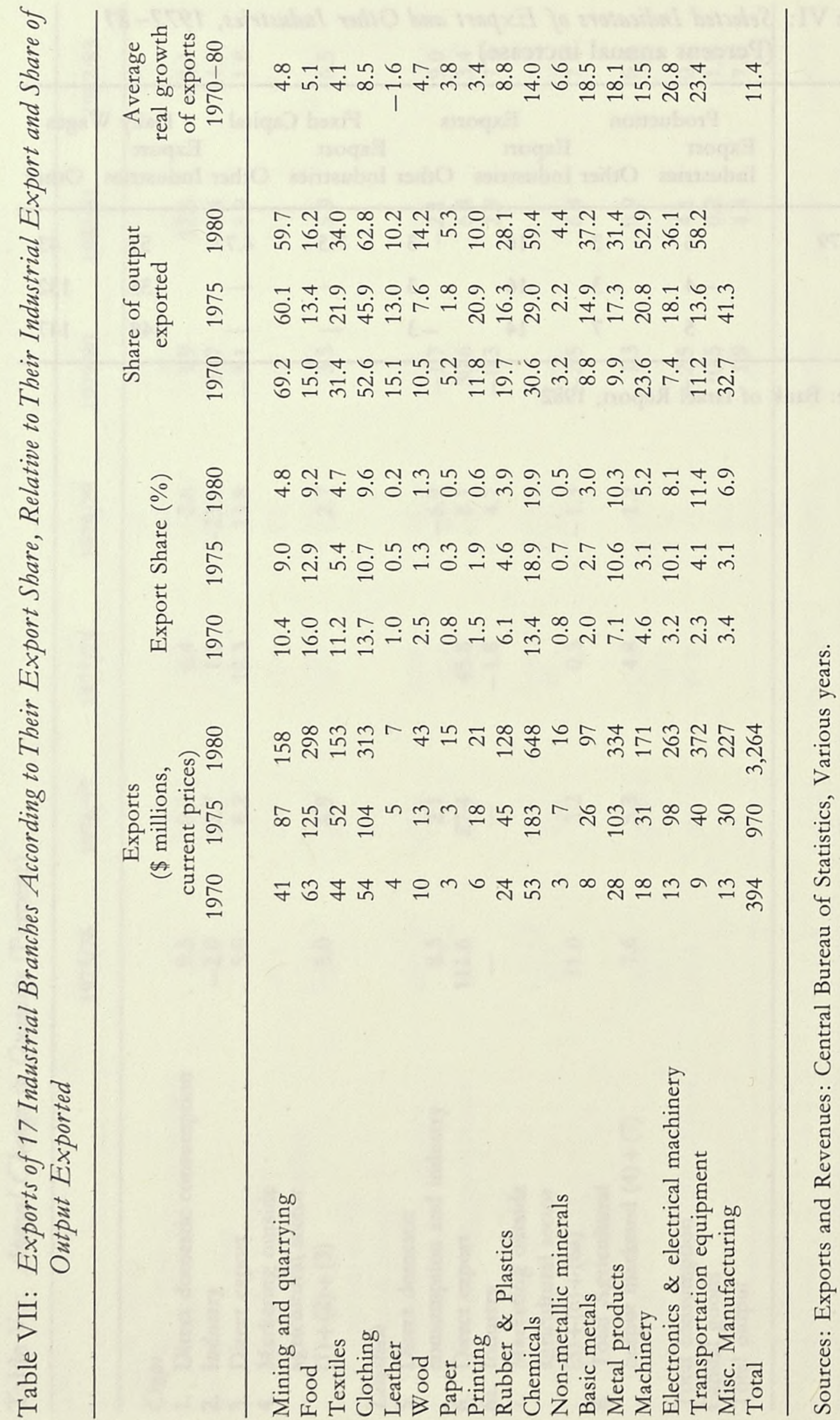


Table VIII: Human Capital Intensive Industrial Sectors in 1970-1980

\begin{tabular}{|c|c|c|c|}
\hline & $\begin{array}{c}1970 \\
(1)\end{array}$ & $\begin{array}{c}1975 \\
(2)\end{array}$ & $\begin{array}{c}1980 \\
\text { (3) }\end{array}$ \\
\hline Mining and quarrying & 8.8 & 10.3 & 12.0 \\
\hline Food & 3.8 & 3.4 & 4.1 \\
\hline Textiles & 4.4 & 5.1 & 6.5 \\
\hline Clothing & 3.6 & 2.3 & 2.9 \\
\hline Leather & 4.3 & 1.5 & 2.7 \\
\hline Wood & 4.9 & 2.7 & 3.8 \\
\hline Paper & 3.9 & 3.7 & 5.5 \\
\hline Printing & 2.7 & 8.8 & 6.4 \\
\hline Rubber \& plastics & 6.6 & 6.0 & 8.8 \\
\hline Chemicals & 14.9 & 14.3 & 19.4 \\
\hline Non-metallic minerals & 5.2 & 4.1 & 6.8 \\
\hline Basic metals & 7.1 & 7.5 & 7.8 \\
\hline Metal products & 7.1 & 9.7 & 10.6 \\
\hline Machinery & 10.3 & 13.6 & 11.6 \\
\hline Electronics \& electrical machinery & 18.5 & 20.6 & 26.2 \\
\hline Transportation equipment & 14.4 & 16.9 & 19.9 \\
\hline Miscellaneous & 5.2 & 9.8 & 11.3 \\
\hline
\end{tabular}

Source: Central Bureau of Statistics, Various years.

Table IX: Concentration of Industrial Exports 1977-1981 (percent)

\begin{tabular}{lrrc}
\hline & 1977 & 1980 & 1981 \\
\hline 25 largest firms & 51 & 53 & 55 \\
50 largest firms & 62 & 65 & $*$ \\
Other firms & 38 & 35 & $*$ \\
Total Industry & 100 & 100 & \\
\hline
\end{tabular}

* Not available.

Source: Bank of Israel Annual Report, 1982. 


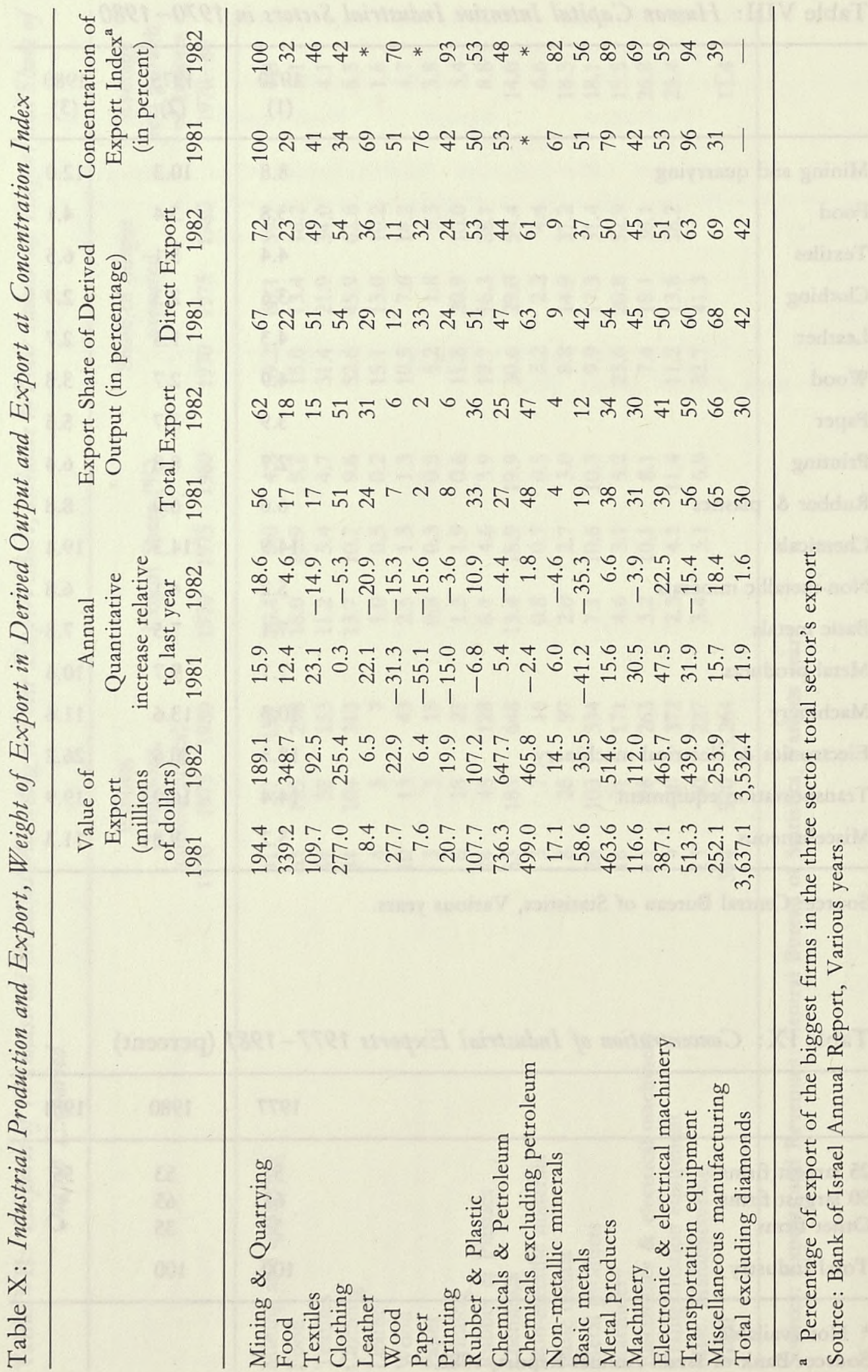


Table XI: Israel's Trade Balance by Geographical Area, 1979-82a

\begin{tabular}{|c|c|c|c|c|c|c|c|c|}
\hline \multirow{3}{*}{ 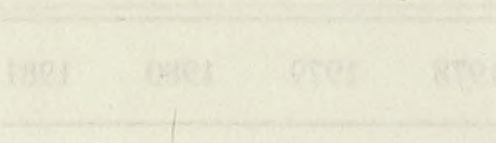 } & \multicolumn{8}{|c|}{ Percentage distribution } \\
\hline & \multicolumn{4}{|c|}{ Imports } & \multicolumn{4}{|c|}{ Exports } \\
\hline & 1979 & 1980 & 1981 & 1982 & 1979 & 1980 & 1981 & 1982 \\
\hline 1. Common Market & 45 & 45 & 47 & 47 & 43 & 45 & 38 & 36 \\
\hline Italy & 7 & 7 & 7 & 7 & 5 & 7 & 5 & 5 \\
\hline Belgium and Luxembourg & 3 & 3 & 3 & 3 & 2 & 1 & 1 & 1 \\
\hline W. Germany & 15 & 16 & 16 & 16 & 11 & 12 & 9 & 8 \\
\hline Netherlands & 3 & 3 & 5 & 4 & 5 & 5 & 4 & 4 \\
\hline United Kingdom & 9 & 9 & 9 & 9 & 11 & 11 & 10 & 9 \\
\hline France & 7 & 6 & 6 & 6 & 6 & 6 & 7 & 7 \\
\hline $\begin{array}{l}\text { Other Common Market } \\
\text { countries }\end{array}$ & 1 & 1 & 1 & 1 & 3 & 3 & 2 & 2 \\
\hline 2. Free Trade Area (EFTA) & 10 & 10 & 9 & 9 & 7 & 7 & 7 & 6 \\
\hline 3. Other European countries & 3 & 2 & 3 & 2 & 5 & 4 & 2 & 2 \\
\hline 4. North America & 29 & 31 & 31 & 29 & 14 & 13 & 18 & 18 \\
\hline USA & 28 & 30 & 30 & 27 & 13 & 12 & 17 & 17 \\
\hline Canada & 1 & 1 & 1 & 2 & 1 & 1 & 1 & 1 \\
\hline 5. Other countries & 9 & 7 & 7 & 8 & 4 & 6 & 5 & 5 \\
\hline Thereof: Japan & 3 & 3 & 2 & 3 & 1 & 1 & 1 & 1 \\
\hline South Africa & 3 & 2 & 2 & 3 & 2 & 2 & 2 & 2 \\
\hline 6. Unclassified countries & 4 & 5 & 3 & 5 & 27 & 25 & 30 & 33 \\
\hline 7. Grand Total & 100 & 100 & 100 & 100 & 100 & 100 & 100 & 100 \\
\hline
\end{tabular}

a Imports and exports exclude diamonds, oil, and trade with the administered areas.

b A Minus sign indicates an export surplus.

Source: Central Bureau of Statistics. 
Table XIIa: Goods and Services Account, 1977-81 ( $\$$ millions, at current prices)

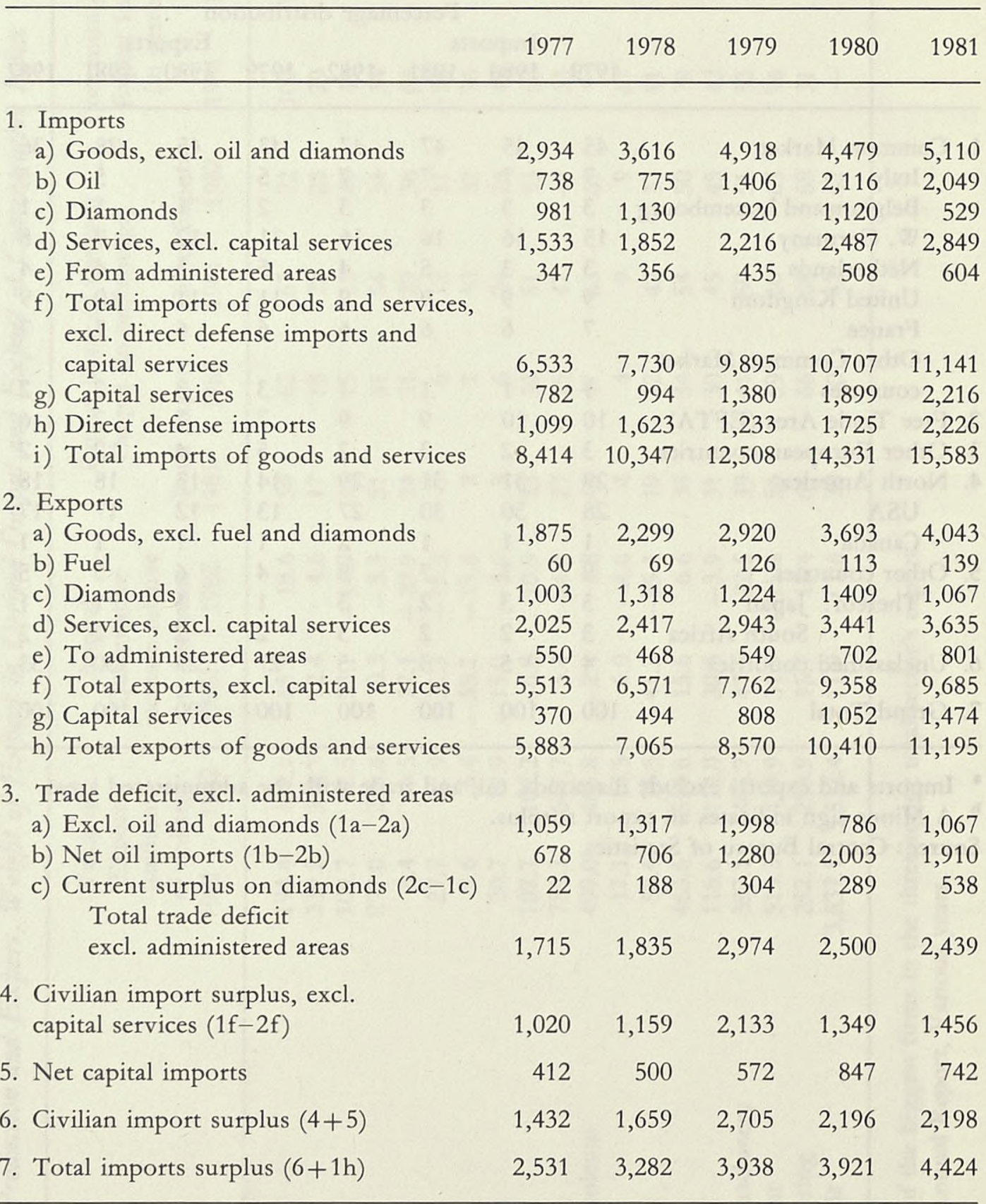


Table XIIb: Goods and Services Account, 1977-81 ${ }^{\mathrm{a}}$ ( $\$$ millions, at current prices)

\begin{tabular}{|c|c|c|c|c|c|c|c|c|}
\hline & \multicolumn{8}{|c|}{ Percent annual increase } \\
\hline & \multicolumn{4}{|c|}{ Quantity } & \multicolumn{3}{|c|}{ Price $^{\mathrm{b}}$} & \multirow[b]{2}{*}{1981} \\
\hline & 1978 & 1979 & 1980 & 1981 & 1978 & 1979 & 1980 & \\
\hline \multicolumn{9}{|l|}{ Imports } \\
\hline a) Goods, excl. oil and diamonds & 10.1 & 17.7 & -20.3 & 18.7 & 11.9 & 15.5 & 14.3 & -3.0 \\
\hline b) Oil & 5.6 & 11.9 & 4.1 & -5.6 & -0.5 & -62.1 & 44.6 & 2.5 \\
\hline c) Diamonds & -29.5 & -25.5 & 11.3 & -46.8 & 63.3 & 9.3 & 9.3 & -11.1 \\
\hline d) Services, excl. capital services & 17.9 & 9.2 & -2.3 & 19.0 & 2.5 & 9.6 & 14.9 & -3.7 \\
\hline e) From administered areas & 15.0 & 0.3 & 1.6 & 17.3 & -10.8 & 21.8 & 14.9 & 1.3 \\
\hline $\begin{array}{l}\text { f) Total import of goods and services } \\
\text { excl. direct defense imports and }\end{array}$ & & & & & & 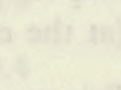 & & \\
\hline capital services & 5.8 & 8.0 & -8.9 & 7.1 & 11.9 & 18.6 & 18.8 & -2.8 \\
\hline
\end{tabular}

g) Capital services

h) Direct defense imports

i) Total imports of goods and services

2. Exports
a) Goods, excl. fuel and diamonds
b) Fuel

$\begin{array}{rrrrrrrr}8.7 & 11.7 & 9.9 & 12.0 & 12.9 & 13.7 & 15.1 & -2.2 \\ 5.0 & -29.0 & -11.1 & 21.0 & 9.5 & 157.1 & 0.9 & 1.4 \\ -16.6 & -12.1 & 9.1 & -20.4 & 57.6 & 5.7 & 5.5 & -4.9 \\ 19.7 & 6.8 & 1.3 & 4.1 & -0.3 & 14.0 & 15.4 & 1.3 \\ -7.1 & -3.8 & 9.8 & 14.1 & -8.4 & 22.0 & 16.4 & 0.2 \\ 6.5 & 3.6 & 6.2 & 4.5 & 11.9 & 14.0 & 13.5 & -0.2\end{array}$
d) Services, excl. capital services
e) To administered areas
f) Total exports, excl. capital services
g) Capital services
h) Total exports of goods and services

3. Trade deficit, excl. administered areas
a) Excl. oil and diamonds (1a-2a)
b) Net oil imports (1b-2b)
$\begin{array}{llllllll}12.9 & 28.3 & -64.5 & 50.6 & 10.1 & 18.2 & 10.7 & -1.9\end{array}$
c) Current surplus on diamonds $(2 \mathrm{c}-1 \mathrm{c})$
Total trade deficit excl. administered area

$\begin{array}{rrrrrrrr}3.1 & 19.5 & -41.2 & 0.8 & 3.8 & 35.7 & 42.9 & -1.3 \\ 1.9 & 32.8 & -64.9 & 25.4 & 11.5 & 38.6 & 75.0 & 2.8\end{array}$
4. Civilian import surplus, excl. capital services ( $1 \mathrm{f}-2 \mathrm{f})$

5. Net capital imports

6. Civilian import surplus $(4+5)$

7. Total import surplus $(6+1 \mathrm{~h})$

a Based on a c.i.f. valuation of commodity imports and f.o.b. valuation of commodity exports.

b The difference between the rate of change in import surplus prices and that in import prices reflects the change in the terms of trade proportionately greater change in import surplus prices indicates a deterioration and vice versa.

Source: Bank of Israel Annual Report 1982. 
Table XIII: Effective Exchange Rate and Prices of Commodity Imports ${ }^{\mathbf{a}}$ Compared with Prices of Domestic Uses, 1977-81

$\begin{array}{lllll}1977 & 1978 & 1979 & 1980 & 1981\end{array}$

Sheqalim per dollar of import

1. Representative exchange rate

$\begin{array}{rrrrr}1.06 & 1.75 & 2.55 & 5.17 & 11.42 \\ 0.41 & 0.44 & 0.67 & 1.16 & 2.58 \\ 1.47 & 2.19 & 3.22 & 6.33 & 14.00\end{array}$

3. Average effective exchange rate $(1+2)$

Percent increase

4. Import prices in the domestic market ${ }^{\mathrm{b}}$ (at the effective exchange rate)

$\begin{array}{lllll}40.0 & 66.5 & 66.8 & 123.5 & 109.2\end{array}$

5. Private consumption deflator, excl. household fuel and light

6. Deflator for domestic business sector uses ${ }^{c}$ (at market price)

a Excludes oil and diamonds.

b The import prices as calculated here reflect the change in the product mix and the differential tax component of the commodity imports.

c Includes direct expenditure on oil. In most years the rise in oil prices was close to the average trend, except in 1980, when they shot up about 200 percent.

Source: Bank of Israel Annual Report 1981. 
Table XIV: Factors Affecting Exports, Excl. Diamonds, 1975-81 (Percent annual increase)

\begin{tabular}{lrrrc}
\hline & $\begin{array}{c}\text { Exports of goods and services } \\
\text { Total }\end{array}$ & $\begin{array}{c}\text { Factors affecting exports } \\
\text { Excl. Diamonds }\end{array}$ & $\begin{array}{c}\text { World trade } \\
\text { Relative price }\end{array}$ \\
\hline $1961-70$ (average) & 12.6 & 12.9 & 8.1 & 3.3 \\
$1971-80$ (average) & 9.6 & 9.6 & 5.5 & 1.1 \\
1975 & 2.0 & 2.5 & -4.7 & 2.5 \\
1976 & 16.2 & 15.4 & 12.3 & 2.2 \\
1977 & 11.7 & 13.1 & 5.5 & 5.9 \\
1978 & 5.2 & 8.6 & 5.6 & 0.4 \\
1979 & 3.3 & 5.2 & 5.9 & 3.3 \\
1980 & 6.3 & 6.0 & 0.3 & -1.2 \\
1981 & 3.9 & 8.5 & -1.0 & -4.6 \\
\hline
\end{tabular}

a As defined in the national accounts, i.e. excludes factor receipts from abroad and public sector interest receipts from abroad.

b Source: IMF, International Financial Statistics for the relevant years.

c The ratio of export prices (excluding diamonds) to the price of domestic business sector uses (at factor cost). Domestic business sector uses are defined as private consumption, public consumption, and fixed investment, less direct defense imports, ships and aircraft, the product originating in public and nonprofit institution services, imputed housing services, and net taxes on domestic production.

Source: Based on Central Bureau of Statistics data. 
Table XV: Geographical Distribution of Export According to Sub-Sectors (1980-81 average in percent)

\section{Europe}

\begin{tabular}{|c|c|c|c|c|c|c|}
\hline & $\begin{array}{c}\text { EEC } \\
\text { countries }\end{array}$ & ETA & $\begin{array}{c}\text { Other } \\
\text { European } \\
\text { Countries }\end{array}$ & $\begin{array}{c}\text { Total } \\
\text { European } \\
\text { Countries }\end{array}$ & USA & $\begin{array}{l}\text { Rest of } \\
\text { the } \\
\text { World }\end{array}$ \\
\hline Agricultural export & 65.6 & 23.4 & 3.0 & 94.8 & 0.9 & 4.3 \\
\hline $\begin{array}{l}\text { Industrial sector/ } \\
\text { (excl. diamonds) }\end{array}$ & 37.3 & 4.5 & 3.7 & 45.5 & 16.9 & 37.6 \\
\hline $\begin{array}{l}\text { Food, beverages, } \\
\text { tobacco }\end{array}$ & 66.3 & 8.6 & 5.4 & 80.3 & 9.0 & 10.7 \\
\hline $\begin{array}{l}\text { Textile, cloth, } \\
\text { and leather }\end{array}$ & 80.7 & 5.1 & 3.5 & 89.3 & 4.9 & 5.8 \\
\hline $\begin{array}{l}\text { Wood, paper and } \\
\text { printing }\end{array}$ & 32.6 & 8.8 & 1.9 & 43.3 & 42.4 & 10.7 \\
\hline Mining and quarry & 31.7 & 5.4 & 6.8 & 44.4 & - & 32.7 \\
\hline $\begin{array}{l}\text { Diamonds and } \\
\text { plastic }\end{array}$ & 49.7 & 5.6 & 7.5 & 62.8 & 10.1 & 27.1 \\
\hline $\begin{array}{l}\text { Basic metals, } \\
\text { machinery }\end{array}$ & 15.6 & 2.5 & 2.2 & 20.3 & 15.4 & 64.3 \\
\hline $\begin{array}{l}\text { Electric and elec- } \\
\text { tronic equipment }\end{array}$ & 23.3 & 3.3 & 1.6 & 28.2 & 25.9 & 45.9 \\
\hline Transport equipment & 4.5 & 0.4 & 0.4 & 5.3 & 25.6 & 69.1 \\
\hline
\end{tabular}

Source: Ministry of Trade and Tourism, 1981. 


\title{
The Impact of the FTA Agreement with the EEC on Israeli Industry:
}

\author{
A Follow-Up
}

BENNY TOREN

\section{Introduction}

Nearly a decade has passed since the Free Area (FTA) Agreement was signed between the Common Market and Israel. For six or seven of these years, some relevant data are available for analysis. An attempt is therefore called for the review the actual effect of the Agreement on Israeli industry. This review will be made in the light of expected results at the time of signature, bearing in mind a number of limitations. First, not all effects of the Agreement can be expected yet, mainly on the import side. The complete abolition of Israeli protective tariffs against competing imports is now scheduled for 1989. At present, protective tariffs on sensitive imports are half the pre-Agreement level of 1975. Second, the present review was conducted in part on an aggregate level of the industrial sector as a whole, while the original estimates and analyses were conducted on a much more detailed level on industries. At such an aggregate level, all different factors or policies cannot easily be distinguished.

With these limitations in mind, the review will take up the major expected effects of the Agreement one by one and compare them to actual developments between 1975 and 1983. The main topics include direct trade effects on exports and imports, their welfare implications, effects on efficiency and effects on direct private foreign investments.

Of necessity some of the discussions will have to be conducted in qualitative terms. An overall evaluation of the impact of the Agreement will round up the discussion with some policy suggestions. In light of the limitations mentioned above, this evaluation must be regarded as tentative, serving mainly as an invitation for further work to follow.

Expected effects of the Agreement will be based mainly on a research project on the economic integration of Israel in the EEC, prepared in 1977-1978. It was jointly carried out at the Horowitz Institute at Tel Aviv University, and the Kiel Institute of World Economics. In more specific terms the discussion will follow the study: "Israel and the European 
Common Market; An Appraisal of the 1975 Free Trade Agreement", prepared by R. W. T. Pomfret and B. Toren, under the guidance of J. B. Donges.

The general idea behind the Agreement for a Free Trade Area between Israel and the Common Market was a brilliant one. The industrial sector in Israel was heading towards a very negative process of polarization. At one end a very small number of avantgarde, science-based, export-oriented firms emerged, concentrated in a small number of industries. At the other end a mass of more conservative industries existed, some of them mainly dependent on the local, highly protected market. Others were catering to the world market, at a level of very low profit margins. Such low profitability was naturally shaking the very existence of such industries, with every quiver of local economic conditions and of the world market. These conservative industries necessarily became more and more dependent on government aid through subsidies and higher walls of protection.

This negative trend of polarization was to be changed through the Agreement. First Israeli exports were to obtain easier access to EEC markets. Effects to competing imports were more important, however. The Agreement was intended to raise efficiency in a gradual manner in the industrial sector manufacturing tradable goods for the protected local market. Industries which would not be able to compete against imports on the basis of natural protection only were to be discontinued, so that their recources would move gradually into more competitive, mainly export-oriented industries. Spill-over effects were hoped to raise efficiency and profitability in all other industries, including export industries and industries of nontradable goods.

Such a structural change by competing imports could not be expected overnight. The Agreement was accordingly scheduled to grant easier access for nonsensitive imports in a gradual process between the mid-seventies and ending not before the mid-eighties. (See the first two columns in table 1.)

\section{Effects on Exports}

The effect of the Agreement on exports was assumed to develop quickly, as customs on Israeli exports to the EEC were scheduled to be (and were in practice) completely abolished by 1.7 . 1977. Exports of manufactured goods were expected to rise through the Agreement by $\$ 56$ million per year on a 1971 basis $^{1}$.

This figure must be taken as an overestimate, because it was based on the full Common External Tariff (CE') of the Common Market, while an

1 R. Pomfret and B. Toren, "Israel and the European Common Market: An Appraisal of the 1975 Free Trade Agreement", 101 Kieler Studien (1980). 
average of $50 \%$ was already granted to Israel, through the Preferential Trade Agreement of June 1970. A correction factor of $5.6 \%$ on c.i.f. basis, or approximately $6.2 \%$ on f.o.b. basis, instead of $9.15 \%$ used in the analysis quoted, limits the 1971 basis estimate from $\$ 56$ to 38 million $^{2}$. This estimate must be transformed to a 1980 basis. Exports of manufactured goods (excluding mining, food and diamonds) have risen between 1971 and 1980 by 7.9 times in current dollars (from $\$ 356$ million to 2,809 million). This corrects the earlier estimate translated to 1980 basis to $\$ 300$ million of which about half, or $\$ 150$ million can be estimated as value added.

In practice, exports of manufactured goods (excluding diamonds) to Common Market countries, rose between 1976 and 1980 much faster than exports to other destinations. They also rose faster than agricultural exports to EEC countries, as these were practically excluded from the Agreement. The share of agricultural exports in total exports of goods to the EEC area dropped from $24.5 \%$ in 1975 to $16.8 \%$ in 1980 .

While the effect of the Agreement on industrial exports cannot be doubted, the size of the impact is not very clear. If the growth in exports to all countries is takes as a standard, exports to EEC countries grew by $9.7 \%$ per year more rapidly to EEC countries than to the whole world $(37.9 \%$ to $28.2 \%$ as a table 2). Applying this lower growth factor to the $\$ 332.8$ million in 1976 Israeli exports would have been $\$ 899$ million in 1980 instead of the actual figure of $\$ 1,203$ million, or a difference of $\$ 304$ million $^{3}$.

This striking similarity between the expected effect (after correction and updating), and the extra growth factor of trade with the EEC tends to lend support to the view, that these $\$ 300$ million can be explained by the Agreement.

Economists in the Ministry of Industry and Trade also emphasize the positive effect of the Agreement on exports until 1980. Their argument rests mainly on the distribution of this increased export trade, such as textiles and clothing. These increased their EEC export share in total from 56.6\% in 1975 to $81 \%$ in 1980 (see table 3).

These arguments may be accepted as at least partially true. Not completely, however, because of developments in relative values of the different currencies, e.g. the US\$ compared to an average of Common Market currencies. Table 4 shows that if costs and relative prices are measured through wholesale prices and corrected for a forward transaction option, then exports to the EEC gained between 1975 and 1980 in competitiveness in comparison to the dollar by $7 \%$ (13.87 divided by 12.96). A loss in competitiveness was measured between 1980 and 1983 by $26.8 \%$ (1.00 minus 10.52 divided by 14.37). The competitiveness of the EEC was measured

2 Weighted average of EEC tariff rate in column 1, table 3, p. 56 of Pomfret and Toren, supra note 1.

$3332.8 \times\left(1.379^{4}-1.282^{4}\right)=1,203-899=304$. 
through average annual exchange rates of all present members including Denmark, Luxembourg, Greece and Ireland. Averages were weighted with exports of manufactured goods (excluding diamonds, minerals and food), in 1983.

The above mentioned changes in relative competitiveness in the EEC in comparison to the dollar are not smaller, and since 1980 much larger than the $6.2 \%$ savings in customs due to the Agreement as mentioned earlier. The higher weight to be attached to relative changes in exchange rates is further indicated, in the period 1980-1983, when exports to the EEC fell sharply from $\$ 1,203$ million in 1080 to $\$ 926$ million in 1983 (see table 2). This decline by an annual rate of $8.4 \%$ over a period of three years was noted in spite of the Agreement with all its concessions.

It must therefore be concluded that the Agreement is to be credited for some of the extra exports to EEC markets up to 1980, and may possibly have hindered an even larger decline in exports between 1980 and 1983. It is not reasonable, however, to assume that the Agreement was the dominant factor to explain a $\$ 300$ million of extra growth in exports to the Common Market.

The welfare effect of this abolition of customs, can be estimated for 1980 at the volume of customs saved, i.e. $6.2 \$$ of $\$ 1,203$ million, or $\$ 75$ million. It fell in 1983 to $\$ 57$ million, due to the fall in exports (see table 2).

\section{Effects on Imports}

The study of expected effects concluded that if the Agreement would be implemented on the Israeli import side without delay, imports of manufactured goods would rise by some $\$ 180$ million, or $15 \%$ on 1971 basis. The final figure was expected to depend on import elasticities 4 .

As already mentioned, the original Agreement delayed the final abolition of customs on sensitive imports until 1985, while this date was further postponed recently to 1989 . Customs on sensitive items are since January $198350 \%$ of their original rates in 1975 .

On top of this delay in implementation, protection from imports was continued in a number of cases, where the abolition of customs caused serious market disruption in a sector of economic activity or a region, as defined in para. 15 and 16, chapter I of the Agreement. It must therefore be concluded that plans for a very slow process of implementation of the Agreement on the import side were implemented even more slowly than originally contemplated.

Diversion of trade could have been expected here even less than on the export side. Israel started a global and unilateral trade liberalization policy before the Agreement, and continued to lower its customs vis-à-vis third

4 Pomfret and Toren, supra, at 51-54. 
countries in line with custom cuts on imports from the Common Market. A minor discriminatory gap in favor of the EEC was first created in a number of items since January 1983, but even here it is too soon and too early to note any trade diversion.

In reality imports from the EEC contributed $\$ 1,039$ million out of a total of 2,425 million, or $42.8 \%$ in 1980 and rose further to $51.6 \%$ in 1983 . The growth in the import share of the EEC between 1976 and 1980 is of special interest, because the $7 \%$ relative improvement in competitiveness for exports meant a $7 \%$ relative deterioration for importers from the EEC compared to importers from the US. Here the further rise in the EEC share in imports between 1980 and 1983 was more in line with relative changes in competitiveness ( 8.768 compared to 12.62 in table 4 ). There may have been some announcement effect of the Agreement.

The relative role of the two factors, namely the Agreement on the one hand and changes in the relative competitive position on the other, is made clear in table 5. Manufactured goods marked an uninterrupted rise in the share of EEC in the total of Israeli imports. Other imports, on the other hand, followed the changes expected due to competitiveness. Imports from the EEC became less competitive between 1976 and 1980, and the share of the EEC in total imports declined in this period. Imports from the EEC became more competitive between 1980 and 1983, and the share of the EEC in total imports rose in non-manufactured imports in this period. Total imports followed the pattern of non-manufactured imports, because purchasing power seems to be a much more important factor than the more psychological factor connected with the Agreement.

In summary, it seems too early to draw conclusions on the trade effects of the Agreement on the import side. In any case such an analysis should be made on a much more detailed basis.

Turning now to net welfare gains on the import side; these were estimated at IL69-190 million on 1971 basis and prices. This rise amounted to $0.44-1.21 \%$ of total consumption ${ }^{5}$.

This estimate must also be adjusted for the slow implementation. In reality welfare gains may not have materialized, even if a measurement ex post does not seem feasible.

Here, however, an additional factor cannot be overlooked, namely the assumed neutrality of very substantial welfare transfers from producers and government to consumers. Their size was estimated respectively as 6.5 and 13 times larger than the higher alternative net welfare gain. Very large transfers from producers to consumers may upset any equilibrium in existing relations between the two, mainly in times of unstable economic conditions. The basic need for such a transfer may depend on personal attitudes. Most Israeli economists would not have supported it, because in the last three years Israel

5 Id., at 62. 
experienced an 8.35 annual rate of increase in private consumption (or $6.3 \%$ per capita), compared to $1.9 \%$ average annual increase in GDP (or $1.7 \%$ ).

Effects of increased imports on welfare are closely related to efficiency gains and will therefore be discussed in combination with efficiency in the next section.

\section{Gains from Efficiency}

Gains from efficiency were assumed to result from heavier competition expected from imports of manufactured goods with protection before the Agreement ${ }^{6}$. It was assumed that the process of lowering protective tariffs would act in stages. First profit margins, mainly of a monopolistic nature would suffer. Second, costs of production would fall and efficiency would be gained. Finally, whenever imports increase, local output was expected to shrink or to be discontinued, and resources would be freed to be gradually reemployed in more competitive, mainly export industries. At this last stage, expected mainly in cases of relatively strong pressure from Common Market competition, allocative efficiency gains were expected. In quantitative terms $1 \mathrm{~L} 1.5$ billion in terms of value added in 1975 prices were expected on gains from efficiency, which implied a cumulative impact of $6.9 \%$ on output (see table 6).

Actual development will be discussed here in two stages. First the slowerthan-expected implementation of the Agreement will be evaluated in terms of its adjusted impact on expected efficiency. Second, actual changes in efficiency will be compared to these originally expected and adjusted increases in efficiency.

The very slow implementation of the Agreement on the import side has a direct bearing. The very gradual pressure from competing imports cannot be expected as yet to have caused a noticeable volume of resource re-allocation and allocative efficiency. At best it could be expected to have narrowed profit margins and increased X-efficiency.

Again some very tentative quantitative estimates can be mentioned. Half the scheduled cut in customs must have achieved less than half the expected rise in efficiency, as some element in protection does not immediately affect profits. This is indicated by the $40 \%$ gap between the average effective rate of protection of $43 \%$ and the effective rate of protection on cost basis or the cost per dollar saved of $26 \%{ }^{7}$. In line with this gap, it will be arbitrarily assumed that actual benefits of X-efficiency will be $60 \%$ of the relative cut in customs of $50 \%$ or a net effect of $30 \%$ (see table 6 ).

Id., at $100-102$.

7 B. Toren, "The Competitive Position of Israeli Industrial Branches", in The Economic Integration of Israel in the EEC, 204-206 (Tel-Aviv Conference, 1980). 
In terms of an increase in gross output this implies a $1.6 \%$ instead of the $6.9 \%$ cumulative increase or an annual average rate of $0.18 \% \quad(=1.016$ $1 / 9-1)$ instead of the $0.67 \%(=1.0691 / 10-1)$.

It may be noted that this estimated effect of the slower implementation of the Agreement disregarded a further slow-down involved in the mentioned recourse to para. 15 and 16 of chapter I in the Agreement.

Actual changes in efficiency can only be studied by comparing the needed rises in productivity with actual developments. For this comparison the Effective Rate of Protection (ERP) on cost basis is taken as a proxy for needed changes in factor productivity, in spite of existing differences between the two concepts.

Changes needed in order to abolish the average ERP on cost basis of $26 \%$ in the original time table implied no more than an annual increase in factor productivity of $2.33 \%$ (see table 7 ). This was a moderate target in light of the fact that highly protected industries were to be excluded by discontinuing their production and shifting their resources to competitive export industries. Second, actual factor productivity rises before the Agreement were substantially higher even without the pressure added through the Agreement. Until the Yom Kippur War in 1973 they were somewhat below 6\% per annum, or for the whole period 1960-1975 4.8\% per annum.

The change in productivity since the Agreement was close to zero or even slightly negative, as indicated by table 7 . The story on reallocation of resources in industry is not so gloomy. It reallocation is meant to indicate a change in the structure of output, then such a restructuring of industry did actually take place. Table 8 summarizes changes in gross output in a number of science-based industries compared to the industrial sector as a whole, excluding diamonds. The period of the Agreement is compared to the decade before it. The shift of weight towards science-based high-skill industries continued before and after the Agreement, with their share rising from 8 to $19 \%$ between 1965 and 1975 , and from 19 to over $22 \%$ between 1975 and 1980. The rate of growth of output in science-based industries was more than double the rate in other industries. This very rapid reorientation of industrial output towards science-based industries was not continued after 1980 because of stagnation in industrial output including a number of sciencebased industries.

The shift of emphasis towards science-based industries is even more pronounced in the case of exports. Table 9 shows a very rapid rise in the share of science-based industries in total industrial exports (excluding diamonds) from $18.4 \%$ to $37.6 \%$ between 1968 and 1975 and a further, more moderate shift to $45.6 \%$ in 1980 and $48.7 \%$ in 1982 . This restructuring of the industrial sector, even if positive in itself, may be regarded as irrelevant. Reallocation of resources, in the simple sense of the word, exists when resources leave an industry, e.g. a high protection industry, and move to another industry, e. g. 
an export industry. The real question should therefore be whether resources actually left some of the industries.

A partial answer to this question was offered by a detailed analysis of changes in real output since the Agreement. Table 10 indicates that out of seventy-six sub-branches specified, twenty were found with a fall or complete stagnation in real output. In terms of the value of gross output in 1975 these sub-branches produced about one-sixth of industrial output (excl. diamonds).

These industries were further studied. Some of them produce non-tradeable commodities such as quarrying stone and sand for construction. In others a technological process of substitution, rather than competing imports explain the fall in output. Declining industries were only assumed to have been affected by competing imports, where such imports were substantial in 1982 and defined by the Central Bureau of Statistics as competing with, rather than complementary to local production. Through this further analysis 8 additional industries were eliminated, so that twelve were left with $10.6 \%$ of the gross value of output. What quantitative conclusions emerge from this discussion? Can we conclude that over $10 \%$ of resources of industry were actually reallocated? The answer is clearly negative. First, because output in the twelve affected industries did not disappear but rather fell by no more than average of $10.7 \%$ until 1982 . Only part of their output was affected. Second, because some resources were reallocated in parts of growing subbranches of industry or even within the same company, changing its production program within the same sub-branch ${ }^{8}$. Finally not all cases of increased imports with falling output are a result of import liberalization. Some of these industries had low protection before the Agreement and technological changes explain substitution between local output and import explain the change.

All told the actual shift of resources must be substantially lower than the $10.6 \%$ mentioned and may possibly lie between half or two-third of this sum. This would imply an actual shift of resources of $1 \%$ or somewhat less per GDP of the business sector?.

The case of the transfer from the budget to consumers is much clearer and very negative in a period of chronic budget deficits and un unforeseen fall in income tax revenues. The social and economic cost of regaining lost revenues must be assumed to be quite substantial.

It is for these reasons, that marginal welfare gains, which may have been realized on the import side, should practically be disregarded in the analysis or rather is objected to, as general economic conditions have neutralized such gains with substantial damage.

8 Pomfret and Toren, supra, at 99.

9 Bank of Israel Report (1983) (Hebrew). 


\section{Direct Foreign Investments (DFI)}

The study of expected effects yielded contradicting influences ${ }^{10}$. The multiple regression analysis failed to reveal any effect of DFI on the competitive position of industries before the Agreement, neither in exports nor in the substitution of imports ${ }^{11}$. On the other hand, a positive impact of the Agreement was hoped for, because of a number of reasons ${ }^{12}$.

First, it was hoped that the Agreement in combination with the General System of Preferences (GSP), granted by the USA and nine other countries would render Israel as a two-way custom-free bridge to be used by American firms trying to avoid customs in the EEC, and by European firms trying to avoid customs in the US.

Second, it was hoped that two additional developments would improve the investment climate for foreign companies in Israel. These included the liberalization of the foreign currency regime, in November, 1977, following the appointment of Ministers of Finance and Trade and Industry from the Liberal party a few months earlier. Further it was hoped that peace with Egypt (Israel's largest neightbor and former enemy) would not only improve the economic climate in the region, but would furthermore open many opportunities for US-Egypt-Israel tripartite investment deals, based on Egyptian labor, American capital and marketing potential, and Israeli engineers, R \& D potential and tax-free entry into the EEC and the US.

Finally it was hoped that a positive impact on foreign investments in industry would not replace local investments, but rather reinforce them and increase the overall volume by more than the increase in private foreign investments ${ }^{13}$.

Actual development did not lend full support to the optimistic view mentioned above ${ }^{14}$. While the relation between investments and exports is not easy to evaluate on an aggregate basis, total gross foreign investments did not change substantially in dollar terms between 1975 and 1983, as indicated in table 10. Abstracting from a downswing in 1978-79 and a hike in 1981, the level of direct foreign investments fluctuated around the US\$100 million mark, while the dollar lost $45 \%$ of its value (see table 4$)^{15}$.

Another question concerns the regional distribution of investor's home countries. Available data on this question are not completely applicable to the analysis, (see table 12). The Investment Center reports on approvals rather than actual investments and specifies six EEC member countries, excluding

Pomfret and Toren, supra, part III, chapter 4.

Id., at $159-161$.

Id., at $145-148$.

13 Id., at 154.

14 Bank of Israel Report, supra note 9.

15 Business Week, May 7, 1984, (Special Supplement on Israeli Technology for Business Growth). 
the US and the UK together with Canada. In these two regions no upward trend could be discerned in the volume or concentration of investments coming from them.

Next, the volume of investments in industry was expected to rise. Here again the upward trend could not be noted in gross investments in industry, between 1975 and 1981. (See table 13). In the years 1982 and 1983 a rise of around $20 \%$ was noted in real terms. It must be doubted, however whether this rise could be connected in any form with the Agreement.

More important than any data are attitudes and opinions of potential investors. The question had therefore to be asked whether the Free Trade Area Agreement with the Common Market had a sizable positive impact on investment decisions.

The Investment Authority feels quite strongly that potential investors in high technology industries in Israel will actually be influenced by their decisions by four more general factors, which could not be easily separated:

a) The liberalization of the Israeli foreign currency region of 1977

b) Peace with Egypt

c) The Free Trade Area Agreement with the EEC

d) The General System of Preferences, mainly in the US, hopefully to be replaced by another free trade area agreement with the US.

Negotiations with potential investors included in fact a number of cases questions and clarifications sought on classification and rules of origin status of potential exports from Israel to the EEC. Such questions were dealt with in two of the most important foreign investments in the high-technology sector in Israel in recent years.

Reasons for investment decisions were recently discussed with an impressive list of businessmen, who have already invested in the high technology industry in Israel ${ }^{16}$. Most of these interviews did not reveal a strong US-EEC penetration strategy or an emphasis on the effect of the Free Trade Area Agreement. While all of them mentioned the availability of high level manpower, or the R \& D potential as a major factor, the Agreement was mentioned only as an additional factor in two or three out of twelve interviews. Other investors did not deem it of relevance to mention their added possibilities in their exports to the EEC.

This lack of interest may be connected with the fact that most Israeli exports of high technology products are sold on the American market, with a relatively small share exported to Europe. In electronics, communication and scientific equipment the US absorbed over a half and the EEC less than a quarter of Israel's exports with specified destination in 1982. For all industrial goods excluding diamonds, the US absorbed $32 \%$, compared to $44 \%$ for the EEC. This concentration of high technology exports on the American market may definitely be true, but then foreign investments are rare in other 
fields of industry, which may add another proof to the feeling that foreign investors come to Israel mainly for its high-technology potential. Easy access to the Common Market is only one among a number of factors.

Summing up, direct foreign investments did not manage to raise total investments in fixed assets in the industrial sector. Furthermore, no change in the distribution of investors' home countries could prove any systematic attempt to use the agreement as a custom-free bridge to Europe for American investors. Hopes for tripartite investment deals of Egyptian, American and Israeli firms did not materialize for political reasons. Finally, when consultations with foreign investors in Israel were conducted recently, all of them regarded the availability of high-level manpower and a research potential as the dominant factors in their decision.

In spite of these negative results, it cannot be overlooked that some of the most important foreign investments in Israel in recent years, regarded their custom-free entry into Europe as a meaningful asset. This very clear achievement of the Agreement can by no means change the overall impression that the actual effect of the Agreement on direct foreign investments cannot be disregarded as more than marginal.

\section{Summary and Evaluation}

The Free Trade Area Agreement with the EEC had some positive effects on Israeli exports between 1975 and 1980. These were noted to a large extent in textiles and clothing, where tariff concessions by the EEC were reinforced with a preferential system of quantitative import controls. It is not reasonable, however, to credit the Agreement with the full amount of the unexpected rise of US $\$ 300$ million in exports to the EEC, which were clearly influenced by changes in relative exchange rates. Furthermore, a modest gain in welfare due to savings in EEC tariffs of $\$ 57-75$ million should also not be overlooked.

An expected indirect effect of an increased export potential on direct foreign investments did not materialize to a large extent. The overall effect of the Agreement on the export side may have improved the access of Israeli exports to the EEC, and may have had some effect on welfare. All told this was a marginal impact, while other factors, such as the differential developments in the various currencies, must have been more important.

Turning now to the import side, there was a clear increase in the share of EEC countries as suppliers of industrial imports to Israel. As tariff discrimination did not exist, this was neutral in its effect on the Israeli industry, while it may have benefitted the EEC. It indicates an increasing awareness of integration and had at least a psychological effect.

It must be borne in mind, however, that the major economic aim of the Agreement was the integration of the Israeli industry in the EEC and the 
increase in the level of international competition. In a broad sense this aim was only partially achieved until now, for a number of reasons:

First, because the Agreement was implemented on the import side in such a slow manner that it lost in practice much of its quantitative meaning.

Second, because to a large extent success depends on a transfer of resources from highly protected, import-substituting industries to export industries. Such a transfer was in reality much slower than expected. The fact that the government came to the rescue and avoided the shutdown of many factories under pressure and avoided the increase in imports in many cases. Dumping became sometimes an excuse, not always a legitimate criterion based on hard facts.

Last and not least, because of the severe economic instability, and the continuous relative stagnation, which rendered any increase in productivity practically impossible. In an economy where real earnings are being eroded through inflation by $20 \%$ in ninety days, an annual increase in productivity of $6 \%$ does not seem relevant or worthwhile. Higher efficiency or a realization of resources to more competitive industries can only be achieved through the fullest and undivided attention of management and labor (and government), who cooperate in a gradual and painstaking effort.

Nobody can deny very positive developments in the Israeli industry in the seventies and early eighties. These included first and foremost the very rapid growth of high-tech industries, based on $\mathrm{R} \& \mathrm{D}$. This, however is not the result of the Agreement and most of it would have occured without it.

The increasing polarization of Israeli industry between a science-based export oriented sector and a highly protected import substituting sector, was mentioned above. This process of polarization was not increased to a substantial degree. Only a massive reallocation of resources and increased efficiency in protected industries can remove their negative drift towards deeper and deeper dependence on government support.

In summary the Free Trade Area Agreement of Israel with the Common Market may have had important political implications. Its economic effect on Israeli industry was only marginal, due to general economic conditions in Israel. The rigid implementation of the Agreement by the EEC Authorities in Brussels was not a major factor in limiting its results.

In light of this disappointment, the question may be asked, whether it is economically justified, to continue with the implementation of the Agreement. Even more relevant, whether another agreement for a free trade area with the US is advisable, on economic grounds.

The answer leans on the positive, even if this may sound contradictory. As part of a broader policy to stabilize and revitalize the economy, it seems advisable to include the implementation of the FTA Agreement with the EEC on the import side. The full effect of such a policy would be enhanced by a symbolic action of acceleration in the abolition of remaining sensitive import tariffs. Such a proposal is indicated in the last column of table 1 and 
should be used in negotiations with the EEC on the accession of Spain, Portugal and Greece to the Common Market.

A similar attitude would be justified in relation to the proposed free trade agreement with the US. This pending agreement may be justified on political grounds. Its expected benefits to exports by replacing the GSP regime with a better free trade agreement would possibly be neutralized by the negative impact on Israeli freedom of action in the promotion of all her exports.

The expected effect of the agreement with the US on the import side is highly beneficial to the Israeli industry but only under the above mentioned conditions. These include:

- A stabilization of prices. Accordingly it is proposed that the lowering of protective tariffs will be started only after a year.

- A revival of economic development with an emphasis on industry.

- A renewed improvement in the balance of payments, not by controlling imports, but rather by the reallocation of resources from protected import replacing industries to more competitive export industries.

It must be admitted that quite a lot of intelligence and public courage are needed to defend a balance of payments policy, which implies the growth of imports. Without such an industrial development strategy, based on the survival of the fittest and a transfer of resources from many industries to other more competitive ones, no integration policy is going to assist the ailing Israel economy. 
Table 1: Time Table of Tariff Reductions on Sensitive Imports (Original and Adjusted Agreement and Proposal)

\begin{tabular}{rccc}
\hline $\begin{array}{r}\text { Rate of Decrease, } \\
\text { on 1975 Basis }\end{array}$ & Original & $\begin{array}{c}\text { Agreement Proposed } \\
\text { Adjusted, 1984 }\end{array}$ & Acceleration \\
\hline $5 \%$ & 1.7 .1977 & 1.7 .1977 & - \\
$20 \%$ & 1.7 .1978 & 1.7 .1978 & - \\
$30 \%$ & 1.7 .1979 & 1.7 .1981 & - \\
$50 \%$ & 1.1 .1981 & 1.1 .1983 & - \\
$65 \%$ & - & - & 1.7 .1985 \\
$80 \%$ & 1.1 .1983 & 1.1 .1987 & 1.7 .1986 \\
$95 \%$ & - & - & 1.7 .1987 \\
$100 \%$ & 1.1 .1985 & 1.1 .1989 & 1.1 .1989 \\
\hline
\end{tabular}

Source: Agreement between the State of Israel and the European Economic Community, 7 May 1985, p. 2 h. 2.

Mrs. G. Cohen, Chief Economist, Foreign Trade Section, Ministry of Industry \& Trade.

Table 2: Exports of Manufactured Goods to the EEC, US and total World, 1976-1983

\begin{tabular}{ccccc}
\hline Year & EEC & US & World & $\begin{array}{c}\text { Share of EEC } \\
(\%)\end{array}$ \\
\hline \$ Million & & & & \\
1976 & 332.8 & - & $1,122.9$ & 29.6 \\
1980 & 1,203 & 467 & 3,030 & 39.7 \\
1983 & 926 & 752 & 3,019 & 30.7 \\
Average Annual & & & & \\
Increase (\%) & 37.9 & - & 28.2 & \\
1976-1980 & $(-) 8.4$ & 17.2 & $(-) .1$ & \\
1980-1983 & 15.7 & - & 15.2 & \\
$1976-1983$ & & & &
\end{tabular}

Source: Foreign Trade Statistics Quarterly, December 1979, October-December 1983, No. 4, Central Bureau of Statistics. 
Table 3: The Share of EEC in Total Exports in Groups of Industries 1975-1980, Compared to 1975 Tariff Rates (CET)

\begin{tabular}{|c|c|c|c|}
\hline \multirow[t]{2}{*}{ Industry } & \multicolumn{2}{|c|}{$\begin{array}{l}\text { Share of EEC Exports } \\
\text { in Total }(\%)\end{array}$} & \multirow{2}{*}{$\begin{array}{c}\text { Average } \\
\text { Tariff } \\
\text { Rate }(\%)\end{array}$} \\
\hline & 1975 & 1980 & \\
\hline $\begin{array}{l}\text { Industrial Exports } \\
\text { (excl. diamonds) }\end{array}$ & 36.7 & 41.5 & - \\
\hline Food, Beverages, Tobacco & 65.7 & 69.2 & - \\
\hline Textiles, Clothing, Leather & 56.6 & 81.0 & 12.3 \\
\hline Wood, Paper, Printing \& Misc. & 32.3 & 36.7 & 8.2 \\
\hline $\begin{array}{l}\text { Minerals and Non-Metallic } \\
\text { mineral products }\end{array}$ & 42.6 & 28.9 & 7.4 \\
\hline Chemicals, Rubber \& Plastics & 31.0 & 51.1 & 8.9 \\
\hline Metals \& Electronics & 17.2 & 16.4 & 6.2 \\
\hline
\end{tabular}

Source: Exports - The export from Israel, Countries of Destination \& Branches, 1982, Center for Industrial Planning, Ministry of Industry \& Trade, Tables 6, 7;

Tariff Rates - Pomfret and Toren, "Israel and the European Common Market: An appraisal of the 1975 Free Trade Agreement", 101 Kieler Studien 165, 166 (1980). 


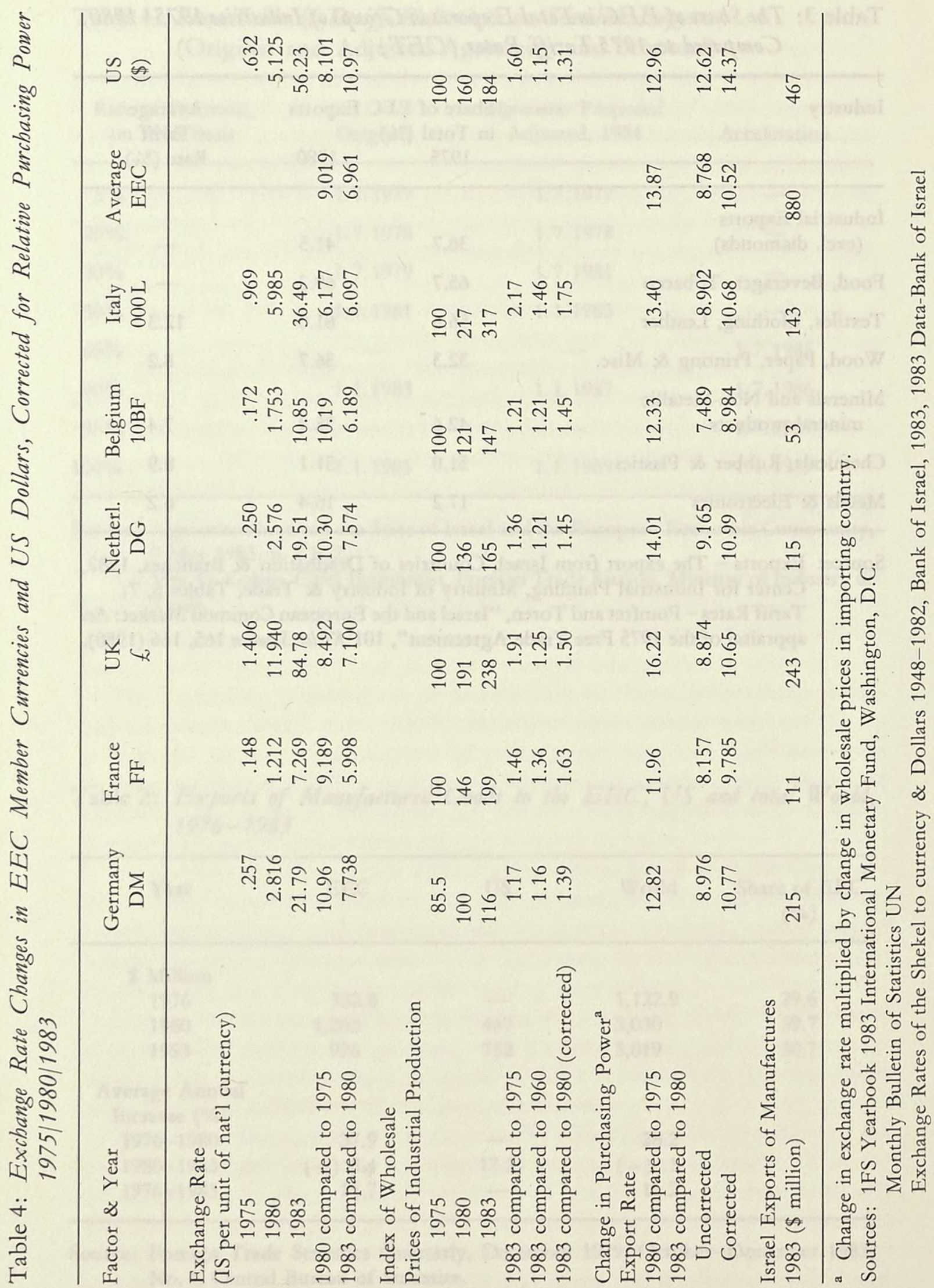


Table 5: EEC Share of Israeli Imports of Manufactured and Non-Manufactured Goods (\$ million)

\begin{tabular}{|c|c|c|c|c|}
\hline Area & 1975 & 1976 & 1980 & 1983 \\
\hline \multicolumn{5}{|l|}{ 1. Total Imports } \\
\hline $\mathrm{EEC}$ & $1,751.5$ & $1,595.0$ & $2,703.8$ & $3,474.5$ \\
\hline World & $4,172.6$ & $4,140.4$ & $8,027.3$ & $8,587.4$ \\
\hline EEC Share (\%) & 42.0 & 38.5 & 33.7 & 40.5 \\
\hline \multicolumn{5}{|l|}{ 2. Imports of } \\
\hline \multicolumn{5}{|l|}{ Manufactured Goods } \\
\hline EEC & - & $1,039.1$ & 1,903 & 2,719 \\
\hline World & - & $2,425.3$ & 3,869 & 5,269 \\
\hline EEC Share (\%) & - & 42.8 & 49.2 & 51.6 \\
\hline \multicolumn{5}{|l|}{$\begin{array}{l}\text { 3. Imports of } \\
\text { Non-Manufactured Goods }\end{array}$} \\
\hline EEC & - & 555.9 & 800.8 & 755.5 \\
\hline World & - & $1,715.1$ & $4,158.3$ & $3,318.4$ \\
\hline EEC Share (\%) & - & 32.4 & 19.3 & 22.8 \\
\hline
\end{tabular}

Table 6: Estimates of Actual Efficiency Gains Compared to Expectations Through Lowering Protective Tariffs (IL billion, 1975 Prices)

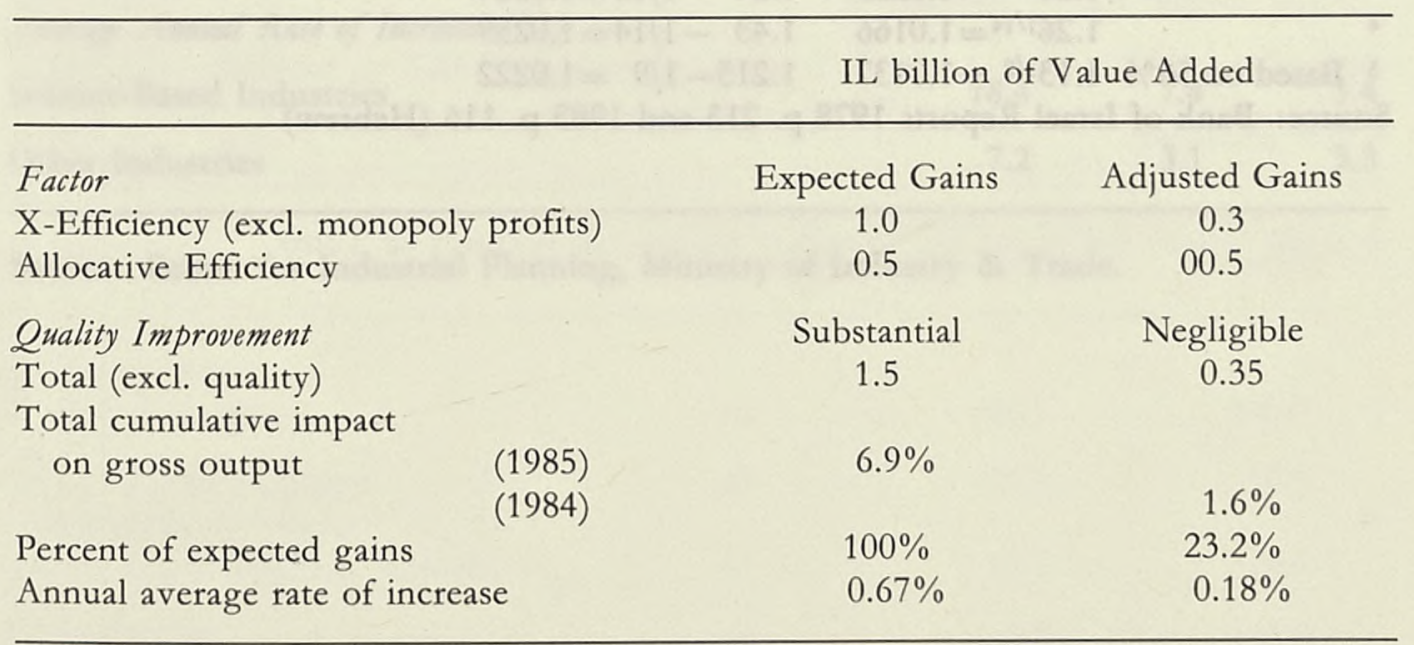

Source: Pomfret and Toren, "Israel and the European Common Market: An appraisal of the 1975 Free Trade Agreement", 101 Kieler Studien 165, 166 (1980). 
Table 7: Average Annual Increase in Factor Productivity in Industry ${ }^{1}$, Actual 1960-1983 and Implied by the Agreement (in percent)

\begin{tabular}{lccc}
\hline Period & $\begin{array}{c}\text { Actual Rise } \\
\text { in Productivity }\end{array}$ & $\begin{array}{c}\text { Implied Rise } \\
\text { in Productivity }\end{array}$ & $\begin{array}{c}\text { Effective Rate } \\
\text { of Protection }\end{array}$ \\
\hline $1960-1965$ & 5.9 & & \\
$1966-1972$ & 5.8 & & \\
$1973-1975$ & 0.8 & & \\
$1976-1978$ & 2.2 & & \\
$1979-1983$ & $(-))$ & & \\
$1960-1975$ & 4.8 & 2.33 & 2.64 \\
$1976-1983$ & $(-) 0.5$ & 1.66 & 2.59 \\
$1975-1985$ (Original Agreement) & & \\
$1975-1989$ (Adjusted Agreement) $^{4}$ & 1.37 & 2.22 \\
$1975-1984$ (Implementation) $^{5}$ & & & \\
\hline
\end{tabular}

1 Annual rise in net output divided by a weighted average rise in inputs, i.e. labor (58\%) and capital $(42 \%)$.

2 Needed decline in Effective Rate of Protection on cost basis.

3 See B. Toren, "The Competitive Position of Israeli Industrial Branches", in The Economic Integration of Israel in the EEC 204-206 (1980).

$\begin{array}{rll}1.26^{1 / 10}=1.0233 & 1.34-1 / 10=1.0364 \\ 4 & 1.26^{1 / 14}=1.0166 & 1.43-1 / 14=1.0259 \\ 5 \text { Based on } 50 \% & 1.13^{1 / 8}=1.0137 & 1.215-1 / 9=1.0222\end{array}$

Source: Bank of Israel Reports 1978 p. 213 and 1983 p. 116 (Hebrew) 
Table 8: Gross Output in Science-Based Industries, Compared to Total Industry, 1965-1982 (in IS million of 1981)

\begin{tabular}{|c|c|c|c|}
\hline No. Branch & 1965 & 1975 & 1980 \\
\hline Science-Based Industries (S.B.) & & & . \\
\hline 200 Basic Chemical Industry & 1,238 & 3,334 & $5,656 \quad 5,750$ \\
\hline 201 Pharmaceuticals & 336 & 1,417 & $1,614 \quad 1,860$ \\
\hline 205 Insecticides & 175 & 1,590 & $2,011 \quad 1,960$ \\
\hline 233 Heating \& Cooling Utensils & 123 & 375 & $540 \quad 490$ \\
\hline 256/9 Metal Products & 1,083 & 6,671 & $9,090 \quad 10,305$ \\
\hline 241 Industrial Machinery & 910 & 1,472 & $1,903 \quad 2,270$ \\
\hline 250 Electrical Motors & 288 & 703 & $677 \quad 575$ \\
\hline 254-6 Electronic Communication Equip. & 345 & 5,204 & $7,805 \quad 9,335$ \\
\hline 262/3 Aircraft \& Maritime Vessels & 461 & 5,800 & $9,299 \quad 8,890$ \\
\hline 280/1 Precision \& Optical Equip. & 192 & 1,188 & $1,227 \quad 1,170$ \\
\hline Total Science Based & 5,151 & 27,844 & $39,822 \quad 42,605$ \\
\hline 10-26 Total Industry (excl. diamonds) & 63,918 & 146,500 & $177,894 \quad 189,915$ \\
\hline Total Industry (excl. S. B.) & 58,767 & 118,656 & $138,072 \quad 147,310$ \\
\hline $\begin{array}{l}\text { Share of S. B. in Total (\%) } \\
\text { Average Annual Rate of Increase (\%) }\end{array}$ & 8.1 & 19.0 & 22.4 \\
\hline Science-Based Industries & & 18.4 & 7.4 \\
\hline Other Industries & & 7.2 & 3.1 \\
\hline
\end{tabular}

Source: Center for Industrial Planning, Ministry of Industry \& Trade. 
Table 9: Exports of Science-Based Industries compared to Total Industry 1968-1982 (in \$ million of 1981)

\begin{tabular}{lrrrr}
\hline No. 1 Branch & 1968 & 1975 & 1980 & 1982 \\
\hline 200 Basic Chemical Industry & 31.0 & 113.7 & 334.5 & 319.8 \\
201 Pharmaceutical Industry & 12.4 & 40.2 & 22.7 & 39.3 \\
205 Insecticides & 27.0 & 76.5 & 117.2 & 105.2 \\
233 Heating \& Cooling Utensils & 3.0 & .9 & 10.1 & 7.0 \\
$236 / 9$ Metal Products & 67.2 & 126.6 & 286.7 & 383.2 \\
241 Industrial Machinery & 10.5 & 33.9 & 53.4 & 69.6 \\
250 Electrical Motors & .5 & 5.1 & 14.0 & 21.9 \\
254-6 Electronic \& Communication Equip. & 12.2 & 110.6 & 208.8 & 380.4 \\
262/3 Aircraft \& Maritime Vessels & 29.5 & 54.9 & 406.4 & 397.9 \\
280/1 Precision \& Optical Equip. & 3.4 & 17.3 & 36.5 & 62.4 \\
Total Science Based & 196.7 & 579.7 & $1,501.3$ & $1,786.7$ \\
10-26 Total Industry (excl. diamonds) & $1,070.5$ & $1,541.9$ & $3,293.5$ & $3,667.2$ \\
Share of S. B. in Total (\%) & 18.4 & 37.6 & 45.6 & 48.7 \\
Total Industry & & & & \\
$\quad$ (excl. S. B. and diamonds) & $5,873.8$ & 962.2 & $1,792.2$ & $1,880.5$ \\
Average Annual Rate of Increase (\%) & & & & \\
Science-Based Industries & & 16.7 & 21.0 & 9.1 \\
Other Industries & & 1.4 & 13.2 & 2.4 \\
\hline
\end{tabular}

Source: Center for Industrial Planning, Ministry of Industry \& Trade. 
Table 10: Total Gross Foreign Investments in Israel, (excl. marketable securities) ${ }^{1}$ (1975-1983 \$ million)

\begin{tabular}{lcc}
\hline Year & Investment Mil. \$ & \% Change over previous year \\
\hline 1975 & 95.9 & - \\
1976 & 93.0 & -3.0 \\
1977 & 102.2 & 9.9 \\
1978 & 69.2 & -32.3 \\
1979 & 87.0 & 25.7 \\
1980 & 109.2 & 25.5 \\
1981 & 107.0 & 71.2 \\
1982 & 106.9 & -42.8 \\
1983 & 95.7 & -10.8 \\
\hline
\end{tabular}

1 Investments are defined as acquisition of ownership and management rights by foreigners in the Israeli economy. Sale of debentures and loans by owners are excluded in most cases. Includes undistributed profits earned by foreign owners.

Source: Foreign Trade Dept., Central Bureau of Statistics.

Table 11: Analysis of Declining and Stagnant Industries 1975-1982 by. Factors Explaining Decline (Gross Output in 1975 in IS billion 1981 prices)

Number of

Sub-branches
Gross Value of Output 1975

IS Billion

Percent

Industrial Sector (excl. diamonds)

76

20

12

8
146.5

24.3

15.5

8.8
100.0

16.6

10.6

6.0

Other Factors

Source: Data on Output - Center for Industrial Planning

Ministry of Industry \& Trade

Data on Imports - Competing and Supplementary Imports by Industrial Origin, 1982, Foreign Trade Test.

Central Bureau of Statistics. 
Table 12: Approvals of Investments in Foreign Currency in Israel by Region of Investor's Origin

\begin{tabular}{lrrrrrrrr}
\hline & \multicolumn{2}{c}{ All Foreign } & \multicolumn{2}{c}{ USA-Canada } & \multicolumn{2}{c}{ 6 EEC Members ${ }^{1}$} & \multicolumn{2}{c}{ All Others } \\
Year & $000 \$$ & $\%$ & $000 \$$ & $\%$ & $000 \$$ & $\%$ & $000 \$$ & $\%$ \\
\hline 1975 & 114,381 & 100 & 65,764 & 58 & 14,174 & 12 & 34,443 & 30 \\
1976 & 74,812 & 100 & 32,268 & 43 & 4,222 & 6 & 38,322 & 51 \\
1977 & 174,942 & 100 & 66,300 & 38 & 67,5693 & 393 & 41,073 & 23 \\
1978 & 96,528 & 100 & 42,559 & 44 & 3,401 & 4 & 50,568 & 52 \\
1979 & 111,133 & 100 & 64,505 & 58 & 11,339 & 10 & 35,289 & 32 \\
1980 & 144,889 & 100 & $102,383^{4}$ & 714 & 14,352 & 10 & 28,154 & 19 \\
1981 & 65,379 & 100 & 25,869 & 40 & 3,125 & 5 & 36,385 & 55 \\
1982 & 79,193 & 100 & 43,227 & 55 & 11,161 & 14 & 24,805 & 31 \\
1983 & 150,100 & 100 & 90,000 & 60 & 2 & 2 & 60,100 & 40 \\
\hline
\end{tabular}

1 Italy, Belgium, W. Germany, Denmark, Netherlands and France

2 Included in all other.

3 Of which $\$ 55,975,000$ (or $32 \%$ ) is a loan by a financial institution.

4 Of which $\$ 80,948,000$ (or $56 \%$ ) is carried out by a financial institution.

Source: 30 years of the Investment Center, Jerusalem May 1981 - Table 26 (Hebrew) Investment Center Report 1982, Table 15 (Hebrew)

1983 Provisional data, Investment Authority 
Table 13: Gross Domestic Capital Formation in Industry (1975-1983)

\begin{tabular}{lcc}
\hline Year & 15 Million & Change over previous year $(\%)$ \\
\hline 1975 & 1975 Prices & - \\
1976 & 391 & -4.6 \\
1977 & 373 & -10.5 \\
1978 & 334 & 13.2 \\
1979 & 378 & -1.9 \\
1980 & 371 & -13.2 \\
& 322 & - \\
1980 & 1980 Prices & 0.4 \\
1981 & 3,527 & 21.9 \\
1982 & 3,540 & 18.2 \\
1983 & 4,314 & \\
\hline
\end{tabular}

a Estimate on basis of volume increase of $18.2 \%$ over 1982 .

Source: Statistical Abstract of Israel, 1983 p. 178.

Bank of Israel Report 1983, p. 23. 


\title{
The 1975 Free Trade Agreement and its Impact on Israeli Exports to the EEC
}

\author{
Jacques Silber and Zeev M. Berrebi
}

\section{Introduction}

On May 1, 1975 Israel and the EEC signed an agreement establishing a free trade area between them, an agreement which entered into force on July 1 , 1975. This agreement was supposed to have short-run as well as long-run effects for Israel. In the short run it would prevent discrimination in exporting to the EEC markets in favour of competitors in Europe, in the Mediterranean basin and even in Africa. In the long run the agreement would hopefully change the structure of the Israeli economy and make it better suited for integration into the world markets.

The purpose of this paper is to try to analyze the impact of the 1975 Free Trade Agreement on Isreali exports in general, on those directed towards the EEC in particular. When looking at general trends in the size and commodity composition of Israeli exports during the 1970's it is naturally very difficult to distinguish between changes which are related to the general growth of the Israeli economy and those which are a consequence of the Free Trade Agreement. This paper has not the ambition to draw a dividing line between these two potential effects. Its goal is rather to verify whether the commodity composition of Israeli exports towards the EEC has become during the 1970 's more similar to the overall commodity composition of imports by EEC members, a change which could be assigned to Israel's economic growth as well as to the Free Trade Agreement.

The paper will proceed as follows : After describing, in a first section, the main trends in the commodity composition of Israeli Exports and of the EEC's Imports during the 1970's, we try, on the basis of well known international trade theories, to predict the changes which should have occurred in the commodity composition of the more specific trade flow originating in Israel and directed towards the EEC. The purpose of the last two sections is then to verify whether the empirical data correspond to the predictions made earlier. In order to do so we build various indices of export similarity (which are defined in section 3) comparing the commodity composition of Israeli exports to Israel and that of imports made by the EEC 
from various parts of the world. Changes in the value taken by these indices over time (during the 1970s) and differences which may be observed when using different indices are then analyzed in the fourth and last section. Some policy implications of the results are tentatively given in the Conclusion.

\section{Trends in the Composition of Israel's Exports and of the EEC's Imports during the 1970s:}

In table 1 we present data on the composition of Israeli exports during five different years: 1970, 1975, 1978, 1980 and 1982. For each year the composition in percentage of agricultural exports as well as that of industrial exports (at the exclusion of polished diamonds) are given as well as the relative weight of these agricultural and industrial exports. The original data (in millions of dollars) are given in the Appendix, in table A-1. Even when diamonds are excluded, it is clear that the weight of industrial exports has risen over the period, from $75 \%$ in 1970 to $86 \%$ in 1980 or 1982 whereas the weight of agricultural exports correspondingly declined. In absolute value however, agricultural exports grew over the period, at an average annual rate of $16 \%$, whereas industrial exports grew at a rate of $24 \%$. (These rates measure the growth in dollar terms and do not represent growth in real terms.) There are also clear trends in the composition of agricultural and industrial exports (c.f. table 1). Over the period 1970-1982 the share of citrus fruits in agricultural exports decreased from $66 \%$ to $34 \%$ whereas that of the category "others" (which includes such items as flowers and cotton) increased from $22 \%$ to $47 \%$. Concerning industrial exports one should notice the decrease in the relative weights of categories such as "food", "textiles, clothing and leather", and the rise of the category "metal, machinery and electronics". Trends in the composition of exports by destination are more difficult to analyze because as table 2 indicates, the category "unclassified destination" which represented $3.2 \%$ of all the exports in 1970 has a weight of $18.6 \%$ in 1982 . As a whole there was certainly a rise in the weight of exports towards the EEC since the data indicate such a trend, despite the rising weight of unclassified items.

Was there any clear trend in the structure of the imports of the EEC? Tables 3 and 4 give data on the composition of the imports of the EEC, by category of goods and by area of origin. The most striking result is the rise in the weight of mineral and fuel, which represented $11 \%$ of the EEC's imports in 1970 and $25 \%$ in 1981 . This effect of the oil crisis appears also naturally when one looks at the areas of origin. The category "Mediterranean countries, at the exclusion of Israel" had a weight of $4.2 \%$ in $1970,10.4 \%$ in 1975 and $9.3 \%$ in 1982. The overall rise in the share of "imports from developing countries" is probably also related to the oil crisis. 
Having given a general picture of the broad trends in the composition of Israel's exports and of the EEC's imports during the 1970's, one may wish to take a more specific look at the trade flows between Israel and the EEC. Since this study stresses mainly Israel's exports to the EEC, we will ignore the trade flow originating in the EEC and directed towards Israel. As was stated earlier, the question we wish to examine in more detail in this study concerns the similarity between the composition of Israel's exports towards the EEC and that of imports by the EEC from various parts of the world: in other words, have Israel's exports to the EEC become, over the period 1970-1981, more similar to the typical imports made by EEC members? Before we present results of our inquiry, it should be of interest to summarize the kind of predictions that international trade theory would make concerning this problem.

\section{The Composition of the Trade Flow from Israel towards the EEC: the Predictions from International Trade Theory}

According to standard international trade theory one may certainly predict that in principle every country will try to produce much of its requirements as possible at home in order to avoid transportation costs. There are however limiting forces such as the size of the domestic market which may be too small for certain production processes or the impossibility of finding a substitute for certain production factors or conditions that are absent (e.g. technical skills, climate). In his analysis of the determinants of the overall trade flows between any pair of countries, Linnemann (1966) distinguished between three categories of explanatory variables ${ }^{1}$ :

- factors indicating the total potential supply of country A (the exporting country) on the world market.

- factors indicating the total potential demand of country B (the importing country) on the world market.

- factors representing the "resistance" to a trade flow from potential supplier A to potential buyer B. This "resistance" refers to factors such as transportation or information costs as well as to artificial trade impediments such as tariffs, quotas and other regulations.

This distinction between three main determinants of a given trade flow, though very useful as a general framework of analysis, cannot however help us understanding the commodity composition of this trade flow. In fact, once one is not concerned with the forces determining the growth and fluctuations of the general trade flows between two countries, but with its commodity composition, it is impossible to refer to some "well known predictions of

1 H. Linnemann, An Econometric Study of International Trade Flows (1966). 
international trade theory". The only solution seems to be to combine the results of various trade theories. Hufbauer (1970) distinguished between seven basic approaches which viewed trade as "the offspring of an economic marriage between product characteristics and national attributes" 2 . Let us briefly give the main elements of each theory. According to the factor proportions approach (which the Hecksher-Ohlin theorem made famous), the relative abundance of physical capital leads to the export of capital intensive goods whereas the relative abundance of labor leads to the export of labor intensive goods. A second approach puts the emphasis on the skill requirements of production and distribution so that countries with relatively abundant highly trained labor will export skill-intensive goods. A third theory focuses on the extent of scale economies in so far as a large home market is conducive to the export of goods produced under increasing returns to scale. The import substitution school takes a different view since it presupposes that a stage of production sequence underlies trade. Newly developing countries tend to export consumer goods whereas developed countries specialize in exporting producer's goods. Other theories put the emphasis on the sequence of innovation and imitation arguing that the early manufacture of new goods confers an export advantage which is difficult to maintain in the long run. There is another set of theories which stress the sequential development of production history but instead of emphasizing the time factor it focuses on the transition from product differentiation to product standardization: as the product becomes standardized, firms and nations with less technical expertise may start exporting it.

All the previous (six) approaches saw in trade a compensating mechanism for differences in national structure. There exists, however, a theory (Linder, 1961) which predicts that trade should be most intensive between countries of highly similar structure ${ }^{3}$. In other words "the composition of nation i's manufactured exports will be more similar to the composition of nation $j$ 's imports as $i$ and $j$ more closely resemble each other in per capita income and economic structure". It is precisely this kind of similarity between the composition of Israel's exports and that of the EEC imports which will be tested in the empirical section of this paper. The purpose of this paper, however, is not to check which of the seven previously mentioned theories is most correct, when applied to the trade flows existing between Israel and the EEC. As Hirsch (1974) puts it "actual trade flows cannot be explained in terms of a simple all-embracing model. On the other hand it is possible to divide the universe of traded goods into a reasonably small number of

2 G. C. Hufbauer, "The Impact of National Characteristics and Technology on the Commodity Composition of Trade in Manufactured Goods", in The Technology Factor in International Trade (Universities-National Bureau of Economic Research Conference, New York, 1970).

3 S. B. Linder, An Essay in Trade and Transformation (1961). 
categories to which existing trade models apply" 4 . Hirsch distinguishes between goods (mainly minerals and agricultural products) where comparative advantage is largely determined by the natural endowment of the country, Hecksher-Ohlin goods (mainly manufactured goods but not all of them) where comparative advantage depends on the relative endowment in labor and capital, and product cycle goods which have been manufactured as a result of recent innovations and research and development efforts, hence the importance of an additional production factor, skilled labour, mainly at the first stages of the product cycle, when the product is new. Hirsch's typology implies that developing countries will export mainly Ricardo goods and labor-intensive mature goods (for which the availability of skilled manpower becomes less critical) whereas developed countries' exports will contain a high proportion of mature capital-intensive goods and new goods.

The distinctions made by Hirsch should be very useful when trying to understand the evolution of Israeli exports over time. With respect to the 1970-1980 period, there is no doubt that the commodity composition of Israel's exports might have been strongly affected by the growth of the Israeli economy, and the data presented in the first section concerning the commodity composition of Israeli exports as a whole have already shown important basic shifts of the type predicted by some of the theories which have just been mentioned. More detailed data would probably also stress the growing role of "intra-industry" trade, that which consists in the exchange of almost identical commodities : in analyzing the commodity composition of a trade flow between developed countries, one should make a distinction between an inter-industry trade which is the outcome of specialization and an intra-industry trade which cannot be explained by relative factor endowments differences and should be related to product differentiation, technical progress and economies of scale. The structure of consumer preferences plays then a much more important role than the potential interaction between commodity characteristics and country attributes ${ }^{5}$.

Predictions concerning the similarity of the commodity composition of Israeli exports and that of the EEC imports should however not be based only on theoretical considerations. Institutional factors, which belong to what was called earlier "resistance" elements are not to be forgotten. In this respect it is important to think of possible impacts of the 1975 Free Trade Agreement. A thorough review of this agreement and those which preceded it may be found in Cohen (1980) whereas a comparison of these agreements with those signed by the EEC with other Mediterranean countries is made by Pomfret and

4 S. Hirsch, "Hypotheses regarding Trade between Developing and Industrial Countries", in The International Division of Labour: Problems and Perspectives (1974).

5 C.f. A. Aquino, "Intra-Industry Trade and Inter-Industry Specialization as Sources of International Trade in Manufactures", 119 Weltwirtschaftliches Archiv 279 (1983). 
Tovias $(1980)^{6}$. In short, the agreement implied the gradual abolishment by the EEC of customs tariffs and of quantitative restrictions (at the exclusion of some quota ceilings for industrial products) as well as a strong reduction of duties on agricultural imports. These trade concessions made by the EEC (we do not mention here the concessions made by Israel) represented certainly a change in "resistance" elements and one may safely predict that they implied an increase in the volume of the trade flow from Israel to the EEC, but probably also a relative increase in the share of industrial goods in this trade flow since concessions were ultimately to be greater for them than for agricultural products.

In the next two sections we will precisely try to see, whether such forecasts concerning the commodity composition of Israeli exports based on institutional as well as on theoretical grounds, have been confirmed in practice. The analysis will be based on the estimation of similarity indices, which will be defined in the following section.

\section{On the Measurement of "Export Similarity"}

Finger and Kreinin have recently proposed to measure the similarity of the export patterns of countries " $a$ " and " $b$ " to market " $c$ " by using an index $\mathrm{S}(\mathrm{ab}, \mathrm{c})$ defined as

$$
\mathrm{S}(\mathrm{ab}, \mathrm{c})=\left\{\sum_{\mathrm{i}} \text { Minimum }\left[\mathrm{s}_{\mathrm{i}}(\mathrm{ac}), \mathrm{s}_{\mathrm{i}}(\mathrm{bc})\right]\right\}
$$

where $\mathrm{s}_{\mathrm{i}}(\mathrm{kc})$ is the share of commodity $\mathrm{i}$ in the exports of country $\mathrm{k}$ to market $c^{7}$. It is easily shown that $S(a b, c)$ has a lower bound of 0 and an upper bound of 1 (In fact Finger and Kreinin's index, as originally presented, varied between zero and one hundred, that is it was equal to $100 \mathrm{~S}(\mathrm{ab}, \mathrm{c})$; we prefer however to use an index which varies between 0 and 1).

Pomfret has shown that Finger and Kreinin's index S (ab, c) could be written as SIMFK where

$$
\operatorname{SIMFK}=1-(1 / 2) \sum_{\mathbf{i}} \mid\left[\mathrm{s}_{\mathrm{i}}(\mathrm{ac})-\mathrm{s}_{\mathbf{i}}(\mathrm{bc})\right]
$$

6 Y. Cohen, "Israel and the EEC, 1958-1978: Economic and Political Relations", in The Economic Integration of Israel in the EEC 13 (H. Giersch ed. 1980); R. Pomfret and A. Tovias, "The Global Mediterranean Policy of the EEC", in The Economic Integration of Israel in the EEC, Id. at 41.

7 J. M. Finger and M. E. Kreinin, "A Measure of 'Export Similarity' and its Possible Uses”, 89 Econ. J. 905, (1979). 
and that this index was the same as the Grubel-Lloyd intra-industry trade index as amended by Aquino ${ }^{8}$, which can be written as

$$
\mathrm{IIT}=1-(1 / 2) \sum_{\mathrm{i}}\left|\left(\mathrm{X}_{\mathrm{i}} / \mathrm{X}\right)-\left(\mathrm{M}_{\mathrm{i}} / \mathrm{M}\right)\right|
$$

where $\mathrm{X}_{\mathrm{i}}$ and $\mathrm{M}_{\mathrm{i}}$ are a country's global exports and imports of the ith good and $\mathrm{X}$ and $\mathrm{M}$ the country's total exports and imports.

However, since it is easily shown that

$$
2=\operatorname{Max} \sum_{i}\left|s_{i}(a c)-s_{i}(b c)\right|
$$

(where Max refers to the maximal potential value) one may redefine $\mathrm{S}(\mathrm{ab}, \mathrm{c}$ ) in a more general way as

$$
S=1-\frac{d[s(a c), s(b c)]}{\operatorname{Max} d[s(a c), s(b c)]}
$$

where $\mathrm{d}[\mathrm{s}(\mathrm{ac}), \mathrm{s}(\mathrm{bc})]$ measures the distance between the vectors $\mathrm{s}(\mathrm{ac}), \mathrm{s}(\mathrm{bc})$ representing respectively the shares of the various commodities in the exports of country a and in those of country b to market $c$.

It is well known that there are various ways of measuring the distance $A B$ between two points $A$ and $B$ (or between two vectors $0 A$ and $0 B$ where 0 is the origin of the axes).

$$
\begin{aligned}
& \text { If } O A \text { is a vector }\left\{x_{1}, x_{2} \ldots x_{i} \ldots x_{n}\right\} \\
& \text { and } O B \text { a vector } \quad\left\{y_{1}, y_{2} \ldots y_{i} \ldots y_{n}\right\}
\end{aligned}
$$

then the distance $A B=0|A B|$ may be measured as

$$
|A B|=\sum_{i=1}^{n}\left|y_{i}-x_{i}\right|
$$

and this is precisely the distance concept used by Finger and Kreinin, Pomfret, Kellman and Schroder in their measurements of export similarity?

There are however other concepts of distance. One famous distance is the euclidean distance which would give us

$$
|A B|=\left[\sum\left(y_{i}-x_{i}\right)^{2}\right]^{1 / 2}
$$

8 R. Pomfret, "The Impact of EEC Enlargement on Non-Member Mediterranean Countries' Exports to the EEC", 91 Econ. J. 726, (1981); H. G. Grubel and P. J. Lloyd, Intra-Industry Trade - The Theory and Measurement of International Trade in Differentiated Products, (1975).

9 Finger and Kreinin, supra, note 7; Pomfret, supra, note 8; M. Kellman and T. Schroder, "The Export Similarity Index: Some Structural Tests", 93 Econ. J. 193, (1983). 
When applying this concept of distance, one would obtain a similarity index SIMSQ defined as

Since

$$
\operatorname{SIMSQ}=1-\frac{\left[\sum_{\mathbf{i}}\left(\mathrm{s}_{\mathbf{i}}(\mathrm{ac})-\mathrm{s}_{\mathbf{i}}(\mathrm{bc})\right)^{2}\right]^{1 / 2}}{\sqrt{2}}
$$

$$
\sqrt{2}=\operatorname{Max}\left[\sum_{i}\left(s_{i}(a c)-s_{i}(b c)\right)^{2}\right]^{1 / 2}
$$

Naturally (6) and (7) could be generalized to the use of a non-euclidean space where the powers a and $1 /$ a would respectively replace the powers 2 and $1 / 2$.

There is however another interesting way of measuring the distance $|A B|$ between 2 points $A$ and $B$, when it is known that the components $x_{i}$ and $y_{i}$ of the vectors $0 A$ and $O B$ are such that $\sum_{i} x_{i}=\sum_{i} y_{i}$. In such a case it should be clear that the angle $\alpha$, where $\alpha=\widehat{A 0 B}$, is a good index of the distance $|A B|$ since there is a one to one relation between $\alpha$ and $|A B|$. Since $\cos \alpha$ is inversely related to $\alpha, \cos \alpha$ would then be a good measure of similarity.

Since we are measuring here the similarity of vectors of shares, $\sum_{i} x_{i}=\sum_{i} y_{i}=1$, so that $\cos \alpha$ can be used as an export similarity index. In fact $\cos \alpha$ has already been used in the literature ${ }^{10}$ to compare exports and imports shares (which gives us implicitly a measure of intra-industry trade) as is mentioned by Grubel and Lloyd (1975) ${ }^{11}$.

In the empirical section of this paper, which follows, we will precisely try to compare the results obtained in measuring "export similarity" when using Finger and Kreinin's index SIMFK defined in (2), the similarity index SIMSQ defined in (7), and the similarity index SIMCOS which is equal to $\cos \alpha$, and may be defined as

$$
\operatorname{SIMCOS}=\frac{A B}{|0 A| 0 B \mid}=\frac{\sum\left[s_{i}(a c) \times s_{i}(b c)\right]}{\sqrt{\left[\sum s_{1}^{2}(a c)\right]} \sqrt{\left[\sum s_{1}^{2}(b c)\right]}}
$$

\section{On the Similarity Between Israel's Exports to the EEC and the Exports of Other Countries to the EEC}

In tables 5 and 6 similarity indices have been computed between the commodity composition on one hand of Israeli exports to the EEC and on the other hand of imports by the EEC from various parts of the world. Seven imports vectors have been used: total imports of the EEC, imports by the

10 Linnemann, supra, note 1 ; Hufbauer, supra, note 2.

11 Grubel and Lloyd, supra, note 8. 
EEC from OECD countries, imports by the EEC from countries which are themselves members of the EEC (this corresponds to trade within the EEC), imports from developing countries, imports from Mediterranean countries at the exclusion of Israel, imports from Israel, imports from the USA, imports from developing countries at the exclusion of Mediterranean countries. Two kinds of commodity classifications were used. In table 5 the SITC double digit classification has been used. The results of table 6 were based on more aggregated data using the SITC one-digit classification.

What do the results indicate? Firstly, when the SITC double digit classification is used (table 5) the similarity between Israeli exports on one hand and imports by the EEC from OECD countries, from EEC members and from the USA on the other hand, increased over time (between 1970 and 1981), these results being independent of the similarity index chosen.

Secondly, the similarity between Israeli exports to the EEC and imports by the EEC from developing countries and from other Mediterranean countries seems to have decreased over time although there have been some fluctuations. This result also is independent of the choice of similarity index. Thirdly, these results as a whole seem to hold also when using the one-digit SITC classification (c.f. table 6 ) but they are less striking. As a rule, in table 5 as in table 6 the changes over time are smallest when using SIMCOS, a result which was already emphasized by Hufbauer ${ }^{12}$.

In tables 7 and 8 we have ranked for each year the values taken by the similarity indices, this being done separately for each of the three indices used. It is clear that for a given SITC classification, the ranking is dependent on the index used, this being true for any year one may want to choose. Correlations coefficients between the three indices for a given year have been computed and the results are presented in table 9. As a whole the correlation is quite high but although we use only seven observations it is far from being perfect. It is usually higher between SIMFK and SIMSQ. This is a crucial result because it indicates that one should be careful in drawing inferences from a similarity analysis, since the results seem to be quite dependent on the type of similarity index which is used.

As a whole however, our similarity analysis has confirmed the predictions made early at the end of our review of the international trade literature related to this topic. During the seventies, as Israel became a country whose per capita income and economic structure became more similar to that of EEC members, the commodity composition of Israeli exports to the EEC became more and more similar to the commodity composition of EEC imports from OECD countries, the USA and even from other EEC countries, and less and less similar to the commodity composition of EEC imports from developing countries. 
Naturally, these results, should not be assigned only to economic factors that is to the effect of economic development on the Israeli economy. It was mentioned earlier that among the factors determining the trade flow between two countries an important role is to be played by "resistance" elements such as trade barriers. The 1975 Free Trade Agreement between Israel and the EEC, with the reduction in tariffs which it implied, certainly played a role in this structural change of the commodity composition of Israeli exports.

\section{Conclusion}

At this stage it might be of interest to think of possible policy implications of the export similarity analysis which has been conducted in this study. In his study of the impact of EEC enlargement on non-member Mediterranean countries exports to the EEC, Pomfret"13 suggested that Israel "whose primary exports to the EEC are substantial and similar to those of Spain" might be one of the country most affected by the enlargement although "Israel is less reliant on non-manufactured exports than any other Mediterranean country (except Malta)".

Pomfret's analysis included only primary products whereas in this paper an export similarity analysis was made including all categories of goods (though only at a double digit level) and it indicated clearly that Israel's exports to the EEC have become in the 1970's less and less similar to those of Mediterranean countries and more and more similar to those of developed countries. If such a pattern were to be followed in the future by Spain, Portugal and Greece, the impact on Israel of their accession to the EEC might be much more serious in the long run than in the short run, although competition in the exports of agricultural products will certainly be felt in the short run. On the other hand the growing similarity between the commodity composition of Israeli exports and that of the EEC's imports is a sign of very important structural transformations, a change which should be welcome and in which the 1975 Trade Agreement has certainly played a key role. In the long run free trade has only positive effects : the economic history of the EEC members proves that negative side effects are only temporary.

13 Pomfret, supra, note 8. 
Table 1: The Composition of Israeli Agricultural and Industrial Exports (excluding polished diamonds) (Percentage)

\begin{tabular}{lrrrrr}
\hline & 1970 & 1975 & 1978 & 1980 & 1982 \\
\hline I & & & & & \\
\hline Agricultural Exports & 67 & 64 & 45 & 42 & 34 \\
Citrus Fruits & 11 & 12 & 17 & 15 & 20 \\
Fresh Fruits and Vegetables & 22 & 24 & 38 & 43 & 46 \\
Others & 100 & 100 & 100 & 100 & 100 \\
$\quad$ Total & & & & & \\
Industrial Exports & 11 & 9 & 5 & 5 & 6 \\
Mining, Quarrying and Non-metalic & 16 & 13 & 11 & 9 & 10 \\
$\quad$ Mineral Products & 26 & 16 & 13 & 14 & 10 \\
Food & 4 & 4 & 3 & 2 & 2 \\
Textiles, Clothing, Leather & 6 & 5 & 4 & 4 & 3 \\
Wood, Paper, Printing & 16 & 20 & 19 & 22 & 12 \\
Rubber, Plastics & 18 & 30 & 40 & 37 & 44 \\
Chemicals & 3 & 3 & 5 & 7 & 7 \\
Metal, Machinery, Electronics & 100 & 100 & 100 & 100 & 100 \\
Miscellaneous & & & & & \\
$\quad$ Total & 75 & 78 & 81 & 86 & 86 \\
\hline Total shares of Agricultural \\
versus Industrial Exports
\end{tabular}


Table 2: Breakdown of Israeli Exports by Area of Destination (Percentage)

\begin{tabular}{lrrrrr}
\hline Destination & 1970 & 1975 & 1978 & 1980 & 1982 \\
\hline EEC & 28.9 & 38.8 & 35.4 & 39.4 & 33.4 \\
EFTA & 18.9 & 8.7 & 7.2 & 9.3 & 6.5 \\
Other countries in Europe & 5.5 & 3.6 & 3.5 & 3.5 & 2.6 \\
Asia & 15.0 & 20.1 & 16.7 & 11.0 & 10.0 \\
Africa & 5.3 & 3.8 & 2.8 & 3.4 & 3.6 \\
North America & 21.3 & 17.6 & 18.7 & 18.3 & 22.0 \\
Central America & 0.1 & 0.5 & 0.2 & 0.3 & 0.3 \\
South America & 1.0 & 1.9 & 1.3 & 2.6 & 2.1 \\
Oceania & 0.7 & 1.0 & 0.9 & 0.9 & 1.3 \\
Unclassified destination & 3.2 & 4.2 & 9.8 & 11.2 & 18.6 \\
\hline
\end{tabular}


Table 3: Commodity Composition of the EEC's Imports (Percentage)

\begin{tabular}{lrrrrr}
\hline Commodity Category & 1970 & 1975 & 1977 & 1978 & 1982 \\
\hline Food and live animals & 13.4 & 13.0 & 12.9 & 12.4 & 10.2 \\
Beverages and tobacco & 1.2 & 1.3 & 1.1 & 1.3 & 1.1 \\
Crude materials & 12.1 & 8.7 & 8.4 & 7.7 & 7.0 \\
Minerals and fuels & 10.7 & 19.5 & 18.3 & 16.5 & 24.8 \\
Fats (and oil) & 0.9 & 0.8 & 0.7 & 0.7 & 0.5 \\
Chemicals & 7.3 & 7.4 & 7.9 & 8.0 & 8.1 \\
Manufactured goods & 22.7 & 18.4 & 18.5 & 19.1 & 16.0 \\
Machinery and transport & 22.4 & 20.7 & 21.8 & 23.3 & 21.7 \\
$\quad$ equipment & & & & & \\
Art Works and miscellaneous & 8.0 & 8.8 & 9.3 & 10.0 & 9.6 \\
$\quad$ manufactured goods & 1.2 & 1.4 & 1.0 & 1.2 & 1.2 \\
\hline Unclassified goods & & & &
\end{tabular}

Table 4: EEC Imports, by Area of Origin (Percentage)

\begin{tabular}{lrrrrr}
\hline Area of Origin & 1970 & 1975 & 1977 & 1978 & 1981 \\
\hline OECD & 76.1 & 71.8 & 72.0 & 74.0 & 71.8 \\
EEC & 48.4 & 49.1 & 49.4 & 50.9 & 47.9 \\
Developing Countries & 18.9 & 22.9 & 23.0 & 24.6 & 27.8 \\
$\begin{array}{l}\text { Middle East Countries } \\
\quad \text { (excl. Israel) }\end{array}$ & 4.2 & 10.4 & 9.4 & 7.8 & 9.3 \\
Israel & 0.2 & 0.2 & 0.3 & 0.3 & 0.3 \\
USA & 10.2 & 8.3 & 7.6 & 7.6 & 8.5 \\
\hline
\end{tabular}




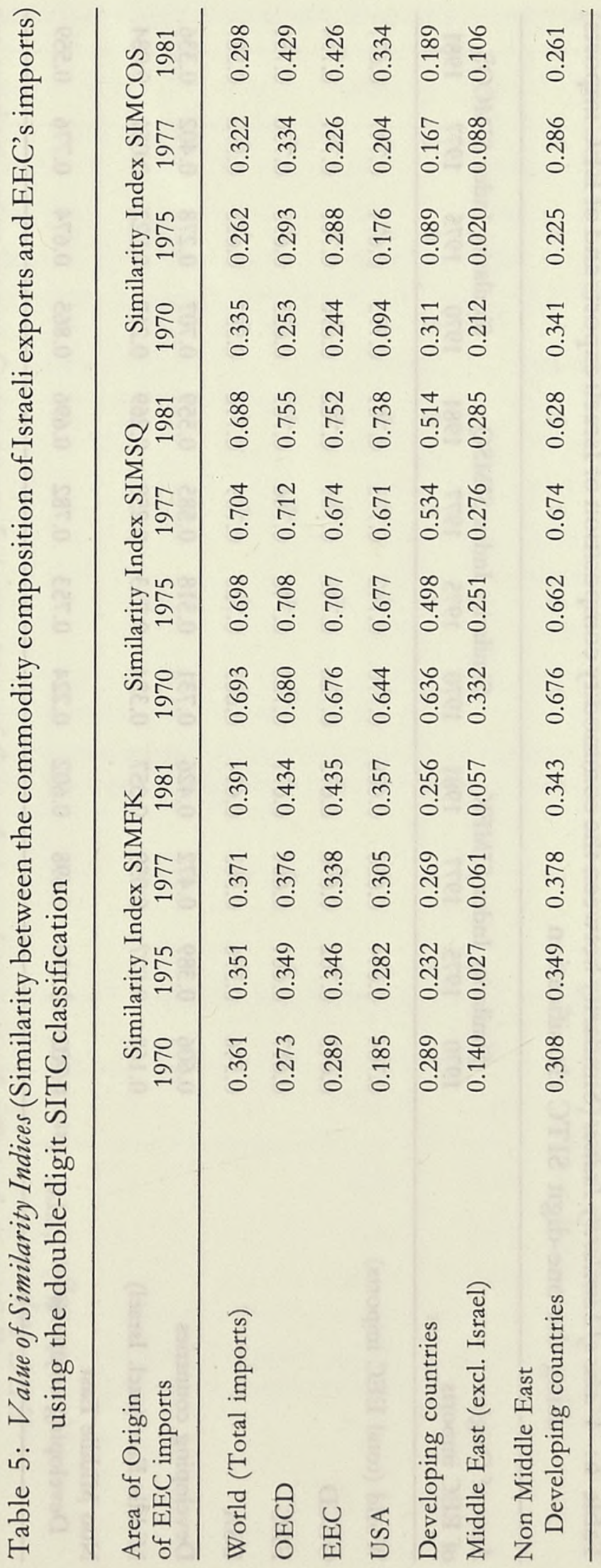




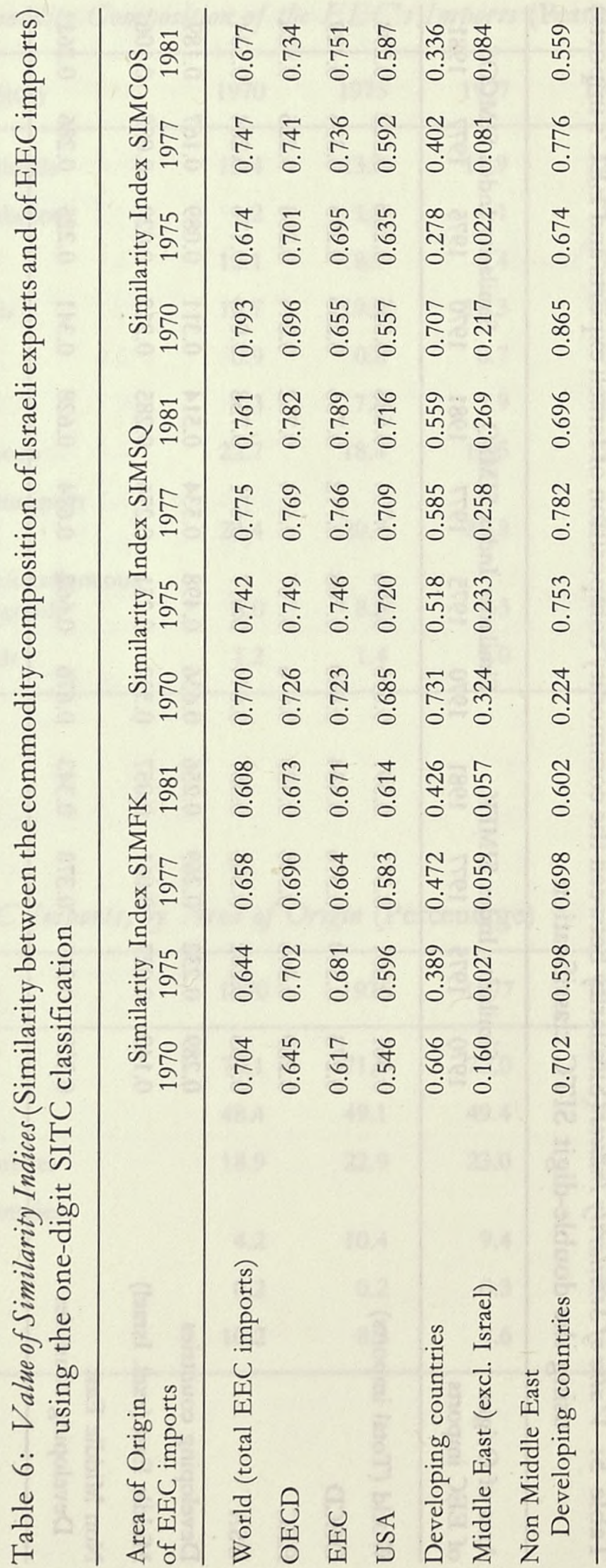




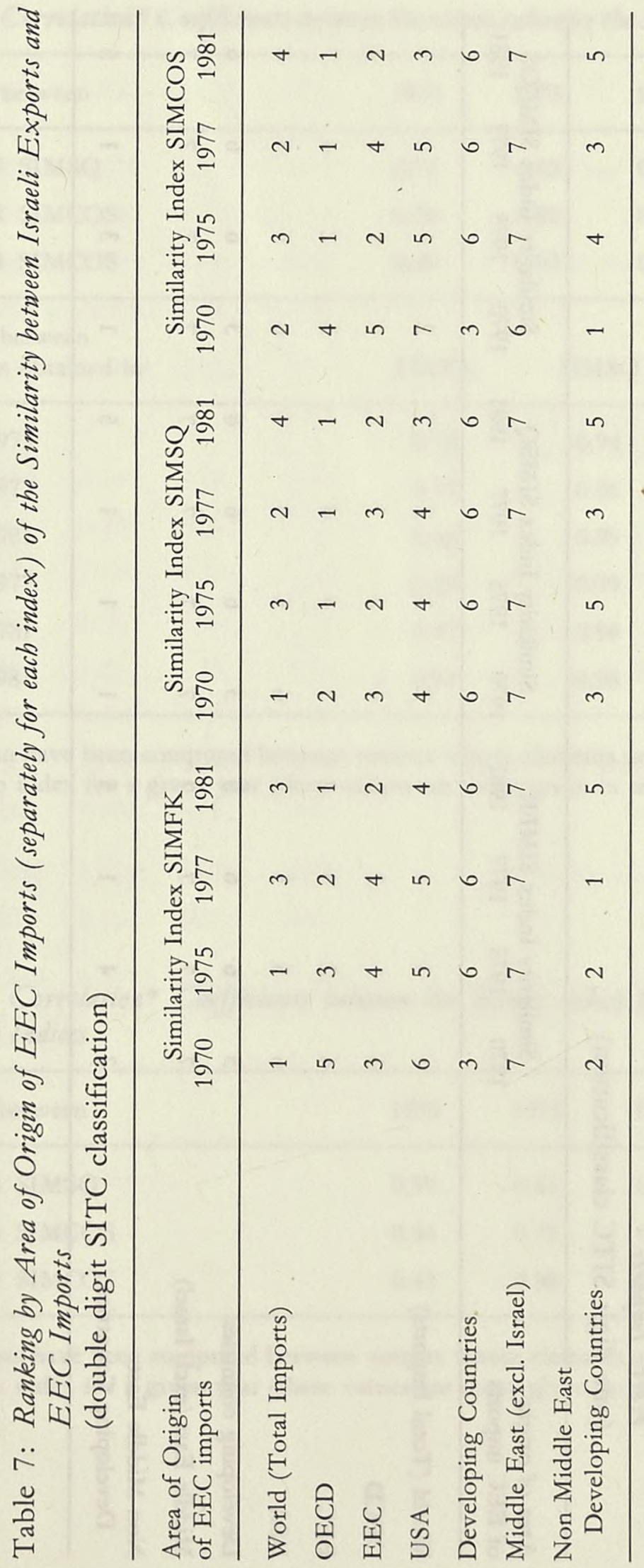




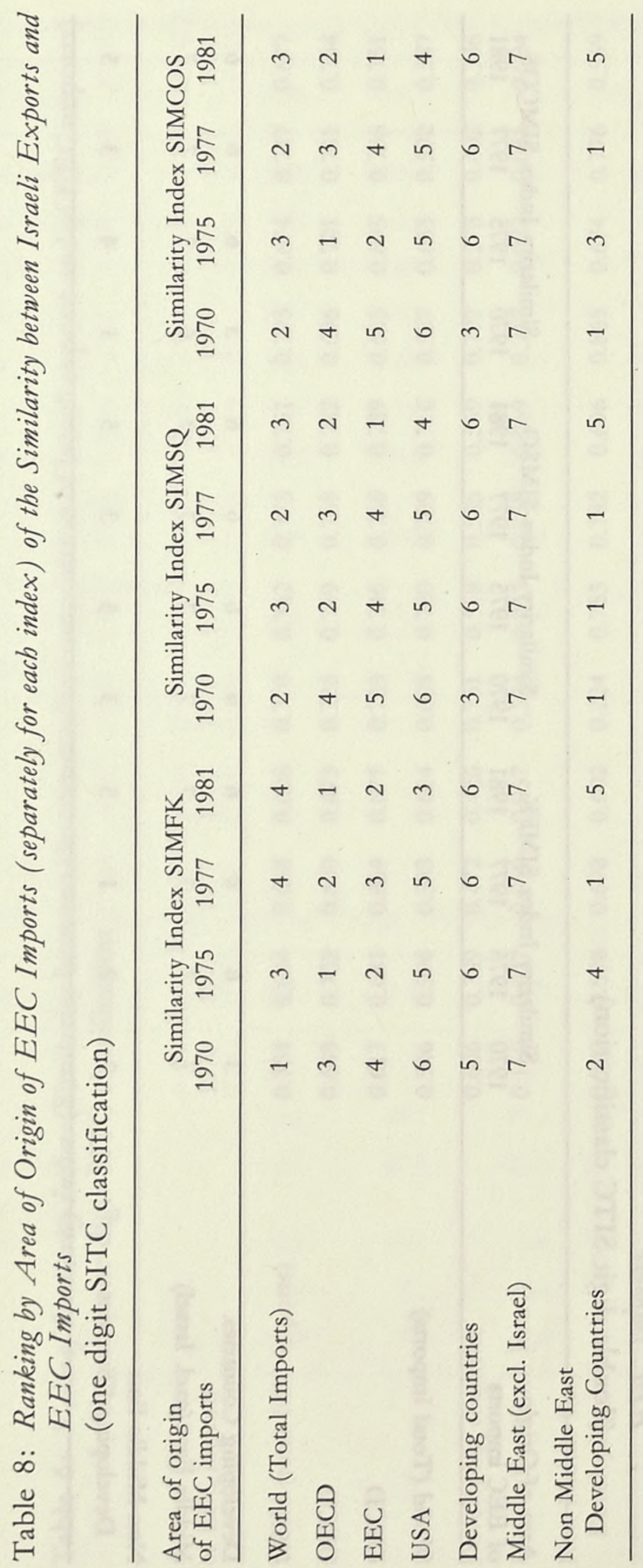


Table 9: Correlation* Coefficients between the values taken by the Similarity Indices

\begin{tabular}{llccc}
\hline Correlation between & 1970 & 1975 & 1977 & 1981 \\
\hline SIMFK and SIMSQ & 0.78 & 0.58 & 0.96 & 0.58 \\
SIMFK and SIMCOS & 0.78 & 0.92 & 0.91 & 0.92 \\
SIMSQ and SIMCOS & 0.29 & 0.93 & 0.88 & 0.93 \\
\hline $\begin{array}{l}\text { Correlation between } \\
\text { the Values obtained in }\end{array}$ & SIMFK & SIMSQ & SIMCOS \\
\hline 1970 and 1975 & 0.78 & 0.94 & 0.21 \\
1970 and 1977 & 0.79 & 0.96 & 0.41 \\
1970 and 1981 & 0.66 & 0.89 & -0.15 \\
1975 and 1977 & 0.99 & 0.99 & 0.89 \\
1975 and 1981 & 0.97 & 0.98 & 0.91 \\
1977 and 1981 & 0.94 & 0.96 & 0.70 \\
\hline
\end{tabular}

* Correlation have been computed between vectors whose elements are the values taken by a given index for a given year (these values are those given in table 5).

Table 10: Correlation* Coefficients between the Ranks taken by the Similarity Indices

\begin{tabular}{lllll}
\hline Correlation between & 1970 & 1975 & 1977 & 1981 \\
\hline SIMFK and SIMSQ & 0.59 & 0.61 & 0.87 & 0.96 \\
SIMFK and SIMCOS & 0.84 & 0.71 & 0.89 & 0.96 \\
SIMSQ and SIMCOS & 0.43 & 0.96 & 0.97 & 1 \\
\hline
\end{tabular}

* Correlations have been computed between vectors whose elements are the ranks taken by a given index for a given year (these values are those given in table 7). 
Table A 1: Israeli Agricultural and Industrial Exports (\$ millions)

\begin{tabular}{llrrrr}
\hline & 1970 & 1975 & 1978 & 1980 & 1982 \\
\hline I $\quad$ Agricultural Exports & 129.6 & 277.6 & 455.3 & 555.7 & 553.0 \\
Citrus fruits & 86.1 & 176.4 & 202.7 & 231.1 & 185.6 \\
Fresh fruits and vegetables & 14.8 & 34.5 & 77.2 & 82.9 & 110.3 \\
Others & 28.7 & 66.7 & 175.4 & 241.7 & 257.1 \\
II Industrial Exports & 638.7 & 1626.1 & 3434.2 & 4955.5 & 4690.1 \\
Mining, quarrying and & & & & & \\
$\quad$ Non-metallic mineral & 44.8 & 90.9 & 92.5 & 174.5 & 203.6 \\
$\quad$ products & 63.0 & 128.9 & 215.0 & 298.1 & 348.7 \\
Food & 101.5 & 161.9 & 254.7 & 473.4 & 354.4 \\
Textiles, clothing, leather & 16.9 & 34.1 & 51.6 & 65.8 & 49.2 \\
Wood, paper, printing & 23.5 & 44.7 & 72.1 & 128.2 & 107.2 \\
Rubber, plastics & 60.9 & 200.9 & 368.8 & 722.6 & 647.7 \\
Chemicals & 70.0 & 294.0 & 795.1 & 1251.2 & 1547.7 \\
Metal, machinery, electronics & 13.5 & 30.0 & 107.0 & 226.6 & 253.9 \\
Miscellaneous & 244.6 & 640.7 & 1477.4 & 1615.1 & 1157.7 \\
III & 10.4 & 37.0 & 31.8 & 26.3 & 38.4 \\
Polished Diamond Exports & 778.7 & 1834.6 & 3716.1 & 5291.9 & 5016.8 \\
\hline Other & & & & & \\
Total (gross) Exports & & & & & \\
\hline
\end{tabular}


Table A 2: Total Israeli Exports by Destination (\$ millions)

\begin{tabular}{lrrrrr}
\hline Destination & 1970 & 1975 & 1978 & 1980 & 1982 \\
\hline Total & 778.7 & 1940.7 & 3921.3 & 5537.5 & 5281.5 \\
EEC & 224.8 & 753.3 & 1389.9 & 2183.9 & 1766.2 \\
EFTA & 147.0 & 169.5 & 283.3 & 516.8 & 322.5 \\
Other countries in Europe & 42.9 & 65.2 & 135.8 & 191.1 & 138.6 \\
Asia & 116.8 & 390.4 & 653.5 & 611.2 & 528.9 \\
Africa & 41.5 & 73.5 & 109.9 & 190.9 & 190.2 \\
North America & 166.2 & 341.1 & 733.8 & 1014.4 & 1160.3 \\
Central America & 0.9 & 9.7 & 8.1 & 14.7 & 13.7 \\
South America & 8.2 & 37.6 & 51.1 & 146.6 & 108.6 \\
Oceania & 5.5 & 18.9 & 34.7 & 49.8 & 69.8 \\
Unclassified & 24.9 & 81.5 & 386.1 & 618.1 & 982.7 \\
\hline
\end{tabular}



Part Three

The Second Enlargement of the EEC:

Effect on Euro-Israel Relations 


\title{
Spain and the Enlargement of the EEC
}

\author{
Francesco Granell
}

\section{The Third Enlargement of the European Communities}

According to the Preamble of the Treaty of Rome, the European Community is an open area in the sense that any European country wishing to pool its resources to share the ideal of preserving and strengthening peace and liberty may join the Common Market. Based on this principle, the United Kingdom, Denmark and Ireland became full members of the Community in January of 1973. This was the first enlargement of the Community and did not include Norway, who previously had wished to join. It was with the political dimension firmly in mind that preparations for the second enlargement got under way ${ }^{1}$. Greece applied to join the EEC on June 12, 1975; Portugal applied on March 28, 1977 and Spain on July 28 of the same year. Negotiations with Greece opened in July 1976, with Portugal in October 1978, and with Spain in February 1979.

Greece became a full member of the EEC in January 1981. The EEC-Spain and EEC-Portugal negotiations have suffered from the EEC's inability to strengthen the European integration process, to adapt the work of the EEC institutions, or to apply new policies.

Given this situation, the integration of Portugal and Spain took place in 1986, five or more years later than Greece's membership. The Agreements for membership were signed in Lisbon and Madrid in June 1985.

Due to the fact that Spain is much more important to the European economy than either Greece or Portugal, the membership of Spain must be considered as a new and separate issue for the Community and not only as a mere continuation of Greece's entry.

When the Commission of the EEC published its report on the second enlargement, the integration of three countries was considered together ${ }^{2}$.

1 Commission of the E.C., The Second Enlargement of the European Communities (EUR. DOC. series, 5/79).

2 Commission of the E.C., "Enlargement of the Community: General Considerations"; "Transitional Period and Institutional Implications"; and "Economic and Sectoral Aspects", Bull. E.C. 3-1978 (Supp. 1-3). 
The framework of the Treaty of Rome has withstood the integration of ten million Greeks; it would be able to withstand the impact of ten million Portuguese, but a general consensus exists that the integration of forty million Spaniards will necessitate changes in the Community structure itself to cope with the impact.

At the first ministerial meeting of the conference on Spain's application to join the community in February 1979, Spain's minister for EEC relations agreed that the basis for the negotiations would be full acceptance by Spain of the "acquis communautaire" subject to possible transitional measures to solve any problems of adjustment which may arise on either side, and, that the problems of adjustment would not be solved by changes in the Community rules. Recent developments in the Community make clear the need for a transformation in the Common Agricultural Policy (CAP) and in the Community budget before integration pursued by the founders of the Common Market can be continued ${ }^{3}$.

In this perspective, the full acceptance of the "acquis communautaire" by Spain and Portugal is one of the key rules of the game both for Spain and for the Community. But, as the Commission has pointed out recently, the obstacles to enlargement stem not only from the specific difficulties involved in integrating Portugal and Spain into the existing Community, but also from the difficulties connected with the functioning of the Community itself ${ }^{4}$. The problem is that during recent years, there has been no growth of faith in the institutions of the EEC; on the contrary there has been a growing debate about the possibilities and limits of European unity and its meaning for the future of Spain.

\section{The Economic Links Between Spain and the EEC Countries}

Regardless of the problematic process of negotiation now concluded Spain and the EEC have developed very important economic ties. Spain has long been a country with few external relations due to a tradition of high protectionism and isolation. The Franco regime was denied membership in international organizations and other forms of cooperation after the Second World War. In March 1945, President Roosevelt stated "the fact that our government maintains formal diplomatic relations with the present Spanish regime should not be interpreted by anyone to imply approval of that regime and its sole party". However the Franco regime was tolerated and in 1953

3 Ernst B. Haas, "International Integration: The European and the Universal Process", 15 INTERNATIONAL ORGANIZATION 366 (1961), reprinted in The Stichting Groting Seminar: Limits and Problems of European Integration 6 (1963).

4 Commission of the European Communities: Problems of Enlargement, Taking Stock and Proposals, EUR. INFO. DEV., OF 46, X/134/1983. 
Spain signed a defense agreement with the USA ${ }^{5}$. In 1955, Spain became a member of the United Nations; in 1958 the IMF and the IBRD; in 1959 the OEEC; in 1963 Spain joined the GAT'T. In 1959, the Spanish government launched a stabilization program in Spain which included new tax measures, a substantial devaluation of the peseta and a radical change in the trade and payments system. During the sixties Spain experienced substantial growth and developed a more open trade system, but compared with other OECD countries, Spain still maintains a low level of foreign trade (table I). In 1984, the value of Spain's exports equalled some $\$ 23.5$ billion and her imports some $\$ 28.8$ billion.

Table I: Importance of Foreign Trade for Selected Countries 1983

\begin{tabular}{lccr}
\hline & $\begin{array}{c}\text { Imports per } \\
\text { Capita }(\$)\end{array}$ & $\begin{array}{c}\text { Exports per } \\
\text { Capita }(\$)\end{array}$ & $\begin{array}{r}\text { GDP per } \\
\text { Capita }(\$)\end{array}$ \\
\hline Belgium* & 5,464 & 5,237 & 8,126 \\
France & 1,919 & 1,667 & 9,538 \\
Italy & 1,414 & 1,281 & 6,208 \\
UK & 1,775 & 1,628 & 8,072 \\
Greece & 983 & 455 & 3,505 \\
Spain & 764 & 519 & 4,137 \\
Portugal & 792 & 451 & 2,055 \\
Japan & 1,061 & 1,231 & 9,693 \\
USA & 1,100 & 855 & 13,969 \\
\hline
\end{tabular}

* Including Luxembourg.

Source: OECD.

An important detail must be pointed out concerning Spain's position in the world market because of its level of development and its comparative trade advantages. Spain presents the image of an underdeveloped country if we consider the commodity composition of exports to developed countries; yet it presents the image of a developed country if we consider the trade flows to developing countries. This is due to a recent evolution of the relative labor cost, and a technological shift to a more developed export structure (see table II).

5 A. Pollis: United States Policy Towards Authoritarian Regimes in the Mediterranean, 4 MILLENNIUM J. Int'l Stud. 28 (1975). 
Table II: Spanish Export Commodity Composition (Percentage)

\begin{tabular}{lrrr}
\hline Sections SITC & 1964 & 1975 & 1983 \\
\hline 0. Food and live animals & 42.13 & 17.47 & 12.42 \\
1. Beverages and tobacco & 4.68 & 3.12 & 1.80 \\
2. Crude materials & 7.94 & 3.09 & 3.01 \\
3. Mineral fuels & 4.98 & 3.07 & 9.39 \\
4. Oils and fats & 6.00 & 1.58 & 1.63 \\
5. Chemicals & 5.74 & 5.45 & 7.73 \\
6. Manufactured goods & 12.09 & 25.70 & 27.95 \\
7. Machinery \& transport & 8.67 & 25.61 & 26.42 \\
8. Manufactured articles & 7.60 & 14.53 & 10.40 \\
9. Other & 0.17 & 0.22 & 0.51 \\
\hline
\end{tabular}

Source: Dirección General de Aduanas: Informe Comercio Exterior, 1983.

In $1984,33.4 \%$ of the Spanish imports came from the ten members of the EEC, while the EEC imported $49.1 \%$ of Spanish exports in the same year.

During the same year $50 \%$ of the foreign investment attracted by Spain came from the EEC. Most of the remittances of Spanish migrant workers $(\$ 1,200$ millions in 1984) came from the EEC. In addition $80 \%$ of the income from tourism ( $\$ 7,000$ million in 1984) was from EEC nationals.

Today Spain has a greater degree of foreign trade with the EEC than some of the members of the Community have among themselves.

Spain is the seventh largest non-OPEC supplier to the EEC and ranks as its fourth largest customer. In 1982 Spain supplied $1.54 \%$ of the EEC's world imports against $0.83 \%$ in 1962.

For these reasons, Spain is today a good partner for the Community. Spain cannot substitute the Community market for other markets for some products both in the manufacturing and in the agricultural sector. For example, $45.5 \%$ of the oranges produced in Spain are sold to EEC, $21 \%$ of onions, and $15 \%$ of tomatoes.

Today Spain has a diversified economy (see table III). However, sometimes the importance of the exports of primary products is overvalued by the implications of agriculture. 
Table III: Spain's Economic Sectors - 1981

\begin{tabular}{|c|c|c|}
\hline Sectors & $\begin{array}{l}\text { value added } \\
\text { (billion pts) }\end{array}$ & $\begin{array}{l}\text { employment } \\
\text { thousand }\end{array}$ \\
\hline 1. Agriculture & 943.6 & 2,093 \\
\hline Cereals & 126.4 & \\
\hline Vegetables & 216.5 & \\
\hline Fresh fruits & 150.8 & \\
\hline Dried fruits & 22.9 & \\
\hline Grapes for wine & 87.8 & \\
\hline Olives & 64.9 & \\
\hline Milk & 155.7 & \\
\hline Eggs & 67.9 & \\
\hline Meat & 443.7 & \\
\hline 2. Fishing & 129.4 & 118 \\
\hline 3. Mining \& refining & 259.3 & 113 \\
\hline 4. Supply of water, gas and electricity & 374.7 & 87 \\
\hline 5. Manufacturing & $3,938.5$ & 2,857 \\
\hline Food Proc. \& tobacco & 599.9 & 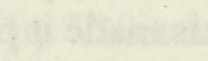 \\
\hline Textiles \& clothing & 425.2 & \\
\hline Leather \& shoes & 104.4 & \\
\hline Wood \& cork & 186.1 & \\
\hline Paper \& printing & 354.2 & \\
\hline Chemicals & 510.1 & \\
\hline Ceramics, glass \& cement & 220.4 & \\
\hline Steel \& basic metals & 239.6 & \\
\hline Cars \& trucks & 248.2 & \\
\hline Electrical \& electronic equipment & 241.9 & \\
\hline Mechanical equipment & 227.6 & \\
\hline 6. Building & $1,105.4$ & 1,000 \\
\hline 7. Trade, services \& Government & $9,947.8$ & 5,715 \\
\hline Total & $16,698.7$ & 11,983 \\
\hline
\end{tabular}

Source: Adapted from Banco de Bilbao: Renta Nacional de España y su distribución Provincial, 1981. 


\section{Spain's Institutional Links with the EEC}

As early as 1962, the Spanish government expressed interest in an association with the EEC, possibly leading to eventual full integration ${ }^{6}$. Preliminary talks were held from 1964 to 1966 with the aim of negotiating a purely commercial agreement. The negotiations lasted from 1967 to 1970, and the EEC-Spain Agreement was signed on June 29, 1970 - the same day as the EEC-Israel Agreement was signed. It came into force on October 1 of the same year and provided the framework for the progressive elimination of trade barriers between the parties.

In the industrial sector, the EEC applies tariff concessions of $40 \%$ or $60 \%$, depending on the product, to nearly all imports originating in Spain. About half of agricultural imports are granted tariff concessions of $25 \%, 40 \%$ or $60 \%$. Spain offers tariff concessions of $25 \%, 40 \%$ or $60 \%$, again depending on the product, to a sizeable proportion of its imports from the EEC. The 1970 Agreement was renewed and adapted at the time of the first enlargement and later on when Greece entered the EEC, but the Community has asked many times for a new agreement, because of the increase of imports from Spain and because of GAT'T pressures from the inobservance of the rules of article XXIV of the General Agreement ${ }^{7}$.

After the coronation of King Juan Carlos I in 1975, the Spanish government indicated that it wished to conduct its relations with the Community with the intention of eventually becoming a member of the EEC. This made it pointless to conclude the proposed free-trade agreement within the framework of the Community's overall Mediterranean policy ${ }^{8}$ (approved by the Council of the Communities on June 27,1972) which served as the base for the free-trade agreement with Israel of March 30, 1983 and other Maghreb and Masrek agreements.

On July 28, 1977, following democratic elections, Spain formally presented its application for Community membership. The Commission adopted an opinion on Spain's application for membership in November $1978^{9}$. The official negotiations for Spain's accession to the Community opened on February 5, 1979.

The negotiations for Spain's membership took place between September 1979 and May 1985. The Community's rules have been divided into nineteen chapters for the adoption of the transitional periods for each item.

A period of seven years was established to dismantle industrial trade barriers. The transitional period for agricultural products will be ten years in some cases. Spain must adopt the European patent in 1992 and the value

Spain and the European Community, EUROPA INFO. (External Rels.) m 69/83.

A. Tovias, Tariff Preferences in Mediterranean Diplomacy (1977).

8 G. P. Papa, "The Mediterranean Policy of the EEC" (1973), EURO, Y.B.

9 Commission of the E.C., Opinion on Spain's application for membership, Bull. E.C. 9-1978 (supp.). 
added tax system from 1986. Spanish trucks and buses will be obliged to begin mileage control in three to four years. More freedom for capital movements and international investment and settlements will be established in a few years. Spaniards already working in the Community will have access to the same rights that nationals of the EEC have. In seven years Spain will adopt the EEC's external customs tariff and its foreign relations policy as well, including the Lomé Convention with ACP countries, and the generalized system of trade preferences favoring developing countries' industrial exports (GSP).

Many people in Spain seem to ignore the fact that the Spanish government has accepted the Community rules and principles exactly as they stand now, and that the negotiations have been merely about what is going to happen in the transitional period and not at all about what would happen afterwards. This is the case despite the fact that the Spanish government has established joint committees with chambers of commerce, trade unions, employers' organizations and with the governments of the regions and autonomous communities to explain the meaning and the progress of the negotiations ${ }^{10}$.

\section{The Effects of Membership on the Spanish Economy}

Spain's membership in the Common Market would have both static and dynamic effects on Spain's domestic economy and its foreign relations. Static effects include trade creation and trade diversion (as defined by Viner and explained in detail by Wells) ${ }^{11}$ as follows:

- Trade creation. Trade would be created and the welfare effect would be positive when the removal of the tariff barrier inside the customs union results in a transfer of output from a high- to a low-cost source of supply within the nation, i.e. when it represents an improvement in resource utilization.

- Trade diversion. If the removal of the internal barrier results in a switch from a low-cost external source of supply to a high-cost internal source, there would be trade diversion, representing a deterioration in resource utilization.

It is generally pointed out that the initial effects of joining the EEC will be unfavorable to Spain in static terms, but that these would be more that offset by the so-called dynamic effects of membership (following the pattern of $\mathrm{N}$. Kaldor for Britain) ${ }^{12}$ :

10 F. Granell, "Las Comunidades Autonomas y la negociación para el ingreso de España en la Comunidad Europea”, (1982) REVISTA DE INSTITUCIONES EUROPEAS 815.

11 S. J. Wells, International Economics (1973).

12 N. Kaldor, The Dynamic Effects of the Common Market, quoted in D. E. S. Lewis, Britain and the European Economic Community (1978). 
1. A wider market may encourage greater use of the economies of scale;

2. The effect of the increased competition which may tend to keep prices down to eliminate firms working below their optimum size, and hence give greater incentive to business managers and stimulate firms with a high growth potential to realize this;

3. A stimulus to not only domestic investment, but foreign investment from countries outside the customs union as well;

4. The possibility of a psychological change - a means of introducing some dynamism into the domestic economy.

The Spanish government has never agreed to write a white paper on the effects of full membership in the Community arguing that the British experience in conducting this kind of study shows that it is impossible to establish an ex ante balance sheet of gains and losses. Only one overall study, following the British government's methodology, has been done by the Circulo de Economia in Barcelona ${ }^{13}$.

From the static point of view it is clear that by becoming a member of the Common Market, Spain will open the economy to foreign trade which may then lead to an increase of imports.

Spain is now one of the European countries with the smallest proportion of foreign trade (see table I).

According to my estimates ${ }^{14}$ additional imports resulting from Spain's membership in the EEC would consist in 1983 of $\$ 3,000$ million a year. This is the result of applying a hypothetical degree of opening of the Spanish economy (now with an imports/GDP ration of $17.4 \%$ ) lower than either France $(21.4 \%)$ or Italy $(24.7 \%)$. This will create a need for more exports because traditional inputs of tourism, income from workers in Europe and foreign investment will not compensate for the additional imports on the balance-of-payments level. But what will be the value in terms of other currencies of the Spanish peseta when Spain needs those additional exports? Also, from the static point of view, the adoption of the EEC's common customs tariff will reduce to one-fifth the protection granted today by the Spanish customs tariff. The reduction of the tariff protection will be from $20.2 \%$ to $4 \%$ and with a decrease of $9 \%$ of the added value.

An additional problem is the very low level of association between the structure of protection offered by the current Spanish customs tariff and the future structure of protection provided by the EEC customs tariff. The EEC tariff, combined with GSP, ACP special relations and other trade

13 J. Muns, F. Granell \& J. Ortega, La opción europea para la economía española: Libro blanco sobre las repercusiones economicas de la integración de España en las Comunidades Europeas (1973).

14 F. Granell, "La integración en la Comunidad Europea y sus efectos sobre la exportación Española”, INFORMACION COMERCIAL ESPANOLA 135-141 (Aug.-Sept. 1982). 
agreements ${ }^{15}$ will have an impact on some domestic products which will be more important than the impact produced by sophisticated products made by EEC members. Here, also, the value of the Spanish peseta and its eventual inclusion in the European Monetary System (EMS) will be very relevant.

The consumer's point of view is normally not considered in Spain in the discussions about the static effects of membership. Some declining and noncompetitive industries fear the possibility of more competition from foreign products, and have tried to influence public opinion against a rapid elimination of tariffs. Consumers are never told that one of the main reasons for participating in a Common Market is the gains that will be obtained through a reduction of industrial prices that, in the case of EEC membership, will not be fully outweighed by the increase of prices of food caused by full participation in the CAP prices system and by the price impact of the adoption of value added tax (VAT). From the dynamic-effects point of view, there are no grounds for believing that membership itself will promote growth if it is not accompanied by a shift to a more rational allocation of resources.

Spain's fast economic growth in recent years may be due to factors which membership of EEC would not affect, such as the big proportion of the Spanish working population still available to be transferred from low productivity in agriculture to higher productivity in manufacturing or services (see table IV). The most important dynamic-effects argument in favor of Spain's membership is that free trade within the enlarged EEC will increase productivity by enhancing the scale of production, according the well known principle of the international division of labour. Today this argument is in disfavor because of unemployment, and protectionist practices commonly applied within the Common Market ${ }^{16}$. Many EEC countries are showing a preference for protecting domestic production and employment instead of allowing a drop in internal prices due to cheaper imports. We must recognize that all these considerations about the welfare and production implications of EEC membership make it difficult to assess the economic impact of the issue by means of a simple cost-benefit analysis.

It seems paradoxical then, if Spain is so profoundly ignorant of the realities of the EEC economic situation and the consequences that could result from Spain's membership in the Community, that negotiations for entry had been supported with an enthusiastic political determination, in spite of the criticism and scepticism manifested by many economic sectors both in Spain and the EEC. The explanation for this, however, is very clear. The prospect of economic gain and the increased economic growth is one of the main

15 F. Melo \& M. A. Mones, La integración de España en el Mercado Común. Un estudio de Protección Arancelaria Efectiva (1982).

16 F. Granell, “Les circonstances économiques du second élargissement de la Communauté Européenne” (1979) RMC 263. 
Table IV: Civilian Employment (Percentage)

\begin{tabular}{lrrrrrr}
\hline & \multicolumn{2}{c}{ Agriculture } & \multicolumn{2}{c}{ Industry } & \multicolumn{2}{c}{ Services } \\
& 1960 & 1983 & 1960 & 1983 & 1960 & 1983 \\
\hline USA & 8.5 & 3.5 & 35.3 & 28.0 & 56.2 & 68.5 \\
UK & 4.7 & 2.7 & 47.7 & 33.6 & 47.6 & 63.8 \\
Italy & 32.6 & 12.4 & 33.9 & 36.1 & 33.5 & 51.5 \\
Japan & 30.2 & 9.3 & 28.5 & 34.8 & 41.3 & 56.0 \\
France & 23.2 & 8.1 & 38.4 & 33.8 & 38.5 & 58.1 \\
Spain & 38.4 & 18.0 & 30.4 & 33.5 & 31.2 & 48.4 \\
Portugal & 44.1 & 25.9 & 31.4 & 37.1 & 24.5 & 37.0 \\
\hline
\end{tabular}

Source: OECD Economic Outlook, Historical Statistics 1960-1983 and "OECD OBSERVER", March 1985.

reasons why a country enters a regional economic integration, but political motives - namely the support of the democratic system established after Franco's death - are, in Spain's case stronger than any calculations of economic gain or loss. A good example of this is the excessive importance attached to resolving agricultural questions or semipolitical questions such as the renunciation of fiscal sovereignty that will result from the adoption of the VAT. Agricultural products were very important in the context of the Spanish economy when Minister Castiella sent the first letter to the EEC in 1962. Since then, Spanish industry has grown and other factors have become much more important ${ }^{17}$. For example, questions regarding industrial sectors and how they could be affected by the introduction of new technologies ${ }^{18}$ or by the competition from Newly Industrialized Countries (NICs) ${ }^{19}$; or the shortage in savings to be applied to investment for modernizing agriculture and declining industrial sectors; or the capacity of a Spain integrated in the EEC to attract foreign direct investments are issues normally ignored. The same can be said with respect to the future of the services sector which is increasingly important in the Spanish economy.

17 A. Tovias, "Los plazos de adaptación como factor determinante del impacto de la segunda ampliación de la Comunidad sobre los países Mediterraneos", VIII I Jornadas de Estudios Socieconómicos de las Comunidades Autonomas 297.

18 Ministerio de Industria y Energía, Libro Blanco de la Reindustrializacion (1983).

19 J. B. Donges y F. de la Puente, La industria española ante los nuevos paises industrializados (1982). 


\section{The Impact of Spain's Membership on Third Countries}

Since the signing of Treaty of Rome,the EEC has tried to promote not only intra-community trade but world trade in general, primarily in industrial goods. After the first enlargement, the EEC accepted a new role and overall responsabilities in most areas of the world. These responsabilities must be developed with the current enlargement ${ }^{20}$. Spain has agreed to accept the EEC policies regarding ACP, Latin America, GSP and Mediterranean countries, saying that the opening of the Spanish market of 40 million consumers will be positive for third countries. The Latin American Economic System (SELA) has expressed concern about the trade diversion that may occur when Spain applies the protectionists barriers of the CAP to Latin American agricultural products ${ }^{21}$. Mediterranean countries are concerned about some of the implications that will result from Spanish membership. These troubles were summarized by the Ambassador Minerbi in the exploratory conversations between Israel and the Commission ${ }^{22}$. The most relevant points raised were:

- Enlargement will give Spain tariff advantages and if so, increase her competitiveness in the Community.

- Accession will stimulate increases in Spain's output of sensitive products, which will lead to surpluses and hence, restrictions on Israel's exports.

- Israel has few markets other than the Community.

- The impact of enlargement can be catastrophic for Israel's agriculture and serious for her industry.

- The difficulties caused by enlargement can be permanent, if a long transitional period is unable to resolve them.

Today, these arguments apply to all economic sectors, thus exceeding the former limited concern for Israel's exports of citrus, flowers, fresh vegetables, avocados, and melons ${ }^{23}$. With the exception of the problems created by the lack of diplomatic relations between Spain and Israel, now rectified, the problems that other Mediterranean countries have are quite similar to those of Israel, and only vary according to the flows of trade ${ }^{24}$.

20 W. Wallace and I. Herreman, A Community of Twelve?: The Impact of Further Enlargement on the European Communities (1978).

21 R. Tamames, El Mercado Comun Europeo: Una perspectiva espanola y Latinoamericana, (1982).

22 Commission of the European Communities: Mediterranean Policy for an Enlarged Community, "Exploratory conversations between Israel and the Commission", Brussels, 8th and 9th June, 1983, Note of Meeting, mimeo, 11th November 1983.

23 S. Minerbi, "The EEC and Israel" in The EEC and the Mediterranean Countries, (A. Shlaim and G. N. Yannopoulos eds. 1976).

24 Rapport de la Commission au Conseil relatif aux conversations exploratoires avec les pays mediterranés et les pays candidats à l'adhésion, Doc. miméo COM (84) 107 final of March 28, 1984. 
In the field of external relations, the only specific question that Spain has tried to introduce in the negotiation, deals with its special relation with Latin American countries with whom Spain currently has no special tariff or trade policy agreement.

Some time ago it was suggested that after Spain and Portugal enter into the EEC a kind of new Lomé Convention pertaining to trade in Latin American countries must be arranged. However Lomé III has been so intensely criticized that the possibility of establishing a new arrangement of this sort appears highly questionable. Regarding the protectionist worries of some third countries caused by the increase in self-sufficiency of the EEC in agricultural products when Spain becomes a member, Spain has always said that the physical structure of the country will not allow an unlimited development of Spanish crops as some producers in the Community and some exporters in third countries have maintained. The Spanish government believes that the trend of a decline in the share of agriculture in the GDP will continue despite income and production effects stimulated by the CAP and the higher agricultural prices that Spanish farmers will receive with the application of the CAP.

Spain says that the current CAP will not be very advantageous to Spanish farmers because the EEC's budgetary situation will restrict actual aids. But new lines of aid can be perhaps considered. By asking for a new cotton policy in the framework of CAP, Greece is supposed to be an example for the future. For Spain the future of the CAP is not just a question of a new market organization for additional agricultural products; it is also a question of additional resources for the guidance section of the "European Agricultural Guidance and Guarantee Fund". The question of the current organization of the CAP is one of the key issues of today's Community. Liberals are arguing that the actual CAP is too expensive both for taxpayers and consumers and Spain's and Portugal's membership - which will increase the number of farmers by $37 \%$ - only further aggravates the current irrationality and imbalances of the CAP system.

Budgetary pressures and criticism from the USA and other important agricultural producing countries will, perhaps, force drastic changes in the CAP before the end of the transitional period of Spanish and Portugal accession. If no changes are introduced in the CAP Spain will be forced to play the game that the other members of EEC are trying to play: trying to obtain a positive balance of payments in its relation with the EEC. This attitude is far away from the liberal approach but is consistent with the policy that all members of the EEC are currently following without considering the rationality of the market and the interests of the Community above their own. 


\section{The Spanish views on the EEC - present and future}

Years before the death of General Franco, Spain experienced a spontaneous movement of popular opinion in favor of integration in the EEC. The tone of the most responsible opinions used to be pro-European and the same can be said of the statements supporting the entry of Spain in the the EEC now coming from many economic entities when they are asked by the government. The position adopted by all the political parties in the Spanish Parliament's session of this topic held on June 27, 1978, revealed them all to be pro-European, with a notable absence of dissident voices quite apparent in other European countries. All this serves to point out clearly that today in Spain no one favors remaining politically or economically outside of Europe, as was the case on other occasions in our relatively recent history. Few issues involving both the Spanish economy and society have obtained such a great degree of general consensus.

The Spanish government and public, however, obliged the EEC to accept realistic conditions and transitional periods for Spain's accession to the EEC during the negotiations which closed in May 1985. Spain was no longer prepared to be led blind, as it might have been before the consolidation of the external face of Spanish democracy that has come with Spain's full participation in the Council of Europe since November 24, 1977, and in NATO since May 30, 1982. Spain's fear of finding itself isolated in a world consisting of self-sufficient blocs is today unfounded. Spain has increasing economic relations with the EEC countries, and the EFTA countries (with whom Commercial agreements similar to Spain-EEC Agreement have been in force since 1980) and with other areas of the world. The problems which Spain has had, and presently has will not be removed or reduced just by the fact of its entry into the EEC, although the stimulus for a more free economy - accepting the EEC rules - could help the Spanish economy to adapt to more realistic market conditions.

With the world economy growing rapidly the formation of a customs union or the incorporation of new countries into it, were considered positive for the development of the national integrated economies. The advantages were considered greater than the inconveniences coming from tariff reductions and the resulting changes in trade flows. We all know what has happened after the seventies' crisis. Protectionism has emerged in many different countries and European integration has suffered a slowdown. The history of the EEC since then has been marked by economic stagnation and a paralyzing institutional preoccupation. In spite of protectionist pressures coming from the vulnerable sectors most affected by the economic crisis, free trade in the interior of the EEC has been saved. Just in some cases member states have been just as willing to go their own way, putting national interest above community law: France by blocking Japanese videos; Germany by 
restricting beer imports; Britain by stopping French turkeys at the border; Belgium and Italy by cheating on subsidies for their steel industries ${ }^{25}$.

Today, the market of 300 million people is an irreversible fact for the majority of the most important economic sectors in European economic activity.

But, on the other side of the balance, there have been major setbacks experienced by projects to establish new lines of integration, and attempts to implement common positive policies in the fields in industrial restructuring, agriculture structural policy, monetary cohesion and in a greater degree of political cooperation and unity.

If Spain has joined the Community in the early sixties the most important problems for our economy would have been those pertaining to the agricultural sector (due to its relative importance in the Spanish economy at that time) and those pertaining to tariff protection both of which are quite well covered by the EEC regulations.

But with floating exchange rates, reduction tariffs and other trade barriers by successive GATT commercial rounds and a decreasing importance of agriculture, the fundamental questions now affecting Spain's membership are the increased economic dynamism Spain has to expect from future integration in the Community, the official Community aids to the Spanish sectors in crisis, and the policies that could be adopted for regional or industrial restructuring with the help of the Community budget or the European Investment Bank resources.

This is, of course far away from the liberal point of view of reliance in a greater degree of free competition, but is the game that all EEC members are today playing and that is converting the EEC into a sort of supranational welfare state.

The Community in which Europeans, including Spaniards, are interested is an economic union able to help to transform its backward industries into a force that can survive an onslaught by highly advanced foreign rivals. This is something more than a well-functioning customs union with the additives of free circulation of capital and labour, but with the insufficient common policies that the EEC has now.

Spain has no practical alternative to becoming a member of the EEC. For this reason, Spain hopes that the EEC will be able to overcome its current problems to help Europe accomplish its role in our bipolar and divided world and in order to help the Spanish economy to restart the process of economic development that made Spain one of the most successful countries during the golden sixties.

25 Wall St. J., Nov. 3, 1984, at 1; A. Mattera, "Protectionism inside the European Community", $18 \mathrm{~J}$. World Trade L. (1984). 


\title{
The Impact of the Second Enlargement of the EC upon Israel's Balance of Payments*
}

\author{
Alfred Tovias
}

\section{Introduction}

Israel, as a Mediterranean country, has competed since her very establishment with the three new member countries (Spain, Greece and Portugal) in the same Western European markets, covering a wide range of nearly identical products, as well as certain semi-manufactured and manufactured products, such as textiles. New trade discrimination in favour of any of the three new member countries as a result of accession must inevitably alter the internal balance of the Global Mediterranean Policy of the EC, determined twelve years ago as a means of preserving the exporting interests of all Mediterranean bordering countries (including Israel).

At the same time, the Second Enlargement offers new opportunities for the Israeli industry, in that three very closed markets (Spain, Greece and Portugal) will be opening to EC, EFTA and other EC preferred countries, including Israel.

We shall focus upon these two aspects, particularly on the first, while, referring incidentally to two other issues (aid and tourism flows), all of which may affect in one way or another the Israeli Balance of Payments as a result of enlargement.

\section{Preference erosion and preference inprovement}

The EC has promoted imports from the four countries by offering tariff preferences for similar products within the framework of the respective agreements. Equilibrium between Israel and the other three countries with regard to concessions is disrupted by the accession of the latter into the EC. Preferences formally conceded to Israel under its 1975 agreement will undergo erosion. Observe that the impact upon Israel of the entry of each of

\footnotetext{
* The present paper is based on excerpts of a study prepared for The European Research
} Center of the Hebrew University. 
the three candidates into the EC (hereinafter: the Three) will differ because their pre-enlargement institutional links with the Community were by no means identical. Note that this is true independently of the other differentiating variables so frequently mentioned in the literature (such as the Three's economic dimensions, the extent of their trade's overlap with Israeli exports, etc.). Schematically, the most relevant changes for Israel are the following:

1. Spain will obtain free access to the EC for its agricultural products, improving its status of preferred Mediterranean country, which entails very few tariff reductions at present. The same is essentially true for Portugal, although not significantly so for Greece, whose agricultural exports (e.g. citrus fruit) were mostly exempted from tariff duties even before its accession in 1981.

2. The three countries join the CAP upon accession to the EC, with all the advantages that this implies (penetration prices, export refunds, guaranteed prices, etc.), but also have to respect certain common disciplines (corresponsibility prices, production restrictions, quality requirements, etc.) and apply the principle of Community preference and common agricultural prices.

3. The three countries must adopt the EC's CET (Common External Tariff) for industrial goods and abandon their own tariffs towards other countries. This invariably implies a reduction in tariff protection levels on other countries' exports.

4. Spain, on the one hand and the EC and EFTA on the other must increase their margins of preference on mutual industrial trade to $100 \%$, thereby attaining a level of free trade in industrial goods. In this respect, the change in the industrial field is much more significant for Spain than for Greece and Portugal, as the latter benefited from free access to the EC (except for textile trade) even before the enlargement and offered the EC a wider access to their markets than did Spain (through implementation of the 1961 Association Agreement with Greece and the 1972 Free Trade Agreement with Portugal).

5. The three countries and Israel will enjoy mutual free trade in industrial goods and preferential trade in agricultural products after a transitional period.

The following table sums up these changes and their a priori impact upon Israel. In general, three types of effects have been distinguished (from the Israeli perspective): trade diversion in favour of the three candidates' exports and against Israel's; trade creation and trade diversion in favour of exports of the three candidates or Israel, and against those of other countries.

Previous studies on the impact of the Second Enlargement upon Mediterranean countries have focused almost exclusively upon 1C, 2A, 2B and $2 \mathrm{C}$, for two reasons:

- From a quantitative point of view, these effects may dominate all others. 
Table 1: Changes in new Member's trade links with the EC

\begin{tabular}{|c|c|c|c|}
\hline & $\begin{array}{l}\text { A } \\
\text { Greece }\end{array}$ & $\begin{array}{l}\text { B } \\
\text { Portugal }\end{array}$ & $\begin{array}{l}\text { C } \\
\text { Spain }\end{array}$ \\
\hline $\begin{array}{l}\text { 1. Free access to EC } \\
\text { agricultural markets }\end{array}$ & & $\begin{array}{l}\text { general } \\
\text { trade diversion }\end{array}$ & $\begin{array}{l}\text { general } \\
\text { trade diversion }\end{array}$ \\
\hline 2. Joining the CAP & $\begin{array}{l}\text { general } \\
\text { trade diversion }\end{array}$ & $\begin{array}{l}\text { general } \\
\text { trade diversion }\end{array}$ & $\begin{array}{l}\text { general } \\
\text { trade diversion }\end{array}$ \\
\hline 3. Adopting the CET & $\begin{array}{l}\text { general } \\
\text { trade creation }\end{array}$ & $\begin{array}{l}\text { general } \\
\text { trade creation }\end{array}$ & $\begin{array}{l}\text { general } \\
\text { trade creation }\end{array}$ \\
\hline $\begin{array}{l}\text { 4. a) Free access to EC } \\
\text { and EFTA } \\
\text { industrial markets }\end{array}$ & $\begin{array}{l}\text { textile trade } \\
\text { diversion to EC } \\
\text { and general trade } \\
\text { diversion to EFTA }\end{array}$ & $\begin{array}{l}\text { textile trade } \\
\text { diversion to EC }\end{array}$ & $\begin{array}{l}\text { general } \\
\text { trade diversion } \\
\text { to EC and EFTA }\end{array}$ \\
\hline $\begin{array}{l}\text { b) Free acceptance } \\
\text { of EC and EFTA } \\
\text { industrial goods }\end{array}$ & $\begin{array}{l}\text { general } \\
\text { trade creation }\end{array}$ & $\begin{array}{l}\text { genaral } \\
\text { trade creation }\end{array}$ & $\begin{array}{l}\text { general } \\
\text { trade creation }\end{array}$ \\
\hline $\begin{array}{l}\text { 5. a) Free trade in } \\
\text { industrial goods } \\
\text { with Israel }\end{array}$ & $\begin{array}{l}\text { general trade } \\
\text { creation and trade } \\
\text { diversion in } \\
\text { favor of partner }\end{array}$ & $\begin{array}{l}\text { general trade } \\
\text { creation and trade } \\
\text { diversion in } \\
\text { favor of partner }\end{array}$ & $\begin{array}{l}\text { general trade } \\
\text { creation and trade } \\
\text { diversion in } \\
\text { favor of partner }\end{array}$ \\
\hline $\begin{array}{l}\text { b) Preferential trade } \\
\text { with Israel in } \\
\text { agricultural } \\
\text { products }\end{array}$ & $\begin{array}{l}\text { general trade } \\
\text { creation and trade } \\
\text { diversion in } \\
\text { favor of partner }\end{array}$ & $\begin{array}{l}\text { general trade } \\
\text { creation and trade } \\
\text { diversion in } \\
\text { favor of partner }\end{array}$ & $\begin{array}{l}\text { general trade } \\
\text { creation and trade } \\
\text { diversion in } \\
\text { favor of partner }\end{array}$ \\
\hline
\end{tabular}

- Studies, particularly if government-initiated, tend to stress the effects which harm the non-candidate's exports and in light of which it may expect some meaningful concession or compensation from the EC, as discrimination is indeed in evidence.

This last point requires some elaboration: in Israel, relatively little emphasis has been placed upon $4 \mathrm{~A}, 4 \mathrm{~B}$ and $4 \mathrm{C}$, as she is already receiving free trade treatment in the EC, while Spain and Portugal (the latter for textiles) are not. Hence there is little which Israel can request as compensation in the industrial field ${ }^{1}$. This, however, does not imply that actual trade diversion on these items will be insignificant; logically, therefore, these effects deserve considerable attention.

The changes noted in lines 3 and $4 \mathrm{~b}$ lead to trade creation favoring Israel;

1 In this respect, Israel may seek compensation from EFTA countries in the future, after the negotiations with the EC are concluded. In any case there is no urgency as long as Israel continues to enjoy GSP benefits from some EFTA countries. 
by opening their markets fully to the EC and EFTA and improving access for other countries, the new members will increase their import demand for final goods, thus increasing, in turn, third-party countries', demand for Israeli intermediary products. This, of course, would occur quite independently of the fact that direct trade between the new member and Israel is expected to undergo an overall increase at both the final and intermediary goods levels (see lines $5 \mathrm{a}$ and $5 \mathrm{~b}$ ). However, given the indirect nature of effects falling under 3 and $4 b$, we will ignore them and concentrate on the remaining.

\section{Overlap}

Israel and the Three are competing in the same Community markets in the export of "sun-intensive" Mediterranean agricultural products or of certain industrial raw materials (e.g. cotton). Furthermore, some of their comparative advantage is based upon relatively abundant unskilled labour, pools based upon processing of relatively cheap local inputs and raw materials (primarily processed food, textiles, clothing and chemicals). We are interested therefore in measuring with suitable indexes the exact degree of overlapping of Israel's exports with each of those three countries, the focus being laid on exports to the world at large. This, basically for two reasons: By doing so, we can compare the indexes relating to the Three with those relating to other areas, and in particular the EC itself. Furthermore, we assume large substitution possibilities to be operated among the customers of the four Mediterranean countries concerned (e.g. between EFTA and EC countries), in particular because their export baskets are by and large composed of standardized products. Later on, however, and for the sake of completeness, we consider similarity indexes of exports to the EC proper.

We intend to measure the evolution of those indexes over time, thereby striving to determine whether clear trends are in evidence.

Insofar as the overall commodity composition of trade is concerned, we have relied upon the following index:

$$
\text { Index }=100-\frac{1}{n}\left[\sum_{i}\left(\left|a_{i j}-a_{i k}\right|\right)\right] \times 100
$$

where a represents the share of exports of sector $\mathrm{i}$ in overall world exports disaggregated at the two-digit level or in world exports of primary products (SITC 0 to 4), disaggregated at the three-digit level; $j$ denotes Israel and k, alternatively stands for Spain, Greece, Portugal and the Nine; $n$ is the number of countries compared (two in this case). An index of 100 indicates complete overlap. The results for 1968, 1973 and 1978 appear in table 2, from which the following conclusions may be drawn:

1. Of the Three, Spain is most similar to Israel, in terms of overall export commodity composition with no change in the ranking observed over time. 
Table 2: Primary-Product Exports of New Members (Percentage)

\begin{tabular}{lllllll}
\hline Country & $\begin{array}{l}\text { Total } \\
\text { Exports }\end{array}$ & $\begin{array}{c}1968 \\
\text { Primary } \\
\text { Products }\end{array}$ & $\begin{array}{l}\text { Total } \\
\text { Exports }\end{array}$ & $\begin{array}{c}1973 \\
\text { Primary } \\
\text { Products }\end{array}$ & $\begin{array}{l}\text { Total } \\
\text { Exports }\end{array}$ & $\begin{array}{c}1978 \\
\text { Primary } \\
\text { Products }\end{array}$ \\
\hline Spain & 51.01 & 38.09 & 45.64 & 41.60 & 47.99 & 38.62 \\
Greece & 42.36 & 22.15 & 39.56 & 27.35 & 32.07 & 39.51 \\
Portugal & 44.02 & 12.02 & 44.93 & 14.68 & 37.00 & 11.99 \\
The Nine & 39.88 & 20.31 & 40.06 & 21.09 & 43.44 & 20.31 \\
\hline
\end{tabular}

Source: UN Commodity Trade Statistics, various years

2. With regard to total exports, the similarity of Israeli exports with those of any of the three candidates has decreased over the decade 1968-1978, with a particularly striking drop in the case of Greece. On the other hand, similarity has increased between Israeli exports and those of the EC. Most interesting is the fact that Portugal emerges as more similar to Israel than Greece (even over time) when industrial exports are included in the test.

3. Similarity of Israeli primary product exports has not diminished in relation to Spain ${ }^{2}$. Note that the index for Spain was always much higher than for Portugal. Moreover, it appears that the primary product exports of Israel and Greece became increasingly similar over time, whereas those of Israel and Portugal had always been highly dissimilar.

These results are compatible with those of Pomfret and Donges et al. in previous studies ${ }^{3}$. While our product coverage differs from theirs, we have considered also exports to the world, not only to the Community. This has enabled us to observe that Israel's export commodity pattern is slowly approaching that of the EC and drifting away from that of Greece or Portugal, while Spain's overall export patterns slowly drift away from those of Israel. If these trends continue, it is likely that Israel's export basket will eventually become more similar to that of the EC than to that of the three candidates.

Briefly stated, Spain should attract by far the most attention among the Three with regards to Israel's commodity export basket, expecially in light of the fact that Spain is quantitatively the most important EC trading partner among them. Firstly and foremostly, we should focus upon Spain's primary

2 Indexes for primary products are generally lower in absolute figures than those related to overall exports. This results from the fact that the first type of index has been calculated by disaggregating product categories at the SITC three-digit level, while the second relates to the two-digit level.

3 See R. Pomfret, "The Impact of EEC enlargement on Non-Member Mediterranean Countries' Exports to the EEC”, Econ. J. 726 (1981); Donges et al., The Second Enlargement of the European Community, pp. 162-168 (1982). 
product exports, whose high degree of overlap with Israel's has not diminished over time (while there does appear to be some disengagement as far as other exports are concerned). With regard to Greece, attention should be concentrated upon agricultural exports.

In selecting our index, which relates to exports of Israel or other Mediterranean countries to the world (and not exclusively to the EC), the underlying assumption was that it is easy to switch export markets for the standardized goods which primarily comprise those countries' export baskets. We now assume that this is not the case (as Pomfret and Donges et al. did implicitly). Following Pomfret's method, we calculated the FingerKreinin index for SITC Categories 0, 1, 2 and 4, i. e. those 16 three-digit level categories of EC commodities imported from the four countries in which EC imports from Israel reached at least $\$ 1$ million, utilizing OECD data for 1980 . Results obtained were as follows:

Greece/Israel

72.19
Spain/Israel 60.45
Portugal/Israel 39.55

The results now coincide with those of Donges et al. but contradict those of Pomfret, which referred to $1977 .{ }^{4}$ Note that the ordinal results did not change when only agricultural produce and processed food were considered. Greece's exports of primary products to the EC are very similar to those quantitatively relevant to Israel, while this is less so where the world at large is concerned. That is, the EC is the meeting place for similar Israeli and Greek primary products. This is somewhat less true of Spain, which confronts Israeli competition in primary products in the world at large (e. g. in EFTA or US markets).

\section{Revealed Comparative Advantage in Trade with the EC}

This section adopts an alternative approach to the issue of Israel's competitiveness in EC markets in relation to that of the Three. We assess the evolution of Israel's comparative advantage in EC markets in the 1970s and compare the trend with that of Spain. Moreover, we attempt to discover whether the sectoral composition of Israel's comparative advantages coincides with that of the three countries.

Firstly, we calculated indexes of "revealed comparative advantage" (RCA) by sector (at the SITC two-digit level) for the four countries, using 1979 data

4 Promfret found for that year and for SITC categories 0, 1, 2 and 4 that Spain's exports to the EC were slightly more similar to those of Israel than Greek exports are. See Pomfret (1981), ibid. The study by Donges et al. found that the reverse is true when only the five most important agricultural exports of Israel are considered, which accounted for $49.1 \%$ of total EC agricultural imports from Israel in 1978. See Donges et al., ibid, p. 168. 
published by the $\mathrm{OECD}^{5}$. Secondly, we calculated rank correlation indexes between Israel's sectoral RCAs and the corresponding RCAs of the other three countries. Thirdly we repeated the same procedure for Israel and Spain for the year 1970 .

The most popular index of comparative advantage is the "relative tradebalance" index ${ }^{6}$, i.e. a relative export-to-import ratio of each sector, used originally by B. Balassa to identify "revealed comparative advantages" of a given country. A positive trade balance in a given sector is said to represent a comparative advantage of that sector, while a negative trade balance reveals a disadvantage. The balance is then related to total trade, which acts as a normalizer. Nevertheless, the RCA index is only a rough approximation of the "true" comparative advantage. Ideally, the index should be based upon trade figures resulting from a free trade setting and not upon "real world" figures, which are obviously the only ones available. The index is also very sensitive to the level of disaggregation used and to product heterogeneity. Finally, since it is a ratio, it does not distinguish between large and small absolute values of trade.

The results of the empirical analysis can be seen in tables A1 and A2 in the Appendix to this paper.

A quick glance reveals that of those categories of goods for which Israel and Spain display high RCA indexes $(>0.4)$ in trade with the EC (1979), overlap concerned "fruits and vegetables", "clothing" and "cork and wood manufactures (excluding furniture)".

In the case of Greece, the following categories overlap with Israel's: "Fruits and vegetables", "clothing", "metalliferous ores and metal scrap", "crude fertilizers and crude minerals".

Finally, when dealing with Portugal, overlap with Israel's comparative advantage in exports to the EC relates, to the following categories: "wood and cork manufactures (excluding furniture)", "clothing", "manufactured fertilizers", "fruites and vegetables", "metalliferous ores and metal scrap".

The three Spearman rank correlation indexes of RCA index series for 1979 have been also calculated as follows:

$$
\begin{array}{ll}
\text { Spain-Israel } & 0.687 \\
\text { Greece-Israel } & 0.559 \\
\text { Portugal-Israel } & 0.352
\end{array}
$$

Perfect correlation would entail an index of 1 , while no correlation would imply an index of 0 . It appears thus that as EC trade partners, Spain and Israel

5 OECD Statistics of Foreign Trade, Series B: Trade by Commodities. Analytical Abstracts, 1980 and 1971.

6 The methodology and corresponding empirical evidence related to Spain and Israel may be found, respectively in J. Donges, Towards Spain's Accession into the EEC, Kiel, Kiel Working Paper No 94, pp. 9-13; and in H. Giersch (ed.), The Economic Integration of Israel in the EEC, pp. 132-143 (1981). 
have a more similar structure of comparative advantage displayed in EC markets than do Israel and Greece or Portugal. The latter pair, in fact, display a high degree of dissimilarity.

A rapid overlook at RCA indexes for Spain and Israel in 1970 (see table A2) indicates that the number of Spanish or Israeli sectors performing well in EC markets increased by several times during the 1970s, but that new overlap between Israel and Spain only covers "clothing", where Spain appears to have strengthened her position in the 1970s. Its index jumped from 0.092 to 0.603 , while Israel's improved slightly from 0.754 to 0.851 . One might reach the erroneous conclusion that in terms of competitiveness, Spain's clothing industry progressed more than Israel's, even if in absolute values, it appears that Israel still has an edge over Spain. In fact, it appears that 1979 was a totally atypical year. Considering 1980 data for example, we note that the RCA in clothing was 0.474 for Spain, while Israel's reached 0.934. Spain had actually attained this moderate RCA level by the mid-1970s and has stagnated since then. For example, the RCAs for 1974 and 1975 are 0.533 and 0.563 , respectively. Note that corresponding RCA indexes for Greece and Portugal (1980) are 0.884 and 0.925 , respectively, each as impressive as that of Israel.

The 1970 Spearman rank correlation index of RCA between Israel and Spain reached 0.624, as compared with a 1979 index of 0.687. Accordingly, it appears that the relatively high level of similarity between Spain's and Israel's sectoral distribution of RCAs in EC markets was maintained and even increased marginally during the 1970s.

These results are compatible with the aforementioned remarks on export similarity, provided we undertake a careful comparison of the hypotheses applied in each case: export similarity between Spain and Israel decreased somewhat between 1968 and 1978, when exports to the world are considered. On the other hand, the structure of the two countries' comparative advantages in relation to the EC was as similar in 1979 as in 1970. This divergence of behavior may be explained by the fact that Spain has been penetrating OPEC and South American machinery and transport equipment markets, while Israel has initiated large scale-exports of technologically advanced products to the United States. In other words, the extent of similarity between Israeli and Spanish export baskets into the EC has remained stable through the 1970 s.

\section{Trade Diversion: What is at Stake?}

Table 3 roughly evaluates the extent of Israel's vulnerability by recording the total value of 1978 Israeli exports for the SITC three-digit level categories of goods for which the Three and Israel exported more than $\$ 10$ million annually to all destinations: 
Table 3: Potentially Vulnerable Israeli Exports (1978)

Category

Amount (\$ millions)

Fruits and vegetables, fresh/frozen

Fruits and vegetables, preserved

Crude vegetable materials

Petroleum products and residuals

Diverse chemicals

Rubber articles

Textile yarn, fabric, made-up articles

Clothing and apparel

Aluminium

Source: UN Commodity Trade Statistics: Israel, 1978

The above total represented $36 \%$ of all Israeli exports during the same year. Observe that vulnerability must have diminished since 1978, in relation to petroleum products, considering the drastic reduction in those exports since the evacuation of Sinai. Furthermore, the EC Common External Tariff on chemical inputs is negligible, if not nil; hence the latter are not affected by the enlargement of the EC. Obviously the focus thus rests upon fresh agricultural products, processed food, textiles and clothing. Table 4 displays 1980 export figures published by Israel's Central Bureau of Statistics pertaining to those vulnerable categories.

Table 4: Vulnerable Exports, Israel, 1980

Fruits and vegetables (fresh, frozen, preserved)

Crude materials, animal and vegetable (mainly flowers)

Textile yarn, fabrics, made-up articles

Clothing and apparel

Total

Source: Statistical Abstract of Israel, 1981. 
This figure represents $19 \%$ of Israeli exports to all destinations for that year. However, the share of these categories on total exports is much higher when only exports to the EC are considered. A similar breakdown indicates that agricultural and textile-related exports account for $44 \%$ of total exports to the EC in 1980, as the EC's share in total Israeli exports of the potentially threatened sectors is much higher than average (i.e. $38 \%$ ), at times reaching double that figure (e.g. $79 \%$ for textiles).

Table 5: Israeli Exports to the EC and the World in Vulnerable Sectors; Share of EC in Total Exports, 1980

\begin{tabular}{lccc}
\hline & \multicolumn{2}{c}{$\begin{array}{l}\text { Exports } \\
\text { (\$ millions) } \\
\text { All Desti- } \\
\text { nations }\end{array}$} & $\begin{array}{l}\text { Share of EC among } \\
\text { All Destinations }\end{array}$ \\
\hline Agricultural exports & 354.7 & 558.2 & $64 \%$ \\
Food, beverage and tobacco & 201.3 & 298.1 & $68 \%$ \\
Textiles, clothing and leather & 375.2 & 473.4 & $79 \%$ \\
Exports of above categories & 931.2 & 1329.7 & $70 \%$ \\
Total exports (SITC 0-9) & 2121.1 & 5540.0 & $38 \%$ \\
Share of above categories & $44 \%$ & $24 \%$ & \\
in total exports & & & \\
\hline
\end{tabular}

Source: Statistical Abstract of Israel, 1981

To sum up, when considering the impact of the second EC enlargement, we relate to nearly half of Israel's exports to the EC and to one-sixth of her total exports. Note that levels of dependency on vulnerable categories have not changed over recent years:

\begin{tabular}{lcccc}
\hline & 1977 & 1978 & 1979 & 1980 \\
\hline $\begin{array}{l}\text { Share of selected categories in total } \\
\text { exports to the EC }(\%)\end{array}$ & 45.2 & 44.3 & 46.8 & 43.9 \\
$\begin{array}{l}\text { Share of selected categories in total } \\
\text { exports to all destinations (\%) }\end{array}$ & 16.1 & 15.2 & 17.5 & 16.8 \\
\hline
\end{tabular}

Finally, observe that these dependency indicators would reach much higher levels if calculated on a value-added or an employment basis. ${ }^{7}$

7 No figures are available on value added or employment regarding export activities in general and EC-oriented exports in particular. 
Regarding the former case, the proportion of value added by the domestic economy for the categories selected is much higher than the average, whereas the reserve is true for exports of polished diamonds, for example. ${ }^{8}$

In relation to total employment in industrial and agricultural branches, the share of employed persons in citriculture, fruit growing, food processing, textiles and the clothing industry, all of which are export-oriented (in particular to the EC), reached $24.5 \%$ for the year 1980 . This is a reasonable proxy for the share of those branches in the total of employed persons engaged in export-related activities, to be compared with the share of the same branches in total exports $(16.8 \%)$, i. e. the sectoral exports considered are especially labor-intensive.

\section{Trade creation or diversion favouring Israel}

For Israel, in fact, the enlargement implies the addition of three markets (up to now very closed) with a GNP roughly equivalent to that of the Benelux countries, to which she can export at privileged prices. The higher the difference is between average European (EC-EFTA) and world prices, the higher the expected impact. Israel will only obtain preferential treatment (not free access) on part of her agricultural and food products (see table 1, line 5b), as in the rest of the EC. In this respect, there is no room for too much optimism as for industrial exports.

Israeli exports which should benefit from the enlargement include not only products already marketed to the Three (such as cotton, refined petroleum products, fertilizers, other chemical products, diamonds and irrigation equipment), but also those which were previously not sold there at all because of high tariffs and preference for EC products in those markets. This latter group could include clothing, metal products, furniture, electrical machinery, electronic equipment, plastic and synthetic raw materials, non-electrical machinery, other manufactured products, transport equipment, optical and precision instruments, some rubber articles, some pharmaceutical products and telecommunication equipment. ${ }^{9}$ It has often been stressed that most of these products are not exported to the Three because of their low income in relation to the EC's average. However, the significance of this factor diminishes with time. And of the Three, the largest (Spain) has a per capita

8 While 1980 exports of precious and semi-precious stones amounted to $\$ 1.672$ million, net exports (i. e. exports minus imports) only amounted to $\$ 452$ million, a figure which is less than the corresponding one for fruits and vegetables (even on a net basis).

9 Predictions based on Spanish data on effective protection, Greek and Portuguese data on average nominal tariff protection, preferences offered by the Three to the EC and import demand elasticity data also for the three countries. Details can be found in the study prepared for the European Research Center by this author. 
Table 6: Israeli Exports to Selected EC Member States

\begin{tabular}{llcrc}
\hline Destination & $\begin{array}{l}\text { Israel } \\
\text { exports } \\
\text { (\$Millions, 1980) }\end{array}$ & \multicolumn{2}{c}{$\begin{array}{c}\text { GNP of Destination } \\
\text { (\$, 1980) }\end{array}$} & $\begin{array}{l}\text { Mid-1980 } \\
\text { population } \\
\text { (millions) }\end{array}$ \\
\hline Greece & 55.6 & 4520 & 42.190 & 9.239 \\
Spain & 36.7 & 5350 & 199.780 & 37.378 \\
Italy & 285.1 & 6480 & 368.860 & 56.940 \\
UK & 465.8 & 7920 & 442.820 & 55.886 \\
\hline
\end{tabular}

Source: 1981 World Bank Atlas: Statistical Abstract of Israel, 1981.

GNP higher than that of Ireland (a member of the EC), only marginally smaller than that of Italy, and not substantially inferior to that of the United Kingdom (see table 6). The same is essentially true of Greece, whose per capita GNP is only about $10 \%$ lower than Spain's and higher than that of Israel. No one can deny that the British or the Italian markets are of particular importance to Israel, despite their lack of purchasing power. In table 2, Israel's exports to Spain, Greece, Italy and Britain in 1980 are related to the latter's respective overall per capita GNPs. There is a striking difference between the two pairs of markets as outlets of Israeli exports: for example, were Italy to have the same population as Spain, Israeli exports to the former, ceteris paribus, would have come to about $\$ 187$ million, or five times as much as actual exports to Spain. Parallel calculations for the United Kingdom led to similar results (Israel's exports would have reached $\$ 311.5$ million, i.e. 8.5 times as much as to Spain). However, Israel's exports to Britain (in 1979 and 1980 ) included $17 \%$ of agricultural products and $23 \%$ of food products ( $40 \%$ of total exports); hence we could exclude such exports from our calculations for a better approximation of the prospects, assuming that Israel is a priori not going to export much food or agricultural produce to Spain. Israel's nonagricultural and non-food exports to Britain would have reached ceteris paribus about $\$ 186.9$ million in 1980 , had Britain had the same population as Spain, i.e. five times the actual amount of Israeli exports to Spain, a proportion roughly coinciding with that calculated for Italy.

In absolute terms, the difference between projected and actual 1980 Israeli industrial exports to Spain ${ }^{10}$ comes to more than $\$ 150$ million, assuming for the moment that GNP per capita are the same in Spain, Italy and the UK. A somewhat smaller figure, taking minor differences in standard of living into account, should be considered then. Note that when similar calculations are

10 Industrial exports essentially coincide with total exports, as Israel exported only $\$ 10.5$ million of agricultural and food products to Spain in 1980. 
undertaken for Greece, the results indicate no additional export potential for Israel.

The impact on Israeli imports from the Three is more difficult to assess, as we do not possess data on import demand elasticities and effective tariff protection rates by branches. A priori, however, we may suggest the following:

1. Most Israeli nominal rates presently range between $5 \%$ and $15 \%$, a much lower level than in Spain, Greece and Portugal. The outstanding and well-known exception is motor vehicles, an item of particular interest to Spanish exporters.

2. Israeli tariffs are particularly low for machinery, mineral products and chemicals and higher than average for manufactured products. Even so, for all these categories, tariff rates are on the average lower than Spain's; this was an obvious conclusion drawn by this author when tariff profiles for the two countries were established (not shown here).

3. Most present Israeli imports from the Three are in categories for which the Israeli tariff is below average or average (food, tobacco, mineral products, chemical products). Also the general rule is for these categories to be rather price-inelastic. Therefore the impact of the enlargement upon Israeli imports of these products would be minimal.

4. One may anticipate a non-negligible increase for the few manufactured imports from the Three, both because price elasticities tend to be higher and because Israeli tariff rates are also higher than average. Products of this kind would include paper, cotton fabrics, some textile products, glass, steel and cars. Observe that in the latter case, there is no competing domestic production. Therefore the enlargement will lead in that case to trade diversion, not trade creation, a factor that could add to the substantial welfare costs of having a discriminatory trade agreement with the EC.

\section{EC Aid and Cooperation Policies}

Israel has benefited from the EC financial aid since 1978. Two financial protocols have already been concluded for the periods 1977-1981 and $1981-1986$, for a total of 70 million EC units of account in the form of loans at market interest rates. Even if the amounts are reduced and loan conditions appear unfavorable, Israel is certainly interested in obtaining credit from as many sources as possible.

Upon enlargement, Israel's prospects of maintaining or enlarging her credit envelope are virtually nil, for various reasons:

1. EC countries with a per capita annual income similar to or lower than that of Israel (i.e. the Three and Ireland) may strongly object, quite independently of their political motivations. 
2. The geographic distribution of EC cooperation aid may be altered, i. e. in the direction of Latin America, once Spain and Portugal become full members. Most of the reduced foreign aid offered by Spain was formerly directed towards Latin American countries (e.g. 69\% of the total for the period 1969-1973).

3. The net cost of the enlargement will exert new pressures upon the EC budget. Not only must the supplementary costs of sustaining agricultural markets be taken into account, but also the issue of restructuring aid to the southern Mediterranean regions of the EC (Southern France, Italy and the Three). Enlargement or maintenance of EC credits is particularly awkward at a time when the EC has few alternative options to compensate Israel for the damage inflicted by the second enlargement on Israel's agriculture and processed food industry.

\section{Conclusions}

The global impact of the second enlargement upon Israel's balance of payments has been broken down into two main types of effects, namely:

a) trade diversion in favour of the three new member countries and against Israel;

b) trade creation favouring Israel and the Three, or trade diversion favouring Israel.

As we will see below, there is a third type of effect, i.e. reverse trade diversion against the Three and in favour of Israel.

As a rule, the three types of effects upon Israel will be much greater where the accession of Spain to the EC is concerned than when considering that of the other new member countries. This is due not only to the different economic dimensions of the three countries and the degree of export overlap with Israel, but also to the fact that Spain has lagged behind Greece (since 1961), Portugal (since 1972) and even Israel (since 1975) in obtaining preenlargement concessions from the EC.

Trade diversion in favour of Spain and against Israel in fruits and vegetables is an inescapable consequence of the enlargement. This is apparent in all the tests presented in the paper and has been abundantly exposed in the literature on the subject. ${ }^{11}$ The same holds for processed food.

For industry, the predicted institutional changes will lead the Three to expand industrial exports primarily at the expense of third countries trade with the EC, rather than Israel's (with minor exceptions). Paradoxically, Israel may be hurt in EFTA countries, particularly if the GSP treatment offered by them is made more restrictive or suppressed altogether in relation

11 See, e.g., I. Minerbi, "The Accession of Spain to the EEC and its Implications for Mediterranean Third Countries: The Israeli Case", Jerusalum J. Int'l Rels. 27 (1982). 
to Israeli exports. Fortunately for Israel, most imports considered "sensitive" by the EC (and highly restricted when originating in the Three before the accession date) do not compete with Israeli products, with the important exception of certain classes of textiles. These categories together with wood and paper manufactures, will be adversely affected by the second enlargement, because of Portugal and Greece as well as Spain.

Finally, although aid and trade flows are not one and the same thing, strictly speaking, we note that EC financial aid to Israel may also be shifted to other destinations. In this respect, even if Israel were prepared to accept financial aid as compensation for trade diversion (a possibility which Israel rejects at present), it appears that the EC would not select such an option, for a variety of reasons, as mentioned above.

Expanded trade between Israel and the Three derive both from net export expansion and from export diversion towards the new partner. In this respect, Israeli exporters have much to gain. For instance, additional Israeli exports to Spain are guess-estimated to be several times the present amount. The Israeli consumer of Spanish, Greek or Portuguese intermediary inputs will also benefit, especially with regards to paper products, cotton fabrics, some textile products, glass and steel. It is interesting to note that there is little import potential in final consumer goods, but for the remarkable exception of motor vehicles.

The impact of the enlargement should not be considered only in relation to fruit and vegetable exports, but rather with respect to Israel's Balance of Payments, which also includes both financial flows (like aid) and payments for services offered to or received from foreigners. One such service, incoming tourism, will benefit from the enlargement. In this sense, one may speak of "reserve trade diversion" in favour of Israel. Prices of food, labour and road transports will increase in the three new member countries, following accession; moreover, the Canary Islands may lose their customsfree zone status upon Spain's entry into the EC. Logically, price-conscious European tourists (particularly those traveling during the winter season) may well switch to other Mediterranean destinations, including Israel. Moreover, tourism to and from the three new member countries will also increase once trade and transportation channels are improved thanks to the enlargement; in any event, all this could be facilitated and improved even further, should Spain and Greece establish full diplomatic relations with Israel, something that according to some was linked to the enlargement. Unfortunately, this expectation has proven to be untrue in the case of Greece.

To sum up, the enlargement will undoubtedly lead to a clear-cut deterioration in Israel's agricultural trade and unilateral transfer balances, if no measures are taken by the EC authorities. The situation is far more complex for industrial trade as a whole or for services. Thus, quantitatively speaking, it is rather difficult to assess the net impact of the enlargement upon Israel's balance of payments. 


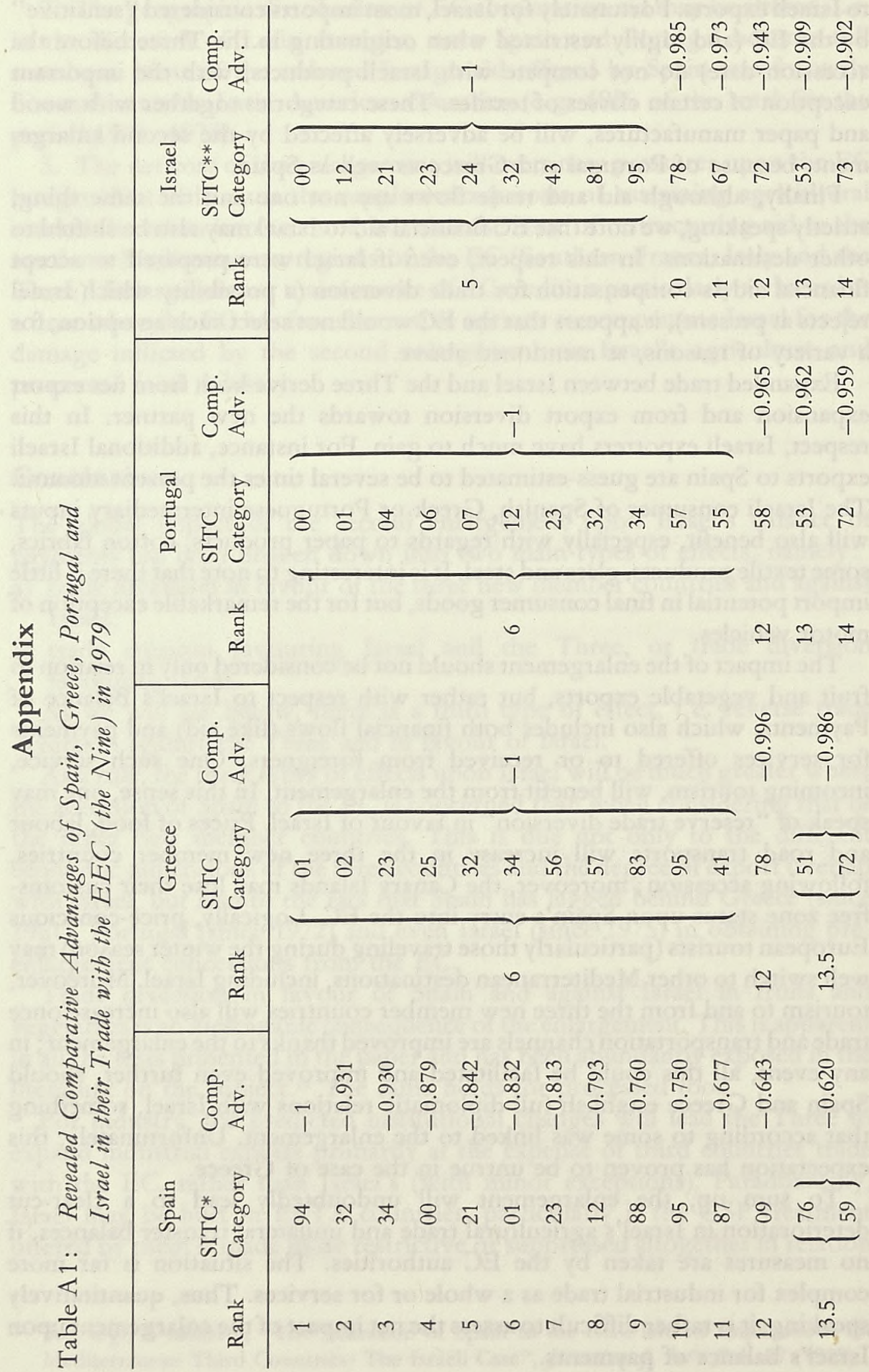




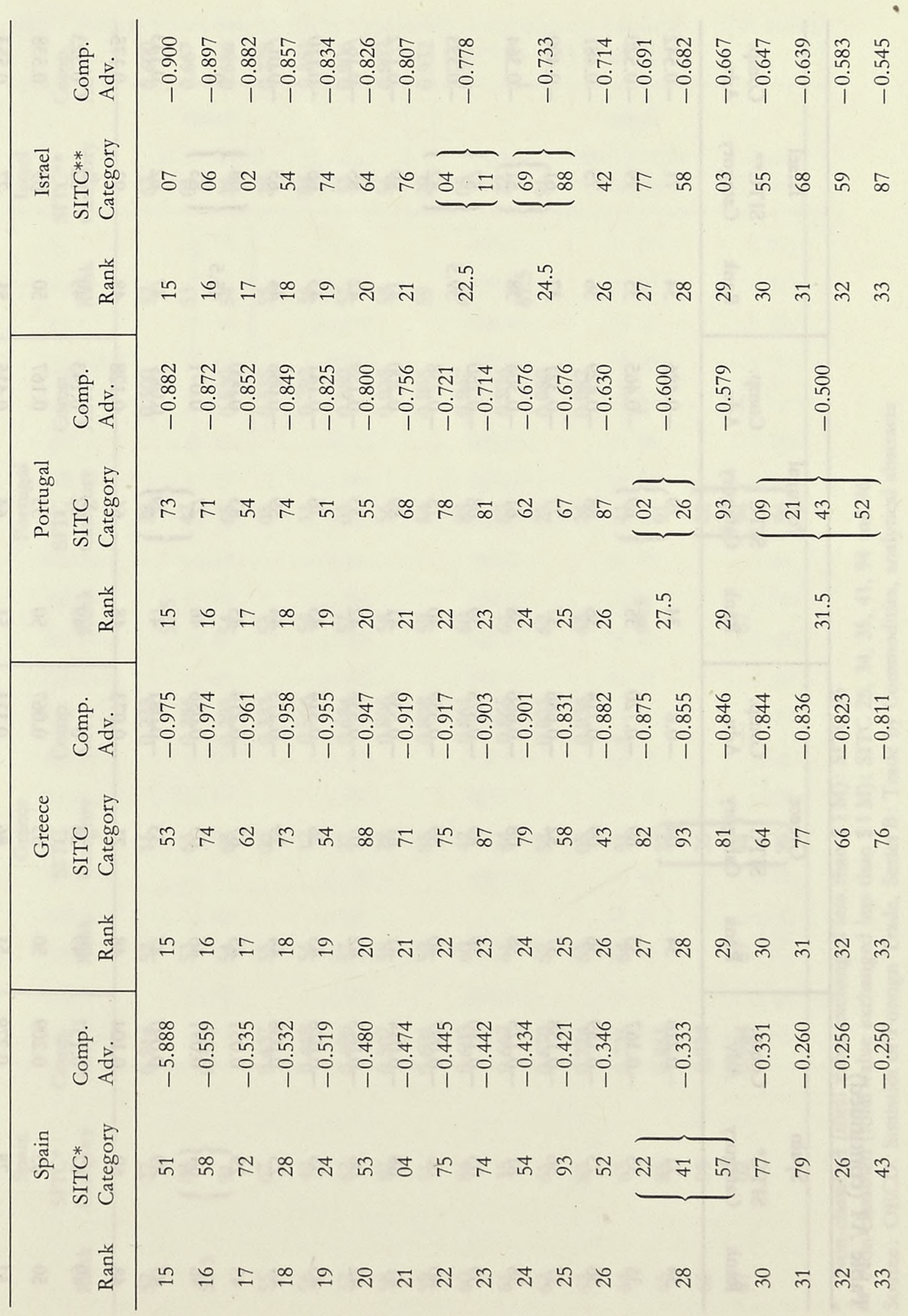




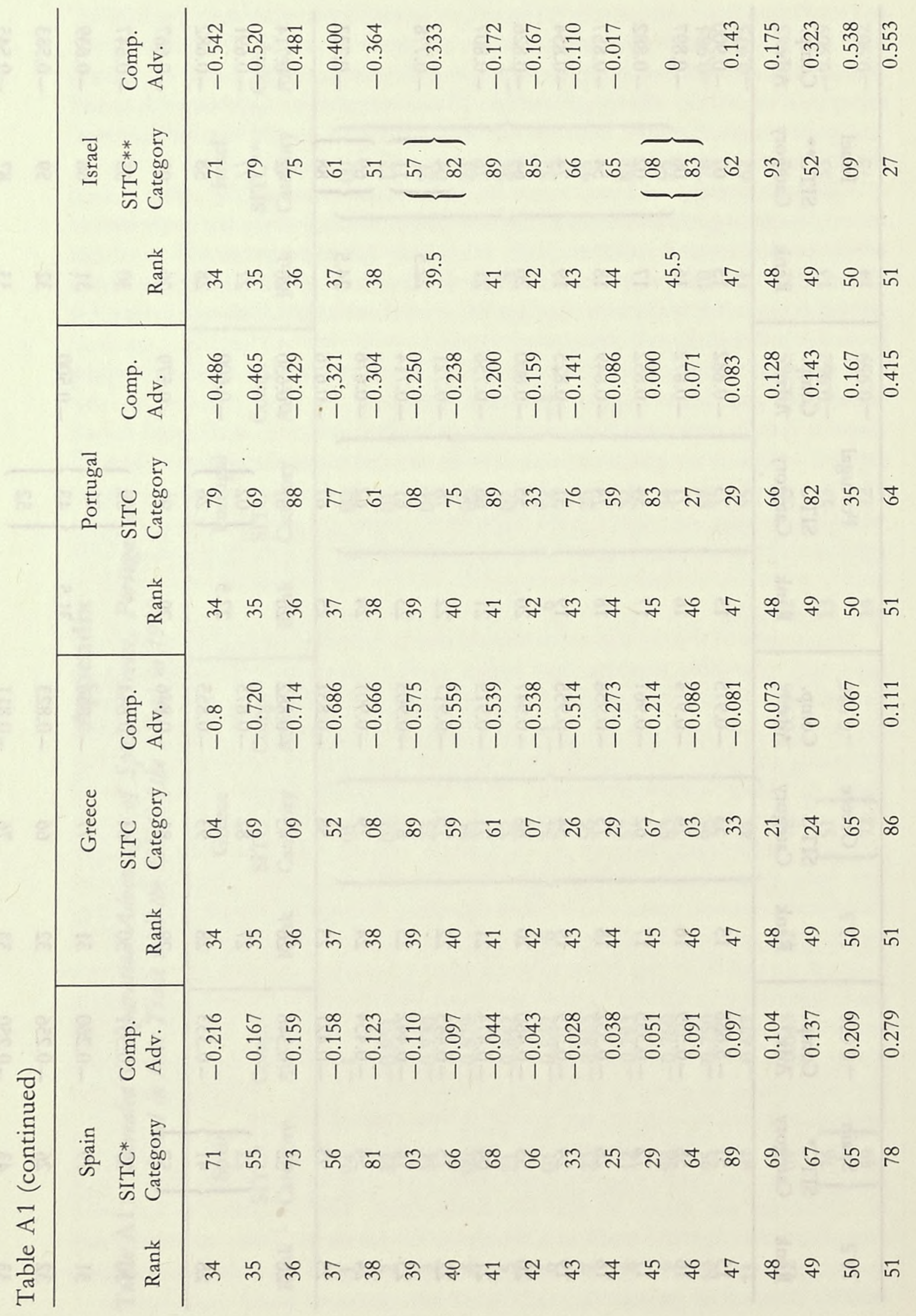




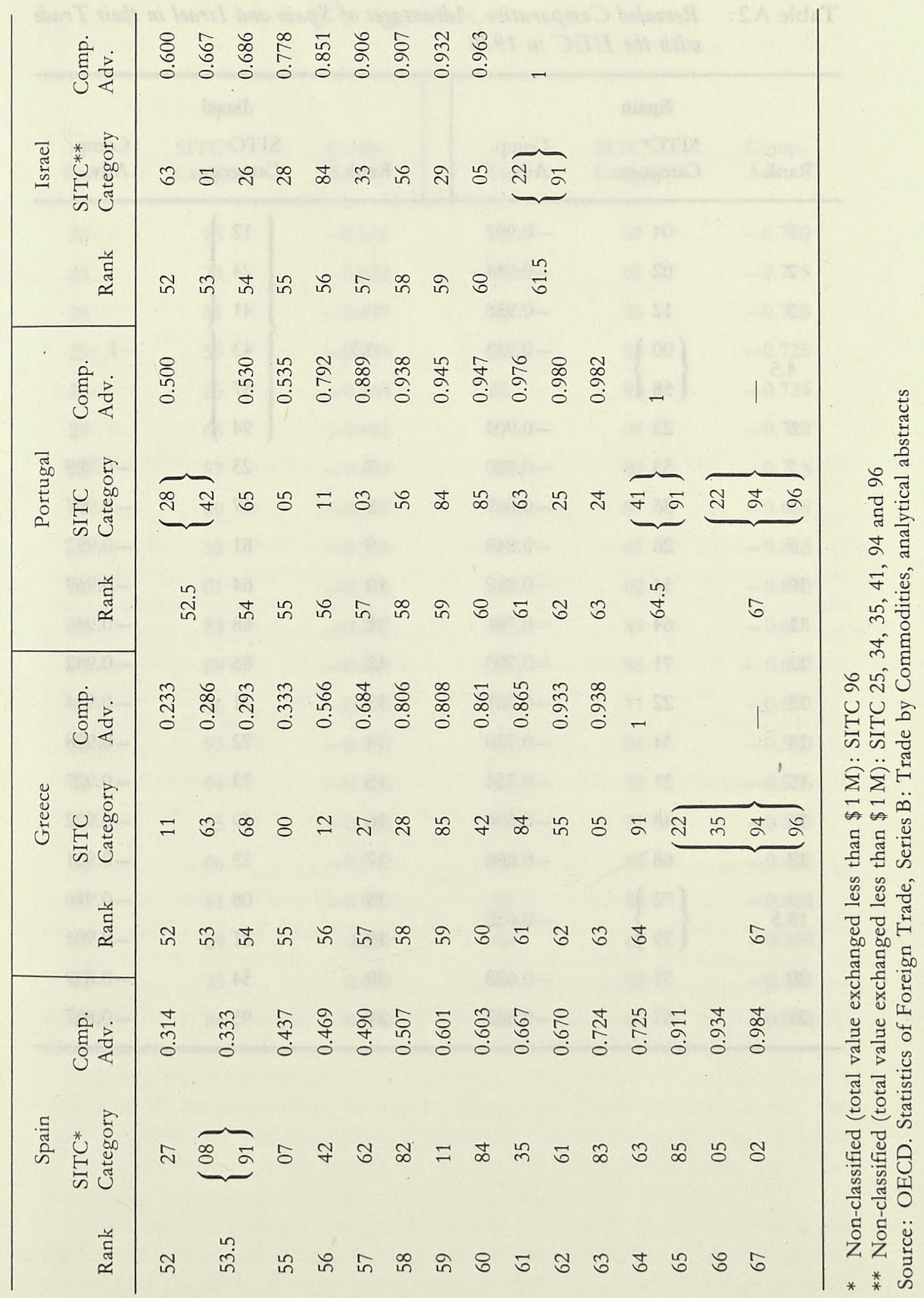


Table A2: Revealed Comparative Advantages of Spain and Israel in their Trade with the EEC in 1970

\begin{tabular}{|c|c|c|c|c|c|}
\hline Rank & $\begin{array}{l}\quad \text { Spain } \\
\text { SITC* } \\
\text { Category }\end{array}$ & $\begin{array}{l}\text { Comp. } \\
\text { Adv. }\end{array}$ & Rank & $\begin{array}{l}\quad \text { Israel } \\
\text { SITC } \\
\text { Category }\end{array}$ & $\begin{array}{l}\text { Comp. } \\
\text { Adv. }\end{array}$ \\
\hline 1 & 04 & -0.997 & & 12 & \\
\hline 2 & 02 & -0.944 & & 24 & \\
\hline 3 & 12 & -0.936 & & 41 & \\
\hline 4.5 & $\left\{\begin{array}{l}00 \\
58\end{array}\right\}$ & -0.925 & 3.5 & $\begin{array}{l}43 \\
57\end{array}$ & -1 \\
\hline 6 & 23 & -0.904 & , & 94 & \\
\hline 7 & 53 & -0.880 & 7 & 23 & -0.999 \\
\hline 8 & 86 & -0.869 & 8 & 67 & -0.997 \\
\hline 9 & 26 & -0.848 & 9 & 81 & -0.992 \\
\hline 10 & 54 & -0.812 & 10 & 64 & -0.969 \\
\hline 11 & 64 & -0.791 & 11 & 68 & -0.946 \\
\hline 12 & 71 & -0.790 & 12 & 86 & -0.942 \\
\hline 13 & 22 & -0.761 & 13 & 71 & -0.934 \\
\hline 14 & 34 & -0.750 & 14 & 72 & -0.928 \\
\hline $15^{\prime}$ & 21 & -0.734 & 15 & 73 & -0.927 \\
\hline 16 & 43 & -0.684 & 16 & 69 & -0.922 \\
\hline 17 & 68 & -0.666 & 17 & 53 & -0.921 \\
\hline \multirow{2}{*}{18.5} & $\{72\}$ & & 18 & 08 & -0.916 \\
\hline & $\{59\}$ & -0.650 & 19 & 21 & -0.901 \\
\hline 20 & 51 & -0.628 & 20 & 54 & -0.899 \\
\hline 21 & 67 & -0.562 & 21 & 95 & -0.887 \\
\hline
\end{tabular}




\begin{tabular}{|c|c|c|c|c|c|}
\hline \multicolumn{3}{|c|}{ Spain } & \multicolumn{3}{|c|}{ Israel } \\
\hline Rank & $\begin{array}{l}\text { SITC* } \\
\text { Category }\end{array}$ & $\begin{array}{l}\text { Comp. } \\
\text { Adv. }\end{array}$ & Rank & $\begin{array}{l}\text { SITC } \\
\text { Category }\end{array}$ & $\begin{array}{l}\text { Comp. } \\
\text { Adv. }\end{array}$ \\
\hline 22 & 95 & -0.536 & 22 & 59 & -0.790 \\
\hline 23 & 73 & -0.528 & 23 & 03 & -0.775 \\
\hline 24 & 41 & -0.497 & 24 & 55 & -0.726 \\
\hline 25 & 55 & -0.490 & 25 & 58 & -0.725 \\
\hline 26 & 25 & -0.463 & 26 & 93 & -0.724 \\
\hline 27 & 66 & -0.412 & 27 & 04 & -0.722 \\
\hline 28 & 57 & -0.404 & 28 & 82 & -0.715 \\
\hline 29 & 69 & -0.367 & 29 & 07 & -0.668 \\
\hline 30 & 52 & -0.356 & 30 & 65 & -0.645 \\
\hline 31 & 01 & -0.318 & 31. & 02 & -0.630 \\
\hline 32 & 83 & -0.257 & 32 & 89 & -0.611 \\
\hline 33 & 89 & -0.245 & 33 & 85 & -0.607 \\
\hline 34 & 56 & -0.198 & 34 & 11 & -0.597 \\
\hline 35 & 93 & -0.178 & 35 & 06 & -0.570 \\
\hline 36 & 94 & -0.156 & 36 & 32 & -0.556 \\
\hline 37 & 65 & -0.135 & 37 & 51 & -0.553 \\
\hline 36 & 06 & -0.042 & 38 & 66 & -0.497 \\
\hline 39 & 81 & -0.037 & 39 & 83 & -0.482 \\
\hline 40 & 29 & 0.059 & 40 & 61 & -0.339 \\
\hline 41 & 33 & 0.063 & 41 & 09 & -0.101 \\
\hline 42 & 84 & 0.092 & 42 & 62 & -0.083 \\
\hline
\end{tabular}


Table A2 (continued)

\begin{tabular}{|c|c|c|c|c|c|}
\hline \multicolumn{3}{|c|}{ Spain } & \multicolumn{3}{|c|}{ Israel } \\
\hline Rank & $\begin{array}{l}\text { SITC* } \\
\text { Category }\end{array}$ & $\begin{array}{l}\text { Comp. } \\
\text { Adv. }\end{array}$ & Rank & $\begin{array}{l}\text { SITC** } \\
\text { Category }\end{array}$ & $\begin{array}{l}\text { Comp. } \\
\text { Adv. }\end{array}$ \\
\hline 43 & 91 & 0.109 & 43 & 26 & -0.076 \\
\hline 44 & 24 & 0.169 & 44 & 27 & 0.157 \\
\hline 45 & 28 & 0.185 & 45 & 91 & 0.274 \\
\hline 46 & 61 & 0.247 & 46 & 01 & 0.342 \\
\hline 47 & 09 & 0.250 & 47 & 42 & 0.668 \\
\hline 48 & 32 & 0.266 & 48 & 29 & 0.704 \\
\hline 49 & 82 & 0.284 & 49 & 84 & 0.754 \\
\hline 50 & 07 & 0.371 & 50 & 63 & 0.771 \\
\hline 51 & 27 & 0.396 & 51 & 00 & 0.877 \\
\hline 52 & 08 & 0.435 & 52 & 33 & 0.895 \\
\hline 53 & 62 & 0.450 & 53 & 56 & 0.912 \\
\hline 54 & 03 & 0.608 & 54 & 28 & 0.924 \\
\hline 55 & 11 & 0.637 & 55 & 22 & 0.974 \\
\hline 56 & 63 & 0.742 & 56 & 05 & 0.977 \\
\hline 57 & 85 & 0.861 & 57 & 25 & 0.982 \\
\hline 58 & 42 & 0.939 & 58 & 96 & 1 \\
\hline 59 & 35 & 0.942 & $350.0+$ & 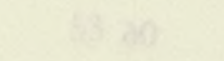 & $x-2 x^{2}$ \\
\hline 60 & 05 & 0.953 & 5800- & 10 & 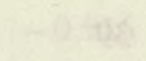 \\
\hline
\end{tabular}

* Non-classified: SITC 96

** Non-classified: SITC 34, 35, 52

Source: See Table A1 (Aggregate values have been computed for trade with The Six plus the UK, Ireland and Denmark). 


\section{The EEC Trade Policies in Manufactures, the Mediterranean Market}

Access Problems and Israel Implications of the Second Enlargement

\section{Rolf J. LANGHAMMER}

\section{Introduction: Discrimination as the Core of EEC Trade Policies}

The EEC is, unlike other major trade entities such as the US or Japan, a group of countries which maintain special trade relations with one another. In its ultimate form, the customs union, the relations imply a discrimination against non-members by the full rate of the external tariff. This $100 \%$ discrimination was allowed as the only major deviation from the GATT principle of nondiscrimination mainly because it was assumed to stimulate world trade if the intra-union trade captured a relatively large part of world trade. The discrimination element would become weaker and the trade liberalization element stronger along with rising shares of the customs union in world trade. If, furthermore, the external tariff would be reduced simultaneously in reciprocal tariff-cutting rounds with non-menbers, concern about negative allocation effects of discrimination should shrink.

However, with regard to the EEC this optimistic view of a customs union is far from reality. There are at least four caveats which cloud this view.

First, EEC internal trade accounts for only about $15 \%$ of world trade $(18 \%$ of non-fuel world trade). If the trade with former EFTA countries, most of which is free of duties, is included, this share does not exceed $22 \%$. Thus, the discrimination argument seems to matter more than the internal trade liberalization aspects.

Second, while the last two GAT'T tariff cutting rounds (Kennedy Round and Tokyo Round) have helped to lower the EEC external tariff, the agricultural sector remained highly protected. Furthermore, barriers to entry in general shifted from tariffs to non-tariff barriers so that the EEC protection level against third-country suppliers is now higher.

Third, conflicts between more liberal and more restrictive members of the EEC have intensified. These disputes have been relaxed by taking recourse to art. 115 of the EEC Treaty (temporary exemption of free internal trade in 
order to make national safeguards effective). The number of cases in which art. 115 has been applied has grown rapidly during the last years ${ }^{1}$. The national safeguard measures imply that within the EEC there are countryspecific deviations from a common average nominal protection level against third countries in both directions.

Fourth, the EEC does not only discriminate against third countries but also between individual third countries. The focus of this trade policy has been the implementation of special trade relations, in short, the establishment of a "pyramid of privilege" which divides the "sheep" (the ACP countries for instance) from the "goats" (the NICs) ${ }^{2}$. It is obvious that this discrimination has its roots in the maintenance of reciprocal trade preferences with former French and Belgian colonies after they became independent (in the Yaoundé agreements) ${ }^{3}$. These preferences became non-reciprocal in the Lomé conventions after long disputes with the US. The preferences for Mediterranean countries, regardless of whether they have been reciprocal or non-reciprocal, represent the second large bloc of special relations. Both ACP and Mediterranean preferences partly overlap with preferences conceded to the Group of 77 members, the Generalized System of Preferences.

The repeated trade policy disputes between the EEC and the US in the past illustrate the basic policy perceptions of special relations from two views. By discrimination between third countries the EEC erodes the transparency and predictability of the international trading system to the detriment of those relatively weak partners, viz., the developing countries, which have the greatest interest in an unconditional, non-discriminatory and transparent trading system ${ }^{4}$. According to this view, which is vigorously supported by the US, the EEC impose arbitrary "divide and rule" policies upon developing countries, that is to treat unequals unequally.

The EEC on the other side justifies its increasing deviation from an unconditional MFN treatment on grounds of justice. The equal treatment of unequals would in its view be unjust to those countries which suffer from comparative disadvantages in acquiring technological, commercial and

1 Appendix table 1 provides an EEC country-third country matrix of applications of art. 115 during the first nine months of 1983 . The table may serve as an indicator of more liberal and more restrictive patterns.

2 For an elaboration of the economic rationale of differentiation see Wolf, "Dividing the 'Sheep' from the 'Goats': Protectionism, the European Community and the Third World", Conference on the EEC and the World Economy, National Committee for the Study of Int'l Affairs, The Royal Irish Academy, Dublin, 17-18 Nov. 1983 (not published).

3 The GATT allowed for special trade relations between metropolitan countries and colonies.

4 T. N. Srinivasan, "Why Developing Countries Should Participate in the GATT System", 5 World Econ. 85 (1982). 
managerial know-how ${ }^{5}$. In view of the recent developments in the EEC and US trade policy towards developing countries, however, criticisms against universal and the demands for uniform rules seem to be well-based. The GSP for example which by its nature should be non-reciprocal, generalized and non-discriminatory, has turned to be just the opposite. It is partly reciprocal for it links preferential treatment in sensitive textiles with self-restraining export agreements. It is not generalized for it excludes certain items and puts rigid breaks to duty-free entry on others, and it is discriminatory for it excludes countries such as Taiwain and Israel who are not members of the Group of 77 .

In short, the above four caveats provide strong evidence for characterizing the EEC trade policy as discriminatory against third countries, regardless of whether they are GATT members or not.

In addition, EEC trade policy has become increasingly controversial among EEC members depending on their susceptibility to sectoral domestic protectionist pressures. It is indisputable that the Mediterranean trade preferences will be affected by these characteristics.

\section{The "Sensitivity" of the Mediterranean Export Supply in Manufactures}

The degree of vulnerability of the Mediterranean countries' export supply of manufactures (including processed agricultural products) to the EEC protectionist measures depends on two factors. First, the importance of products in the total supply of goods classified by the Community as "sensitive" and hence subjected to closed-ended market access (or to permanent surveillance in the case of "semi-sensitive" products). Second, the direction of the Mediterranean countries' sensitive and semi-sensitive exports either to more liberal or to more protectionist EEC members. With regard to the first criterion, the breakdown of Mediterranean exports into various sensitivity categories for GSP-eligible products may serve as an indicator (table 1$)^{6}$.

5 P. Streeten, "What New International Economic Order?" in Ordnungspolitische Fragen zum Nord-Süd-Konflikt (U. E. Simonis ed. 1983) has coined the term uniform (or general) versus universal rules in international trade: uniform rules like the MFN principle are simple but unfair in a world of unequals, whereas universal rules (or specific rules) are complicated (like non-reciprocal preferences) but fair because they pay attention to the varying characteristics of different countries.

6 The data refer to 1979. This year was the last one for which the Statistical Office of the Community compiled the complete list of GSP-eligible imports from those countries which were excluded from either special or generalized unilateral preferences (as for example the applicant countries, Israel and Taiwan). The absolute figures may therefore be outdated whereas the export composition may still allow for conclusions on the susceptibility of Mediterranean exports against quantitative restrictions. 


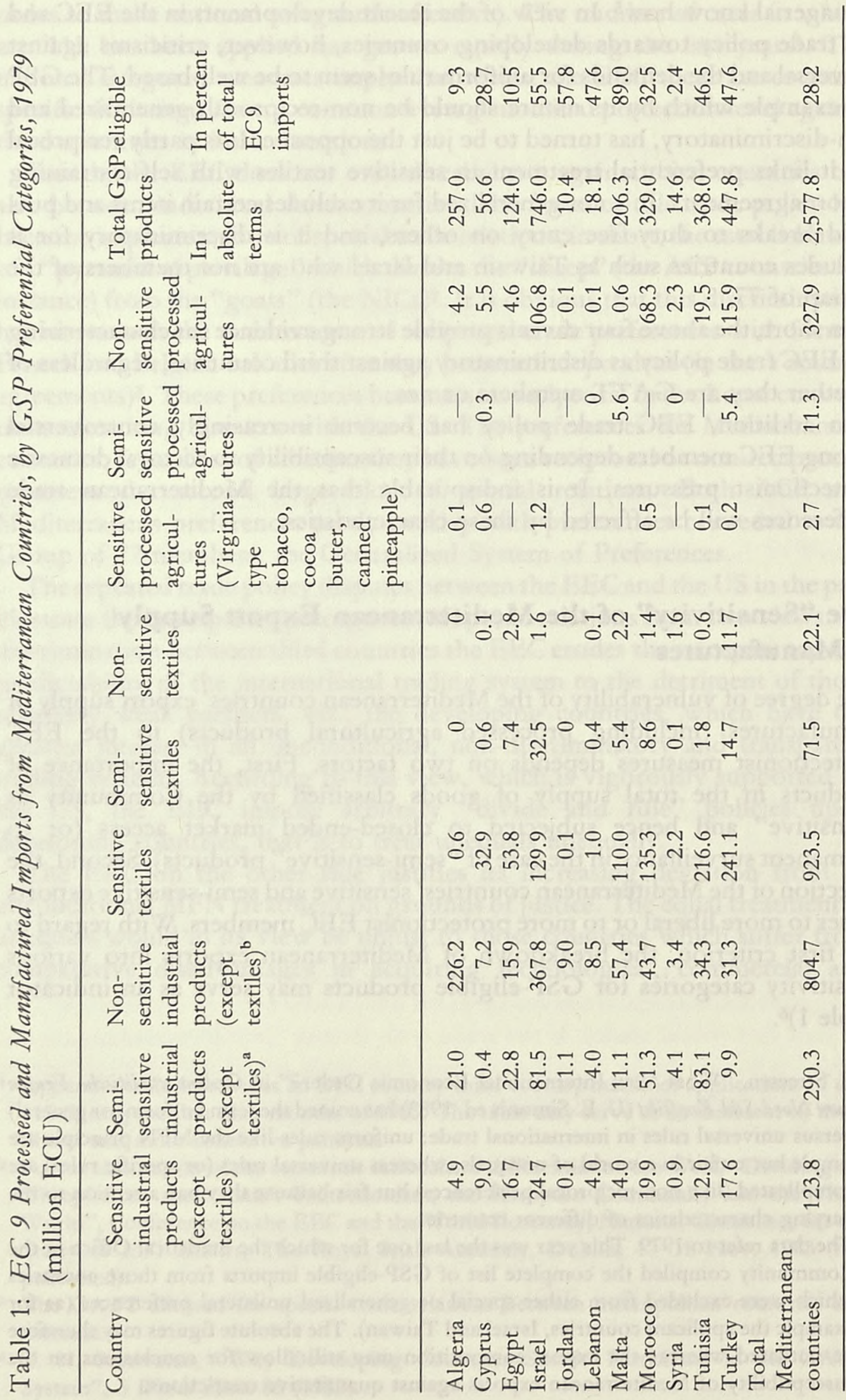




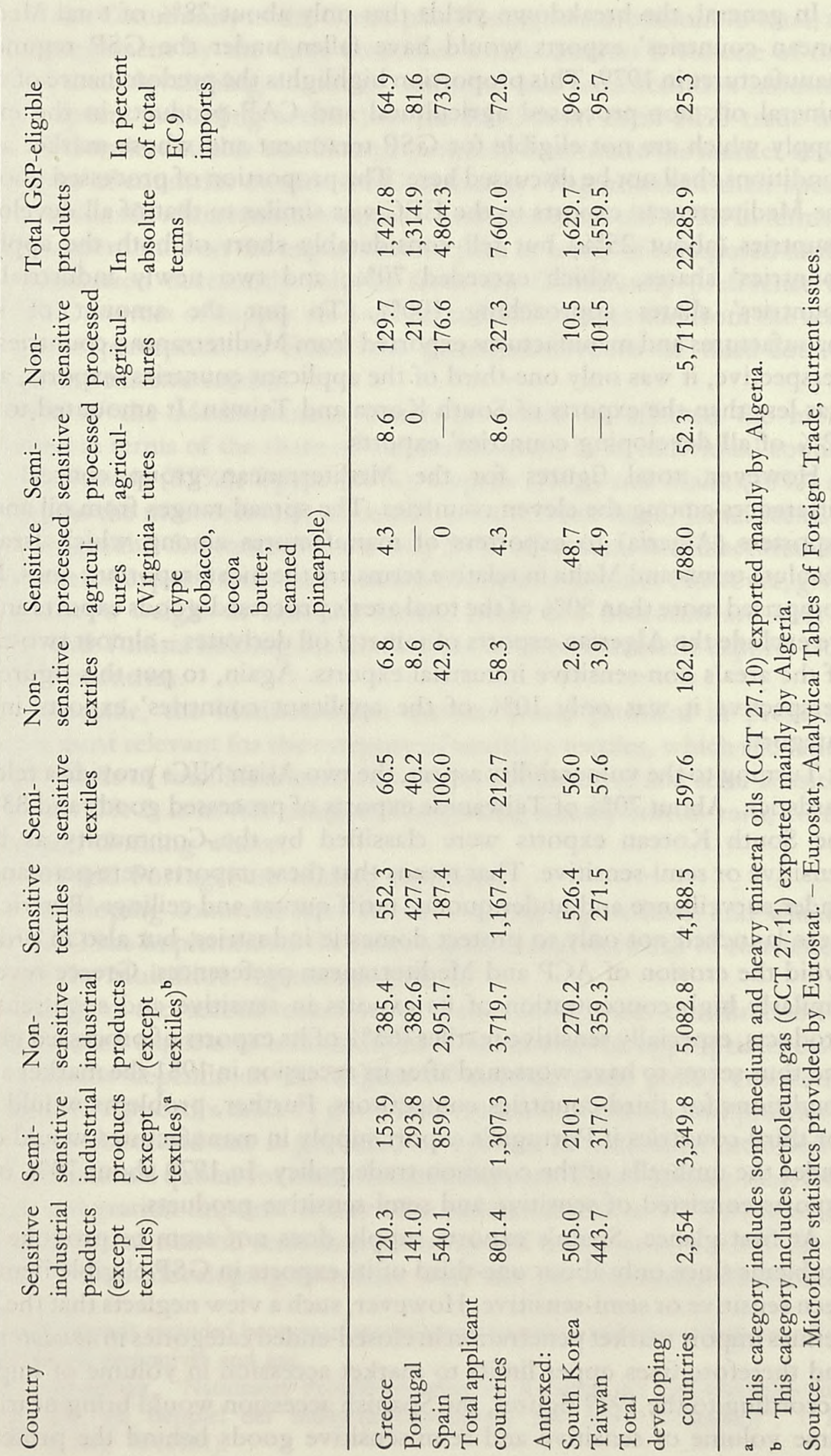


In general, the breakdown yields that only about $28 \%$ of total Mediterranean countries' exports would have fallen under the GSP regime for manufactures in 1979. This proportion highlights the predominance of crude mineral oil, non-processed agricultural and CAP products in the export supply which are not eligible for GSP treatment and whose market access conditions shall not be discussed here. The proportion of processed goods in the Mediterranean exports to the EEC was similar to that of all developing countries (about $25 \%$ ) but fell considerably short of both the applicant countries' shares, which exceeded $70 \%$, and two newly industrializing countries' shares approaching $100 \%$. To put the amount of semimanufactures and manufactures exported from Mediterranean countries into perspective, it was only one-third of the applicant countries' exports, and it was less than the exports of South Korea and Taiwan. It amounted to only $12 \%$ of all developing countries' exports.

However, total figures for the Mediterranean group conceal large differences among the eleven countries. The spread ranges from oil and gas exporters (Algeria) to exporters of manufactures among which Israel in absolute terms and Malta in relative terms are the most important ones. Israel comprised more than $50 \%$ of the total area's processed-goods exports and - if we exclude the Algerian exports of mineral oil derivates - almost two-thirds of the area's non-sensitive industrial exports. Again, to put this figure into perspective it was only $10 \%$ of the applicant countries' exports in this category.

Turning to the vulnerability aspect, the two Asian NICs provide a relevant yardstick. About $70 \%$ of Taiwanese exports of processed goods and $83 \%$ of the South Korean exports were classified by the Community as being sensitive or semi-sensitive. That means that these imports were permanently under surveillance and under quotas, tariff quotas and ceilings. Restrictions were launched not only to protect domestic industries, but also in order to avoid the erosion of ACP and Mediterranean preferences. Greece reveals a similarly high concentration of its exports in sensitive and semi-sensitive products, especially sensitive textiles ( $63 \%$ of its exports of processed goods) and thus seems to have worsened after its accession in 1981 the market access conditions for third-countries competitors. Further, problems would arise for third-countries if Portugal's export supply in manufactures would come under the umbrella of the common trade policy. In 1979 about $70 \%$ of her exports consisted of sensitive and semi-sensitive products.

At first glance, Spain's exports supply does not seem to provoke such problems since only about one-third of its exports in GSP eligible items has been sensitive or semi-sensitive. However, such a view neglects that the EEC defines import market penetration in closed-ended categories in absolute terms and therefore fixes upper limits to market accession in volume of imports. According to the 1979 figures, the Spanish accession would bring nearly the same volume of sensitive and semi-sensitive goods behind the protection 
walls of the Community as the Greek plus Portuguese accession. In total, the EEC enlargement by the three countries would convert a volume of onethird of total developing countries' sensitive and semi-sensitive industrial goods exports (including textiles) to the EEC from extra-EEC trade into intra-EEC trade, and this would most probably deteriorate the market-access conditions of countries outside the Community. Regardless of their special trade relations Mediterranean countries' preferences would suffer in terms of stricter upper limits on the exports rather than in terms of reimposed tariffs. This conclusion necessarily follows from the Community preference for intra-EEC sources of supply vis-à-vis extra-EEC sources and from the zerosum game perception to freeze the penetration ratios of third-country imports in sensitive sectors.

Which of the Mediterranean countries would be affected the most? Measured in terms of the share of vulnerable items in an individual country exports, Tunisia (85\%), Egypt (81\%), Cyprus (75\%) and Malta (70\%) are likely to be the most seriously affected ${ }^{7}$. On the other hand, Israel seems to have less ground for concern since only $36 \%$ of its semi-manufactured and manufactured exports were semi-sensitive of sensitive items. However, given the country's weight in absolute terms, Israel and Morocco are next to Turkey and Tunisia holding the lion's share of sensitive textile exports from the GSP countries.

To conclude, the Mediterranean market access problem in processed goods is most relevant for the category of sensitive textiles, which accounted for two-thirds of total Mediterranean exports of sensitive and semi-sensitive goods in 1979. It is in this category comprising mainly cotton yarn, cotton fabrics and clothing where

- Greece and Portugal are leading suppliers;

- the developing countries have found a strong export base; and where

- the EEC has implemented the most sophisticated network of restrictions through the Multifibre Agreement (MFA)

Turning to the second criterion of vulnerability, i.e. the direction of Mediterranean exports to individual EEC members, the appropriateness of this indicator depends on the degree of national trade policy autonomy. Article 115 (Appendix table 1) gives first evidence of theory and practice of autonomy. A second one is provided by options of individual members to maintain national quotas for manufactured imports. These options stem from the pre-integration imports. It has been estimated that in $197821 \%$ of the EEC imports of non-oil semi-manufactures and manufactures (CCT 25-99 minus 27) from developing countries were not yet commonly liberalized ${ }^{8}$;

7 Algeria again is excluded because of special market access conditions which prevail for mineral oil derivatives and gas.

8 R. Langhammer, "Nationaler Protektionismus im Rahmen der EG-Handelspolitik, dargestellt am Beispiel der Industriegüterimporte aus ASEAN-Ländern", 1 Die Weltwirtschaft 74 (1981). 
that means that at least one member country could restrict its imports by a national quota. France and the UK were the members which overproportionately embarked upon national autonomy (10.8 and $12.3 \%$, respectively, of their individual imports) in contrast to West Germany $(0.1 \%)$ and the Benelux countries $(0.6 \%)$.

To summarize national trade policy autonomy, EEC members do have options either to claim for individual safeguard measures or to apply national quotas if they do not already exist. It is the experience of the trade policies in operation that some EEC members did frequently use their options whereas other members did not.

Thus, it matters to which EEC sub-market third-country exports are traditionally directed through established trade links. Especially in sensitive products, where each EEC member country imposes its own quota, the concept of a customs union in which products should be able to move freely has become a fiction: without controls of intra-EEC trade the member quotas cannot be made effective if some members are more liberal than others. Stricter controls, as a recent report of the French Conseil Economique et Social on the situation of the French textile industry states, are justified because

... les tentatives d'organisation des échanges internationaux se sont en effet heurtées très vite aux difficultés d'application tenant à la souverainté des Etats et aux comportements jalousement autonomes des différents services de douane (même au niveau de la CEE). Il apparaît que trop souvent la France s'efforce de respecter des normes internationales dont les données sont faussées par des partenaires qui, eux, ne les respectent guère?

Even if one analyses the regional export patterns of all developing countries, applicant countries, and the Mediterranean countries on an aggregate level, differences do emerge (table 2). Whereas the three groups run parallel in directing about $40 \%$ of their sensitive EEC textile exports to the West German market, the applicant countries (due to strong Portuguese trade links with the UK) and the developing countries are much more affiliated with the UK market than are the Mediterranean countries. On the other hand, the Italian market and also the French and Benelux markets are more relevant absorbers of Mediterranean textiles than is the UK market.

At a disaggregated level, however, this pattern becomes diffuse. Among the larger exporters, Cyprus and Israel ship the largest part of their textiles to the UK and thus strongly overlap with Portugal. On the other hand, Tunisia, Turkey and Morocco are linked to the West German market with Greece as the competitor from the applicant side. Besides the two largest sub-markets, there are notable textile exports of Morocco to France and Turkish exports to Italy which strongly deviate from the aggregate pattern.

9 Conseil Econ. et Soc., 1982, p. 242. 
Table 2: Direction of Mediterranean and Applicant Countries' Exports of Sensitive Textiles to EEC Member Markets, 1979

(Shares in Total EC Imports of Sensitive Textiles)

\begin{tabular}{|c|c|c|c|c|c|c|c|}
\hline & W. Germany & France & Italy & Benelux & UK & Ireland & Denmark \\
\hline Algeria & 83.3 & 16.7 & - & - & - & - & - \\
\hline Cyprus & 20.4 & 0.9 & 0.6 & 0.7 & 64.7 & 0.6 & 5.8 \\
\hline Egypt & 31.6 & 14.1 & 12.4 & 21.2 & 16.2 & 0.4 & 4.1 \\
\hline Israel & 35.3 & 6.8 & 0.4 & 11.5 & 40.8 & 3.7 & 1.5 \\
\hline Jordan & - & - & - & - & 100.0 & - & - \\
\hline Lebanon & 10.0 & 10.0 & 30.0 & 40.0 & 10.0 & - & - \\
\hline Malta & 61.6 & 2.7 & 3.9 & 16.1 & 12.8 & 1.3 & 1.6 \\
\hline Morocco & 42.3 & 49.2 & 0.4 & 7.0 & 0.9 & - & 0.2 \\
\hline Syria & 59.1 & 9.1 & 22.7 & - & 9.1 & - & - \\
\hline Tunisia & 42.1 & 23.2 & 5.2 & 28.1 & 1.2 & - & 0.2 \\
\hline Turkey & 41.1 & 6.2 & 26.9 & 17.8 & 7.1 & 0.5 & 0.4 \\
\hline $\begin{array}{l}\text { Total } \\
\text { Mediterranean } \\
\text { countries }\end{array}$ & 41.8 & 16.4 & 9.7 & 17.3 & 12.8 & 0.9 & 1.1 \\
\hline Greece & 67.7 & $8: 8$ & 6.1 & 12.0 & 3.3 & 0.1 & 2.0 \\
\hline Portugal & 15.0 & 15.0 & 1.9 & 10.8 & 49.5 & 1.4 & 6.4 \\
\hline Spain & 24.2 & 33.4 & 2.7 & 27.2 & 8.9 & 0.8 & 2.8 \\
\hline $\begin{array}{l}\text { Total } \\
\text { applicant } \\
\text { countries }\end{array}$ & 41.4 & 15.0 & 4.0 & 14.0 & 21.1 & 0.7 & 3.8 \\
\hline $\begin{array}{l}\text { Total } \\
\text { development } \\
\text { countries }\end{array}$ & 42.5 & 10.8 & 5.4 & 12.0 & 26.0 & 0.5 & 2.8 \\
\hline
\end{tabular}

Source: See table 1.

With regard to market access, the MFA involves the tendency to reinforce bilateral trade links through additional national quotas under outward processing regimes of the Mediterranean countries. Mainly clothing exports of Tunisia, Morocco, Turkey, Cyprus and Malta to the West German market are affected by these regimes, which basically allow for the assembling of fabrics originating in EEC countries for finished goods in Mediterranean countries and for exporting the finished goods back to the EEC country 


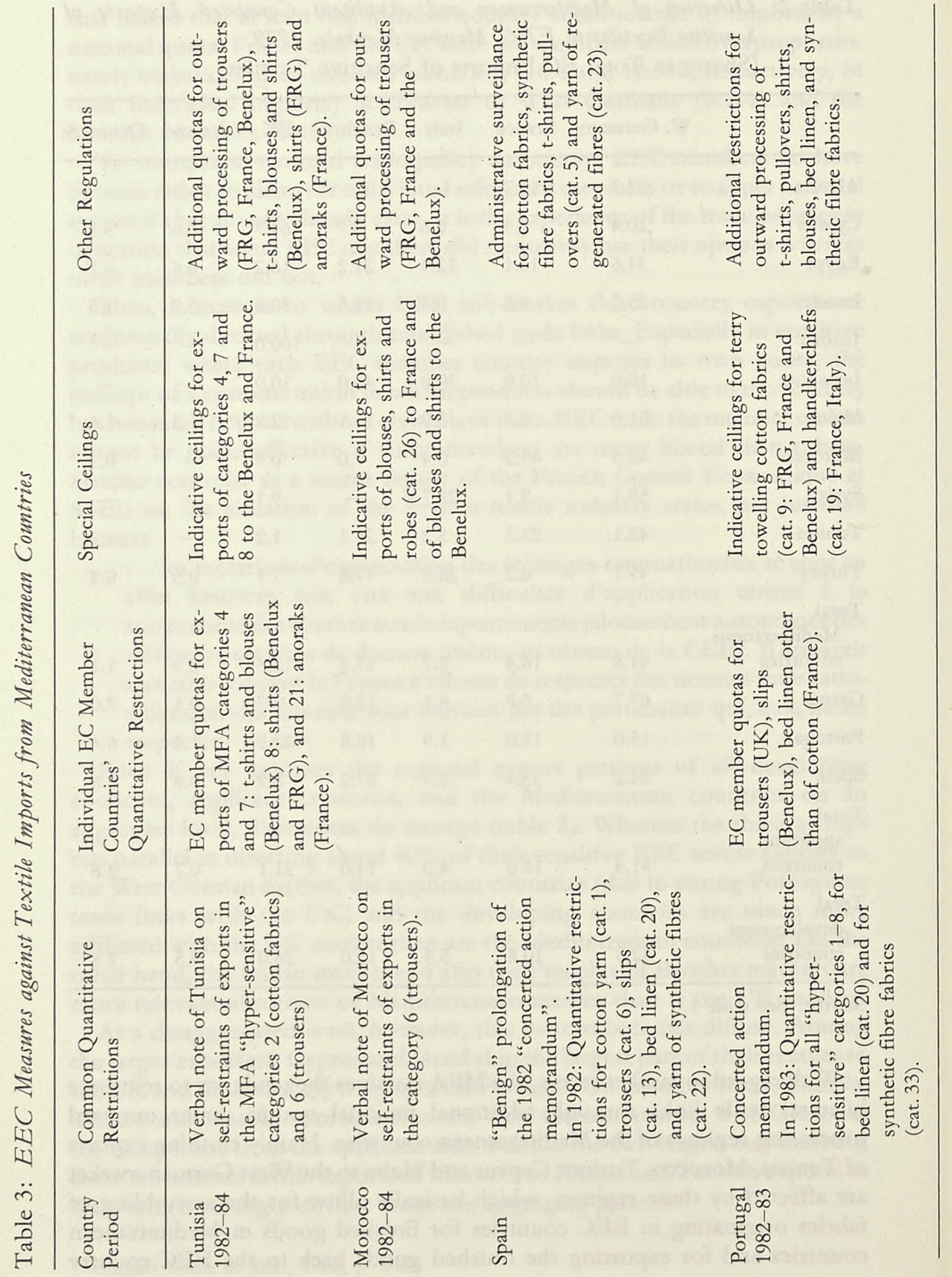




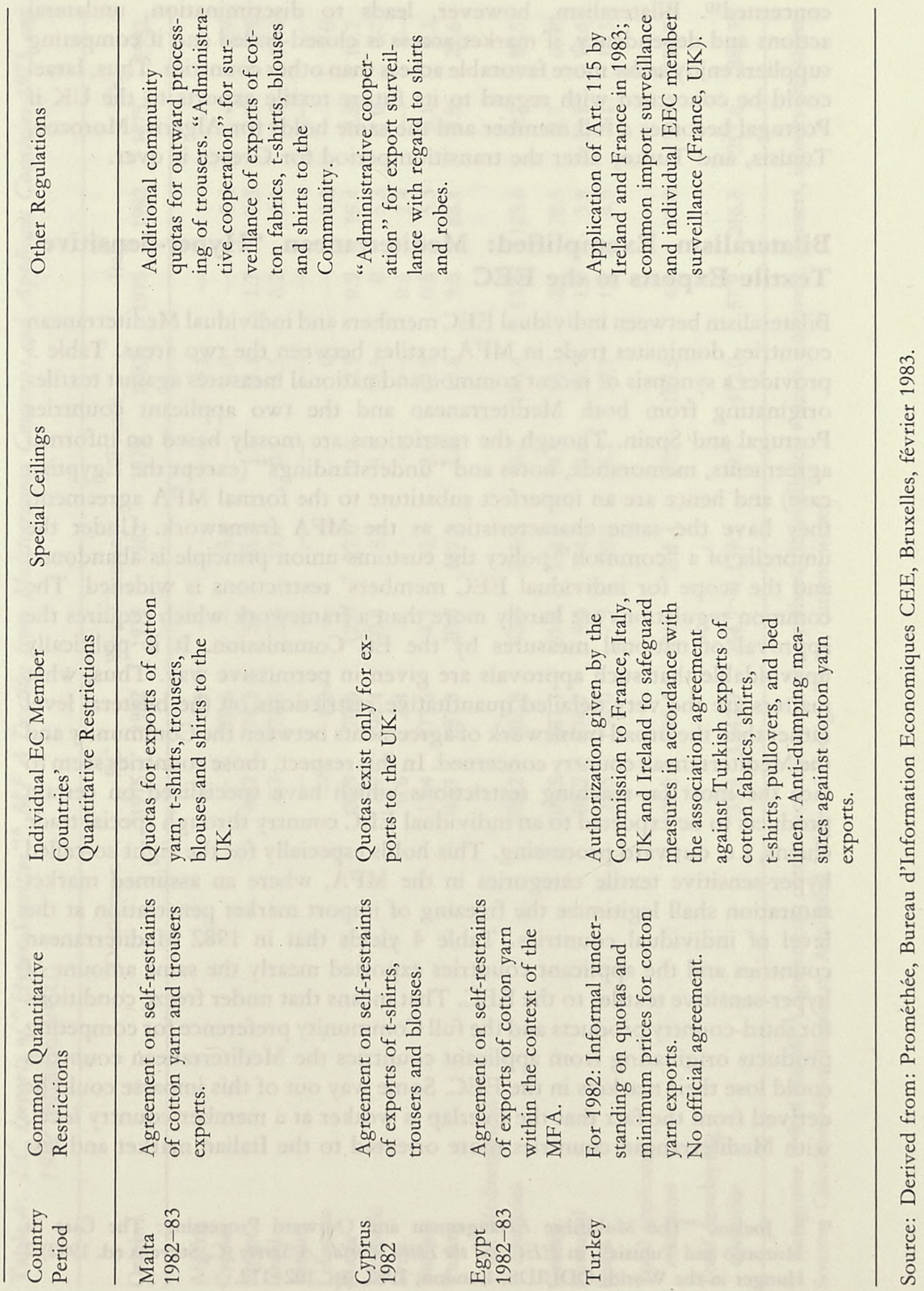


concerned $^{10}$. Bilateralism, however, leads to discrimination, unilateral actions and dependency, if market access is closed-ended and if competing suppliers enjoy ad boc more favorable access than other countries. Thus, Israel could be concerned with regard to its future textile exports to the UK if Portugal becomes a full member and the same holds for Algeria, Morocco, Tunisia, and Turkey after the transition period for Greece is over.

\section{Bilateralism Exemplified: Mediterranean "Hyper-Sensitive" Textile Exports to the EEC}

Bilateralism between individual EEC members and individual Mediterranean countries dominates trade in MFA textiles between the two areas. Table 3 provides a synopsis of recent common and national measures against textiles originating from both Mediterranean and the two applicant countries Portugal and Spain. Though the restrictions are mostly based on informal agreements, memoranda, notes and "understandings" (except the Egyptian case) and hence are an imperfect substitute to the formal MFA agreement, they have the same characteristics as the MFA framework. Under the umbrella of a "common" policy the customs-union principle is abandoned and the scope for individual EEC members' restrictions is widened. The common regulations are hardly more than a framework which requires the approval of national measures by the EC Commission. It is politically unavoidable that such approvals are given in permissive way. Thus, what matters are the very detailed quantitative restrictions on the bilateral level rather than the broad framework of agreements between the Community and the Mediterranean country concerned. In this respect, those countries seem to face the most far-reaching restrictions which have specialized on certain products to be exported to an individual EEC country through special trade chains, i. e. outward processing. This holds especially for the eight so-called hyper-sensitive textile categories in the MFA, where an assumed market saturation shall legitimize the freezing of import market penetration at the level of individual countries. Table 4 yields that in 1982 Mediterranean countries and the applicant countries exported mearly the same amount of hyper-sensitive textiles to the EEC. That means that under freeze conditions for third-country products and the full Community preference for competing products originating from applicant countries the Mediterranean countries could lose their markets in the EEC. Some way out of this impasse could be derived from the fact that the overlap is weaker at a member-country level, with Mediterranean countries more oriented to the Italian market and less

10 S. Joekes, "The Multifibre Arrangement and Outward Processing: The Case of Morocco and Tunisia", in EEC and the Third World: A Survey (C. Stevens ed. 1982) 2 Hunger in the World, ODI/IDS, London, 1982, pp. 102-112. 


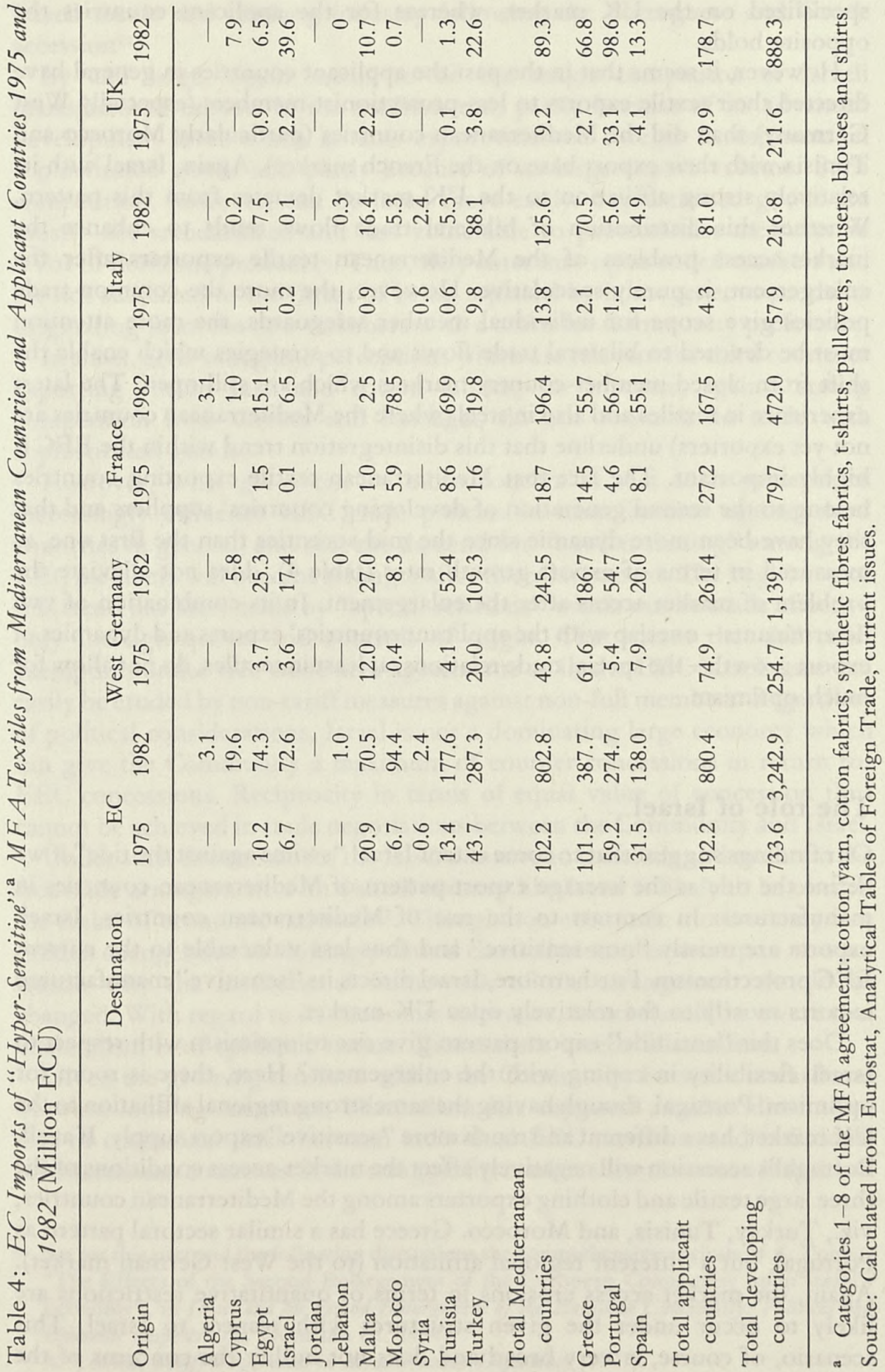


specialized on the UK matker, whereas for the asplicane coumnties the opposite holds.

However, it seems that in the past the applicant covinties in menal lame directed their textile exports to less-provedionise menhess enéalm Wevt Germany) than did the Mediterranean covmenies (senticulatty Virmows and Tunisia with their export base on the French mankes, floain, Istad with int relatively strong affiliation to the UK markes desiate firm this partem. Whether this distribution of bilateral trade flows menids in enifance the market-access problem of the Mediterranean teartie enpurtets after the enlargement, is purely speculative, However, the mone the cummum-imatle policies give scope for individual member safespants, fie mure atermion

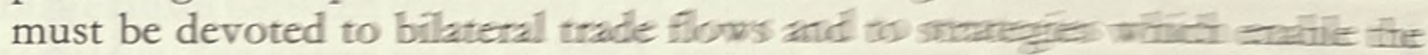
shift from closed member-country markess which are will wow. The latest

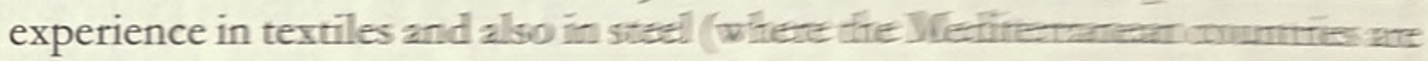
not yet exporters) underline thet this disimregration werit wintinn ffe HAC: is highly important. The fact thet Medinemmeam terrile eanouming cuumnies belong to the second generation of developine crumrtes surnites ant that they have been more dynamic since the mit-serentre flart fite first ome, as

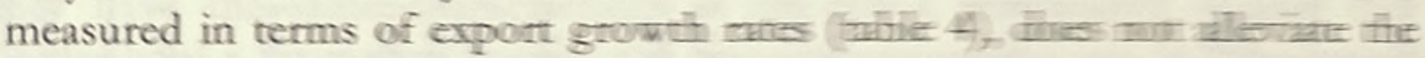
problem of market access after the enllirgement. In its connmantum off IWD

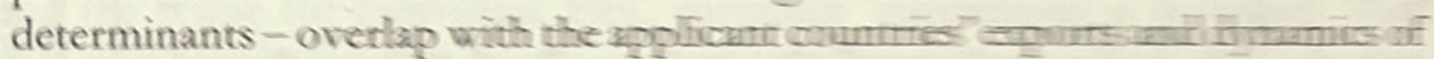

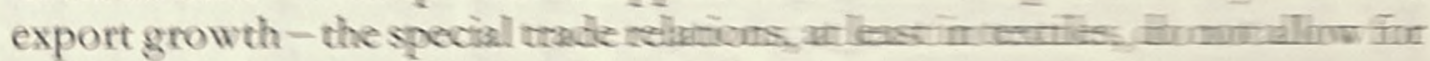
much optimism.

\section{The role of Israel}

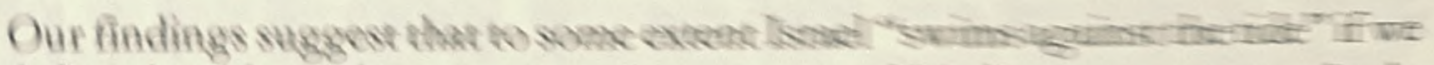

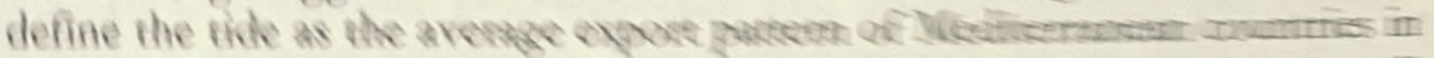

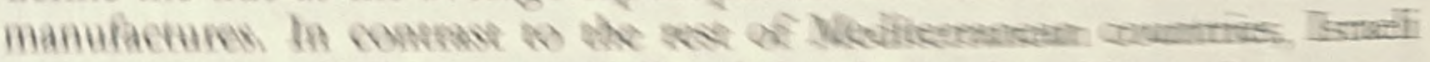

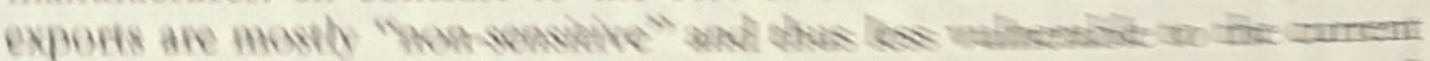

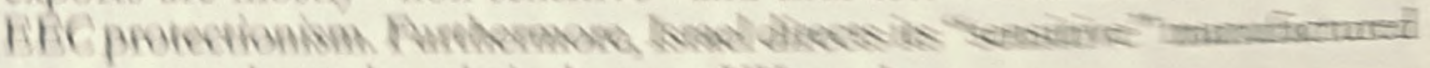

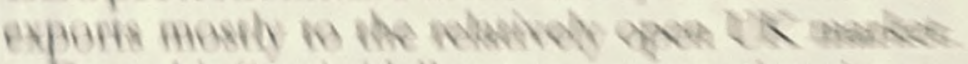

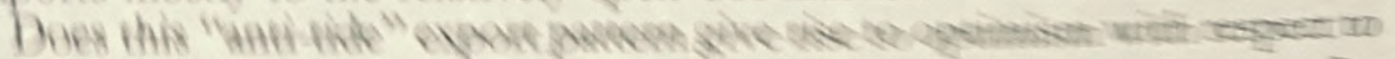

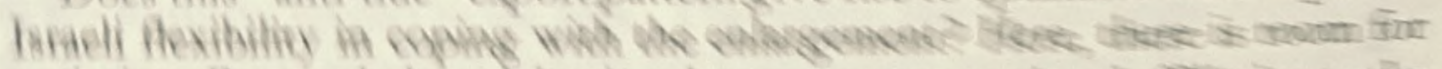

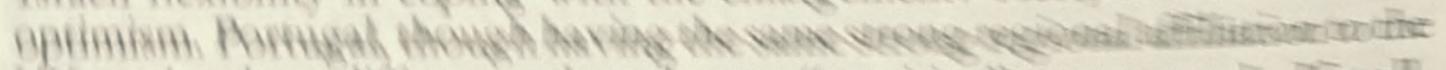

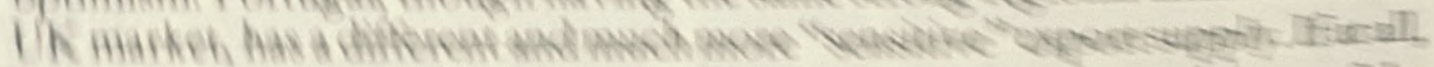

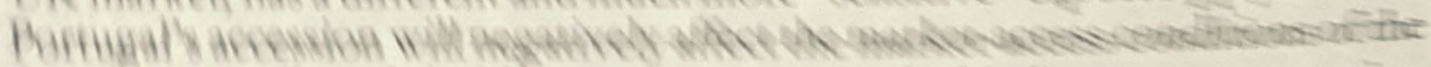

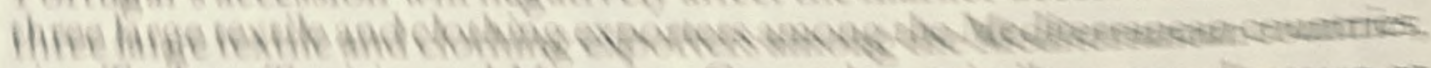

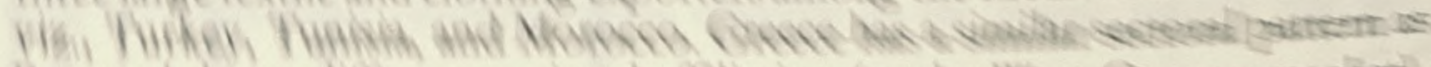

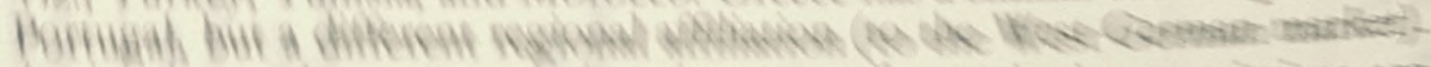

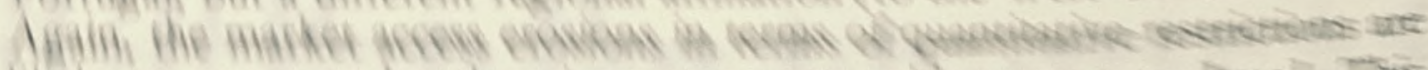

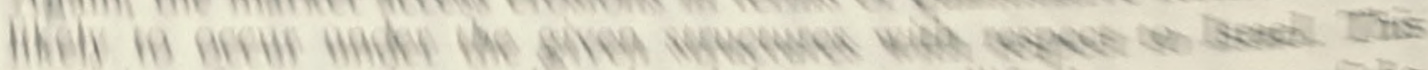

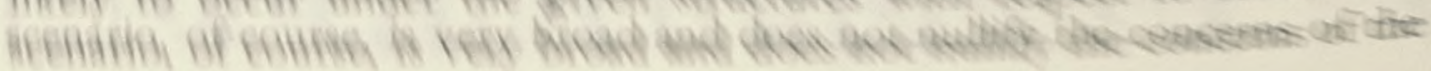


Israeli textile and clothing industry following the Portuguese and Greek $\operatorname{accession}^{11}$.

By and large, Spain seems to be the major competitor of Isracli manufactured exports in the medium run, partly because of its advanced development level which attracts export-oriented foreign investments in sophisticated goods and partly because of its large export volume. Such competition, however, can be faced more easily. Sophisticated goods are mostly not standardized and less vulnerable to protectionist measures in favor of domestic producers. Thus, they enter into open-ended markets and are not subjected to the threat of being replaced by homogeneous products originating from the new members with a claim for Community preference.

In short, zero-sum game perceptions which are relevant for third countries exporting cotton yam and cotton fabrics, for instance, against strong competition from Greece and Portugal, do not dominate in trade with sophisticated goods.

However, what gives rise to more concern is that such perceptions increasingly influence EEC trade policies in manufactures against third countries in general, and that the demand for "burden sharing" among the EEC members will become stronger after the enlargement. The beginning of this trend has been made by "special relations" which can be made effective only through quotas and controls of origin. That means that full tariff exemption under free trade area agreements as in the EEC-Israeli case can easily be eroded by non-tariff measures against non-full members. Regardless of political considerations, Israel is not a dominating large economy which can give the Community a maximum of counter-concessions in return for EEC concessions. Reciprocity in terms of equal value of concession thus cannot be achieved in trade negotiations between the Community and Israel.

Under such circumstances the EEC's motive to conclude and maintain the free trade arrangement with a small country like Israel is likely to be outside the realm of economic rationale ${ }^{12}$. Though non-economic motives may face sudden changes due to shifting political constellations, there is up to now no reason why the institutional framework of the arrangement should be changed. With regard to its economic relevance, Israel should be aware that bilateralism is of epidemic nature. Bilateralism breeds bilateralism.

Given the growing tensions within the Community between inward and outward-looking members, bilateralism has captured another dimension, that of traditional links between individual EEC members and individual Mediterranean countries. If the struggle for market access between individual

11 See for this part and the following discussions the comprehensive analysis of $A$. Tovias, "The Effects of the Second Enlargement of the European Community upon Israel's Economy", in Israel and the Second Enlargement of the Suropean Community : Palitioul and Economic Aspects" (E. Gutmann ed, 1984),

12 A. Tovias, Tariff Preferences in Meditorranean Diplomacy (1977), 
members after the enlargement breaks out in Brussels, then our findings indicate that Israeli interests will be most likely represented by the UK rather than by France, whereas the opposite may hold for the Arabic countries. Under the current isolation of the UK position in the EEC, however, the lobbying power of the UK in favor of individual countries seems to be rather small.

\section{Final Remarks}

The EEC of the eighties seems to be far from being a customs union. Free trade arrangements between the Community and the individual Mediterranean countries therefore become increasingly obsolete if individual members are allowed to resort to national quotas and safeguards in "sensitive" sectors. What matters is the imposition of NTBs on third countries imports crossing national borders rather than the full tariff exemption conceded in the arrangements. Though steel and textiles are still the only two manufacturing industries where free-trade arrangements with third countries have been fully eroded, it is realistic to assume that market access will not become easier in the future. This holds first because restrictive measures once they have been introduced are lasting and not temporary. Second, the current world economic growth trends put the EEC under stronger adjustment requirements than the Community exerts upon other countries by means of its own competitiveness. Under these conditions national governments pursue very different policy responses and as a result the Community suffers from centrifugal forces. Third, the second enlargement does not enrich the Community with leadership and economic stimulants. Instead, more attention will be devoted to flows of transfers. Fourth, specific interests either of regions or of sectors will dominate over common interest.

Under such a scenario Mediterranean countries are well advised to activate traditional bilateral links in order to be supported by a member-country sponsor in negotiations with the Commission. In this respect, the Israeli position - at least in manufactures - gives less ground for concern than those of other Mediterranean countries. 
Appendix Table 1: Frequency of Application of Art. 115 EEC Treaty in 1983 (Through 9/73)

\begin{tabular}{|c|c|c|c|c|c|c|c|c|c|}
\hline $\begin{array}{r}\text { EEC member } \\
\text { applying } \\
\text { Art. } 115 \\
\text { against }\end{array}$ & $\begin{array}{l}\text { West } \\
\text { Ger- } \\
\text { many }\end{array}$ & France & Italy & $\begin{array}{l}\text { Bene- } \\
\text { lux- } \\
\text { Coun- } \\
\text { tries }\end{array}$ & UK & Ireland & Denmark & Greece & EEC \\
\hline PR China & 1 & 4 & 1 & 2 & 4 & - & - & - & 12 \\
\hline South Korea & 1 & 5 & 1 & 1 & 2 & 5 & - & - & 15 \\
\hline Romania & - & 1 & 2 & 4 & 1 & - & - & - & 8 \\
\hline Taiwan & - & 8 & 1 & 3 & 3 & 3 & - & - & 18 \\
\hline Hongkong & - & 2 & - & 1 & - & 16 & - & - & 19 \\
\hline Macao & - & - & - & 1 & - & 1 & - & - & 2 \\
\hline Hungary & - & 1 & - & 1 & - & 2 & - & - & 4 \\
\hline Spain & - & 1 & - & - & - & - & - & - & 1 \\
\hline Brazil & - & 1 & - & - & - & - & - & - & 1 \\
\hline Malaysia & - & 2 & - & - & - & - & - & - & 2 \\
\hline Pakistan & - & 2 & - & - & - & 1 & - & - & 3 \\
\hline Peru & - & 1 & - & - & 1 & - & - & - & 2 \\
\hline Thailand & - & 2 & - & - & - & 1 & - & - & 3 \\
\hline Czechoslovakia & - & 1 & 1 & - & - & - & - & - & 2 \\
\hline India & - & 1 & - & - & - & 2 & - & - & 3 \\
\hline Yugoslavia & - & 1 & - & - & - & 1 & - & - & 2 \\
\hline Japan & - & 2 & 8 & - & - & - & - & - & 10 \\
\hline East Germany & - & - & - & - & 1 & - & - & - & 1 \\
\hline Philippines & - & - & - & - & - & 4 & - & - & 4 \\
\hline Turkey & - & - & - & - & - & 1 & - & - & 1 \\
\hline $\begin{array}{l}\text { Banana- } \\
\text { Exporting- } \\
\text { Countries of the } \\
\text { Dollar-Zone }\end{array}$ & - & - & 1 & - & 1 & - & - & - & 2 \\
\hline Poland & - & - & - & - & - & 1 & - & - & 1 \\
\hline USSR & - & - & 3 & - & - & - & - & - & 3 \\
\hline Sum & 2 & 35 & 18 & 13 & 13 & 38 & - & - & 119 \\
\hline
\end{tabular}

Source: Official Journal of the European Communities, Series C, current issues. 
The Institutional Dimension of EEC Israel Relations 


\title{
The Institutional Context of EEC-Israel Economic Relations
}

\author{
Claus Dieter EhlermanN*
}

\section{The Present Bilateral Contractual Relations Between Israel and the Communities - The Different Agreements and Negotiations}

\section{Trade}

1.1. Trade between Israel and the EEC (with the exception of Greece) is regulated by the (Free Trade) Agreement between the European Economic Community and the State of Israel, signed on 11 May 1975 (Official Journal $1975, \mathrm{~N}^{\mathrm{o}} \mathrm{L} 136 / 3$ ).

1.2. Trade in coal and steel products between Israel and the Member States of the ECSC (with the exception of Greece) is governed by the Agreement between the Member States of the European Coal and Steel Community and the State of Israel, signed on 11 May 1975 (Official Journal 1975, N L 165/62).

The content of the Coal and Steel Agreement is practically identical to the content of the Free Trade Agreement.

1.3. In accordance with Article 22 of the Free Trade Agreement, the time limits of Israel's tariff dismantling programme were extended for certain sensitive imports by the Second Additional Protocol to the (Free Trade) Agreement between the European Economic Community and the State of Israel. This protocol was signed on 18 March 1981 (Official Journal 1981, $\mathrm{N}^{\mathbf{o}}$ L 102/2).

\section{Cooperation}

2.1. Cooperation between Israel and the EEC (with the exception of Greece) takes place in the framework of the Additional Protocol of the (Free Trade) Agreement between the European Economic Community and the State of Israel, signed on 8 February 1977 (Official Journal 1978, Nº L 270/2).

\footnotetext{
* The views expressed are strictly personal.
} 
2.2. The financial provisions of the Cooperation Protocol of 8 February 1977 were implemented through the (First) Protocol concerning the financial cooperation between the European Economic Community and the State of Israel, also signed on 8 February 1977 (Official Journal 1978, Nº 270/9). 2.3. As the (First) Protocol applied only until October 1981, Israel and the EEC have agreed on a (Second) Protocol relating to financial cooperation between the European Economic Community and the State of Israel, signed on 24 June 1983 (Official Journal 1983, No L 335/8).

\section{Relations with Greece}

3.1. Neither the Free Trade Agreement nor the Cooperation Protocol were automatically extended to the enlarged Community of Ten (Nine+ Greece). Such extension is subject to the entry into force of the Protocol to the Agreement between the European Economic Community and the State of Israel consequent on the accession of the Hellenic Republic to the Community, initialled on 18 December 1980.

In the same way, the extension of the Coal and Steel Agreement of 11 May 1975 requires the entry into force of a (parallel) protocol between the ten Member States of the ECSC and Israel; this protocol was also initialled on 18 December 1980.

3.2. Until the entry into force of these Accession Protocols, trade between Israel and Greece is governed by Council Regulation (EEC) N $N^{\mathbf{0}}$ 637/81 of 24 February 1981 laying down the arrangements applicable to trade between Greece and Israel (Official Journal $N^{0}$ L 70/1); insofar as coal and steel products are concerned, a parallel Decision of the Representatives of the Governments of the Member States of the ECSC, meeting within the Council, also of 24 February 1981 (Official Journal 1981, N L 70/25).

\section{The Communities' Treaty-Making Powers illustrated by the Bilateral Agreements with Israel}

\section{A. The Communities' treaty making powers in general}

1. ECSC

1.1. According to Article 71 of the ECSC Treaty, "The powers of the Governments of Member States in matters of commercial policy shall not be affected by this Treaty, save as otherwise provided therein".

1.2. The ECSC enjoys implied treaty-making powers, according to the priciples laid down by the EC Court of Justice in Opinion 1/76 and its judgement in the ERTA case (see infra 2.3.).

1.3. In addition, a treaty-making power flows from Article 95 of the ECSC Treaty, according to which: "In all cases not provided for in this [ECSC] Treaty where it becomes apparent that a decision or recommendation of the 
High Authority is necessary to attain, within the common market in coal and steel ... one of the objectives of the Community ... the decision may be taken ... with the unanimous assent of the Council..." This article was used in the case of the export limitation arrangement between the ECSC and the US of October 1982 (Official Journal 1982, Nº L 307/13).

2. EEC

2.1. The EEC Treaty expressly gives the Community the power to conclude "trade agreements" (Article 113).

Since the end of the transitional period (1 January 1970), this power has become an exclusive Community power. Its scope is controversial.

2.2. In addition, the EEC Treaty provides expressly for the conclusion of agreements "establishing an association involving reciprocal rights and obligations, common action and special procedures" (Article 238). This power is by nature an exclusive Community power; the scope of it is, however, also controversial.

2.3. The EC Court of Justice has recognized "that whenever Community Law has created for the institutions of the Community powers within its internal system for the purpose of attaining a specific objective, the Community has authority to enter into the international commitments necessary for the attainment of that objective even in the absence of an express provision in that connexion". (Opinion 1/76 - "Draft Agreement establishing a European laying-up fund for inland waterway vessels" - [1977] ECR 741, 755).

This power becomes an exclusive Community power with respect to those international agreements which might affect common rules which the Community has already adopted. (Case 22/70 - ERTA - Commission v Council [1971] ECR 263, 274, 275).

2.4. The Courts' reasoning applies obviously also to Article 235 of the EEC Treaty according to which "If action by the Community should prove necessary to attain, in the course of the operation of the common market, one of the objectives of the Community and this Treaty has not provided the necessary powers, the Council shall, acting unanimously ..., take the appropriate measures".

\section{Euratom}

The Euratom Treaty is not relevant in this context.

\section{B. The specific case: the bilateral treaty relations with Israel}

\section{Trade}

1.1. The Free Trade Agreement of 1975 is part of the EEC's common commercial policy. Though much wider in scope than the two previous agreements (of 1964 and 1970), it is also a trade agreement, based on Article 
113 of the EEC Treaty (cf. Regulation [EEC] No 1274/75 of the Council of 20 May 1975 concluding the agreement, Official Journal 1975, No L 136/1). Though only a trade agreement, the 1975 Agreement included an important provision on cooperation (Article 18). It is noteworthy that this cooperation was not limited to the area of trade, but extended to "spheres which are in the mutual interest of the Contracting Parties"; the Joint Committee was given the task of "seek[ing] ways and means of ... facilitating the transfer of technological knowhow, and encouraging private investment and contacts and cooperation between the industries of the Community and Israel". Article 18 demonstrates a reasonable - but unfortunately rather rarely applied - conception of the scope of the Community's powers to shape a common commercial policy (this conception is perfectly in line with Opinion 1/78International Agreement on Natural Rubber - [1979] ECR 2871).

1.2. The separate agreement between the Member States of the ECSC and Israel for coal and steel products results from the absence of powers analogous to those under the EEC's common commercial policy in the ECSC Treaty (cf. Article 71 of the ECSC Treaty); the (questionable) practice of not applying Article 113 of the EEC Treaty to coal and steel products (cf. Opinion 1/75 - Local Costs Standard - [1975] ECR 1355, 1365); the reluctance of Member States to allow the Communities to make use of potential (non exclusive) treaty making powers. The ECSC-USA agreement limiting European exports of steel is an exception to this rule (see supra A 1.3.).

\section{Cooperation}

2.1. In contrast to the Free Trade Agreement of 1975 based on Article 113, the Cooperation Protocol of 1977 was concluded by the Community under Article 238 of the EEC Treaty (cf. Council Regulation (EEC) No 2217/8 of 26 September 1978 concerning the conclusion of the Cooperation Protocol and of the First Financial Protocol, Official Journal 1978, No L 270/1). While the EEC alone is a party to the Free Trade Agreement, the Cooperation Protocol was concluded by the EEC and all its Member States. Member States participate as the Cooperation Protocol is considered to be wider than the exclusive EEC treaty making powers resulting from Article 238 and the refusal to make use of potential, i.e. non-exclusive powers.

It is difficult to ascertain what parts of the Cooperation Protocol were thought to exceed the exclusive powers flowing from Article 238. Only certain aspects of the agreed cooperation? Or also the financial aspects? (see, however, infra 2.2.).

2.2. Like the Cooperation Protocol of 1977, the First Financial Protocol was concluded - on the basis of Article 238- by the EEC and all its Member States (see supra 2.1.). The Second Financial Protocol is also founded on Article 238 but the Member States no longer participate (cf. Council Regulation (EEC) 
$N^{0} 3354 / 83$ on the conclusion of the Second Financial Protocol, Official Journal 1983, No L 335/7).

The change from joint (EEC+Member States) to exclusive EEC participation could be easily explained if it corresponded to a change in funding (for example funding originally by Member States, later by the EEC). However, no such change has apparently occurred. Both Protocols are limited to loans from the European Investment Bank, granted on normal market conditions.

\section{Relations with Greece}

3.1. International agreements and enlargement

3.1.1. In the case of enlargement, the Communities apply the principle of movable treaty boundaries: International treaties are considered to extend automatically to the enlarged Community territory (cf. Article 4(1) of the first and second Acts of Accession).

3.1.2. The principle of automatic extension is tempered by the principle of adaptation if the interests of the Community or of the other contracting party require an adaptation of the agreement (cf. Article 108(1) of the first and Article 118 of the second Art of Accession).

3.1.3. The principle of automatic extension is not applicable to international agreements in which not only the Communities but also Member States participate (cf. Article 4(2) of the first and second Acts of Accession).

\subsection{The specific case of Greece}

3.2.1. The Free Trade Agreement of 1975 was not automatically extended, as its application to Greece requires transitional measures.

3.2.2. The Cooperation Protocol of 1977 in which the EEC and its Member States participate jointly could not be automatically extended; Greece has to accede via a formal amendment procedure.

3.2.3. Instead of keeping the Free Trade Agreement and the Cooperation Protocol separate by following two different procedures (parallel to those applied in 1975 and 1977), the adaptation of the first and the amendment of the second will be the result of one international agreement: the Protocol of 18 December 1980. The Protocol will be concluded by the EEC and its Member States; it is envisaged that EEC participation will be based on Article 238 of the EEC Treaty.

3.2.4. Council Regulation (EEC) $N^{0} 637 / 81$ (supra I 3.2) which regulates trade between Greece and Israel in the meantime has however been adopted in accordance with Article 113 of the EEC Treaty. 


\section{The Interpretation of the Free Trade Agreement of 1975}

\section{A. The questions:}

1. Until now, the 1975 Free Trade Agreement has been the subject of one case before the EC Court of Justice. ${ }^{1}$

2. Other international agreements to which the EEC is a party or which are binding on the EEC have been interpreted by the Court of Justice. To what extent are these decisions also relevant for the interpretation of the 1975 Free Trade Agreement?

3. The following discussion will concentrate on two aspects:

3.1. What is the scope of the provisions to be examined? If the 1975 Free Trade Agreement has used terms identical to those of the EEC Treaty, do they have the same substantive meaning? Or not?

3.2. Can individuals rely on the provisions of the 1975 Free Trade Agreement as they can rely on similar provisions of the EEC Treaty? Or is "direct effect" limited to the provisions of the EEC Treaty?

3.3. The importance of this last question cannot be overestimated: International agreements which are binding on the Community form an integral part of the Community legal system (case 181/73 Haegeman v Belgian State [1974] ECR 449, 459; case 104/81 Hauptzollamt Mainz v Kupferberg [1982] ECR 3641, 3662). As such they are not only superior to national law, but also to autonomous secondary Community law (i.e. regulation, directives and decisions adopted by the EC Council or the EC Commission). In contrast to other legal systems, the Community institutions do not have the power to disregard binding international rules which can be relied on by an individual (which have "direct effect").

\section{B. The interpretation of international agreements by the EC Court of Justice in general}

1. The Court of Justice takes into account "the international origin of the provisions in question" (case 104/81 Hauptzollamt Mainz v Kupferberg [1982] ECR 3641, 3663).

2.1. It determines the substance of the provisions "in the light of both the object and purpose of the agreement and of its wording" (case 270/80 Polydor v Harlequin Records Shops [1982] ECR 329, 346). Terminology used in other cases with respect to the substance of the provisions:

Interpretation "in the light of the general structure both of the ... Agreement, of which it forms part, and of the totality of the provisions contained in the Protocol itself' (case 181/73 Haegeman v Belgian State [1974] ECR 449, 460).

1 Note: In July 1984, the first reference relating to the 1975 Free Trade Agreement was made by the High Court of London: Case 174/84 - Bulk Oil v. Sun Oil International a. o. This case has now been decided and confirms all statements by the author (eds.). 
Interpretation "in accordance with both the general scheme and the objectives of the Agreement" (case 52/77 Cayrol v Rivoira [1977] ECR 2261, 2276).

Interpretation of the provision concerned "according to its terms and the light of the objective which it pursues in the system of free trade established by the Agreement" (case 104/81 Hauptzollamt Mainz v Kupferberg [1982] ECR 3641, 3666).

2.2. Equally, the question of direct effect must be answered "in the light of both the object and the purpose of the Agreement and of its context" (Case 104/81 Hauptzollamt Mainz v Kupferberg [1982] ECR 3641, 3665).

Terminology used in other cases with respect to the problem of "direct effect":

"For this purpose, the spirit, the general scheme and the terms of the General Agreement must be considered" (joined cases 21-24/72 International Fruit Company v Produktschap voor Groenten en Fruit [1972] ECR 1219, 1227). "It ... follows from the wording ... and from the objective and nature of the Association Agreement ..." (case 17/81 Pabst \& Richarz v Hauptzollamt Oldenburg [1982] ECR 1331, 1350).

3. Taking a broad view of the cases decided until now by the Court of Justice, three groups of agreements clearly emerge, each group being composed by one or several agreements with special distinctive characteristics.

3.1. The first type of agreement is represented by the Association Agreement with Greece of July 1961. This agreement comes closest to the EEC Treaty, as its "purpose ... was to prepare for the entry of Greece into the Community by the establishment of a customs union, by the harmonization of agricultural policies, by the introduction of freedom of movement for workers and by other measures for the gradual adjustment to the requirements of Community law" (case 17/81 Pabst \& Richarz v Hauptzollamt Oldenburg [1982] ECR 1331, 1350; see also case 181/73 Haegeman v Belgian State [1974] ECR 449, 460).

3.2. The second group is formed by the free trade agreements with the EFTA countries. The Court of Justice notes that the purpose of these agreements - in concreto the Free Trade Agreement with Portugal of July 1972 - "is to create a system of free trade in which rules restricting commerce are eliminated in respect of virtually all trade in products originating in the territory of the parties, in particular by abolishing customs duties and charges having equivalent effect and eliminating quantitative restrictions and measures having equivalent effect" (case 104/81 Hauptzollamt Mainz v Kupferberg [1982] ECR 3641, 3665; see also case 270/80 Polydor v Harlequin Record Shops [1982] ECR 329, 347).

But the Court recognizes also that the Free Trade Agreement with Portugal "does not have the same purpose as the EEC Treaty, in as much as the latter ... seeks to create a single market reproducing as closely as possible the 
conditions of a domestic market" (case 270/80 Polydor v Harlequin Record Shops [1982] ECR 329, 349; see also case 104/81 Hauptzollamt Mainz v Kupferberg [1982] ECR 3641, 3666).

3.3. The third type of agreement is GATT, to which the Court of Justice has repeatedly refused to attribute direct effect. The Court reached this conclusion "on the basis of considerations concerning the general scheme of GAT'T, namely that it was based on the principle of negotiations undertaken on a reciprocal and mutually advantageous basis and was characterised by the great flexibility of its provisions, in particular those concerning the possibilities of derogation, the measures which might be taken in case of exceptional difficulty and the settlement of differences between the contracting parties" (joined cases 267-269/81 Amministrazione delle Finanze dello Stato [State Finance Administration] v Società Petrolifera Italiana a. o. [1983] ECR 801, 830; following joined cases 21-24/72 International Fruit Company v Produktschap voor Groenten en Fruit [1972] ECR 1219, 1227; and case 79/73 Schlüter v Hauptzollamt Lörrach [1973] ECR 1135, 1157).

3.4. The three groups of international agreements -

1. Association Agreement with Greece in view of accession,

2. Free Trade Agreement with EFTA countries, and

3. GATT

do not comprise all the agreements interpreted by the Court of Justice, nor do they reflect the great variety of agreements concluded by the Community. They do constitute, however, a relatively clear set of parameters which allow some comparison to be made between provisons of the 1975 Free Trade Agreement with Israel and the decisions of the Court of Justice concerning other international agreements.

4. Before looking at specific decisions of the Court of Justice, it is useful to situate the 1975 Free Trade Agreement with respect to the three groups of international agreements outlined above.

4.1. The 1975 Free Trade Agreement is neither a pre-accession agreement (like the Association Agreement with Greece) nor an agreement which resembles the GATT.

4.2. However, it displays striking similarities with the free trade agreements with EFTA countries, specifically with the Free Trade Agreement with Portugal (see the synopsis in the Annexe).

4.2.1. The Israel Agreement contains practically all the substantive provisions of the Portugal Agreement, in particular all those mentioned by the Court of Justice in its Polydor decision. With respect to the establishment of the free trade zone, the only differences relate to the (limited) tariff concessions for agricultural products and the lists of industrial products imported into Israel/Portugal benefiting from a slower pace of tariff reductions.

4.2.2. The Israel Agreement provides for greater flexibility as the programme for the dismantling of tariffs by Israel can be changed (Article 22(2)). 
4.2.3. From the very beginning, the Israel Agreement had the purpose of establishing cooperation between the contracting parties (Preamble and Article 18). The Cooperation Protocol of 1977 has considerably strengthened this part of the Agreement.

4.3. The conclusion of the Cooperation Protocol in view of the development of Israel has not weakened the provisions establishing a free trade zone. The Israel Agreement provides for reciprocal treatment of EEC imports (even if the timetable takes into account differences in the level of economic development), while the agreements with Maghreb and Machrak countries do not establish reciprocity. In addition, they do not contain a number of provisions typical of the free trade agreements with EFTA countries and the Israel Agreement. In other words: in these agreements the free trade zone aspect is weaker, the development and cooperation aspects are stronger.

4.4. The preamble to the Israel and Portugal Agreements show one significant difference, however:

The Israel Agreement states "that the Community is anxious to develop economic and trade relations with countries of the Mediterranean basin" (a reference to the Community's global Mediterranean policy);

The Portugal Agreement expresses the desire "to consolidate and to extend, upon the enlargement of the ... Community the economic relations existing between the Community and Portugal and to ensure... the harmonious development of their commerce for the purpose of contributing to the work of constructing Europe" (emphasis added).

\section{Comparison with specific decisions of the EC Court of Justice}

1. Probibition of charges having an effect equivalent to customs duties on imports:

1.1. Case 87/75 Bresciani v Amministrazione Italiana delle Finanze [1976] ECR 129, 140-142:

1.2. Article 2(1) of the Yaoundé Convention of 1969 has the same scope and the same (direct) effect as Article 13 of the EEC Treaty.

1.3. The Court's decision is based on the three following considerations:

1.3.1. Absence of reciprocity (typical of the Yaoundé and Lomé Conventions) does not prevent recognition of direct effect. This consideration is not relevant in our context.

1.3.2. "By expressly referring, in Article 2(1) of the Convention, to Article 13 of the Treaty, the Community undertook precisely the same obligation towards the Associated States ... as, in the Treaty, the Member States assumed towards each other."

Such a reference is not made in the Israel Agreement. It is submitted that in the light of the Polydor and Kupferberg decisions (infra 4 and 5.5.) the scope of the prohibition in the Israel Agreement is smaller than the similar prohibition in the EEC Treaty. 
1.3.3. "Since this obligation is specific and not subject to any implied or express reservation on the part of the Community, it is capable of conferring on those subject to Community law the right to rely on it before the courts."

It is likely, in view of the Kupferberg decision (infra 5.5.), that the Court will arrive at the same conclusion for the prohibition of charges having an effect equivalent to customs duties on imports, contained in the Israel Agreement.

\section{Probibition of quantitative restrictions on imports}

2.1. Case 52/77 Cayrol v Rivoira [1977] ECR 2261, 2276:

2.2. Article 1 of Annex I to the Trade Agreement with Spain of June 1970 does not prohibit the application of quantitative restrictions on imports of grapes during the part of the year during which no tariff concession applies. 2.3. The question of interpretation arose because of the expansive wording of the Spain Agreement. The wording of the Israel Agreement is more precise. The question of interpretation does not arise therefore (cf. Article 5 of the Agreement, Article 4 of Protocol 1, Joint Declaration of the Contracting Parties on Article 8 of Protocol 1).

\section{Probibition of measures having an effect equivalent to quantitative restrictions on imports}

3.1. Case 270/80 Polydor v Harlequin Record Shops [1982] ECR 329, 346-350.

3.2. Article $14(2)$ in connection with Article 23 of the Free Trade Agreement with Portugal does not prohibit the enforcement of copyright as against imports into the Community of products lawfully manufactured and placed on the Portuguese market by licensees of the copyright proprietor.

3.3. The Court decision is based on the following considerations:

3.3.1. "The provisions of the Agreement on the elimination of restrictions on trade ... are expressed in terms which in several respects are similar to those of the EEC Treaty... However, such similarity of terms is not a sufficient reason for transposing to the provisions of the Agreement the ... case-law [on] ... the protection of industrial and commercial property rights and the rules on the free movement of goods."

3.3.2. "... The Treaty by establishing a common market and progressively approximating the economic policies of the Member States, seeks to unite national markets into a single market having the characteristics of a domestic market...

The considerations which led to that interpretation of Articles 30 and 36 of the Treaty do not apply in the context of the relations between the Community and Portugal as defined by the Agreement. It is apparent from an examination of the Agreement that although it makes provision for the unconditional abolition of certain restrictions on trade between the 
Community and Portugal, such as quantitative restrictions and measures having quantitative equivalent effect, it does not have the same purpose as the EEC Treaty...

... such distinction [between the Treaty and the Agreement] is all the more necessary inasmuch as the instruments which the Community has at its disposal in order to achieve the uniform application of Community law and the progressive abolition of legislative disparities within the common market have no equivalent in the context of the relations between the Community and Portugal."

3.4. It is submitted that this interpretation applies also to the Free Trade Agreement with Israel.

\section{Probibition of quantitative restrictions on exports and of measures baving equivalent effect}

4.1. Case 225/78 Procureur de la République v Bouhelier [1979] ECR 3151, 3159-3161.

4.2. The Trade Agreement with Spain of June 1970 does not prohibit quantitative restrictions on exports or measures having equivalent effect.

4.3. The reasoning of the Court:

4.3.1. "The agreement does not contain any provision relating to the prohibition of quantitative restriction on exports, or of measures having equivalent effect."

4.3.2. Such a prohibition cannot be inferred from Article 12 of the Agreement (which corresponds to Article 36 of the EEC Treaty) and which allows - superfluously - restrictions on exports.

4.4. It is submitted that this interpretation applies also to the Israel Agreement. This was confirmed in the Sun v. Bulk Case.

\section{Probibition of discriminatory internal taxation}

5.1. Case 17/81 Pabst \& Richarz v Hauptzollamt Oldenburg [1982] ECR $1331,1350$.

5.2.1. Article 53(1) of the Association Agreement with Greece of July 1961 precludes a national system of relief from providing more favourable tax treatment for domestic spirits than for those imported from Greece.

5.2.2. The provision can be relied upon by an importer before a national court.

5.3. The reasoning of the Court:

5.3.1. Article $53(1)$ - "the wording of which is similar to that of Article 95 of the Treaty, fulfills, within the framework of the Association ... the same function as that of Article 95. It forms part of a group of provisions the purpose of which was to prepare for the entry of Greece into the Community by ..." 
5.3.2. Article 53(1) "contains a clear and precise obligation which is not subject, in its implementation or effects, to the adoption of any subsequent measure".

5.4. It is submitted that the interpretation of Article 53(1) of the Association Agreement with Greece is not transposable to the Free Trade Agreement with Israel, as the purpose of the two agreements is substantially different.

5.5. Case 104/81 Hauptzollamt Mainz v Kupferberg [1982] ECR 3641, 3661-3669.

5.6.1. There is no discrimination within the meaning of Article 21 (1) of the Free Trade Agreement with Portugal "where a Member State does not apply to products originating in Portugal a tax reduction provided for certain classes of producers or kinds or products if there is no like product on the market of the Member State concerned which has in fact benefited from such a reduction".

"Products which differ inter se both as regards the method of their manufacture and their characteristics may not be regarded as like products" within the meaning of Article 21(1).

5.6.2. Article 21 may be applied by a court and this produces direct effects throughout the Community.

5.7. The reasoning of the Court:

5.7.1. With respect to the substance:

"The EEC Treaty and the Agreement on free trade pursue different objectives. It follows that the interpretations given to Article 95 of the Treaty cannot be applied by way of simple analogy to the Agreement on free trade."

"Article 21 must be interpreted according to its terms and in the light of the objective which it pursues in the system of free trade established by the Agreement."

5.7.2. With respect to direct effect:

The Court of Justice rejects all arguments against direct effect, such as:

- the danger of lack of reciprocity;

- the institutional structure of the Free Trade Agreement;

- the possibility of invoking safeguard clauses.

It considers that it is necessary to analyse Article 21 in the light both of the object and purpose of the Agreement and of its context.

It concludes that Article 21 is "an unconditional rule against discrimination in matters of taxation, which is dependent only on a finding that the products affected by a particular system of taxation are of like nature, and the limits of which are the direct consequence of the purpose of the Agreement".

5.8. It is submitted that the Kupferberg decision is transposable to the Free Trade Agreement with Israel. 


\section{Conclusions}

1. The network of present bilateral agreements between Israel and the Communities is complicated. Unfortunately, most things related to the Communities are complicated.

2. The bilateral agreements with Israel show a significant evolution of the EEC's treaty making powers - or rather the use made of existing treaty powers.

3. The interpretation of international agreements by the EC Court of Justice, in particular its decisions on direct effect, have given considerable weight to most of these agreements. It is submitted that this case law also enhances the scope and relevance of the Free Trade Agreement with Israel.

Annexe: Synopsis of the Provisions of the Free Trade Agreement with Portugal of 1972 and the Free Trade Agreement with Israel of 1975.

\begin{tabular}{llll}
\hline & Portugal & & Israel \\
\hline $\begin{array}{l}\text { Provision } \\
\text { duties on imports }\end{array}$ & $3(1)$ & $3(1)$ & \\
$\begin{array}{l}\text { Progressive abolition of } \\
\text { existing customs duties on } \\
\text { imports }\end{array}$ & $3(2)$ & $\begin{array}{l}\text { Imports into EEC } \\
\text { 1 Prot. 1 }\end{array}$ & $\begin{array}{l}\text { Imports into Israel } \\
\text { 1 Prot. 2 }\end{array}$ \\
$\begin{array}{l}\text { Customs duties of fiscal } \\
\text { nature }\end{array}$ & 4 & 3 Prot. 1 & 4 Prot. 2 \\
$\begin{array}{l}\text { Definition of basic duties } \\
\begin{array}{l}\text { Prohibition of new charges } \\
\text { having an equivalent } \\
\text { effect to customs duties } \\
\text { on imports }\end{array}\end{array}$ & 5 & 2 Prot. 1 & 2 Prot. 2 \\
$\begin{array}{l}\text { Progressive abolition of } \\
\text { existing charges having an } \\
\text { equivalent effect to cus- } \\
\text { toms duties on import }\end{array}$ & $6(2+3)$ & 3 Imports into EEC & Imports into Israel \\
$\begin{array}{l}\text { Prohibition of new customs } \\
\text { duties and charges having } \\
\text { an equivalent effect on } \\
\text { exports }\end{array}$ & 7 & 1 Prot. 1 & 1 Prot. 2 \\
$\begin{array}{l}\text { Abolition of existing cus- } \\
\text { toms duties and charges } \\
\text { having an equivalent } \\
\text { effect on exports }\end{array}$ & 7 & $4(1)$ & \\
\hline
\end{tabular}


Annexe (continued)

\begin{tabular}{|c|c|c|}
\hline Provision & Portugal & Israel \\
\hline $\begin{array}{l}\text { Possibility of adaptation as a } \\
\text { consequence of the evo- } \\
\text { lution of the common } \\
\text { agricultural policy }\end{array}$ & $10(1)$ & $7(1)$ \\
\hline Taking account of interests & $10(2)$ & $7(2)$ \\
\hline $\begin{array}{l}\text { Procedure in case of reduc- } \\
\text { tion of tariffs in favour of } \\
\text { third countries }\end{array}$ & 13 & 6 \\
\hline $\begin{array}{l}\text { Prohibition of new quantita- } \\
\text { tive restrictions on im- } \\
\text { ports and measures having } \\
\text { an equivalent effect }\end{array}$ & $14(1)$ & 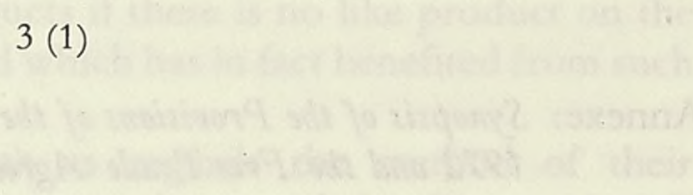 \\
\hline $\begin{array}{l}\text { Abolition of existing quant- } \\
\text { itative restrictions on im- } \\
\text { ports and measures having } \\
\text { an equivalent effect }\end{array}$ & $14(2)$ & $\begin{array}{ll}\text { Imports into EEC } & \text { Imports into Israel } \\
4 \text { Prot. } 1 & 5 \text { Prot. } 2\end{array}$ \\
\hline $\begin{array}{l}\text { Special regime for EEC im- } \\
\text { ports of petroleum } \\
\text { products }\end{array}$ & 16 & $5+6$ Prot. 1 \\
\hline $\begin{array}{l}\text { Evolution clause for trade in } \\
\text { agricultural products not } \\
\text { covered by Agreement }\end{array}$ & $17(1)$ & Joint declaration on agricultural products. \\
\hline $\begin{array}{l}\text { Non-discrimination in veti- } \\
\text { nary, health and plant } \\
\text { health matters }\end{array}$ & $17(2)$ & Joint declaration on agricultural products. \\
\hline $\begin{array}{l}\text { No more favourable treat- } \\
\text { ment than between Mem- } \\
\text { ber States }\end{array}$ & 19 & 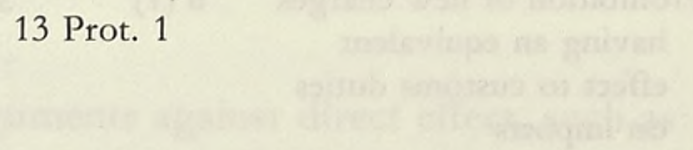 \\
\hline Reserve for customs union & 20 & 8 \\
\hline $\begin{array}{l}\text { Prohibition of fiscal } \\
\text { discrimination }\end{array}$ & 21 & 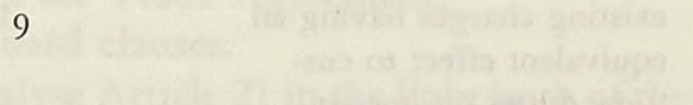 \\
\hline $\begin{array}{l}\text { Prohibition of excessive tax } \\
\text { refunds }\end{array}$ & 21 & 9 \\
\hline Freedom of payments & 22 & 10 \\
\hline $\begin{array}{l}\text { Reserve equivalent to Art. } \\
36 \text { EEC }\end{array}$ & 23 & 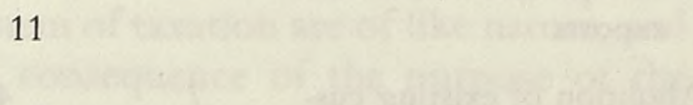 \\
\hline $\begin{array}{l}\text { Reserve for security inter- } \\
\text { ests, trade in arms, etc. }\end{array}$ & 24 & 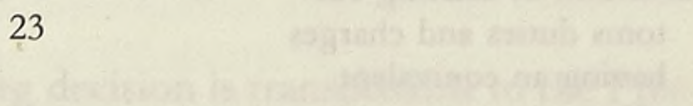 \\
\hline Clause of good behaviour & 25 & 25 \\
\hline
\end{tabular}




\begin{tabular}{|c|c|c|}
\hline Provision & Portugal & Israel \\
\hline $\begin{array}{l}\text { Prohibition of restrictive } \\
\text { practices, abuse of domi- } \\
\text { nant position, public aids }\end{array}$ & 26 & \\
\hline $\begin{array}{l}\text { Safeguard clause } \\
\text { (equivalent to Article XIX } \\
\text { GATT) }\end{array}$ & 27 & \\
\hline Dumping & 28 & 218 \\
\hline $\begin{array}{l}\text { Sectoral and } \\
\text { regional safeguard clause }\end{array}$ & 29 & \\
\hline $\begin{array}{l}\text { Procedure for safeguard } \\
\text { measures etc. }\end{array}$ & 30 & \\
\hline $\begin{array}{l}\text { Balance of payments } \\
\text { safeguard clause }\end{array}$ & 31 & \\
\hline Joint Committee & $32-34$ & -21 \\
\hline General clause for evolution & 35 & \\
\hline Denounciation & 37 & \\
\hline \multicolumn{3}{|c|}{ Most significant provisions of Protocols } \\
\hline $\begin{array}{l}\text { Progressive abolition of cus- } \\
\text { toms duties for imports }\end{array}$ & into Portugal & into Israel \\
\hline List $\mathrm{A}+$ list $\mathrm{B}$ & $\begin{array}{l}4(1) \\
\text { Prot. } 1\end{array}$ & $\begin{array}{l}1(1)=\text { for products other than those } \\
\text { Prot. } 2 \text { listed in Annexe } \\
\text { II to the Treaty } \\
1(2)=\text { for products } \\
\text { Prot. } 2 \text { listed in Annexe }\end{array}$ \\
\hline $\begin{array}{l}\text { Products originating in } \\
\text { Denmark, Norway and } \\
\text { the United Kingdom, } \\
\text { specified in lists } \mathrm{A}+\mathrm{B}\end{array}$ & $\begin{array}{l}4(2) \\
\text { Prot. } 1\end{array}$ & \\
\hline Industrialization clause & $\begin{array}{l}6 \\
\text { Prot. } 1\end{array}$ & $\begin{array}{l}3 \\
\text { Prot. } 2\end{array}$ \\
\hline \multicolumn{3}{|c|}{ Provisions specific to the Israel Agreement } \\
\hline Cooperation clause & replaced by & $\begin{array}{l}18 \text { Agreement of } 1975 \\
2-7 \text { Cooperation Agreement of } 1977\end{array}$ \\
\hline $\begin{array}{l}\text { Review and } \\
\text { flexibility clause }\end{array}$ & & 22 \\
\hline $\begin{array}{l}\text { Prohibition of } \\
\text { discriminations }\end{array}$ & & 24 \\
\hline
\end{tabular}


Part Five

The Political Dimension 


\title{
The Evolution of a European Foreign Policy: Mechanisms and Institutions
}

\author{
JOSEPH H. H. WeILER*
}

\section{The Historical, Conceptual and Comparative Framework}

The troublesome evolution of mechanisms and institutions for the formation and execution of a common European foreign posture represents a microcosm of the wider story of European integration within the EEC framework. For within this evolutionary tale are encapsulated all the principal ambiguities, conflicting forces and contradictions which have characterised the European Community from its inception.

To understand the European process it may be useful to contrast it with other non-unitary actors and in particular the federal state. Typically, in the history of most federal states, the international environment provided one of the cardinal incentives for initial unification or for the movement from confederal arrangements to some form of federation. ${ }^{1}$ And although constitutions of federal states, normally based on a doctrine of enumeration of powers between central government and the constituent units, describe with greater or lesser detail the respective competences allocated to each level of government, "... it is usually assumed that the foreign relations of a federation will be controlled predominently, if not exclusively, by the general government of the whole territory."2

A useful prism through which to illustrate this point is provided by the manner in which states contract international treaties. Let us examine first the collective experience of federal states which in fact demonstrates strong converging trends. The first issue concerns the question of international personality and capacity of member units of a federation. In many federations

* This is a modified version of Chapter I of Ilan Greilsammer and Joseph Weiler, Europe's Middle East Dilemma: The Quest for a Unified Stance, Boulder, Westview Press, 1986.

1 This theme is discussed more fully in Weiler, "The External Legal Relations of NonUnitary Actors: Mixity and the Federal Principle”, in Mixed Agreements (D. O'Keefe and H. G. Schermers eds.). See also Capelletti, Seccombe, Weiler, Integration Through Law (Introduction) (1986).

2 K.C. Wheare, Federal Government 169 (1963). 
this is denied constitutionally. Historically, even in federations such as the Federal Republic of Germany, Switzerland and to a certain measure the $\mathrm{USA}^{3}$, where there is some constitutional provision for member state international capacity, the actual exercise of such capacity has been dying. In recent times member states have rarely concluded independent treaties and have preferred to rely on the federal government with, as in the FRG, certain constitutional guarantees.

For its part, the world order (as encapsulated in public international law) takes little cognizance of the internal structure of federations: "Federal clauses" were always an inconvenient disturbance, at best tolerated and for the most part resisted, and both international capacity and international responsibility (the hallmarks of statehood and sovereignty) were only grudgingly and to a limited and declining extent accorded to constituent units of federations. From the legal point of view the world order is composed of unitary actors.

Not surprisingly, the internal (central) treaty-making power has been construed in most federal states in very wide terms. With a few theoretical exceptions the general trend is to recognize plenary treaty-making power limited by substantive constitutional provision but not by allocational ones. In all federal states, treaty-making power has not been limited to those areas over which the central government enjoys internal competences. And to cap it all, with the well known exception of Canada, and to a lesser extent the Federal Republic of Germany, federal (central) governments have been allowed by constitutional courts to implement treaties even if the implementing legislation crosses the internal demarcation of competences. Court after court has ruled that the exigencies of the external environment may override the internal federal demarcation.

Even if federations have a unitary external posture, it is arguable that the federal principle may vindicate itself in the internal process of foreign policymaking. Thus, in schematic terms, although it will be the US qua single state that concludes a treaty, senate approval could mean that constituent state interests would have been represented before ratification. To be sure, the role of parliamentary organs at the central level in the foreign policy process, especially in the US (but not in the European Community) has increased dramatically in recent years by imposing a measure of democratic control on the foreign policy field, historically regarded as a domaine réservé of the executive. But it could be argued that federal legislative organs even if designed to represent state interests have lost some of their mediatory function and have come to be regarded as part of the central authority displaying less sensitivity, or ability, in this sphere to represent their original

3 While the U.S. Constitution forbids the States from entering into any "treaty" or "alliance", a State may, with the consent of Congress, enter into an "agreement or compact ... with a foreign power". U.S. Const. art. I, $\ 10$. 
constituencies. Indeed, the process of foreign policy making is for the most part not conceived as being a legitimate interest of the constituent units qua units of the federation.

We should note however that this unitarist image must be qualified, at least partially, by political fact. Across the board we find that even where federal governments were given the possibility to encroach on member state competences through the exercise of treaty-making power, they have been very reluctant to conclude treaties which would have that effect. Moreover, there is a growing trend of evolving structures of cooperative federalism to overcome some of the problems to which the unitary solution gives rise. It remains, however, true that in the strict constitutional/international legal sense, federal states face the world as unitary actors and their internal policy process is essentially centralised.

How can we explain then that in the federal state, based on a notion of division of competences, such exclusive power would be allowed to rest in the hands of central government? Historically the rationale behind this exclusive concentration of foreign-affairs powers in the hands of the central government rested on two premises:

The first premise was that in matters of external relations a united posture would maximize the power of the individual units. This was particularly felt in the areas of defence and security. One can go even further. The unified foreign posture and international personality emerged probably as the single most important factors in giving federations, in their formative years, the quality of statehood as compared with all other types of federal arrangements. This was certainly true in the formal relations among actors in the world order and recognized in public international law. ${ }^{4}$ But a unified foreign and defence posture did not have only an external and formal significance. The federation's flag, the "federal" army, the "national" hymn and other such paraphernalia - all being, at least in part, expressions of the unified posture vis-à-vis "outsiders" imbued the formal distinction with social meaning. Thus even at the social and human level, whereas citizens of a federation could in internal matters regard themselves as being Texans or Tasmanians, vis-à-vis the outside world they would normally regard themselves as respectively Americans or Australians. To be a federal state was to have a unified foreign posture.

But this premise alone would not explain the willingness of the member states of federations - expecially in formative periods where traditionally there was a much stronger insistence than today on preserving the rights and autonomy of the constituent units - to vest the execution of virtually all foreign power in the hands of the central government.

It is here that the second premise comes into play. For there was a widespread belief that matters of foreign policy and contacts with foreign

4 See Oliver, The Enforcement of Treaties by a Federal State, 141 RDC I 333 (1974). 
states would, ipso facto, interest the general government and would, by contrast, be of lesser relevance to the constituent states and the domestic powers usually ${ }^{5}$ vested in them. It seemed therefore that one could gain the benefits that a unified foreign posture was to yield without encroaching on the internal division of powers between the two levels of government as regards domestic policy.

It is this premise which accounts for the fact that until the advent of the European Community there was with few exceptions ${ }^{6}$ no such thing as a genuine "federal foreign policy". Federal states distinguished themselves by their unified, non-federal, external relations.

Finally, there was perhaps the belief, characteristic of early federal theory, that the representation of state interests within federal government, would give sufficient protection to state interests - if indeed these would exist.

The first premise whereby a united posture is more effective than individual foreign policies, arguably retains much of its force till this day and constitutes the principal mobilizing drive for those pushing for further integration in the external posture of the EEC. By contrast, it is doubtful whether the second premise was ever wholly correct? ${ }^{7}$. And in today's interdependent world it is clear that there are few areas of so-called domestic jurisdiction which do not have some international dimension and equally few areas of international activity which do not have internal ramifications. ${ }^{8}$

We are now in a position to understand the evolutionary dialectics and conceptual framework of the foreign relations apparatus of the EEC. The emergence of European institutions and mechanisms for the formulation and conduct of a common external posture was not a result of a preconceived and rational design. It was instead the outcome of a process conditioned by conflicting interests and forces.

On the one hand, the belief in the alleged benefits of 'speaking with one voice', at least in some contexts, provide the Member States with integrative impetus. Moreover, the fact that internal matters tend to have an international dimension meant that even in areas where the Community was not vested with explicit external competences, there was pressure to create such competence so as to enable the EEC to pursue in an adequate manner its internal policies.?

On the other hand it is easy to understand the source of Member State ambivalence and resistance to a unified foreign policy: The very fact that historically a unitary external posture and single international personality

5 Of course there was an interest in questions of foreign trade even by constituent units.

6 The Soviet Union claims some sort of federal foreign posture with the advent of Byelorussia and the Ukraine. See Weiler, note 1 supra at $35 \mathrm{ff}$.

7 Note 4 supra.

8 See Case 22/70 [1971] ECR 263.

9 See Pescatore, "External Relations in the Case-Law of the Court of Justice of the European Communities, 16 CML Rev. 615 (1979). 
emerged as the hallmarks of the federal state - distinguishing it from other non-unitary entities - was and remains a potent potion, maybe even poison, for the Member States. Even the most integration minded of these did not bargain for the creation of a European "super-state" under whatever federal nomenclature. The area of foreign relations acquired thus a sensitivity unparalleled in any other field.

Furthermore, the patent falsity of the abovementioned second premise, that one can delimit the interaction of internal and external powers, means that were the Member States to vest the exclusive conduct of foreign policy in Community institutions they would not only lose their much cherished international personality, but would also be impeded from autonomously conducting national policy in areas which at first sight might appear to be wholly within domestic jurisdiction. The history of all federal states has demonstrated clearly that implementation by federal government of federal foreign policy involves inevitable excursions into and encroachment of the areas reserved to states. ${ }^{10}$

Given then these conflicting interests we should not be surprised to find that all activities of the Community in the international environment are imbued with a strong ambivalence on the part of the Member States. The alleged external utility of the joint posture is always weighed against the alleged individual statal loss of power.

We shall analyse first the initial pattern and evolution of the Community posture in the external economic relations field, and then develop more fully the structure and purpose of its political foreign posture through the Framework for Political Cooperation. Finally in this chapter we shall indicate the breakdown between the two external activity areas and reflect on a conceptual and evaluative framework into which the external posture may be fitted. The way will then become open to approach the central theme of this volume - European policy towards the Arab-Israeli conflict.

\section{The Treaty Framework - The External Relations of the EEC}

\section{The starting point}

The EEC was created in 1958 against the failure of the more ambitious proposals in the mid-50s for European political and defence communities. European integration was to evolve on the economic plane. The reluctance of the Member States to extend their joint venture to defence (outside the NATO framework) and to foreign policy was reflected in the Treaty of Rome in two ways.

First, an "iron curtain" was drawn between what later became known as "high" and "low" politics. The Community was to have inter-national

10 See I. Bernier, International Legal Aspects of Federalism (1973). 
competence only in respect of external [economic]relations (low politics). The Member States would retain in their individual capacity exclusive competence over foreign affairs (high politics). There could thus be a series of European commercial and trade agreements with many countries, including Israel commencing already in the early 60 s. ${ }^{11}$ There could not be - until the creation of the Framework for Political Cooperation in the late $60 \mathrm{~s}-$ even the semblance of a joint European policy towards the political issues besetting the region. Here one would have to have a French policy, a Dutch policy, and so forth.

Anticipating a theme to which we may return below, this very example serves to illustrate the untenability of a conceptual and operational distinction between high and low politics - between external relations and political cooperation. For one has to be singularly blind and dogmatic to believe that external economic relations operate in a political vacuum and that one can pursue a vigorous foreign policy without recourse to economic instruments. ${ }^{12}$ The Member States were to learn that lesson slowly and reluctantly. The theoretical division, so neatly drawn in the Treaties setting up the Community, was to become slowly an unworkable solution, despite its ideological attraction.

Second, even within external relations, the international capacity of the Community expressed in particular through its treaty making power was explicitly granted only in relation to the international trade policy of the Community. Thus the Treaty provides that

the common commercial policy shall be based on uniform principles, particularly in regard to changes in tariff rates, the conclusion of tariff and trade agreements ...13

The Treaty did provide for the conclusion by the Community of association agreements in fairly wide terms:

The Community may conclude with a third State, a union of States or an international organisation agreements establishing an association involving reciprocal rights and obligations, common action and special procedures ... ${ }^{14}$

But despite this wide language, when association agreements covered matters which could not be regarded as coming under the general subject matter of international trade, the Member States prevented the Community from concluding such agreements alone and insisted on joint participation. Here as well the untenability of the initial document is evident. Could the Community which had explicit competences, at times even exclusive, over matters such as fisheries and transport, operate as if the Europe of the Six (and later Nine, Ten and Twelve) were a planet with no connections with third states and other international actors? Could there be a Community fisheries

11 The first agreement with Israel was concluded in 1964.

12 This was evident in the debate over the participation of the EEC in the Commodity Agreements: Opinion 1/78 [1979] ECR 2871.

13 Article 113 EEC.

14 Art 238 EEC. 
policy without Community agreements [treaties] with other fishing nations sharing the same high seas?

\section{Mutation of the starting point}

For these and other reasons it was not long before the initial Treaty formulae were subjected to powerful mutations. The pattern of external relations today is a far cry from the initial blueprint. We may mention in particular the following developments in the context of external economic relations:

a) In quantity, external contacts of the Community formalized through international agreements have grown and run into the hundreds. The Community also has a network of international contacts, through legations, which is equally impressive. ${ }^{15}$ Any expectation that the external relations of the Community could or would be contained was inevitably proved erroneous.

b) This growth was and is connected to two constitutional changes effected by decisions of the European Community Court of Justice. In a landmark decision of $1971^{16}$, the Court gave a much wider interpretation to the treaty making powers of the Community and hence to its ability to engage in international affairs. The Court held first that:

in its external relations the Community enjoys the capacity to establish contractual links with third countries over the whole field of objectives defined in Part One of the Treaty ...

It added that:

[s] uch authority arises not only from an express conferment by the Treaty - as is the case with Articles 113 and 114 for tariff and trade agreements ... but may equally flow from other provisions of the Treaty and from measures adopted, within the framework of those provisions, by the Community institutions.

Thus the treaty making power of the Community would extend to all areas in relation to which the Community had internal power. The confinement of Community agreements to international commerce and trade was removed.

c) In a third development the Court, in the so-called Rubber case gave an extremely wide interpretation to the reach of the Community Common Commercial Policy. This was significant since in relation to this policy the Community was not only entitled to conclude agreements but had exclusive competence vis-à-vis the Member States. ${ }^{17}$

Specifically the Court held that:

[i]t is... not possible to lay down, for Article 113 of the EEC Treaty, an interpretation the effect of which would be to restrict the common commercial policy to the use of instruments intended to have an effect only on the traditional aspects of external trade to the exclusion of more highly developed mechanisms...

The same conclusion may be deduced from the fact that the enumeration in

15 Most First and Third-World countries have legations to the EC.

16 Note 7 supra.

17 Note 11 supra. 
Article 113 of the subjects covered by commercial policy (changes in tariff rates, the conclusion of tariff and trade agreements, the achievement of uniformity in measures of liberalization, export policy and measures to protect trade) is conceived as a nonexhaustive enumeration which must not, as such, close the door to the application in a Community context of any other process intended to regulate external trade.

These developments could at first sight suggest a process not unlike that which occurred in most federal states: a monopolization of external contacts by, and a concentration of treaty making power in the hands of, the central government. This conclusion could not be further than the truth for reasons inherent in the institutional structure of the Community amplified by its political process. In particular we can mention the following two factors:

First, we must remember that the above process of expansion was confined to areas of external economic relations, however widely defined. Explicit problems of, say, defence and other issues of foreign affairs in the classical sense remained entirely in the hands of the Member States.

Second, the Member States reacted to the increased margin of competence of the Community to engage in external relations by tightening their grip on the actual procedure of the treaty making, negotiating and implementing process. It must never be forgotten that the central legislative/decisional body of the Community - the Council of Ministers and its sub-organs consists of representatives of the Member State governments. As such it was able over the years to reduce the autonomous role of the Commission in the external relations process in all its phases.

Although Article 228 and Article 113 provide explicity that negotiations of Community agreements would be in the hands of the (supranational) Commission, and only final conclusion of the agreement would fall to the (intergovernmental) Council of Ministers, the Member States were able to emasculate this provision. They did so by insisting that a seemingly innocuous sub-committee of the Council established by the Treaty to assist the Commission in negotiations would in fact hold the latter to a mere plenipotentiary status. In addition, by insisting all too often that prospective Community agreements be concluded on a mixed basis - by the Community and the Member States together - there would be automatic Member State representation at the negotiation phase.

Thus, although the external and internal environment forced the Community to an expanded external economic posture, the process of its execution moved away from a "supranational" centralised model, to a more classical intergovernmental one. As Community external relations grew so did the role of the Member States within this process. This has been a classical trait of almost all Community activity. 


\section{The Emergence of the Framework for Political Cooperation ${ }^{18}$}

\section{The Starting Point}

Whereas Community activity in the field of external economic relations found its basis in the Treaties themselves, foreign policy proper (high politics) was as we have seen, excluded from the Community process. The creation of the Framework for Political Cooperation as a mechanisms for joint European activity in this area might therefore seem as a process distinct and even detached from the internal Community processes described above. Although this is the classical view taken in the literature, a closer look will reveal that the same forces which shaped the evolution of external relations mechanisms conditioned the development of Political Cooperation.

There was a multiple rationale for the creation of the Framework. The "objective" reason was of course rooted in the claim that given the actual state of internal European integration, the failure to operate in the field of foreign policy was a waste of a significant potential. In other words that a common European foreign policy would be able to project into the world environment the joint power of the partners, a power that was greater than the sum of the individual units. A Europe which would act and react as a single actor to world events would by this vision be more effective than before.

There was also an internal, "subjective", reason. In 1969, when the idea of the Framework was concretely launched, the Community was emerging from of period of sustained political stagnation associated with de Gaulle's long term in office and recovering from the most immediate after-effects of the Luxembourg crisis. ${ }^{19}$

The Community was to be "relaunched"20 and alongside the decision to accept the three new Member States, the principal concrete political initiative was the plan to set up the Framework for Political Cooperation. We may call this second reasoning the "reflexive" function of European Political Cooperation; later, the interplay between the active-reactive external function and the reflexive internal function will provide us with an important evaluative tool.

Whereas both the objective and subjective rationale pointed towards a rosy future in terms of the Framework for Political Cooperation, we find in reality already at its inception powerful countervailing forces. Recalling our brief account of the evolution of external relations, it should come as no surprise that the first important steps in the evolution of Political Cooperation

18 For an up to date treatment on which we relied and a full bibliography, see Stein, European Political Cooperation as a Component of the European Foreign Affairs System", 43 ZaoRV 49 (1983).

19 See Greilsammer, "Theorizing European Integration in Its Four Periods”, 2 Jerusalem J. Int'l Rels 129 (1976).

20 Id. 
coincided with the institutionalized strengthening of the intergovernmental component in the European Community, namely the creation of the European Council of Heads of State and Government. This appears to be an almost constant factor in the mature phases of European integration. Substantive progress is bought at the price of decline in the unique decisional characteristics of the Community. ${ }^{21}$ In this case, the equation was at its extreme: the Framework for Political Cooperation was to be completely outside the Treaties. It was not sufficient that in the Community of the 70 s, in which the Luxembourg Accord was an accepted way of life, the decisional process was dominated totally by the intergovernmental Council of Ministers, often at the constitutional expense of the Commission. For Political Cooperation, at least as initially conceived, any EEC contact was considered anathema. The European Political Cooperation institutions and procedures were thus to be insulated from any "contaminating" European Community contact. In a famous incident the Foreign Ministers of the Community were forced to end a meeting in Copenhagen wearing one hat, and travel to Brussels to meet wearing their other hat. ${ }^{22}$ The Commission was emarginated from the Political Cooperation procedures or, at best, barely tolerated. It is telling that the only Community organ which had an official role in Political Cooperation was the European Parliament. But, not only was this an organ which had virtually no impact on the Community game, especially in the predirect-election days, its role in Political Cooperation was extremely limited. ${ }^{23}$ This separation, symptomatic of the inherent contradiction of the process of European integration, was reflected in the very definition of the objectives of the Framework.

\section{The setting up and initial evolution of the Framework}

At the famous December 1969 Hague Summit, the Heads of Government and State launched the idea of the Framework for Political Cooperation by agreeing

to instruct the Ministers for Foreign Affairs to study the best way of achieving progress in the matter of political unification... The Ministers would be expected to report before the end of July 1970.

The result was the October 1970 Luxembourg Report. Later we shall see the mechanisms of the Framework for Political Cooperation but we should note here the cautiousness in which the objectives are expressed. Thus the Ministers defined the objectives as follows:

to ensure, through regular exchanges of information and consultations, a better mutual understanding on the great international problems;

21 See Weiler, "The Community System: The Dual Character of Supranationalism", 1 Y.B. Euro. L. 267 (1981).

22 Recalled in Stein note 17 supra.

23 See J. Weiler, "The European Parliament and its Foreign Affairs Committees". 
to strengthen [Member State] solidarity by promoting the harmonization of their views, the co-ordination of the positions, and where it appears possible and desirable, common actions.

The language is extremely cautious, the objectives limited, and the cleavage between the high aspirations of the Hague - full economic and monetary European Union within a decade - and the grim down-to-earth realism of the Ministers very marked. The operational details set up by the Luxembourg Report were not far reaching. The Framework for Political Cooperation was to be non-organic. It would depend on its activities on the co-ordinated apparatus of the Member States - ministerial meetings and the like - and was to be outside the EEC framework. Thus the Report provided drily:

Should the work of [the Framework for Political Cooperation] affect the activities of the European Communities, the Commission will be invited to make known its views.

In the 1972 Paris Summit, the Heads of State and Government endorsed the creation of the Framework, indeed they sought its improvement by increasing the frequency of meetings among the Foreign Ministers and saw more clearly the linkage of the Framework to the EEC. In the language of the final communiqué:

They considered that the aim of their co-operation was to deal with problems of current interest and, where possible, to formulate common medium and long-term positions, keeping in mind, inter alia, the international political implications for and effects of Community Policies under construction.

Interestingly, the idea of common action is played down; by contrast the relevance of the Community was spelt out more clearly in the past. The Framework for Political Cooperation was consolidated in the July 1973 second Ministerial Copenhagen Report. Beyond the self-congratulatory rhetoric of this report the following points were of significance. Although the basic objective remained the same, the operational machinery was strengthened and in most important aspects was to become the foundation of the Framework to this day. Significantly, each Member State undertook

as a general rule not to take up final positions [on common European foreign policy problems - however these may be defined] without prior consultation with its partners within the framework of the political co-operation machinery.

The linkage to the Community was made more explicit even though the Report insisted on the principled distinction between the Framework and the Community. We can only mention in passing a point to which we shall return in detail in subsequent chapters: The test of the Framework for Political Cooperation as consolidated by the Copenhagen Report was to come more rapidly than the Minister envisaged with the outbreak of the Yom-Kippur War in October 1973. The Framework proved totally inadequte to deal with the situation and Europe was a shameful disunity and individual Member State self-interest. As we shall analyse below, and return to in our evaluative 
conclusions, the Framework did provide a useful mechanism for an orderly capitulation to the Arab oil interest.

If we skip thirteen years ahead from the first Luxembourg Report to the most recent Solemn Declaration on European Union ${ }^{24}$ signed in Stuttgart in June 1983, we shall find that in terms of the objectives there have been no dramatic changes in the conception of the Framework for Political Cooperation. The Member States acknowledge that "increasing problems of international politics [render] necessary [the] reinforcement of European Political Cooperation". And yet despite this acknowledgement the new formulation of the objectives of the framework underscores the inherent ambivalence and contradiction in the notion of a European foreign policy. It is worth citing the new formulation in extensu. The Solemn Declaration defines the following measures:

intensified consultations with a view to permitting timely joint action on all major foreign policy questions of interest to the Ten as a whole;

prior consultation with the other Member States in advance of the adoption of final positions ... The [Member States] underline their undertaking that each ... will take full account of the positions of its partners and give due weight to the adoption and implementation of common European positions when working out national positions and taking national action;

development and extension of the practice by which the views of the Ten are defined and consolidated in the form of common positions which then constitute a central point of reference for Member State policy;

coordination of positions of Member States on the political and economic aspects of security;

increased contacts with third countries in order to give the Ten greater weight as an interlocutor in the foreign policy field;

closer cooperation in diplomatic and administrative matters between the missions of the Ten in third countries;

the search for common positions at major international conferences attended by one or more of the Ten and covering questions dealt with in Political Cooperation.

It is clear thus that one is not speaking here of a single policy, with a single policy making apparatus and a single policy execution apparatus. The objectives of the Framework are in fact inherent in the name: Political Cooperation. The major actors remain the Member States. Where the interest exists joint action would be encouraged with the Framework mechanisms facilitating this joint action. Even the formulation of a common position, the hallmark of the Framework, is to serve as a basis and reference point for national foreign policy. As if to underline this point one can cite the Greek "reservation" at the time of signing the Solemn Declaration in which it stated that:

in signing this declaration Greece states that nothing may restrain its right to determine its foreign policy in accordance with its national interests.

24 Solemn Declaration; Bull EC 6-1983, point 1.6.1. 
In many ways then, Political Cooperation as initially conceived was the story of the mountain which turned out to be a molehill. However, as in the case of external relations, the dynamics of the international environment as well as internal political pressures forced certain mutations on the original framework. The result is still a far cry from a veritable Europe speaking, let alone acting, with one voice. And even today the sober conclusion of von den Gablentz that the Framework for Political Cooperation constitutes "... the world's most advanced model of collective diplomacy ... [but] ... neither the Community nor the Nine seem to have managed to perform the essential task of any foreign policy, namely to convert internal strength and resources into external influence on world affairs" 25 retains its truth today, five years after it was written.

\section{How the Framework for Political Cooperation Works 26}

For our purposes a detailed description of the Framework is not necessary. A brief résumé will be sufficient for present purposes. Since launching the concrete idea of the Framework in the summit of 1969, the institutional aspects of Political Cooperation have been revised several times leading to the following pattern of institutions and mechanisms. ${ }^{27}$

1. At the apex of the institutional framework - formally, in fact, above it stands the European Council of Heads of State and Government which represents since 1974 the formalization of hitherto irregular meetings which characterised Community life since the early 60s. The European Council, itself an organ, strictly speaking outside the Treaty framework, ${ }^{28}$ is thus the ultimate forum for coordination of, and pronouncements on, foreign policy issues. The European Council can be seised of issues by its own motion and/or on the recommendation of the lower tiers of the Framework.

2. At the formal head of the Framework stand the foreign ministers who constitute the mainstay of the framework, with meetings taking place at least 4 times a year and in reality far more frequently. Their formal forum is the Conference of the Foreign Affairs Ministers meeting on European Political Cooperation matters. Their function is both constitutive - they may issue declarations in the name of the Framework - or preparatory for meetings of the heads of state and government.

3. A political committee (the Davignon Committee) consisting of the directors of political affairs in the ten foreign ministries, meet regularly and serve as the main continuous preparatory forum for the political echelons of

25 Von den Gablentz, "Luxembourg Revisited or the Importance of European Political Cooperation”, 16 C.M.L. Rev. 685 (1979).

26 See Stein note 17 supra and references therein.

27 See text to note 23 supra.

28 Although outside the Treaty framework, the European Council is very much part of the EC machinery a fact fully recognized in the Solemn Declaration, note 23 supra. 
the Framework for Political Cooperation. A possible parallel within the Community bureaucracy would be the COREPER which prepares the Council of Ministers' meetings. Although the political committee provides a measure of continuity transcending, for example, political change of office in any one of the Member States, the Framework for Political Cooperation has no permanent secretariat despite the frequent calls to establish one. The presidency of Political Cooperation moves with the presidency of the Community at six-month intervals and the only improvement to the disruption inherent in this modality has been the tripartite model whereby the actual presidency, the previous one and the future one meet in a coordinatory forum throughout the structure of the Framework. ${ }^{29}$

4. Working groups may be set up to study specific issues and they, in turn, may appoint groups of experts. The latter do not have an independent existence and they are strictly issue or region oriented.

5. A "Group of Correspondents" in the various foreign ministries has been set up. They are the Framework for Political Cooperation "desk" in each capital and their task extends also to monitoring and following up Political Cooperation decisions and declarations.

6. Embassies of the Ten are associated within the Framework with a view to a two-way coordination with the European centre. Likewise, the Member State representations within international organisations, especially the UN, have the same association. The ambassadorial contact becomes important in times of crisis such as the Iranian affair. A special telex system COREU is used to handle the communication traffic of the Framework. It is said to carry a significant amount of communications.

7. In the recent 1981 London Report, the foreign ministers "codified" their procedures. It contains improvements to the operational side of the framework (such as better preparation of ministerial meetings) and a better defined role for the rotating presidency as the spokesman of the Ten.

The most noticeable improvement has been the establishment of crisis procedures:

The Political Committee or, if necessary, a ministerial meeting will convene within forty-eight hours at the request of three Member States.

The same procedure will apply in third countries at the level of Heads of Mission. In order to improve the Capacity of the Ten to react in an emergency, working groups are encouraged to analyse areas of potential crisis and to prepare a range of possible reactions by the Ten.

In most other respects the London Report did not adopt any radical changes.

29 See 1981 London Report on EPC, Supp 3 to Bull. EC, 1981. 


\section{European Political Cooperation and the EEC ${ }^{30}$}

In some sense the original rigid distinction between the Community and the Framework for Political Cooperation was not only counterproductive but also impossible. At its highest echelons the persons constituting the leadership of both structures were one and the same and artificial devices such as separate agendas and even separate meeting places could hardly create a de facto separation between the two. Now, not only do the ministers meet in one session, albeit with different agendas, first as the EEC Council of Ministers and then as the Conference of Political Cooperation, but since 1974 in the informal Gymnich style meetings the agenda may include both Community and European Political Cooperation items.

This sense of reality asserted itself also as regards Commission participation in the Framework for Political Cooperation. The 1981 London Report finally affirmed:

Within the framework of the established rules and procedures the Ten attach importance to the Commission of the European Communities being fully associated with political cooperation, at all levels.

This does not mean that the Commission is a full-fledged participant. It is not privy to the full traffic of COREU nor is it a participant in the Group of Correspondents. On the other hand it participates, albeit without decisional power, in meetings of the European Council, the Conference of Foreign Ministers and the Political Committee of Political Cooperation. If there are problems of coordination, these will assert themselves at the operational level, say within various international organisations, where the division of competences between the two setups is not clear, rather than at the central European Community level.

The stickiest point of all, however, is not the organizational cooperation and contact between European Community and the Framework for Political Cooperation. It is the substantive competences of the Community that are at issue. As we noted above the resistance of the Member States to incorporation of Political Cooperation within the Community derives from two interrelated factors:

a) The Member States do not wish to submit themselves in matters of foreign policy to the Community decisional and normative discipline.

b) They do not wish the Community, for its part, to increase its competences into fields considered outside the Treaties.

But as we have maintained all along, world affairs do not arrange themselves in a neat way respecting the division of competences between Community external relations and European Political Cooperation. Thus, for example, it is absurd to think that a decision to open trade negotiations with, say, Yugoslavia or even Israel - matters coming within the exclusive external

30 See Bonvicini, "The Problem of Coordination between Political Cooperation and Community Activities”, 12 Lo Spettatore Internazionale 55 (1977). 
economic relations competence of the EEC - would not be influenced by political considerations which under current definitions fall under the exclusive jurisdiction of the Member States within the Framework for Political Cooperation. The question may be asked in an even more dramatic form. May decisions on EEC trade and cooperation agreements be formally taken on political grounds. This may seem to be an unreal and hair-splitting problem, but it has far reaching constitutional repercussions. In reality, the answer is of course yes. But, if this de facto reply is translated into juridical forms, it would seem that an eventual merge between Community and Political Cooperation is inevitable.

The sensitivity of this issue and its political significance are easily demonstrated in the context of economic sanctions taken by the Community/Member States as a political measure. As will be recalled, immediately after the outbreak of the Falklands/Malvinas crisis, Britain imposed full economic sanctions on Argentina. This in itself is already problematic since economic sanctions, in dry legal language mean a breach of the Community's common commercial policy with its export and import regimes. However, the Treaty provides in Article 224 for the possibility of a Member State finding itself in war of departing from the normal regime, albeit after consultations.

What then of the position of the other Member States who did not find themselves at war with Argentina? It is plausible that the language of Article 224 would allow in such a situation other Member States joining in the sanctions on an individual national basis. The Article speaks of

measures which a Member State may be called upon to take in the event of ... war or serious international tension constituting the threat of war...

Be the legal argument as it may ${ }^{31}$, the Member States took another course of action. The Preamble to Council Regulation (EEC) 877/82 of April 16, 1982 - a strict Community legal measure - provided, inter alia, as follows:

The Council of the European Community

Whereas the serious situation resulting from the invasion of the Falkland Islands by Argentina ... has given rise to discussions in the context of European political cooperation which have led in particular to the decision that economic measures will be taken with regard to Argentina in accordance with the relevant provisions of the Community Treaties;

...

Whereas ... it has proved important to take urgent and uniform measures; whereas the Member States have therefore decided to adopt a Council Regulation pursuant to the Treaty;

Whereas ...the interests of the Community and the Member States demand the temporary suspension of imports of all products originating in Argentina; . .

31 For a full discussion see Kauper, "Community Sanctions against Argentina: Lawfulness under Community and International Law" in Essays in European Law and Integration (D. O'Keefe and H. G. Schermers eds. 1982). 
has adopted this Regulation:

...

Imports of all products originating in Argentina ... are hereby suspended.

This remarkable document is interesting in several senses: First, it illustrates most clearly the almost inevitable breakdown on the institutional level of the demarcation of EEC and EPC. Second, it illustrates that political will existing, the Ten within the Framework for Political Cooperation have at their disposal more than declarations as an instrument of foreign policy. Thirdly, the formal decision imposing sanctions was constituted on the basis of Article 113 of the Treaty of Rome, and was thus to be considered as a measure coming fully within the exclusive common Commercial policy of the EEC. Here then was a case whereby not only were the Member States within the Framework for Political Cooperation "borrowing" a Community instrument to further their political goals, but a strict reading would suggest that henceforth such a decision to impose economic sanctions could legitimately be taken by the Community decisional process, that the decision would be binding on recalcitrant Member States and, most dramatically of all, that since the common commercial policy was exclusive, such action could not be taken by the Member States outside the Community framework. ${ }^{32}$ We have here then in a nutshell both the utility - in terms of efficacy of a Community foreign policy action and the danger - in terms of loss of autonomy - to the Member States of such a construction.

Needless to say the Member States did not remain aloof to the potential dangers. For example, Denmark, relying on a dubious interpretation of a safeguard measure in the Treaty, insisted on implementing the sanctions decision by an act of its own parliament, reasserting Member State sovereignty and underlining the exceptional character of the particular sanction situation. Interestingly, not much later, as we shall see, the Community "froze" for a short period the negotiations for the financial instrument in the Israel - Community Cooperation Agreement.

It is thus inevitable that in the future the artificial gap between the Community and the Framework for Political Cooperation will narrow even further even if a formal integration of the two is still far away.

\section{Political Cooperation Policy Making: Active, Reactive and Reflexive}

The mechanisms which we have described above allow the Member States to coordinate their positions and, if the political will exists, to adopt a common position and even common action. Given this limited operational range, what are the realistic gains which may be obtained through the Framework? Let us consider the Framework for Political Cooperation in the context of the classical distinctions, borrowed form the analysis of economic policy,

32 Id. 
between aims/objectives and instruments/measures. ${ }^{33} \mathrm{It}$ is here that our earlier allusion to active, reactive and reflexive policy may become fruitful.

It is important to remember that these notions are essentially didactic. In reality one will fuse into the other. But they may help us in evaluating the successes and failures of the Framework. If we consider the aims and objectives of the Framework, an active policy will that which seeks to influence events directly; to posit "Europe" as an initiator of policy and a veritable actor. A reactive policy will be one which is less concerned with direct influence, but rather with containing world events so as to minimize costs to the reactive power. Under various guises these two elements exist in most inter-statal foreign policy making. It should however be noted, especially in the context of the Middle East conflict, that the transnational nature of the reactive policy within the Political Cooperation Framework allows the evolution of what has been called the shield effect. Member States may adopt a reactive position, for example critical of Israel, and attribute it to the discipline of the common European policy established within Political Cooperation. The shield effect could, in principle, operate also on the internal political level whereby a government, in the face of, say, internal parliamentary or popular opposition to a course of foreign policy, could explain it as following the common European line.

European Political Cooperation ushers forth a third policy component, additional to the active and reactive ones, namely reflexive policy. Here the chief, though rarely exclusive, concern will be the actual formation of a common policy as an integrative value per se. The shield effect presents itself here in an even more curious manner for activity within the Political Cooperation Framework could be regarded as substitute policies - an empty gesture of European make-believe integration but in reality a cover up for a failure to deal with the more pressing internal problems of Europe.

As we have emphasised, the analysis of the aims and objectives of the Framework must be sought in all three elements interacting and overlapping. Each of these provides us, however, with an instrument which may be useful in explaining, in systemic terms, the activities of the Ten vis-à-vis Israel and the conflict. We shall use these categories in our concluding remarks to the study.

Finally, the active-reactive-reflexive triangle may relate also to the instruments and measures adopted for the prosecution of the policy. What instruments are available to the Framework? In one sense none at all-except the common declaration (at times a potent instrument in international affairs). In another sense, the Framework has at its disposal the entire array of instruments of the Member States as well as those "belonging" to the Community. The tendency to use the declaration as the most common output

33 See Daintith, "Legal Analysis of Economic Policy", Working Paper no. 27 of EUI, Florence. 
of the Framework might suggest a paucity of means which conditions a reactive/reflexive orientation. This in our view would be a mistake. Given the political will, the Member States have at their disposal not only the Community instruments which can be utilised by way of retorsion or sanction but also every combination of national policy instrument. If the Framework has failed to assert itself actively the reason lies in the lack of political will or, indeed, substantive agreement among the partners and not in the absence of instruments.

\section{Towards a Revised Concept of a European Foreign Policy}

How then are we to assess these mechanisms developed for a European foreign policy? The tendency in the literature has often been to dismiss European foreign policy, and especially the Framework for Political Cooperation as a failure, as procedural substitutes for substantive accord, as entirely reflexive with no active or even reactive element. To the extent that one looks at substantive results we cannot but share in these pessimistic conclusions. At the same time one should not minimize the enormous task which the Member States face. For they are trying to achieve something which is completely novel and untried in the international arena. The basic premise of the foreign posture is, in the language of the Hague Summit:

a Europe composed of States which, while preserving their national characteristics, are united in their essential interests.

The federal state experience, as we already noted, would suggest that the task of preserving national characteristics and statehood while operating a common foreign posture is impossible. And indeed much of the negative criticism of the Framework for Political Cooperation is typically rooted in a view which has been conditioned by the foreign policy concept developed in other non-unitary entities and especially the federal state. The criticism is usually based on a criterion against which to judge the Framework which adopts an ideal type model "... in which common institutions are in a position to make and carry through all necessary foreign policy decisions for the Community and thereby replace the national foreign policy of the Member State". ${ }^{34}$

This ideal type model frequently and wrongly referred to as a federal model is not only alien to the original Political Cooperation concept which sought to separate the Framework from Community structures, but is also alien to the entire modern trend of European integration in the field of foreign policy which tends to suggest, both in external relations and in Political Cooperation, a new experiment of a non-unitary foreign policy process and foreign posture which may veritably be called the federal option of foreign affairs.

34 This view is explained in Allen, Rummel, Wessels eds. European Political Cooperation, (1982) who actually reject it. 
In order to justify what might appear to be a colossal terminological faux pas, two clarifications are necessary. The first concerns the concept of federalism. One often finds in the literature a persistent confusion between, and an erroneous identification of, two distinct concepts: federalism as an organizational principle and a federation (the federal state) as one specific manifestation of that principle. Elazar dispels the confusion by reference to the etymology of federalism the roots of which may be found

first in the biblical Hebrew term brit [covenant], then the latin foedus (literally "covenant") from which the modern "federal" is derived... Elaborated by the Calvinists in their federal theology, the concept formed the basis for far more than a form of political organization... The original use of the term deals with contractual linkages that involve power sharing - among individuals, among groups, among states. This usage is more appropriate than the definition of modern federations, which represents only one aspect of the federal idea and one application of the federal principle. ${ }^{35}$

Pescatore reflects the same reasoning in the concrete context of the European Community:

[T] he methods of federalism are not only a means of organising states. It would rather seem that federalism is a political and legal philosophy which adapts itself to all political contexts on both the municipal and the international level, wherever and whenever two basic prerequisites are fulfilled: the search for unity, combined with genuine respect for the autonomy and the legitimate interests of the participant entities. ${ }^{36}$

As we noted above the paradox is that federal states typically have a unitary non-federal foreign policy. By contrast it would seem that the Community and its Member States, clearly not a federation, are experimenting with a genuine federal foreign policy. In the legal world of external relations the key indicator of this development is found in the growing usage of the so called mixed agreement which involves participation in one and the same international treaty of the Community, its Member States and the third state. The first agreements between the Community and Israel were of a "pure" Community type. The more recent financial and cooperation protocols were already of this mixed federal type. In the political world the expression of this federal rationale is the Framework for Political Cooperation which rejects a unitarist centrist model in favour of the far more complex cooperative model.

How does federal conception measure up against the objectives of the Framework for Political Cooperation? Measured against the reflexive objectives it might seem that this federal conception is at odds with a vigorous notion of integration or at least a second best way of achieving integrational goals. We reject this conclusion as too simplistic. It rests on a crude, and perhaps outmoded centre-periphery model according to which

35 D. Elazar, Self Rule - Shared Rule 3 (1979).

36 P. Pescatore in T. Sandalow and E. Stein, Courts and Free Markets (Preface) (1982). 
political systems alway have a centre and periphery:

it is what happens in the centre which is politically important;

integration consists of constructing a powerful centre to which the periphery will be tied.

This has not only been the "pontifical" dogma of Commission and Court. It is an open or tacit conception in most though not all of the literature on the European Community.

The alternative to this view expressed in modern federal theory ${ }^{37}$ rejects the centre-periphery model and regards federalism as a structure which embraces the body politic rather then providing a focus. On this basis integration is no longer measured in terms of centre-periphery relationships but in the cohesion of the framework as a whole. Integration means a strengthening of whole and parts together and interdependently. Mixed agreement in the legal world and Political Cooperation in the political world correspond perhaps to this reflexive model. Certainly the Member States maintain their power and international profile - but they do enhance their capacity of acting out of a common position and on occasion even in concert.

Thinking along a federal conception necessitates a re-evaluation also of the active and reactive objectives and instruments of the system. Perhaps the holiest cow of Political Cooperation phraseology has been the oft-repeated slogan which postulated the Framework as enabling Europe to speak with one voice. This was to become not merely a political mobilizing instrument but also received an intellectual underpinning by those who have asserted that through this unison of voice and action Europe would best be able to translate or realize in the international field the enormous power which is consonant with the Ten's importance. Standard critique has been that through Europe's inability to speak with one voice this potential has not in fact been realized.

At the risk of slaughtering this holy cow, could it be that even on the nonreflexive level there might be advantages in abandoning, at least on occasion the One Voice concept? To be sure, in many situations it will be through concerted and unified action that Europe will best be able to make effective policy. At the same time there might be situations where the united concept will represent a loss: a loss of the potentialities inherent in a pluralistic foreign posture. One voice could represent a loss of subtlety, a need to choose single options and the risk of dichotomising reaction to such a single European policy. A pluralistic approach, perhaps more difficult to manage, gives Europe the potential to play a more subtle "game". It may use the special historical connexions of the Member States to the objects of the policy. Consider in this context the different relationships which, say, Holland, Denmark, Britain and Germany have towards, and the perception of those states in, Israel. It may be through different positions adopted by the Member 
States which could put pressure on other actors while keeping communications open.

We do not propose to elaborate this point much further. If we were to translate it to a slogan we should say that the descriptive and prescriptive trend of European foreign policy is towards a Europe singing like a choir remembering of course that the choir concept is not meant to replace totally the once voice. Sometimes the choir sings in unison, other times in several voices and occasionally there is even scope for soloists.

\section{Conclusion: European Foreign Policy and the Arab Israel Conflict}

We are now in a position to consider our central theme - the formulation and execution of European policy towards Israel in the context of the Arab-Israeli conflict. The conflict has been one of the principal objects of Political Cooperation statements and declarations. In many way it offers the best possible prism through which to evaluate the ability of Europe to realize the objectives of a common external posture. It illustrates all three policy components - active, reactive and reflexive - and to many shows up the mechanisms at their weakest and most ineffective. It also provides us with a laboratory to examine the different conceptual frameworks to understand European foreign policy making. The remaining contributions in this part of the volume will give flesh to the bare skeleton I have outlined. 


\title{
Europe and the Arab World: The Difficult Dialogue
}

\author{
Alain Dieckhoff
}

\section{Introduction}

\section{Framework}

In 1974, the inception of the Euro-Arab Dialogue was, on the part of the Arab States, an attempt to expand areas of cooperation between the Arab world and Europe: the EAD was organized as a form of associative diplomacy.

Several meetings of the EAD took place between 1975 and 1977 but the Dialogue reached a stalemate in 1978 after the signing of the Camp David agreement and the subsequent exclusion of Egypt from the League of Arab States. No more meetings were held until 1981 and after 1981 the EAD was resumed, but on an extremely slow tempo.

The aim of our study is to find out whether the institutional structures built up in 1974-75 are the most efficient to promote a dialogue between Europe and the Arab world. Were the internal structures strong enough to resist the inter-Arab quarrels and the different expectations of the European countries? Did not the structures of the Dialogue (22 members of the Arab League and 10 members of the EC) have an immediate effect on the difficulty of achieving tangible results? Have the inter-Arab contradictions (between oil producers and countries deprived of oil, between "progressive" and "conservative" regimes) not been strengthened by the interregional nature of the EAD?

It is suggested that an answer is given to these questions by a close study of the obvious impediments that the cooperation has encountered owing to the institutional framework of the Dialogue.

\section{Method}

Our aim will be twofold: first, isolate the weaknesses of the EAD (diagnosis); secondly, submit proposals for an improvement of the links between Arab and European countries (cure).

A. For the diagnosis, two tasks have to be achieved:

1. Through an historical review, draw up the inventory of the difficulties encountered by the EAD, within the two delegations and between them. 
2. Isolate the difficulties linked with the institutional (regional) framework of the Dialogue.

B. For the cure:

Investigate the possible solutions for a "relance" of Euro-Arab relations, for instance with more definite objectives or in the framework of more limited forums.

It should be possible to establish such a study on the basis of written contributions of Arab and European officials involved in the EAD, as well as on the basis of academic works (see: Saleh Al Mani, The Euro-Arab Dialogue (1983)).

\section{Further Perspectives}

We might also investigate whether the Arab countries have seen the EC as a model for integration, suitable for their own attempts to realize an Arab unity, when they have laid the foundation for multilateral negotiations between the two blocks.

The progress of the cooperation between some Arab states (for instance in the Gulf Cooperation Council) seems to be linked, in any case, to a desire to emulate the EC.

\section{Motives, developments and hindrances for a European policy towards the Arab-Israeli conflict}

Our study will be divided in two parts: first we will see the grounds for which the EC has focused its attention towards the Middle East and, secondly, we will try to locate the centripetal and centrifugal trends which have an influence over the definition of a European political line in the region.

\section{The reasons for a European role in the Mideast}

Why was the Middle East the chosen candidate for the first meeting of the Foreign Ministers, in Munich, in November 1970? Why was the core problem in the Middle East, the Arab-Israeli conflict, chosen by the then six Member States as the first topic which could be a testing stand for the harmonization of the foreign policies of the Six? Why has this issue-area for fifteen years remained the most important one for the European countries (in the framework of political cooperation)? To answer these questions we would like to isolate the various determinants which prompt the European partners to choose the Middle East question as the main topic for rapprochement of national foreign policies and the building up of a common European stand. We will concentrate our attention on the period between 1970 and 1973, during which the newly created European Political Cooperation (EPC) was shaped, so we will have an insight into the determinative elements which from the beginning led the European 
countries to direct their interest towards the Middle East. The factors which influenced the European move towards the Middle East may be divided into several clusters of different nature: historical and geopolitical, economic and political.

\section{The historical background}

Israeli officials sometimes wonder, with artlessness, at the want of proportion between Europe's close attention towards the Middle East and lack of attention towards other regions of the world. This attitude overlooks the radical uniqueness of European relations with the Middle East for historical reasons. Two pillars of Europe had a determinant influence in the Middle East during the nineteenth and twentieth centuries: France and Great Britain (even if the United Kingdom was not a full member of the Common Market before 1973, it was involved in the political discussions from 1970 on and thus fully co-responsible for the focus on the Middle East).

Under the Sykes-Picot agreement of May 1916, Paris and London carved the Middle East into two spheres of influence and authority. After the breakdown of Turkey in October 1918, even if the plan was not applied in all its provisions, its spirit was kept: at the San Remo conference in 1920, the Middle East was divided in two parts. The French got a mandate for Syria and Lebanon from the League of Nations while the British got Iraq and Palestine, east and west of the Jordan River. In Egypt, too, the British influence had increased since 1881 and in 1914, finally, the country was declared a British protectorate. ${ }^{1}$ In all these countries the British and French administration played a major role up until the fifties, which means that the two countries bore a large responsibility in the "crystallization" of conflicts (along religious and ethnic lines).

The immediate consequence of European penetration into the eastern Mediterranean was to introduce the idea of nationalism and the reality of the nation-state in the region. If the idea of nationalism gave rise to a unitary ideology (Arabism), it was also a direct cause of the advent of clear-cut local patriotisms based mainly on ethnic factors. Colonization was also responsible for the construction of nation-states with largely artificial boundaries surrounding a variety of religious and ethnic groups which very often had no common values to share. This absence of territorial and human homogeneity, a by-product of Western colonization, has undeniable consequences on the political clashes in the Middle East even today.

For instance, in 1920 France created the state of Greater Lebanon which included, apart from the Maronite mountain, Tripoli, Sidon, Tyre and

1 For an appreciation of the British influence on the Middle East: E. Kedourie, England and the Middle East: the Destruction of the Ottoman Empire 1914-1921 (1956); E. Monroe, Britain's Moment in the Middle East 1914-1971 (1981). 
Beirut. ${ }^{2}$ So a large number of Muslims from different rites (Sunnis, Shiis, Alawis, Druze) were included in the new state. This situation led to continuous and growing interreligious unrests which reached their climax with the crisis of 1958 and the civil war which broke out in 1975. In Palestine also, the British intervention led to an inextricable skein. ${ }^{3}$ Britain had promised, in the letters passed by Sir Henry MacMahon, High Commissioner in Cairo, and Sherif Hussein of Mecca in 1915-1916, to recognize and support full Arab independence, but promised also, in the Balfour declaration of November 1917, to facilitate the establishment of a national home for the Jewish people. These contradictory statements show the ambiguous policy followed by Britain, a policy which led to outbreaks of violence between Arabs and Jews, notably in 1929 and 1936, and then, to the invasion of the newborn State of Israel by the Arab states. The war of 1948 was the first of five armed confrontations which give clear indication of the difficulty in bringing about a reconciliation between the rational claims of the Israelis and the Arabs - especially the Palestinians - claims which have been stirred up by the political inconsequences of the British rulers. The influence that France and Britain lost in the fifties, ${ }^{4}$ they could hope to regain, even in a looser way, through the European channel. EPC was thus a tool for the former colonial powers to reintroduce themselves in a region where the burden of their past colonization was so deeply rooted, producing outcomes which are still, as we have seen, connected to the contemporary problems of the Middle East.

\section{The strategic dimension}

The historical background was not the sole cause that induced the Europeans to put the Middle East on their agenda in 1970: the strategic importance of the eastern Mediterranean basin was also taken into consideration. Great Britain, France and Italy - which controlled Libya - were particularly aware, during the days of their imperial power, of the strategic value of the EastWest sea road. Great Britain, for instance, succeeded in gaining control over the key points in the Mediterranean (Gibraltar, Malta, Cyprus, Suez), thus becoming the major naval power in the sea. The Anglo-French intervention at Suez in October 1956 was the last sign of direct involvement of European countries in the area in order to protect their strategic interests, whether political (neutralization of anti-Western trends), economic (supplying of oil and gas), military (utilization of offensive bases), or commercial (protection of communications). These interests still exist, even if the European nations no longer have the military capacity to act as dominant powers. They are, in a

2 For more details about the French involvement in the Middle East: S. Longrigg, Syria and Lebanon under French Mandate (1958).

3 N. Bethell, The Palestine Triangle: the Struggle between the British, the Jews and the Arabs 1935-1948 (1979).

4 H. Sachar, Europe Leaves the Middle East, 1936-1954 (1973). 
sense, more intense since Europe is henceforth centered on herself. The narrowing of her sphere of domination and influence, which is a direct outcome of the aftermath of the Second World War and the disappearance of the European nations as main international actors, has led to a renewed emphasis on regional cares. Among these, the security of the continent has become of peculiar interest and therefore peace in the Mediterranean has become a vital aim for Europe.

The Mediterranean, especially its eastern side, has for forty years been the site of prospective conflict between the superpowers, which are militarily present with the Sixth American Fleet and the Fifth Soviet Escadra. The deployment of these naval forces is a clear indication of the importance Washington and Moscow attribute to the region. A commentator has rightly written: "It is almost as if the United States and the Soviet Union had chosen the Mediterranean as an arena for contest: as a testing platform for their political ideologies, their economics and their weapons."5 Facing this global competition, Europe's interest, for her security, is to remove the danger of direct confrontation between the superpowers which manoeuvre, through their navies, along the southern flank of Europe. To this end, Europe has to maintain a political presence in the eastern Mediterranean.

This concern for security explains why, next to the Middle East, the other topic chosen for the improvement of the political process within the Community was the Conference for Security and Cooperation in Europe. The Helsinki meeting which recognized the status quo on the continent reached de facto at the Yalta Conference was, for the EEC, an ideal forum where the acceptance of détente could be secured, And détente was praised because it was conceived as a new relationship between East and West that guarantees the security of Europe. The preservation of (European) stability southwards and eastwards was, thus, a strategic central goal for the Nine when they initiated the EPC meetings. The Palestinian scholar Bichara Khader points out that it is owing to a clear understanding of their interest that the Europeans have selected the Middle East, together with the Helsinki Conference, as a priority topic: "the selection of these two tasks demonstrates the primary importance accorded by Europe to its own security both in Europe and in the Middle East". ${ }^{6}$

\section{The economic factor}

The dependency of the EEC on the Arab oil-producing countries also had an effect upon the increasing European interest in the Middle East, but this structural dependency was not a prime cause in the initial interest of Europe

5 J. Lewis, The Strategic Balance in the Mediterranean 1 (1976).

6 B. Khader, "Europe and the Arab-Israeli Conflict 1973-1983: An Arab Perspective" in European Foreign Policy-Making and the Arab-Israeli Conflict 163 (D. Allen and A. Pijpers, eds. 1984). 
with respect to the Eastern Mediterranean. Indeed, when EPC started, oil was produced under the traditional concession agreements granted to Western companies, mainly American (Exxon, Texaco, etc.) and, after some price rises in 1970, a relative price stability was reached on the oil market. At that time, Europe could not be brought under pressure by the Arab states in order to reassert a European voice in the Middle East. Europe's choice to hold attention on this region was also the result of her own political will.

In the new impetus given to EPC in 1973, the oil factor played, this time, an essential role. The oil crisis, with the total embargo directed at the Netherlands, the cutbacks in production and the huge price increase, was a catalyzer for European policy in the Middle East. The joint statement of November 6, affirming "the legitimate rights of the Palestinians", and the European unanimity reached on that occasion were directly connected with the oil problem (the presence of four Arab foreign ministers in Copenhagen on December 15 - during the summit meeting - is, in that regard, extremely symbolic). Seventy-one percent of the oil imported by the EEC came from the Arab world. Consequently, a global embargo would have threatened Europe's industrial power and economic growth. To avoid such catastrophic consequences, Europe had to placate the Arabs and, thus, to issue a declaration encompassing the legitimacy of the Palestinian rights. Our perception of the 1973 situation nevertheless places the oil crisis only as a factor which has speeded up European political concern over the Arab-Israeli conflict, especially in its Palestinian dimension. Sooner or later, the EEC would have to take the Palestinian people into account, compelled by the very dynamics of the cooperation process and by the political evolution of the national foreign policies of the Member States. It is therefore inaccurate to explain all European attitudes only by a systematic bias towards the Arab countries motivated by the smell of oil, as did the Israeli ambassador to the EEC when he wrote: "Since November 6, 1973, the Nine have chosen the path of the pro-Arab statements in hopes that they conduce to secure her oil supplies." 7

We ascribe a more peripheral impact to another economic factor: the trade deficit between France and the Arab States. Edward Kolodziej has stated that "France's negative trade balances with the Arab states, particularly with its oil suppliers, advised alignment on foreign policy for the sake of economic gain, all the more so since its three primary suppliers - Algeria, Iraq and Libya - were in the militant wing of the Arab states"' 8 Thus, France might try, at the national and European level, to take a firm pro-Arab stand in order to improve its trade position.

This argumentation seems not very convincing for two reasons. If France

7 S. Minerbi, "Israel et l'Europe", (1981-II) Politique Etrangère 440 (1981).

8 E. Kolodziej, French International Policy under De Gaulle and Pompidou: the Politics of Grandeur 504 (1974). 
had, in the seventies, serious trade deficits with all oil producers, it was also the first exporter, before all its European partners (in 1972, its exports amounted to $12.6 \%$ of the total imports of the Arab League, while Germany's share was $8.1 \%$ and that of Great Britain 9\%). What is more, France was not the only country with a trade deficit: the whole EEC traditionally shows a debit balance vis-à-vis the Middle East and the Gulf States due to the weight of the oil imports. France, thus, shared the same trade pattern with its European partners. If, however, Paris was destined to play a leading role in the focusing on the Middle East, the main impulse was not economical but political. ${ }^{9}$

\section{The global policy for the Mediterranean}

Since 1972 the Community has negotiated a series of parallel trade agreements with almost all of the states on the coast of the Mediterranean. This scheme is known as the global policy for the Mediterranean ${ }^{10}$ and stemmed from a French idea. The cooperation agreements with the Arab Mediterranean countries and Israel were the economic facet of a broader project with political features. Interest in the Middle East is directly linked to the shift to the Mediterranean which was originated, in 1969, by President Pompidou. Under de Gaulle, France always militated against the division of the world into two camps and aimed at the development of a third force. But, while the founding father of the Fifth Republic asserted a global role for France in the management of world affairs, his successor, more aware of France's modest military power and political latitude, emphasized France's role as a third force at the regional level. The Mediterranean was the natural candidate for this policy. France's aim to develop a third course, beside the imperial logic of the United States and the Soviet Union, was praised by the French Foreign Minister, Maurice Schumann: "there is a Mediterranean policy for France which ... has only one aim: to prevent ... the western Mediterranean ... and if possible ... the whole of the Mediterranean basin, from becoming, or from remaining, a theatre for cold war and a supplementary stake in the rivalry of the great powers". ${ }^{11}$

France returned to the EEC as a forum where the idea of nonalignment and third force could be propagated. For France, the refusal of bloc politics in the Mediterranean has to be a European creed and Europe had to take up a stance of its own in order to protect its interests, without relying on powers external

9 That there are no direct correlations between the conquest of new markets and pro-Arab statements, is shown by the fact that Germany, though less inclined to take up politically a pro-Arab profile, was the most successful in developing its commercial relations with the Machrek and Gulf States.

10 For an insight into this Mediterranean policy, see: A. Shlaim \& G. Yannopoulos, The EEC and the Mediterranean Countries (1976); D. Puhl, Die Mittelmeerpolitik der EG (1983).

11 Quoted by E. Kolodziej, "French Mediterranean Policy: the Politics of Weakness", 47 Int'l Affs. 509 (1971). 
to the area. The adoption of the Schumann plan by the Six in May 1971 was the first tangible embodiment of an autonomous European position which was in harmony with the movement towards the Mediterranean. The underlying idea in the search for a European voice in the Middle East, which is also of French inspiration, is that the conflicts in the region (among them, the Arab-Israeli clash) are the fruits of foreign meddling. ${ }^{12}$ To solve the outstanding problems, the countries of the Mediterranean bow have to take their own matters in hand and look for a Mediterranean solution, without the superpowers, but with Europe which is also interested in engaging herself in a more-or-less independent course. The Schumann paper, and the ensuing development of a European policy in the Middle East, owe a good share of their reality to the French idea of a Mediterranean course.

Up to now, we have seen the general reasons which may explain why the Member States have turned their attention to the Middle East. To these global reasons, whether historical or strategic, economic or political, we have to add more peculiar reasons (linked with the diplomatic and political situation in the years 1970-1973) which will help us to understand why the Middle East was put on the agenda.

\section{The American parameter}

First and foremost, relations with the United States are a background of high importance. When the Six approved their first report on May 13, 1971, in Paris, the American initiatives were at a stalemate. The American Secretary of State, William Rogers, in December 1969 had produced a set of proposals calling for secure and recognized boundaries of Israel in conformity with the pre-June 1967 lines and for a contractually binding agreement between the belligerents. In 1970 he tried, unsuccessfully, to get this plan endorsed by Israel and Egypt. Against a total Israeli refusal to agree to territorial concessions, the Rogers plan was dropped in February-March 1971. At the same time, the Jarring UN mission, which started at the end of 1967 in order to promote a peaceful settlement in accordance with Resolution 242 of the UN Security Council, also collapsed because the two sides had different views on the way to implement a peace agreement. After the failure of the Rogers plan and the Jarring mediation, the Americans were deprived of clear strategy, even though they slowly moved towards the proposal of a partial settlement which was later to be embodied in the disengagement agreements of January and September 1975.

In this situation, without a political perspective imposed by the Americans, the Europeans felt free to concert an approach of their own to the question of the Middle East conflict. The attempt to make up a European policy which might outline an approach different from the American one found expression

12 See, for instance: General G. Buis, "Moyen-Orient et Mediterranee Orientale", 3 (1976-III) Politique Etrangère 209. 
in the adoption of the Schumann paper. The latitude left to the Europeans by the United States inaction is also a parameter which exercises an influence over the European capacity to interfere in Middle Eastern affairs: the more cautious or inactive the Americans are, the more the Europeans feel the necessity to promote new options.

This connection between cause and effect is certainly not mechanical, but that the Europeans view the stalemate reached by the Rogers plan as an incentive for an initiative in the region cannot be denied. We found a further confirmation of the "complementary diplomacy" followed by the EEC in the main European initiative concerning the Middle East: the Venice declaration. The statement was issued on June 13, 1980, at a time when the autonomy talks, which had begun in March 1979 on the question of autonomy for the Palestinians in the occupied territories, were in a deadlock because of the hard-line policy followed by Menachem Begin. The failure of the talks was also a snub for the United States which endangered the Camp David framework. Preoccupied with the Iranian crisis (seizure of hostages in the US embassy) and with the impending presidential elections, the Americans were unable to provide another strategy after Camp David revealed its limits. Thus the Europeans initiated the Venice statement because there was, to use Lord Carrington's words, "a political vacuum"13 to be filled. The American setback in the autonomy talks thus gives Europe room for manoeuvre to act independently in the Middle East. ${ }^{14}$ To sum up our argument, we may say that, although the failure of the Rogers plan was not a determinant cause which led the Europeans to turn their attention towards the Middle East, the American setback was a favourable and requisite circumstance for the emergence of a European policy: Europe fills in the blank spaces in America's diplomacy.

The deepening of Europe's involvement in Middle Eastern affairs, in 1973, was also due in part to transatlantic considerations. Indeed, at the beginning of the seventies, there was an increasing incompatibility between America and the Community. The disagreements were due, first of all, to economic considerations affecting monetary and trade matters. Besides economic antagonisms, there was also, in Europe, a fear about joint domination of the Old Continent by the two superpowers. In June 1973, a Soviet-American agreement on the prevention of nuclear war was signed in Washington and some European countries, France above all, were afraid to see the creation of

13 Lord Carrington, "European Political Cooperation: America Should Welcome It", 58 Int'l Affs. 4 (1982).

14 The Link between American failure or passivity and European activism is also noticeable on other topics, for instance the CSCE process. When the USA adopted a low-profile stand in Helsinki (1973-1975), the EEC played a leading role in the negotiations. In Madrid, in 1980, the situation was reversed, the USA being heavily engaged in the discussion, the EEC playing as a bloc a peripheral role. 
a superpower bilateralism which might be used to "short-circuit" Europe. ${ }^{15}$ Finally, in April 1973, Henry Kissinger had launched his "Year of Europe", a political initiative whose aim was to define a new Atlantic charter which might give a new content to the political, security and economic elements of the Atlantic relationship. But the way Washington conducted this new offensive, and Kissinger's personal feeling that European unification was built against America, led the Europeans, at least, to a very cautious reaction and, in the French case, to an utterly negative appraisal of Kissinger's move. ${ }^{16}$

The bickerings between Europe and the United States poisoned the transatlantic atmosphere. To use Michel Jobert's words, "treated like a nonperson, humiliated in its exixtence" by the behaviour of the United States, Europe was inclined to choose its own path when the Yom Kippur war broke out. The row between the Europeans and the Americans was not the sole element which gave a stimulus to the political entanglement in the Middle East: the renewal of violence in the region could not leave Europe indifferent.

\section{The political situation in the Middle East}

In 1970, the level of the confrontation along the Suez canal increased, above all because Israel began "deep penetration" bombing into Egypt which led to the sending of Soviet operational units to Egypt (the escalation was stopped by a cease-fire in August 1970). The same year, there was an attempt to assassinate King Hussein of Jordan, whose rule was later challenged by the hijackings of Western airplanes by the Popular Front for the Liberation of Palestine and by the civil war that broke out in September 1970. In 1971, a cycle of Palestinian guerrilla operations and Israeli reprisals began in southern Lebanon, whilst the expulsion of the Palestinian forces from Jordan was brought to an end in July.

The year 1972 was dominated by a series of Palestinian terrorist operations (attack at the Olympic games in Munich, letter bombs posted to Israeli representatives) and Israeli counter-terror (raids in Lebanon, assassination of Palestinian leaders in Europe). The renewal of the war in October 1973 was the zenith of the hardening of the political positions in the Middle East. The incandescence of the situation which threatened directly Europe's expectations for peace and security in the eastern Mediterranean urged the European Community to be fully involved in the Arab-Israeli confrontation.

The political events between 1970 and 1973 show one main feature: the advent of the Palestinian organizations as major forces in the Middle East. This political fact has to be reckoned with, and this Europe did in 1973.

15 For a picture of Euro-American relations in the years 1970-1973, see A. Grosser, The Western Alliance: European-American Relations since 1945 270-282 (1980); R. Shaetzel, The Unbinged Alliance: America and the European Community 48-80 (1975).

16 For Kissinger's point of view of the Year of Europe, see his memoirs: H. Kissinger, Years of Upheaval 128-194 (1982). 


\section{The new Entente Cordiale}

The last factor which played a role in bringing the Arab-Israeli clash into focus was internal, i.e. linked with the political constellation within the Community. It was the entente between London and Paris which laid the basis for the reassertion of Western Europe's intervention in the region. The former colonial powers had, in 1970, very similar positions towards the ArabIsraeli conflict.

In September 1970, President Pompidou said for the first time that "the Palestinian question has a political character and has to get a political answer". ${ }^{17}$ During a press conference, he mentioned "the problem of the Palestinian people". ${ }^{18}$ Thus, in 1970-71, the French government brought in a national dimension when the situation of the Palestinians was only conceived as a refugee problem. The recognition of the necessity to tackle the question of the Palestinians as one of national identity also became evident in Great Britain when the Foreign Secretary, Sir Alec Douglas-Home, spoke of the Palestinians" "legitimate aspirations" and their desire for "a means of selfexpression". ${ }^{19}$ The Franco-English agreement with regard to the Palestinian problem is symptomatic of a global harmony in Middle Eastern affairs. The two governments shared, for instance, a continued interest in UN Security Council Resolution 242, which moreover had been drafted by the Wilson government. The subordinate status France and Great Britain got in the Rogers plan, which clung to a cooperation with the Soviet Union alone, further enhanced the rapprochement between Paris and London. As the two countries had similar points of view, they were interested in promoting their ideas and having them endorsed by the Community. This strategy worked more easily when Britain entered the Community in January 1973: the "Channel" axis thus became a driving force in the adoption of the November and December declarations and its action was determinant in keeping the political scruples of its partners in the background. ${ }^{20}$ The two "Bigs" of the Community, which have diplomatic assets in the region, were also two actors, within the EEC, which promoted political involvement in the Middle East.

The choice of the Middle East as a central issue to be put on the European agenda was by no means a cowardly one. Of course, it was less risky to choose the Arab-Israeli conflict as a testing stand for the political cooperation process than, for instance, Chad and Black Africa, which is a French chasse

17 Quoted in P.-M. de la Gorce, Tendances de la politique française et européenne vis-à-vis du conflit israelo-arabe 12 (1980).

18 Quoted in 67 Maghreb-Machreck 34 (January-March 1975).

19 The Observer, 1, (1970).

20 That France and Great Britain shared the same political position is noticeable from the fact that they were treated in the same way by the oil producers. Labelled as "friendly countries", they were not subject either to the embargo or to the monthly cutbacks decided by the OPEC. 
gardée, or South Africa, where the larger Community states have big economic interests. Nevertheless, the Middle East was also a sensitive topic for the Six, and then Nine, when they decided to develop a common policy towards this region, because at that moment their positions differed a lot.

If the Europeans drew their attention to the Mideast, in spite of the complexity of the issue, they were prompted to do so for several sets of reasons that we have evolved. Historial links, strategic and economic interests have been inciting factors for a European Community which has turned more and more southwards with its global policy for the Mediterranean. The transatlantic quarrels between the EEC and the United States, the outbursts of violence in the Middle East and the leading role of the ParisLondon duet were also favourable circumstances which facilitated EC involvement in the Arab-Israeli conflict between 1970 and 1973.

All these facts were of importance for the inception of an effective policy in the Middle East, which shows a double-sided feature. There is, undeniably, a global consistency of the European stand over the fifteen years of EPC and, through the matrix of EPC, there has been an increasing coordination of the different national policies. Nevertheless, the harmonization process has not removed all centrifugal forces which impede the intensification of Europe's involvement in the eastern Mediterranean. European activity can thus be either speeded up or restrained, either stimulated or handicapped. Let us examine this dilatation/contraction process closely.

\section{Stimulus and impediments in the formation of a European policy in the Middle East}

The dichotomy between domestic and foreign policy is as fundamental to political actors as it is to political theorists. Statesmen have, generally speaking, considered foreign policy questions of central importance to their state because they are connected with the basic values of the national collectivity (the country's place in the world, its security, its grandeur...). Thus the statesmen have drawn a dividing line between domestic affairs (national ground) where national authorities have more direct influence and foreign affairs (international ground) where the state's actions are more challenged.

This boundary is also recognized as valid by the political scientists who have treated foreign policy as a sensitive area of government, very important for the survival of the state. Even if some students of international politics have shown that they are numerous linkages between these two fields, the distinction remains valid, at least for analytical purposes ${ }^{21}$.

21 The interrelations between national and international politics is stressed by W. F. Hanrieder, "Compatibility and consensus: A Proposal for the Conceptual Linkage of 
To specify the concept of foreign policy, we will use the theoretical framework built by James N. Rosenau. This scholar classifies the causes of foreign policy - i. e. the explanation of the foreign policy-making process - in five variables ${ }^{22}$. First let us make some comments about these variables.

One set of variables is exogenous, that is external, to the actor: these are the systemic variables. In this category we may include the structure of the international system (bipolar, multipolar), the behavior and actions of states, of regional and international organizations and that of the transnational alliances and the political events.

The four other variables are endogenous, linked specifically to the actor.

The idiosyncratic variables are concerned with the personal characteristics of decision-makers: psychological profile, personality. The role variables are concerned with the normative constraints to which they have to conform. These are the expected rules of behavior and job descriptions linked with the public's expectations of that role. The third set of variables are bureaucratic and governmental. They include the structures of the governmental organizations (ministries, departments), the proceedings and processes within the administrative and political machinery, and the method of decision-making. The last variables envelop a wide range of elements of different kinds: geographical (location of the country for instances); economic (e. g. industrial capacity); social (class structure); historic (national and popular memory); cultural (leading values in the society). These all are national variables.

The five variables have an influence, not only on the genesis and progressive formation of foreign policy, but also on foreign policy outcomes. Obviously, these variables play an important role vis-à-vis European Political Cooperation, the first attempt to create a "common European policy". The influence of these variables is not limited to some regions or some issue-areas, but in this paper we focus our attention on one specific issue: the Arab-Israeli conflict.

In the formation of a European policy in the Middle East the exogenous/systemic variables are of first importance. The structural instability of the Arab world (the split between pro-Western and pro-Soviet countries, the market increase in Islamic activism, the military tension in Lebanon and in the Persian Gulf); the political and ideological crisis within Israel (growth of nationalist trends, disturbances in the Occupied Territories following the settlement policy, ethnic and religious tensions in the Jewish population); and the involvement of the Big Powers are three sets of factors which are shaping the political cooperation process in Europe. Like all

External and Internal Dimensions of Foreign Policy", 61 Amer. Pol. Sci. Rev., 971 (1967). For another decisive effort in the same direction, see: James N. Rosenau, Linkage politics: Essays on the Convergence of National and International Politics (1969).

22 J. N. Rosenau, The Scientific Study of Foreign Policy (1980). 
foreign policies EPC is, in part, a response to external challenges: the outcomes stem from a source of disturbance or disruption which acts as an input ${ }^{23}$.

The idiosyncratic variables, more difficult to measure, are meanwhile determinant. The impact of each man's personality upon his country's foreign policy is clear when we recall such great figures as de Gaulle or Adenauer. This impact, even if it is more diffuse within the European context, is still detectable. Thus V. Giscard d'Estaing, the former President of the French Republic, with his self-reliance, his conviction that he knew how Europe should best act to protect its interests has had an impact on the orientation of EPC in its support of the Arab world. (The Venice Declaration of June 1980 is partly the outcome of his personal initiative.)

The role variables, also, have an undeniable influence upon the behavior of the policy makers. Let us take another example. Although François Mitterand was better disposed towards Israel for personal historical and political reasons ${ }^{24}$ he maintains the foreign policy of his predecessor, even emphasizing the importance of the Palestinian problem. In this case Mitterrand's behavior has been modified by the role of statesman: he was obliged to take a stand reconcilable with his country's interests in the region which have, long since, been connected with the Arab world. This move leads to the support for the evacuation of the PLO from Beirut (August 1982), support that he tries - unsuccessfully - to make Europe assume.

We do not deal here with these three variables, neither the exogenous one, nor the psychological (idiosyncratic) and micro-sociological (role) one. We prefer to tackle this question under the two macro-sociological variables, governmental and national because on the one hand it is easier to measure these variables as compared with the idiosyncratic/individual variables or the role variables which are difficult to locate, especially for EPC with its high degree of confidentiality; on the other hand, we will leave out here the environmental factor (systemic variables) because we want to underline the autonomous factors which are influencing Europe's action.

Let us see now more precisely how the two endogenous variables (we will keep calling them structural and fundamental because the typology of Rosenau is more suitable for the national framework than for the European

23 See R. N. Rosecrance, Action and Reaction in World Politics: International Systems in Perspective, (1977).

24 Dominique Moisi of the IFRI (Institut Français des Relations Internationales) sees four elements which have influenced the favourable position of the French President towards the Jewish people and Israel: the Resistance (the fight against nazism) - the Fourth Republic (with its close links with Israel) - the Socialist International (Mitterrand formed friendship with the Labour leaders) - the moral and realistic approach of the international stage (which binds France to have links both with the Arabs and Israel). See: "La France de Mitterrand et le conflit du Proche-Orient: comment concilier emotion et politique", (1982-II) Politique Etrangère 395. 
transnational experience) affect the crystallization of European political cooperation toward the Middle East.

\section{Accelerating causes}

1. Structural variables

We will not describe here the mechanisms of EPC which have been constantly improved from the time of the Davignon Report (July 1970) to the London Report (October 1981), but only see how the institutional framework of EPC has increased the capacity of the Ten to intervene on the international scene, especially on the issue of the Arab-Israeli conflict. ${ }^{25} \mathrm{~A}$ methodological difficulty has to be mentioned: to what extent are common views and attitudes linked with the structure of EPC rather than with changes in the national foreign policies?

If it is not easy to distinguish between these two influences, we can nevertheless measure the impact of the institutionnal network in terms of effectiveness, Thus, while after the Yom Kippur War (1973) the foreign ministers issued a joint statement (November 6) one month after the launching of the Arab onslaught, they adopted, three days after Israel's invasion (June 6,1982 ) a common statement on the situation in Lebanon. The contrast between these two moments in Europe's diplomatic life shows that the capacity to respond promptly has increased. We may assume that this evolution has been caused by the increasing familiarisation with the EPC mechanisms: whereas in 1973 the ministers knew little of the mechanisms of EPC, by 1982 they were far more conversant with the whole framework.

The strengthening of the mechanisms has also led to the development of the activities undertaken under the auspices of EPC. On a quantitative level, there are now far more forums where the foreign policy issues are frequently tackled: the Political Committee, the European Correspondents, the ad hoc working groups (the Middle East group is a very "old" one), the meetings of the ambassadors of the Ten.

On a qualitative level, the meetings of the heads of state and governments, where major issues are discussed, are excellent occasions to promote the harmonization of policy. In these European Councils the momentous statements of London (June 1977) and Venice (June 1980) were made.

As regards the frequency of the meetings, one notes there are the periodic conferences of the foreign ministers (at least four per year) and the Gymnich type meetings (since 1974) where the officials of each country can exchange

25 For a complete picture of the structure of the EPC: P. de Schoutheete, La Coopération Politique Européenne 37-44 (1980). P. Tsakaloyanis, The Origins and Development of Political Cooperation in the European Economic Community, 97-125 (Ph. D. Thesis submitted at the University of Reading, February 1980). R. Rummel \& W. Wesels eds., Die Europäische Politische Zusammenarbeit. Leistungsvermögen und Struktur der EPZ (1978). See especially the chapter written by W. Wessels. 
views on foreign policy. Apart from their frequency one may also note that the ministers can gather in case of emergency at the request of just three Member States (provision introduced by the London Report, October 1981).

The enhancement of the functions of the Presidency of the Council has led to the broadening of diplomatic activities and increased the "unitarian" perception of Europe by the third countries. The European identity has thus been embodied by Gaston Thorn (Luxembourg) and Christian Van der Klaauw (Netherlands) the two presidents of the Council of Ministers who, in 1980-1981, led fact-finding missions in the Middle East. The Presidency plays a more and more representational role outside the European Community: it is potentially the executive organ of an united Europe with tasks of initiative, coordination and representation.

Concerning our initial methodological impediment we can assume that the structure of the EPC has undoubtedly accelerated the process of political cooperation (development of the habit of working together, improvement in the circulation of the information, and greater practice of reciprocal consultation) but we can also imagine that the institutionnal network was not in itself conducive to achieve common views in such an important area as the Middle East. This shift towards some stock of political attitudes shared by all Member States, because it implies unavoidably the modification of the national foreign policies of some Member States, could not occur only on an instrumental basis i.e. through the channel of the "procedure machinery" of EPC. The structure of EPC has been a catalyst for the carrying of common declarations but the evolution of the national environment is the prime cause of the stir towards a "communauté de vues" in the Middle East.

\section{Fundamental variables}

For some fifteen years there has been more and more a convergence of the national positions of the European countries towards the Palestinian/Israeli issue. A good indicator of this process is the progressive rapprochement between France and Germany, two countries which stood on opposite sides when EPC was initiated. France has taken historically a prominent part in the Levant, and has been open to the Arab world for a complex set of reasons including economic interests, diplomatic matters and cultural ties. General de Gaulle thoroughly summarized the geo-political constraints hanging over his country when he said: "All compel us to set up, between the north and the south bank of the Mediterranean, direct and steadfast links."'26

Germany, in the aftermath of war, was in a radically different position. For her, because of the Third Reich and the slaughter of six million Jews, it is a binding condition, in order to go back into the concert of nations, to be on the side of the victims of the hitlerian barbarity and their descendants. As Chancellor Konrad Adenauer said: "The German people want to redress a

26 C. de Gaulle, Discours et messages 11 Cuvres complètes 515 (1970). 
wrong done, in its name, by a criminal regime." 27 To this end strong support toward Israel is required.

This attitudinal difference explains why, during the Six Days War, France followed her "Arab strategy", criticizing harshly Israel's military intervention while Germany declared her neutrality which involves a very strong moral commitment towards the Hebrew state. The political fracture between the two poles of the Community remained unchanged until October 1973 when the oil price explosion and the threatened oil embargo of Europe caused the rapprochement of the national foreign policies of France and West Germany.

The oil crisis which increased the impact of destabilization forces within the European system by threatening directly Europe's economy, was the external factor which bound the Europeans to adopt a common stand with regard to the Middle East.

Gradually, Germany got free of her self-imposed political reservation and reevaluated her attitude towards the Middle East, becoming all the time closer to the French position, especially concerning the recognition of the importance of the Palestinian problem. Between 1974 and 1977 the Federal Republic recognized successively the right of the Palestinians to selfdetermination, the legitimate rights of the Palestinian people (among which was included the right to live under their own state authority), and the need for a Palestinian homeland (Heimatland). In 1979 Germany went so far as to believe that the PLO was ready to give up violence if the right to establish a state was granted to the fedayeen organisation. ${ }^{28}$ Let us add that Bonn also severely criticized the right-wing Likud group which is publicly committed to maintaining Israeli rule over the whole of Eretz Israel i.e. all the remaining occupied territories (Gaza Strip, West Bank and Golan Heights) and to supporting the settlement policy in all the occupied areas.

Germany's position changed, in the meantime of five years (1973-1977), from a pro-Israeli stand to a stand, more or less, identical with that of France which has, since 1970 , spoken about "the problem of the Palestinian people" (in the case of Germany, the EPC framework gives the Federal Republic the opportunity to change its national position under the guise of a common care for a European position). The confluence between France and Germany is symptomatic of the general shift influencing the moderate European countries.

The Netherlands, for instance, which had been hit by the Arab oil embargo

27 Interview of K. Adenauer by K. Marx. 33 Allgemeine Wochenzeitung der Juden in Deutschland (November 25, 1949).

28 For the relations between the FRG and the Arab States: K. Kaiser \& U. Steinbach, Deutsch-Arabische Beqiebungen (1981). For some German official declarations see: Hans Dietrich Genscher, Deutsche Außenpolitik (1977). Note especially interventions at the General Assembly of the United Nations. 
in 1973, became progressively critical of Israel and its political actions (the reunification of Jerusalem, settlements in the West Bank, and the invasion of Lebanon in 1978 and 1982). The same is true for Denmark, Belgium and Luxembourg. The position of Italy and Great Britain, two "Big Powers" within the Community, is also noteworthy.

Very favourable to Israel before 1970, Italy drew nearer to the Arab arguments partly owing to the pressures exerted by the left-wing of the dominant Christian Democrat Party (Amintore Fanfani, Aldo Moro), partly owing to the massive dependance on Arab petroleum ( $85 \%$ of the supplies came from the Middle East producers in 1977). For the last ten years, Italy has criticized Israeli military initiatives, the creeping annexation of the West Bank and the incorporation of East Jerusalem into the Jewish state. At the same time, she has established direct contact with the PLO, first at "subordinate" level (civil servants, foreign ministers), then at top level (the meeting between Sandro Pertini, President of the Republic, and Yasser Arafat in Rome in September 1982; meeting between the Prime Minister, Bettino Craxi, and Y. Arafat in Tunis in December 1984). This last meeting, the first between the prime minister of a great Western country and the Palestinian leader, gives evidence of the pro-Arab stance of Italian foreign policy. ${ }^{29}$

The United Kingdom, which is the foremost imperial power in the area, is thereby in a unique position: she has to take into account these historical ties which give a special "colouring" to her statements, when received by the Mashreck countries. But this does not mean that the political substance of British policy is different from those of the other Western nations. Like them, she now insists on two claims: a need of "a land for the Palestinians" (Anthony Crosland at the UN General Assembly, October 5, 1976) and an end of the Israeli military occupation. The Labour Party, labelled as proIsraeli, and the Conservatives, labelled as pro-Arab (mainly because they have closer links with commercial organizations and because they keep an eye on the Arab market) share the same belief as to the need for a Palestinian homeland, be it an independant state or a confederation with Jordan. A word about the specific positions of Ireland and Greece.

Ireland, which had no diplomatic relations with Israel until 1974, has adopted "harsh" positions on the Middle East (being in favour of the establishment of an independant Palestinian state, and recognition of the PLO as a representative entity). This attitude can be understood by the fact that she feels close to the developing world because she is a rural country (therefore sensitive to the problems of a "less developed" Third World people like the Palestinians) and is a country with a colonial past (therefore

29 For more details on the Italian case: Genevieve Bibes, " $L$ ' Italie a-t-elle une politique étrangère?" Def. Nat. 70-74 (1975). A. Pilati, "Italian Political Parties and the International Scene”, 12-14 Lo Spettatore Internazionale 279 (1977). 
sensitive to the right of self-determination claimed by a dispossessed Palestinian nation).

Greece, the only Community member which has not recognized Israel and is closely linked with the Arab world (in commercial, industrial, and even cultural matters) has, since the return to democracy in July 1974, taken a vigorous pro-Palestinian stand. More cautious during the Karamanlis era, this line became activist after the coming to power of Papandreou, the leader of PASOK, which has a frankly tiers mondiste ideology, implying full support to national liberation movements. Yasser Arafat was moreover invited to Athens in December 1981, not long after the Socialist party had taken office and later returned to the Greek capital after the battle of Beirut (September 1982).

A brief survey of the different national foreign policies toward the ArabIsraeli conflict ${ }^{30}$ shows two main features:

- first, we can locate three groups within the European Community: 1. a pro-Israeli axis including the Netherlands, Denmark and Luxembourg; 2. a "midway" pole with Belgium, Germany and Great Britain; 3. a pro-Arab bloc including France, Italy, Ireland and Greece. Obviously there are degrees within each stratum, Greece being in a far more radical position than France.

- secondly, although there are still fractures between the Member States, they occur within a European norm. On the whole the Ten agree upon some basic principles, and the differences of opinion (nature of the future Palestinian entity, intensity of the criticisms against Israel) are restricted within the limits of this consensus.

This basic consensus was carried out through the progressive shift from the pro-Israeli countries (Benelux, Denmark and Germany) towards what can be seen, in political terms, as a more pro-Arab stand. Such a shift could not have been achieved conversely i. e. from the pro-Arab pole to the pro-Israeli constellation. Indeed, Europe had to integrate the Arab political variable which had been too long neglected. The rise of Palestinian nationalism, the continuous occupation of the territories taken over in 1967, the hardening of Israel's policy under Begin could no longer be tolerated in silence. Coupled with the energy problems which forced the European countries to concern themselves with their Arab partners (a concern quite legitimate in a "wild" international order), the geo-political situation of the Middle East had an influence over the pro-Israeli countries, compelling them to take the Arab factor into account. Because there had been especially since 1976-1977, genral agreement on a set of principles, Europe was able to make a set of common political achievements, mainly in the form of declarations.

30 For more details on the national positions vis-à-vis the Middle East issue, see the first part of D. Allen \& A. Pijpers, Supra note 6. 


\section{Political outcomes}

The EPC mechanism (structural variable) supports the progress towards a communauté de vues which has been facilitated by the general convergence among national foreign policies (fundamental variable).

European policy is built upon two main foundations, one methodical, the other connected with the political content of a peaceful settlement. Contrary to the "step-by-step" approach of the American administration (the series of visits undertaken by Henry Kissinger in 1973-1975, the Camp David process), Europe is in favour of a comprehensive approach which does not seek to work out the problems one by one but to take into consideration, at the same time, all the key-questions of the secular conflict in Palestine. To this end, the European Community tries to take a "neutral" position towards both sides with "balanced" declarations. These declarations make use of three basic points. First, the resolution of the conflict can only be " $€$ ached by the simultaneous recognition of two rights: 1 . Israel's right to live in peace within secure and recognized boundaries; 2 . the Palestinian people's right to "give effective expression of its national identity" (London Statement, 30 June 1977). These two rights will be reconciled solely by dealing with the core-dimension of the Middle Eastern disturbances: the Palestinian hypothesis.

The Europeans demand that Israel respects the international law which emphasizes the inadmissibility of the acquisition of territory by force. Israel should, in their view, end the territorial occupation which it has maintained since 1967 and should stop the implantation of Jewish settlements in these territories (found illegal by the European declaration issued on 18 June 1979). Israel should also put an end to the kind of military action which it carried out in South Lebanon (1978) and in Beirut (1982). Finally, as Israel cannot wish to obtain the security it aspires to have without satisfying the aspirations of the Palestinians, it is essential to materialize these expectations.

Gradually the European states have enhanced their stance vis-à-vis the Palestinian question. On 6 November 1973, they spoke of the "legitimate rights of the Palestinians", thus giving up the previous reference to "Arab refugees" (Schumann declaration of May 1971 which was consistent with UN Resolution 242 of 22 November 1967). The London Council on 29-30 June 1977 explained the substance of these rights. The statement introduces a major innovation with the notion of "Palestinian people" which implies the existence of a homogenous social group, a national collectivity distinct from the Arab neighbours. If the Palestinians have a national identity, it must be translated into fact by the creation of a "homeland". The summit meeting in Venice (12-13 June 1980) marked the last stage in the recognition of the national identity of the Palestinians. The final declaration states that "the Palestinian people ... must be placed in a position ... to exercise fully its right to self-determination". The Europeans do not only recognize this right but also ask for its application. They mention a new element of definition 
concerning the Palestinian nation: it is not only set up on criteria of facts (e.g. ethnic origin, and linguistic unity) but also on a criterion of will ("the consciousness of existing as a people"). Lastly, the declaration points, for the first time, to the need for "associating" the PLO with any future settlement. ${ }^{31}$ The content of the Venice Declaration was reiterated several times, as in Brussels on 29 June 1982, the Ten specifying yet again that the right to selfdetermination must be exercised "with all that this implies", an allusion to the constitution of a Palestinian State. Ever since then, Europe has not added new elements to her policy towards the Middle East (such as possible support for the PLO as the sole representative of the Palestinian people).

Within EPC, Europe has brought out an acquis politique with regard to the Israeli/Palestinian issue. The European Community has succeeded in speaking diplomatically with one voice, a fact that provides Europe with an opportunity - at least theoretically - to play the role of honest broker. But is the European commitment towards the problem not hampered by particular endogenous elements, either structurally or fundamentally? Are not the factors which accelerate the cooperation process on foreign policy matters counterbalanced by factors that set bounds to it?

These questions will be answered in the second section of this part of our study.

\section{Restraining causes}

\section{Structural variables}

Europe's involvement in the Arab-Israeli conflict is hindered by a series of institutional handicaps connected with the process of European Political Cooperation. EPC, which was created to deal with international problems confronting the Member States, does not set up a common foreign policy. Its goal is more modest: the promotion of the harmonization of views, the coordination of positions and, if possible, the building up of a common action. ${ }^{32}$ Because the raison d'être of EPC is only an attempt to bring about coordination among national foreign policies, it has several features which set limits to the capacity for policy-making in the EC.

The institutional deficiency is the first handicap. EPC is deprived of any permanent and central institution like the General Secretariat of the Council for the Communities. There is no administrative secretariat which could help the Presidency to organize the meetings, prepare the topics debated and

31 For further details on the European statements in the Middle East field: I. Greilsammer \& J. Weiler, "EPC and the Palestinian-Israeli Conflict: an Israeli Perspective" and B. Khader: "Europe and the Arab-Israeli Conflict 1973-1983: An Arab Perspective" in D. Allen \& A. Pijpers, Supra note 6 at 121-186.

32 The aims of the EPC are unfolded in the three reports of the Foreign Ministers:

Luxembourg Report Bull. E.C. 11-1970 at 9-14.

Copenhagen Report Bull. E.C. 9-1970 at 12-21.

London Report Bull. E. C. 3-1981 (supp.). 
ensure the political tasks are followed up. In reality it would even be necessary to entrust such an instrument with political burdens: the planning, the organizing and the taking of political decisions. We could imagine, initially, a transnational structure including a group of diplomats from the different foreign offices who would work together. In a later phase this would become a more integrated structure similar to the Commission. Such a secretariat would be very useful, especially in a time of crisis. Thus, the Nine took one month to issue the joint statement on 6 November 1973 after the beginning of the October War when the cease-fire was already in force and the oil weapon utilized. This unavoidably gave the awkward impression that Europe was only motivated by purely selfish considerations and by Arab pressure. Even though in issuing statements such delays have become shorter since 1973, a secretariat would, without any doubt, provide Europe with a swifter means to respond which would enhance its policy-making autonomy.

EPC also suffers from the lack of "strategic goals". It is not rooted in a precise orientation, short and long term, on the goal of the political cooperation process (concerted diplomacy, foreign policy in embryo?). Without a clear and general aim, it is certainly difficult to bring out detailed objectives on specific issues. So the European Community responds in rapid succession, after each event in the Middle East and not within a comprehensive strategy (one exception was the attempt to lay down a European line of conduct with the Venice initiative but this attempt failed, owing to the hostility raised by this project in Israel, in the Arab world, and in America).

The absence of a central authority and excessive pragmatism give to EPC a distinctly reactive aspect. "Without a secretariat, without an agreed set of attitudes and priorities in relation to third countries, without the capacity to plan ahead or to act quickly in a crisis, the Nine could only hope to react to international events, not to impose any pattern on them". ${ }^{33}$ Diplomacy which consists of foreign policy-making and implementation of established policies by the art of negotiation embodies not just reactions to developments in other states and on the international scene. Foreign policy, which is shaped by diplomacy, can thus be viewed as "those official actions (and reactions) which sovereign states initiate (or receive and subsequently react to) for the purpose of altering or creating a condition (or problem) outside their territorialsovereign boundaries". ${ }^{34}$ Foreign policy develops, as a general rule, responsive and innovative decision-making but EPC is deprived of this initiative making character, at least when it deals with "hot politics" (wars, revolutions). The instrumental weakness explains why EPC is more suitable for reaction to external challenges or events. Indeed for action (preventive reduction of conflict, involvement in negotiations) one needs a very effective

33 W. Wallace, "Political Cooperation: Integration through intergovernmentalism", Policy-Making in the European Community 384 (H. Wallace, W. Wallace \& C. Webb, 1983).

34 J. Wilkenfeld, G. Hopple, P. Rossa and S. Andriole, Foreign Policy Behavior 22 (1980). 
foreign-policy system (with decision-makers and diplomatic professionals), all of which fails to appear in the European case.

There is not only the institutional weakness which entrenches EPC on the reactive level but also the limited scope of EPC. We can borrow the distinction between "external relations" and "foreign policy" propounded by Avi Shlaim and say that EPC is restricted to the former. This means that EPC is adapted to multi- and bilateral contacts, to political prospects in international conferences and not to crisis management. To engage in crisis, one must be able to influence events with suitable tools such as economic pressures, military means, commercial blockade and psychological war. Without such tools, the capacity of an actor to influence other actors or international decisions is almost non-existent. Since Europe, as a whole, has none of these tools, it is thus unable to use persuasion, compromise or threat of force which are, according to Hans Morgenthau, the three means at the disposal of an actor who wishes to implement his policy. Europe proposes plans for just and lasting peace but is totally incapable of promoting its solutions. On the contrary, the United States and, to a lesser extent, the Soviet Union, enjoy the possession of these tools and have therefore the capacity for organized action in the Middle East. Nevertheless, Europe seems to be aware of the interaction between, say, the political and the economic dimension and has thereby narrowed the gap between EPC and the Community. So the Ten refused to convene the EEC-Israel Council of Cooperation and postponed the signing of the second financial aid agreement with Israel (which was finally signed after the Council of Stuttgart, June 1983). These measures, taken after Israel's invasion of Lebanon, conforming to previous cases (during the seizure of American hostages in Teheran, after Argentina's invasion of the Falkland Islands) show that Europe now sees economic sanctions as complements to political statements. Europe thus tries to have an effective instrument which will actually implement foreign policy. ${ }^{35}$

In spite of this kind of link the EPC remains a highly reactive process and what is more, a process with declaratory outputs devoid of operational property. The statements are made but there is not the slightest opportunity for Europe to concretize these propositions because she lacks the tools for that purpose. For instance, the Venice Declaration (1980) mentioned the Palestinian people's right to self-determination and the need to involve the PLO in any negotiations but the declaration could not provide concrete proposals to put these ideas into effect. The observation made by the Belgian Ambassador de Schoutheete is not ill-timed: "For want of tools to act together, the concerted diplomacy of the Nine will always have something of a declaratory character: there will be more documents than action". ${ }^{36}$

35 For the imposition of sanctions see: C. Hill and J. Mayall, The Sanctions Problem: International and European Perspectives (EUI Working Paper No. 59, 1983).

36 P. de Schoutheete, Supra note 25 at 130. 
The declaratory and reactive nature of EPC has been until now unsuited for hot politics - coupled directly to international events - and more adapted to cold politics - within the institutional and civilized framework of international meetings (United Nations, CSCE, ... ). In the Middle East, an area which is a favourite scene of hot politics, the Europeans are devoid of a capacity for action because EPC does not form a structure for decisionmaking geared towards political intervention. Not formed for active cooperation, EPC demonstrates a "limited potential for crisis management" 37 , a considerable impediment which excludes Europe from the Middle Eastern scene.

Structural failures are not alone to blame for the limited performance of Europe vis-à-vis the Arab-Israeli conflict. Much remains to be done to reduce the impact of national inputs.

\section{Fundamental variables}

We have seen that there had been, since 1973, an undeniable and increasing consensus among the Europeans vis-à-vis the Arab-Israeli conflict and that they now insist on the centrality of the Palestinian question. But this harmony of views has not always existed and, even now, it is threatened by centrifugal forces. During the "prehistory of the EPC" (1970-1973), the then six foreign ministers approved on 13 May 1971 a document called the Schumann paper, named after the French foreign minister. This document provided for the establishment of demilitarized zones in which international forces would be stationed, the withdrawal of Israeli armed forces with border adjustments, the administrative internationalization of Jerusalem and the choice for the Arab refugees between repatriation or compensation. ${ }^{38}$ The Schumann paper was consistent with UN Resolution 242 which was accepted by all belligerents, except Baathist Syria and the nascent PLO, even if the European provisions were more precise and operational than those mentioned in the Resolution of November 1967. Nevertheless, though there was a general congruence between these two texts, Germany refused to confirm the document, saying it was only a "working paper". Walter Scheel, the German foreign minister, went to Israel in July 1971 where he said that the document was far from being approved. Why this German reserve vis-à-vis the European plan? Because she could not, at that moment, identify herself with a document which was seen as blatantly pro-Arab and was thus received with harsh hostility by Israel. Abba Eban especially attacked Germany, claiming that she had broken her promises in subscribing to a French document. ${ }^{39}$ Owing to nazism and to her pro-Israelism which was an offshoot of her past, Germany could not be indifferent to the criticisms raised by the Jewish state.

37 See the study made by N. Van Praag, "Political cooperation and Southern Europe: Case Studies in Crisis Management" in European Political Cooperation 104 (D. Allen etal. 1982).

38 Die Welt, July 14, 1971.

39 Le Monde, May 22, 1971. 
She felt compelled to underline the differences with Paris and to denounce the "inadequate" Schumann paper. As the successor of the Third Reich, Germany could not extricate herself from the pro-Israelism she was, morally and politically, bound to adopt. This fact was an immanent cause which had a determined influence on the behaviour of the German government: it was not possible for it to accept, at least officially, a European document perceived as French in inspiration (i.e. Arab in inspiration).

This reticence was shared by the Netherlands, also a zealous supporter of Israel, and by Belgium and Luxembourg, two countries which are drawn towards Israel's cause. The "pro-Israeli" bloc was powerful enough to obstruct any European initiative until 1973, when the oil crisis challenged the Community, and obliterate the pro-Israeli scruples of some Member States. Ever since then, the Israeli parameter has not been such an impediment which would have prevented the European Community from reaching a consensus as was the case in 1971. But another parameter is still very active.

On 22 November 1977 the Member States issued a declaration whereby they expressed their support for "President Sadat's bold initiative" and "the unprecedented dialogue begun in Jerusalem". Even if they emphasized that the need for a Palestinian homeland must be guaranteed, the general appreciation of President Sadat's visit to Jerusalem was rather positive. This trend was again noticeable in the statement adopted on 19 September 1978 after the arduous Camp David negotiations when the Europeans termed this outcome "a further major step on the path to a just, comprehensive and lasting peace". The European position towards the Israeli-Egyptian rapprochement, at least in 1977-1978, is worth commenting on.

On the one hand there is common consensus between the Europeans on some untouchable principles: inadmissibility of the acquisition of territory by war; respect of the acknowledgement of the sovereignty, territorial integrity, and political independence of all states in the area; and recognition of the legitimate rights of the Palestinian people.

On the other hand, in spite of this global consensus, the Europeans may support a diplomatic initiative which does not go in the direction of this political attainment. This is the case with Camp David. Indeed, this process follows the American strategy which has a logic, possesses aims, and integrates factors distinct from those of Europe.

While Camp David returns to the step-by-step method inaugurated by Henry Kissinger, Europe has opted for a comprehensive solution to the conflict which includes all outstanding litigious problems. While Camp David corresponds with the specific interests of the United States (strengthening of the pro-American side in the Middle East), Europe, as a major power - but in the second order - has no such wide strategic objectives. Finally, while the Camp David framework for peace only mentions in a peripheral way the Palestinian problem (with the autonomy regime), Europe holds the Palestinian question as the central issue in the area. 
The Europeans supported in 1977-78 the Camp David process, even while it did not correspond with their own strategy, simply because they could not criticize a major initiative of their American ally. All Member States which are closely linked with the United States (especially in the framework of NATO) have thus brought pressure on EPC in order that Europe would approve the unexpected initiative of Sadat and its aftermaths. Germany, which above all relies heavily upon the US for security matters, was a supporter of Camp David and acted as such within the European concert. The same is valid for the Benelux countries, Denmark and, to a lesser extent, Great Britain. The more reticent countries, first of all France - for which the Camp David process inaugurates a separate peace - were constrained to renounce their positions and to subscribe to statements favourable to Camp David.

The impact of the strategic dependance vis-à-vis the US was also effective during Israel's invasion of Lebanon in 1982.

After some hesitations, France became convinced, about the middle of June, that the Israeli offensive had gone too far and was seeking the destruction of the PLO at the very time when France wanted to preserve the "moderate leadership" of the Palestinian organization. The French government tried to have this position supported by its peers during the European meeting in Brussels (28-29 June). It wanted Europe to make an appeal for the neutralization of Beirut and for the disengagement of forces which would rescue Y. Arafat and his lieutenants. France was even in favor of a more precise wording of the European declaration which would have included granting the right to the Palestinians to build a state. Nothing of the sort happened, the moderates (Germany, Denmark and the Benelux) preventing the adoption of a statement which went beyond the Venice Declaration of 1980. France, along with Greece and Ireland, was defeated because the other Member States did not want to let Europe take an autonomous stand different from the one taken by the US. The moderates were favourable to an alliance with the United States and in giving a strong support to the mediation of the American diplomat Philip Habib: they froze therefore any European independant initiative, in the wording desired by France, because this would have thwarted America's plans.

We had to notice that the applauded "entente" of the Reagan administration and its diplomatic actions raise the same objection as previously with Camp David. Washington's aim, with Habib's mission, was to expel the PLO from Lebanon: so the Americans kept their low profile towards the Palestinian problem by trying to move the PLO away from the Middle Eastern field. This objective was not at all congruent with the various European declarations which emphasize the centrality of the Palestinian question. However the moderate preferred to support America's efforts in Lebanon instead of undertaking to promote the European way to peace.

This counter-performance is the result, not only of Europe's limited 
capacity for intervention in this area (so it is easier to rely upon the American superpower), but of its strategic dependence on the United States. Such dependence forbids countries like Germany to take a course opposed to Washington's. A more or less independant defense network would undeniably provide Europe with more political freedom but, until that time, the moderate countries within the Community will continue to be very cautious about not following American initiatives and acting as upholders of the US, the dominant external power in the Middle East which is, for them, a large piece of real estate. If the pro-Israeli parameter is no longer a determining input in Europe's behaviour towards the Arab-Israeli conflict, the "American parameter" is and will remain an influential one.

\section{Conclusions}

Europe, in the framework of the European Community, has become, thanks to EPC, an international actor that is an organized entity not wholly subordinate to another actor in the world system and an actor able to have an impact on the management of world politics. The battle field states, the superpowers, the PLO, the UN (through the General Assembly and its specialised and regional organizations such as UNRWA and UNIFIL), and the European national governments have perhaps been more central. But Europe as a whole has played a role, even though she was out of play fifteen years ago.

A whole range of factors, stretching from historic to economic considerations, have contributed to make the Middle East a top priority subject in the foreign policy coordination process within the European Community. It is above all through the Arab-Israeli conflict that the EEC has become a political unit which articulates a common European interest and maintains its own political voice. It is through this conflict that the European States have perfected the EPC framework and that they have introduced Europe on the international scene as an actor which has an effective capacity to behave continuously and deliberately. Nevertheless, even if the European Community is now an actor, she remains an imperfect one. If we use the satisfactory definition given to the term actor by two respected scholars who see an actor as "a relatively autonomous unit that exercises influence on the behavior of other autonomous actors" 40 , we must admit that Europe is not such a total actor in the Middle East. She remains "some sort of half-developed international actor". ${ }^{41}$

Indeed the key to the situation in the region rested in the hands of the two superpowers and of the local powers which are dependent of the former in

40 R. Hopkins \& R. Mansbach, Structure and Process in International Politics 4 (1973).

41 G. Sjosdet, The External Role of the European Community 12 (1977). 
military and political terms. In the Middle East regional or subordinate system ${ }^{42}$, Europe has without doubt, an actor-capacity, in the sense that she can assume a political role (for instance by means of fact-finding missions or official declarations), but she has not the power to influence the political environment in the region because she still has structural and political deficiencies. In other words, the institutional and policy interactional sides ${ }^{43}$ of the European activity always show some faults.

On the institutional side, without a decision-making machinery which makes possible quick reactions and comprehensive actions, Europe cannot be a source for diplomatic initiatives in the Middle East. A second rank power, Europe cannot act efficaciously without the support of a strong decisionmaking system.

On the political (interactional) side, Europe's actor-capability is limited by the fact that there is not always consistency in the political positions of the EC towards the Middle East clash. Sometimes the actions of Europe lack consistency in relation to her general political attitude: in 1977-1978 for instance, the pro-Camp David stand rests on different premises than the European appeal for a comprehensive settlement. If an improvement takes place on the two sides, the EC may become a more creative force that can offer solutions, derived from her own post-war experience, for a lasting peace in the Middle East.

42 The concept is used by M. Brecher, "The Middle East Subordinate System and its impact on Israel's Foreign Policy", 13-3 Int'l Stud. Q. (1969).

43 We borrow these concepts from J. Nye, "Comparative Regional Integration: Concept and Measurement”, 22 Int'l Org. 864-870 (1968). 


\title{
Reflections on the Capability of the European Community to Play an Active Role in an International Crisis: The Case of the Israeli Action in Lebanon ${ }^{1}$
}

\author{
Ilan Greilsammer
}

\section{Introduction}

Although conceived less than fifteen years ago, the framework for European Political Cooperation (EPC) has already been the object of a great deal of academic research, this as much in the legal sphere as in the spheres of political science and international relations theory. These studies were undertaken by such fine scholars as William Wallace, David Allen, Joseph Weiler, Eric Stein, and Wolfgang Wessels, to name but a few. ${ }^{2}$ The framework is concerned with the capability of the European Community, as a grouping of ten independent states, to achieve some degree of coordination and harmony in the area of foreign policy. Like the foreign policy of a single sovereign state, EPC can be evaluated in different ways, and according to various criteria. Thus, Joseph Weiler has distinguished between three distinct dimensions of EPC: - the active dimension (for example, the playing of an independent role by Europe in world affairs); - the reactive dimension (the furthering, as far as possible, of European interests); - and the reflexive dimension (the utilization of world events in the European internal arena, for

1 This article has been written in the framework of a larger research on the attitudes of Western Europe Fowards international crisis (1973-1986).

2 See, e.g., W. Wallace, "Political Cooperation: Integration Through Intergovernmentalism" in Policy-Making in the European Community, (H. Wallace, W. Wallace and C. Webbs eds. 1983); R. Rummel and W. Wessels eds., Die europäische politische Zusammenarbeit. Leistungsvermögen und Struktur der EPZ (1978); D. Allen and A. Pijpers eds., European Foreign Policy-Making and the Arab-Israeli Conflict (1984); D. Allen, R. Rummel and W. Wessels eds., European Political Cooperation (1982); E. Stein, "European Political Cooperation (EPC) as a Component of the European Foreign Affairs System", 43 ZaRV 49 (1983). 
example to reinforce the internal cohesion of the Community). ${ }^{3}$ Such a distinction, which preserves us against a "one-dimensional" evaluation of the results of European common policies, is fully justified: a given decision, or action, may have negative consequences in one area (or dimension) and postive consequences in another.

The objective of foreign policy is, among others, to react to three kinds of external "incentives":

- long-term developments, not necessarily connected with any conflict (for example the Third World's problems, hunger in Africa, the growth of religious extremism in Islamic countries);

- "conflicts", which are provoked, in the words of Steven L. Spiegel, "by a clash of cultures, a disharmony of interests, a disparity of perceptions". For example, the Arab-Israeli conflict, of the Vietnam War;

- lastly, sudden "crises", of short duration, sometimes constituting a critical stage of an international conflict. Also falling in this category are single events of a brief and dramatic nature, even if unconnected with any international conflict. Each of the wars between Israel and the Arabs, in 1948-49, 1956, 1967, 1973, and 1982 are clearly "international crises". Similarly the Falklands War, the invasion of Afghanistan or that of Grenada, and also events of a purely internal nature, such as a military coup or the assassination of a political figure should be included.

Just as one might expect any state (which has an importance going beyond its territorial boundaries) to take a stand regarding the various kinds of "external incentives", one might expect the European Community to react to such developments in the framework of EPC. And one can try to evaluate the capability of the Community to react.

This article concerns just one of the dimensions of EPC, the active dimension. It is perhaps the most important: since 1970, the drive to develop a common foreign policy has been motivated firstly by the desire to reinforce the community's role in the international arena, to take an independent role between the superpowers, in short, to speak "with one voice" and to be heard. Reactive and reflexive objectives are important, but will not be treated here.

We will also not discuss the efforts of the community to achieve some degree of joint foreign policy towards what we called "long-term developments" in world politics; nor will we deal in any great detail with the Ten's attitude toward the Middle East conflict in general. We have analyzed the

3 Charles F. Hermann defines a crisis as "a situation of unanticipated treat to important values and restricted decision time". See "Some consequences of Crisis which Limit the Viability of Organizations" VIII Administrative Science Quarterly 61 (1963). See also O. R. Holsti, Crisis Escalation War 7-25 (1972). For a critical review of the may usages of the term "crisis" see C. F. Hermann: Crisis in Foreign Policy (1969); James Robinson, "Crisis: An Appraisal of Concepts and Theories" in Contemporary Research in International Crisis (C. F. Hermann, ed. 1973). 
development of this attitude, from the publication of the Schumann Document in 1971, in other articles. ${ }^{4}$ Our topic here is the crisis brought on by the outbreak of the war in Lebanon, between the beginning of the Israeli action on June 6,1982 and the European Council in Stuttgart, one year later. The period of "acute crisis" in the Lebanon War was, in fact, very short, comprising the summer, fall and winter of $1982 .{ }^{5}$ From spring 1983 onwards, the war in Lebanon was relegated to the bottom of the European agenda.

By analyzing the case of the Israeli action in Lebanon, we will try to find an answer to the general question: does the European Community possess the capability to react, take a stand, and take action regarding a sudden and acute international crisis? This question can be divided into sub-questions, as follows:

- does the Community possess the capability to take a stand rapidly and, once taken, is this stand supported by measures of coercion?

- does each Member State react with the same intensity? Is there a "leader" among them?

- what is the impact on the Community's position of the position adopted by the United States? How can we evaluate the role of the Community, in comparison with that of the United States?

- lastly, is the Community's intervention a success or a failure?

\section{The context of the Community's intervention:}

\section{E.P.C. and the Middle East conflict}

Before beginning an analysis of the reaction of the Ten to the outbreak of the war in Labanon, it is necessary to examine the context of this reaction. In other words: what was the state of the Community policy regarding the Israeli-Arab conflict on June 6, 1982?

On June 13, 1980, the Community adopted a major declaration: the Venice declaration. This text added two new elements to the European position which had been formulated at the London summit, in June 1977. It insisted on giving the possibility to the Palestinian people to fully exercise its right of self-determination; it insisted on the need to associate the PLO in any peace negotiations. The Venice declaration constituted a "third stage", after the 1973 declaration (on the legitimate rights of the Palestinians), and the 1977 declaration (on the rights of the Palestinians to a homeland). The major aim

4 See I. Greilsammer and J. Weiler, "European Political Cooperation and the PalestinianIsraeli Conflict: An Israeli Perspective", in D. Allen and A. Pijpers, supra note 2 and I. Greilsammer and J. Weiler, The European Community Framework for Political Cooperation and the Israeli-Arab Conflict (forthcoming).

5 A good account of the war in Lebanon can be found in Z. Schiff and E. Yaari, Milkhemet Sholal, (Hebr.) (1984). 
of Venice was to promote an active role for the Community, instead of a purely declarative one: hence, the term "European initiative" used to define the process set into operation by this text. No one has ever managed to give a precise definition of what the heads of state and government exactly meant by the word "initiative", but the discussions which preceded and surrounded the Declaration suggest that the Europeans wanted:

- to find a role for the Community, which would be independent of the United States and distinct from the Camp David process;

- to rapidly bring about a situation in which the Community would be considered by the parties to the conflict as a necessary factor in any peace solution;

- to further a new Middle East peace process, in a concrete manner, by submitting plans, suggestions, propositions to the parties, of even elements for a final solution of the conflict.

When the war in Lebanon broke out exactly two years after Venice, the Community had not made any concrete progress in any of these areas. In June 1982, the only way ahead was still the American-led Camp David process, even if it ran into serious difficulties. Two months before the war, the Israelis had withdrawn from Sinai, according to the peace treaty with Egypt. The participation of some European states in the MFO (established by the American-led peace process) clearly symbolized the "failure" of the European initiative. ${ }^{6}$ For the Israeli government and the moderate Arab countries the United States continued to play the key role on the Middle East scene. Even the PLO had violently criticized Venice, because it did not speak of a Palestinian state and did not recognize the Palestinian organization as the sole representative of the Palestinian people.

In practical terms, the Community did no more than send "missions" to the Middle East, in 1980, 1981 and 1982. These missions achieved nothing new. The last mission, that of Leo Tindemans just before the war, highlighted once more the extent of the gulf between the parties. The European press was then hinting at the possibility of a change in the terms of the Venice declaration. ${ }^{7}$ We have analyzed elsewhere some of the causes of this European failure to give any real substance to Venice: a serious internal crisis in the Community, the election of a new American president with his own policy, the entry of Greece in the Community (and the victory of PASOK), the election of Mitterrand and the new French policy, the 1981 victory of the Likud in Israel, the assassination of Sadat, the Falkland crisis ...

6 See A. Pijpers, "European Participation in the Sinai Peace Keeping-Force (MFO)", in D. Allen and A. Pijpers, supra note 2 at 211-223.

7 The result of the last contacts before the war was a 35-page document, the philosophy of which can be summarized as a new way of implementing the Venice Declaration, making it maybe more acceptable to the Israeli government. 
A collection of factors conspired to prevent the "European initiative" from getting off the ground. ${ }^{8}$

\section{How Quickly can the European Community Adopt a Common Position when Confronted by an International Crisis?}

The Lebanese War (called by the Israeli government "Peace for Galilee") broke out while the heads of state and government of the seven richest countries in the West were holding a summit conference at Versailles. Among them were the leaders of the four largest member states of the EEC: France, Great Britain, the Federal Rupublic of Germany, and Italy. The entry of Israeli forces into Lebanon came barely hours after the Security Council of the UN called for "the cessation of all military activity", and just before Philip Habib's arrival in the Middle East.

We must here point out that the participants in the Versailles summit were preoccupied on the international level mainly by the Falklands crisis and the Iran-Iraq conflict, and that they were very surprised by the scope of the new Israeli operation. The declaration which they issued was vague:

"We are overcome by the news which has reached us from Lebanon. We are deeply moved by the loss of human life and by the suffering and destruction. We think that this new cycle of violence could have, if it continued, disastrous consequences for the entire region".?

On the European level, the first two weeks of the war were characterized by confusion and indecision. Of course the "invasion" was condemned, and the Community members who sat on the Security Council voted for the resolution of June 7 (one proposed by Japan, the other by Ireland) calling for a cease-fire. But they did not go further. The fact that Israel should have a certain "security zone" free of terrorists on its northern border - the famous "40-50 kilometers" proclaimed by the Israeli Prime Minister Menachem Begin - was, if not explicitly acknowledged, at least partly understood by many Europeans (who, furthermore, were shocked by the assassination attempt against Ambassador Argov).

On the other hand, after a while, the ten governments began taking notably divergent attitudes. For example, Britain adopted a "hard" position, pointing out that the black list found on one of the London terrorists also included the name of Nabil Ramlawy, Chief of the PLO delegation in Great Britain; British representative at the UN Sir Anthony Parsons gave credence to the idea that the PLO had not been responsible for the assassination attempt (and thus the Israeli intervention in Lebanon was unjustified). ${ }^{10}$

8 See I. Greilsammer, "Failure of the European Initiatives in the Middle East" 33 The Jerusalem Quarterly 40-49 (Fall 1984).

9 Le Matin, June 7, 1982.

10 Le Monde, June 8, 1982. 
Ireland was very active in the Security Council, pushing to have Israel condemned. Greece launched immediately a powerful campaign against Israel, placing itself completely on the side of the PLO. In no European country did the Israeli action give rise to such a collective anti-Israel reaction as in Greece, both on the governmental level and that of the political parties, the media, and the public. The Greek government demanded an immediate meeting of the EEC Council of Ministers to determine the sanctions to be taken against the "aggressor". ${ }^{11}$ Papandreou described the Israeli action as "a crime against humanity"12, declaring: "We live in a terrifying era. We have seen what Nazism did to the Jews and now Jews (sic) are doing the same to Palestinians". German Foreign Minister Genscher asked Israel to withdraw its forces, to respect the independence and the sovereignty of Lebanon, and to obey the UN resolutions 508 and 509. ${ }^{13}$ Holland, Belgium, Luxembourg, Denmark and Italy kept a low profile.

As for France, which was at the time president of the Security Council, it seems that François Mitterrand and the ruling circles of his Parti Socialiste were rather confused. Despite evident disenchantment with the Likud government, Mitterrand had sought to re-establish polite, even cordial relations with Israel. The cornerstone of that effort had been his visit to Jerusalem in March. Therefore, in Versailles Mitterrand condemned Israel in vague terms and manifested his "deep reprobation", but he was hesitant to go beyond that and run the risk of being rejected by Israel once again, like de Gaulle, Pompidou and Giscard d'Estaing, as a valid interlocutor and mediator. While condemning the Israeli action, Mitterrand was very careful to emphasize that he " had not hesitated to condemn the other interventions on the Lebanese territory (as well), whenever they were made against the will of the Lebanese government".

Mitterrand's indecisiveness was pointed out by the whole French press: Le Monde, for example, in an editorial of June 9 entitled "France on the Spot", noted that the President's condemnation of Israel "had not come to his lips spontaneously". The paper spoke of "an absence of clarity" in his remarks. At the same time, Mohammed Yazid, a representative of the Arab League, stated that he was "disappointed by France's attitude". He linked the "vagueness" of French reactions to the fact that Mitterrand had made a trip to Israel in March. ${ }^{14}$

In fact, Arab leaders seem to have been shocked because Mitterrand said that Lebanon, occupied by the Israelis, "was already occupied by two other armies, that of the Syrians and that of the Palestinians". That expression seemed to erect a parallel between those "occupations", whereas Syria was in

11 The Jerusalem Post, June 8, 1982.

12 The Jerusalem Post, June 29, 1982.

13 Le Matin, June 8, 1982; Le Monde, June 8, 1982.

14 L'Humanité, June 9, 1982. 
Lebanon as part of the peace-keeping force of the Arab League, and the presence of PLO forces was "accepted" by the Lebanese agreements of 1969 (even though they were frequently violated).

What is important is that none of the ten EEC governments wanted or agreed to wait for a "European common position" in the framework of the EPC before producing its own statement. In that climate of confusion and indecision, the Foreign Ministers of the Ten met in Bonn on June 9 to try to formulate a joint declaration. The day before, the heads of the Arab diplomatic missions in Brussels had appealed to the European Community to take a common position and effective measures:

The moral force represented by the position of Western Europe as expressed in the Venice Declaration has faded... It was neither logical nor moral for Europe to be satisfied with merely following events from a distance. Ethics as well as its interests demanded of Europe that it intervene directly and take coercive measures to force the immediate evaluation of Israeli forces from Lebanon, and to make possible the beginning of a real, global peace process involving all the concerned parties, including the PLO, and regarding the rights of the Palestinian people to an independent and sovereign state on Palestinian soil". ${ }^{15}$

The divergence among the ten European countries broke at the June 9 meeting. After two hours of very hard discussions, the ministers condemned the invasion of Lebanon "which is a flagrant violation of international law, and which can only make the search for a solution to the conflict in the Mid East more difficult". Here it is interesting to note that the Ten find more easily a common denominator on the legal level ("a violation of international law" $)^{16}$ than on the political level. It was difficult for Leo Tindemans, president of the Council, to reach a consensus. Apart from the condemnation in principle of Israel, there was no agreement, except to offer "humanitarian assistance" to the victims and to continue working for "a just and durable solution to the conflict".

Ten days later in Luxembourg, the representatives of the Ten demanded various "assurances" and guarantees of the Israeli government: that it admit international relief organizations to the territory occupied by its forces; that it admit representatives of the press; that it apply the Geneva conventions; that it recognize the sovereignty of Lebanon and the international border between Lebanon and Israel; that it desire neither to annex nor to occupy any part of Lebanese territory; that it not intervene in the internal affairs of Lebanon; that it will cooperate with the Secretary General of the United Nations in every area of his responsibility; that it have no hostile intention towards the

15 Le Soir, June 8, 1982.

16 For a presentation of this thesis, according to which the Israeli action was a violation of international law, see the controversial Israel in Lebanon (1983). 
Palestinian people; that it have no offensive intentions against the neighboring countries, including Syria. ${ }^{17}$

Asking for such vague guarantees can hardly be considered as "taking a common position" or "reacting to a crisis".

For its part, the European Parliament adopted a moderate resolution, condemning equally the Israeli operation and all the terrorists acts previously launched against Israel. In that resolution - the result of a compromise among the center and the center-right parties of the Parliament (Christian Democrats, Gaullists, Liberals and Conservatives) - the Assembly called for the withdrawal of all non-Lebanese armed forces from Lebanon, and for negotiations among the concerned parties. ${ }^{18}$

The European Council at Brussels (June 28-29) met in a climate of general dissatisfaction with the United States. ${ }^{19}$ The strange role of the Reagan administration and especially of Secretary of State Haig during the Lebanese crisis was only a minor aspect of that mood. The economic and commercial "warfare" waged against Europe was maybe more crucial than the war in Lebanon. The alleged "violations" of the summit agreements at Versailles, taxes on the importation of European steel, the technological embargo on European companies who traded with the USSR, high American interest rates and the rise in the exchange rate of the dollar. All partly overshadowed the war in Lebanon.

While there was no major controversy on the necessity to react very firmly to the American economic steps, the Ten were divided on Lebanon. The final communique issued at the end of the summit reflected an uneasy compromise between those (Greece, France) who wanted a much tougher line in support of the Palestinians, and those (Netherlands, Germany) who wanted to excise explicit references to the PLO, given the prospect of its (military) extinction.

Finally, the Ten vigorously condemned the Israeli action, and called for the cease-fire to be respected and linked to an Israel withdrawal from around Beirut, and for the simultaneous evacuation of Palestinian forces from WestBeirut. Separation of the two sides would be controlled during "a short transition period" by Lebanese forces and by UN observers or forces. A final peace would require complete Israeli withdrawal, plus "the departure of all foreign forces except those which may be authorized by a legitimate and broadly representative government of Lebanon". The statement stressed that Israel would not obtain "the security to which it has a right" by using force and creating faits accomplis. Israel would achieve this only by satisfying "the

17 See Agence Belga, June 9, 1982, and the comments in The Times, June 10, 1982 and Le Soir, June 12, 1982.

18 O. Y. No. C 182/54, July 19, 1982.

19 See, for example, The International Herald Tribune, June 29, 1982; The Irish Press, June 29, 1982; Le Quotidien de Paris, June 29, 1982. For an Israeli perspective concerning the European Council. see The Jerusalem Post, June 29, 1982; June 30, 1982. 
legitimate aspirations of the Palestinian people, who should have the opportunity to exercise their right to self-determination with all that this implies". For negotiations to be possible, the Palestinians should be represented at them: this would mean the PLO would be associated with any negotiations.

The main controversy at the European Council was about sanctions against Israel. Indeed, the capacity or the inability to the Community to adopt coercive measures during an international crisis must be considered as a test. On the very first day of the war, Greece asked for Community sanctions against Israel. This demand was again presented by Andreas Papandreou at the European Council of Brussels. But which kind of sanctions could be taken by the Community?

On the theoretical level, the scope of the sanctions which could be adopted by the Ten was rather limited. The Community could first act through its member states. It could ask them to take collectively certain military measures such as to send troops to help the "victim", or to send forces to separate the parties, or to stop any military shipment to the attacker. It could ask its member states to adopt certain political measures, such as breaking diplomatic relations with Israel, or recalling their ambassadors (as was done by President Mubarak). It could recommend economic sanctions, such as an embargo on Israeli goods.

However, the European Community may take direct sanctions only on the economic level. In the case of Israel, the Common Market has three main agreements with this country; the 1975 free-trade agreement, and the two minor 1977 protocols on technological and on financial cooperation. ${ }^{20}$ The harshest decision would (again, theoretically) have been to cancel or to suspend the 1975 Agreement and to re-establish duties on Israeli goods.

Finally, the decision taken by the Ten was not to adopt sanctions, or rather adopt sanctions which could not have any practical effect on Israel.

1. They decided to "freeze" any high-level contact between Community officials and the Israeli government, i.e. not to convene the Council of Cooperation provided by the 1975 agreement.

2. They decided to "freeze" the two 1977 protocols. In particular, they put off "indefinitely" the signing of a second financial aid agreement with Israel (48 million ECU), a postponement which had already been decided on June 14.

Without there being an official "collective" decision of the EEC, the Ten decided to place an embargo on military shipments to Israel. ${ }^{21}$

The British Foreign Secretary Francis Pym admitted that these measures were "weak and woolly". He explained that there had been no agreement

20 See I. Greilsammer, Isrä̈l et l'Europe. Une bistoire des relations entre la Communauté européenne et l'Etat d'Israël (1981).

21 See, for example, The Guardian, July 2, 1982, La Dernière Heure, July 2, 1982. 
among the Ten in favor of economic or arms sanctions against Israel. The decisions made in Brussels were toothless.

First, frequent contacts between the Commission officials and Israeli diplomats continued through the "freeze"; secondly, the very limited scope of the two 1977 protocols had already been pointed out by Israel, and these agreements were considered as highly ineffective. The amount of Community funds promised to Israel was very small. Finally, the famous "military shipments" on which an embargo was place consisted only of individual items and were of minimal importance.

The Ten, contrary to the Greek demand and to what they did in the cases of the Falklands crisis, the establishing of martial law in Poland, or the taking of hostages in Teheran, limited themselves to symbolic actions. The Nine (Mitterrand included) did not believe that sanctions would be effective, and they thought that they would only cause increased Israeli "inflexibility".

In conclusion, the member states showed themselves unable rapidly to establish an effective common position towards the crisis. The European reaction was unclear during the first twenty-three days, up to the adoption of a detailed position at the European Council. The absence of a "crisis thinktank" in the Community is particularly noticeable when we realize that the first two reactions of the European countries took place in non-European fora - the Versailles summit and the Security Council. Only after a lapse of three days from the start of the crisis did the Ten manage, with difficulty, to arrive at the conclusion that the "invasion" violated international law. The guarantees demanded of Israel ten days later were vague and general, and did not call upon the parties to put an end to the crisis itself. Finally, the Declaration of the European Council, overshadowed by other problems, consisted of a delicate compromise between essentially diverging positions. The Ten reacted to the war in Lebanon as if it represented a further stage in the Arab-Israeli conflict, and not a specific crisis. This partly explains the absence of any coercive measure.

\section{Did the Member States of the Community React to the Crisis in Unison, or did they Follow a Leader?}

The war in Lebanon is a good example of a crisis in which one of the Ten plays a leading role, when the others or most of them keep a low profile. France under Mitterrand again took the leading role, as under former French presidents.

The change in the attitude of President Mitterrand and his closest advisers - prominent among them being the Minister of Foreign Affairs, Claude Cheysson - took place during the second week and became stronger during the third week of the crisis. That change must be placed in the context of French policy towards the United States and the PLO. It is no exaggeration to say that Mitterand and his advisers never placed a great deal of confidence in 
the Reagan administration. Their mistrust was manifest from the time of Mitterand's election, and was shown in diverse areas, both strategic and economic.

In the case of the Lebanon crisis, the French president became convinced that Washington had - tacitly - given Begin the green light to launch his offensive, and especially that Secretary of State Haig had agreed in advance to exceeding the 40-45 kilometer line. The Americans' rather moderate attitude towards Israel, their refusal to condemn the bombardment and the blockade of Beirut, as well as their veto of the security Council resolutions gave a final reinforcement to Mitterrand's analysis. The US also seemed to have "accepted" the Israeli occupation of Lebanon quite quickly and did not demand an immediate and unconditional withdrawal. They seemed to have been in agreement with Menachem Begin's government that Israel should only withdraw when the Syrians and the PLO had gone. At that point, Mitterrand refused to accept what he considered as an American-Israeli "conspiracy". In addition, there was Mitterrand's personal analysis of the Palestinian problem and the role of the PLO. Of course, in 1981 he had shown a distance with the Venice Declaration and the "European initiative", because he deeply believed that the Venice text was unbalanced and that a climate of confidence had to be re-established with Israel before Europe could play any role in the Middle East. Therefore he went to Jerusalem. However, his desire to renew cordial relations with Israel was always associated with the idea that the Palestinian problem actually was at the core of the conflict, and the "moderate leadership of the PLO" around Yasser Arafat definitely had a role to play in peace negotiations. All the closest advisers and ministers of Mitterrand insisted on what they considered to be a fundamental division between "extremists" and "moderates" within the PLO. Whereas nothing had to be expected from the "extremists" (e.g. Habbash, Hawatmeh, Jibrill), high hopes could be pinned upon the "moderates" associated with Arafat. Issam Sartawi was seen by the French socialists as the foremost representative of this current. In any case, since the French socialist government considered mutual recognition by the PLO and Israel to be a major objective, the "moderates" of the PLO had to be encouraged and protected.

Now it appeared, during the intensive bombardement of West Beirut and the blockade, with the steady advance of Israeli troops, that the entire PLO leadership, including its "moderates", was in danger of being crushed and annihilated. It appeared clearly to Mitterrand that the "moderate" leadership of the PLO, which was trapped in Beirut, had to be rescued at any price, even at the price of (temporary) tension with Israel. In the view of the French government, the complete destruction of the PLO could only lead to the rebirth, later on, of another Palestinian organization which would be more extremist and entirely devoted to terrorism. (While that analysis had been elaborated among the President's advisers before the Israeli offensive in 
Lebanon, it was reinforced by the climate created in France by the war: the media covered the "horrors" of Beirut, comparing West Beirut to the Warsaw Ghetto). A pro-Palestinian attitude took hold among the circles and groups traditionally linked with the French socialist party. Mitterrand found himself under pressure from certain ministers who wanted him to adopt a clear and "hard" position against Israel. The division between "pro-Israel" and "pro-Arab" circles within the leadership of the party was accentuated, and this time the pro-Arab, and especially the CERES current, won. The French communist party, with its four ministers, was entirely devoted to the cause of the PLO and increased its pressure on Mitterrand.

Thus a paradox soon developed. Whereas Great Britain, which had sponsored the "European initiative" in 1980 under Foreign Secretary Lord Carrington, felt silent and kept a low profile during the crisis, Mitterrand, who had denounced the Venice initiative at the time of his election, became the foremost advocate of European intervention in the Beirut crisis. The change in tone appeared when Foreign Minister Itshak Shamir came to Paris on June 15.22 The French president reaffirmed "the solemn appeal launched by France that an end be put without delay to the bombardments, to the fighting, and to the suffering of the Lebanese and Palestinian populations", and he demanded "the immediate withdrawal of Israeli armed forces from Lebanon, (a demand) already made by the Security Council and by the Ten". For his part, Cheysson re-emphasized to Shamir that France considered the invasion to be "a violation of international law" and "without a normal future for the Palestinian people, a durable peace would not be possible in the Middle East". In Vienna, Mitterrand declared: "International law is determined by the common accord of nations. No matter what objection one may make to that law, no one should substitute his own decisions and actions to the principles that govern the equilibrium of the world". ${ }^{23}$ Contacts between Paris and the PLO leadership became more intense. According to the PLO: "The French attitude becomes very positive"; "there is a qualitative evolution in the relations between the French socialist party and the Palestinians" etc. ${ }^{24}$ Paris's intervention in order to keep the PLO leadership alive became quite concrete in the statement made on June 24 (during the siege of Beirut) by Mitterrand. The five essential points of that text were:

- the French fear that Israel will attack West Beirut;

- Israel must be strongly condemned for not respecting the cease-fire;

- there must be a disengagement of all forces;

- West Beirut must be neutralized;

- the Security Council must intervene. ${ }^{25}$

22 L'Humanité, June 16, 1982; Le Monde, June 16, 1982; June 17, 1982.

23 Le Monde, June 18, 1982.

24 Le Monde, June 19, 1982; June 21, 1982.

25 Le Matin, June 26, 1982; Libération, June 26, 1982; Le Monde, June 26, 1982. 
What is important is that the text became a sort of "program" for France throughout the blockade of Beirut, and in the absence of any equally welldefined line among the other members of the EEC (with the exception of Greece), France attempted to have this platform adopted by the entire Community.

The two months preceding the evacuation of the PLO from Beirut were marked by French diplomatic efforts, contrasting with the passiveness of the other EEC members. France wanted:

1. to guarantee an "honorable retreat" (une retraite honorable) for the PLO from West Beirut. As for the future multi-national force in Beirut, contrary to the Israeli government, which spoke of a "force to supervise the withdrawal of the PLO", Paris spoke only of an "interposed force" (force d'interposition) and emphasized that its deployment had to be approved by all parties, including the PLO;

2. to tie the problem of West Beirut to the whole Palestinian problem and to take advantage of the emotion aroused by the blockade to have Resolution 242 modified (Paris wished to have the "legitimate rights of the Palestinians", the "right to self-determination", and the "necessity of mutual recognition between Israel and the PLO" included in a new Security Council resolution).

On the "intellectual" level, the French attempted, from the beginning of July, to propagate in the Community the thesis according to which the PLO had become "respectable" and had definitely renounced armed struggle, in order to devote itself to strictly political activities. As Cheysson said: "The PLO has accepted the transition from the stage of the armed struggle to the political stage", ${ }^{26}$ The French used, among others, the appeal of MendesFrance, Goldman and Klutznick, Uri Avnery's interview of Arafat, and of course, but with some prudence, Arafat's signature on the McKloskey document. ${ }^{27}$

On the practical level, France increased her contacts with the leaders of the PLO, both in Beirut and in Paris, where for the first time Farouk Kaddoumi was received by the French president. These French initiatives, as well as the allusion of Mitterrand to Oradour-sur-Glane, and the slaying at the rue des Rosiers in Paris were very badly received in Israel, the French giving the impression that they were more concerned with saving a terrorist organization than with fighting terrorism. ${ }^{28}$

Instead of a "European Community axis" at the United Nations, one saw the formation of a "Paris-Cairo axis". Egypt and France coordinated their initiatives at the UN and consulted one another more frequently than the

26 Le Matin, July 7, 1982.

27 Le Matin, July 8, 1982; and on French reactions to the "Arafat Document" see Libération, July 28, 1982; Le Monde, July 28, 1982.

28 Le Quotidien de Paris, July 15, 1982; Libération, July 16, 1982. 
Community members. ${ }^{29}$ There was also a "Paris- Athens axis". The leading position taken by France and Greece, in contrast with the other eight members of the EEC, was demonstrated rather symbolically by the meeting held by Papandreou and Mitterrand in Athens on the very day that the PLO fighters were evacuated from Beirut to Athens (although the French president did not wish to meet the head of the PLO at that juncture). As Mitterrand himself declared in Athens: "France and Greece have contributed to the appeasement in the Near East by holding in common the idea that nothing will be possible unless the rights recognized by international society are acknowledged for all the peoples and states of that region. Greece is a remarkable asset in the necessary steps (towards pacification), even if there is no identity in our daily diplomatic efforts". 30

The eight other countries of the EEC adopted a low profile. For example, after having vigorously condemned the Israeli action at the beginning, the British government felt silent. The Germans, the Dutch and the Danes were scarcely convinced by the French arguments on the "moderates" within the $\mathrm{PLO}$, in the Palestinian renunciation of armed struggle, and, above all, they wanted to coordinate their policies towards the crisis with the Reagan administration. Upon his return from a short visit to the Middle East as the "official" emissary of the EEC, Hans-Dietrich Genscher said that he had received the impression that "the moderate Arab countries would not appreciate a European initiative cut off from American policies". He continued, "We are naturally interested in being in harmony with our American friends, and working towards a joint position with them". ${ }^{31}$

The foreign ministers of the Ten, meeting on July 19 in Political Cooperation, were given the choice between two approaches (apart from the extremist approach of the Greeks): the French, aiming at the Community reinforcing the international status of the PLO "moderate" leadership, and the German, aiming at a low profile and European-American coordination. ${ }^{32}$ The second approach clearly won over the majority of the EEC members. Rather than take an independent initiative, they choose to coordinate their actions with Washington and attempt to have the US put pressure on Israel. The French position was defeated. It is of particular interest to note the differences in the tone and style of the three European speeches which were made at the 28th meeting of the 7th Emergency special session of the General Assembly of the UN (August 1982): that of Helskov (Danish, representing the European Community), Ghikas (Greek), and Louet (French).

The only case in which the Ten truly reacted together was after the Sabra and Shatila tragedy. The massacres were extremely shocking to European public,

29 Le Matin, July 12, 1982; July 13, 1982; Aug. 16, 1982.

30 Le Monde, Sept. 3, 1982.

31 The Financial Times, July 20, 1982.

32 The Irish Times, July 20, 1982; The Guardian, July 20, 1982. 
and the mass media in Europe were particularly unrestrained in attacking Israel. The impact of the massacres led, even in the most moderate governments of the EEC (Germany, Netherlands, Luxembourg, Denmark) to a hardening of their attitudes towards Israel. But the interest taken in that affair was transitory. The Commission of Inquiry established in Israel did a great deal to rehabilitate Israeli democracy, if not the Begin government, in Europe. As to the Declaration of the Ten on Sabra and Shatila (September 20, 1982), we must note that, contrary to the desire of four foreign ministers (Pym, Cheysson, Haralambopoulos and Colombo), Israel was not explicitly accused of the massacres. Her indirect responsibility can only be read between the lines of the declaration, which appears to establish a link between the massacres, the violation of the Habib plan, and the demand for Israeli withdrawal from West Beirut. ${ }^{33}$

W as the Community able to develop an independent stand towards the crisis, or did it merely react to American policy?

Apart from the Arab Summit of Fez, President Reagan's announcement of his peace plan on September 1, $1982^{34}$ truly dominated the Europeans' efforts during the fall of 1982 and the following winter. The convergence of American and European views was expressed on two levels:

- On the one hand, Reagan insisted on the "legitimate rights of the Palestinians", and on the fact that the military losses of the PLO had not diminished the aspirations of the Palestinian people for a just solution to their problem. Even though the formulation of those rights by Reagan was rather vague, it was the first time that Americans had presented the rights of the Palestinians as such a central issue.

- On the other hand, Reagan, like the Europeans, criticized Israel sharply, warning that her military superiority cannot alone bring a just and durable peace and notifying her that the United States opposed any new settlements on the West Bank and the Gaza strip. He warned Israel that the US understood Resolution 242 as "applying to all fronts".

However, important differences separated the Reagan plan and the Venice Declaration. They turned upon two fundamental points of Venice: Reagan avoided evoking a possible role of the PLO in peace negotiations, and he did not speak of "self-determination" but rather of "self-government of the Palestinians of the West Bank", in association with Jordan.

Despite these differences, the Reagan plan was extremely well received in Western Europe. It was especially welcomed by the more "pro-US" governments, which happen to be at the same time the relatively more "proIsrael" governments. They found in that Plan an opportunity to put some distance between themselves and Venice, and to renew political cooperation

33 D'Letzeburger Land, Sept. 24, 1982.

34 Le Monde, Sept. 3, 1982. 
with the US in the Middle East. As the Financial Times put it: "With Reagan now moving some way towards the ideas contained in the EEC Venice declaration on the Middle East, the possibility of a wider consensus might begin to emerge". ${ }^{35}$ And according to the Guardian: "It would be useful if Europe and the US would work together. The US has, after all, come a long way since Europe adopted the Venice declaration, and there is enough in the Reagan package to compensate for what is missing, including a specific role for the PLO". 36

France, which wanted to keep an independent role for Europe in the Middle East and was mistrustful of American initiatives, regarded Reagan's remarks very cautiously. Immediately after the publication of the plan, Mitterrand declared: "The spirit which inspired the Franco-Egyptian text (submitted to the Security Council) continues to be our own. Ronald Reagan's position seems to be oriented in the direction we have defined". ${ }^{37}$ Three months later, the French president showed more reserve: "(The Franco-Egyptian proposal) has an approach with a tighter hold on the reality of that part of the world (the Middle East) than the Reagan plan, but Paris and Cairo wished to give the latter a chance, having considered it as a first stage".

Anyway, from September 1982 the Europeans merely reacted to the Reagan Plan, the Fez declaration and the Franco-Egyptian proposals, whereas the Venice declaration was completely relegated to the background. For the first time since 1980, the September 20 European declaration did not explicitly mention Venice.

During the last months of 1982, the Europeans increased their contacts with both the PLO and Israel in an attempt to convince them to accept the Reagan plan: i.e. as a first step, for the PLO to declare that it renounces armed struggle, and for Israel to freeze its settlement policy. That course of action appears clearly in the speech given by the Danish Foreign Minister Uffe Ullemann-Jensen, in the name of the Ten, at the UN General Assembly. ${ }^{38} \mathrm{It}$ also appears in these remarks of the Belgian minister Leo Tindemans: "We must wait a while to see the direction in which the PLO evolves. If it becomes a purely political organization and if the moderate remarks made by $\mathrm{Mr}$ Arafat at Fez are confirmed, then the PLO will become the most important spokesman of the Palestinian people". ${ }^{39}$ This is also the meaning of the meeting between the Danish Foreign Minister and Faruk Kaddoumi in New York $^{40}$, and of the meeting of Claude Cheysson and Arafat on October 13, while the Palestinian leader was involved in negotiations with King Hussein

35 The Financial Times, Sept. 3, 1982.

36 The Guardian, Sept. 16, 1982.

37 Le Monde, Sept. 4, 1982.

38 The Financial Times, Sept. 28, 1982.

39 La Libre Belgique, Sept. 30, 1982.

40 Le Soir, Sept. 30, 1982; The Times, Sept. 30, 1982. 
on the procedures to be followed in response to the Reagan plan. ${ }^{41}$ Finally, the text adopted by the European Council at Copenhagen (December 3-4) reaffirmed the strong interest of the Europeans in the Reagan plan: "The European Council expressed its disappointment at the delay in grasping the political opportunity created by the initiative contained in President Reagan's speech on September 1, 1982". 42

\section{Was the European Intervention in the Crisis a Success or a Failure?}

The Europeans, like the Americans, were obliged to note that the Reagan plan was rejected by two of the three parties to whom it was addressed: Israel and the PLO. Only the "moderate" Arab states had approved it. The Reagan plan clashed with the basic principles of the Begin government on the very points where it was the closest to the Venice declaration. Israel was hostile to any change or addition to the Camp David agreements. Jerusalem was irritated by the reference of the Ten to the Reagan plan and to the "spirit of Fez". In February 1983, Itshak Shamir went on a tour of European capitals to explain the total rejection of the American and European plans by his government, and to ask that, despite that rejection, the Ten lift the "minisanctions" imposed in June 1982.43

The Palestinian National Council meeting at Algiers in February 1983 did not "formally" reject the Reagan Plan (as the Central Council of the PLO had done in Damascus in November 1982), but it judged it "insufficient", which came to the same thing, because the Reagan plan was presented as a "package deal". ${ }^{44}$ By contrast, the PNC at Algiers proclaimed its enthusiastic support for the Brezhnev Plan of 1981. Another sign of the victory of the "extremist" camp was that Issam Sartawi was not authorized to speak at Algiers. The PLO and several Arab states did not look kindly upon Europe for seeming to abandon all reference to the Venice declaration, that is, a policy independent, distinct, and even contrary to that of the United States, and for simply rallying around the American plan.

The declaration on the Middle East adopted by the Ten at the European Council in Brussels (March 21-22, 1983) represents yet another attempt to encourage the PLO to come to an agreement with King Hussein, in the framework of the Reagan plan. ${ }^{45}$ But European reactions to the text of the European Council were rather disillusioned. The Times noted, alluding to the crisis connected with the British contribution to the budget of the EEC, that when the Ten are not in agreement about anything, they hasten to publish a

41 Le Matin, Oct. 14, 1982.

42 The Financial Times, Dec. 6, 1982.

43 Le Soir, Feb. 9, 1983.

44 Le Monde, Feb. 17, 1983; Feb. 20/21, 1983; Feb. 23, 1983; Feb. 24, 1983.

45 Le Soir, March 22, 1983; La Libre Belgique, March 23, 1983; The International Herald Tribune, March 23, 1983. 
new declaration about the Middle East. ${ }^{46}$ According to La Cité, the Middle East section of the Ten's declaration "contained nothing very new or scintillating". Once more, the Israelis rejected the Ten's declaration, stating that "it had no relation to reality" and was "unbalanced and incomprehensible". 47 The Syrian official newspaper al-Baas accused the Europeans of "continuing to place the aggressor and the aggressee on the same equal footing" and thus effectively supporting Israel.48

Anyway, the failure of the Arafat-Hussein negotiations and the refusal of the Jordanian king to be the only one to embark upon the path of the Reagan plan sounded the death knell for the effort of the Europeans, which had been premissed on the transformation of the PLO into a "political partner". That failure, in addition to the internal crisis of the Community, the questions of Britain's contribution, the problem of Spain and Portugal, doubtless explains the relative self-effacement of the Ten on the political scene of the Middle East, at the end of the period under study. Consequently, the declaration of the European Council of Stuttgart (June 17-19, 1983) on the Middle East is one of the shortest and the least significant published by the Community on that topic for a long while. This failure brought also a relative increase in flexibility of the Europeans towards Israel. This flexibility was linked to three factors:

1. the continuing intransigence of the PLO and its refusal to commit itself to political and not armed struggle;

2. the Lebanese-Israeli agreement, which appeared to be a positive development to the Europeans, in the absence of any other prospects;

3. the role played by the country which was serving as the President of the Community in the first half of 1983, Germany. Germany had fought for the establishment of better relations with Israel (especially after the formation of the Kohl government in May) and for putting an end to the European "intervention" in the Lebanese crisis. It was Germany which insisted upon and obtained the cancellation at Stuttgart of the "sanctions" decided in June 1982.

The Ten decided that after the Lebanese-Israeli agreement, there were no further obstacles to the signing of the second financial agreement with Israel or to convening the Council of Cooperation. Greece, which had opposed the removal of the sanctions up to then, abstained in Stuttgart, a sign that it did not want to appear "biased", being for the first time on the verge of assuming the Presidency of the Community. One should also note that the Stuttgart conference, which put an end to European direct involvement in the Lebanese crisis, did not criticize Israel, and did not even raise the question of the settlements in the territories.

46 The Times, March 23, 1983.

47 La Libre Belgique, March 23, 1983.

48 Quoted by Le Soir, March 24, 1983. 


\section{Conclusions}

It seems that, in order to be able to react effectively to an international crisis, and to draw some benefit in terms of active policy (that is, to play a role in the development of the crisis and its outcome), Europe must first resolve a number of preliminary problems:

1. The EEC came up against the Israeli action in Lebanon when it was experiencing very serious internal difficulties, in particular in relation to the British and the Greek. In order to take an effective position and play a role during a crisis, the Community must first resolve its own internal contradictions and appear solid and unified;

2. The Ten must find a solution to the problem created for them by American foreign policies, before they can be in a position to act effectively. Thus, in the case of the Lebanese crisis, the Europeans (or some of them) began with an accusation of "Israeli-American conspiracy", and ended by adopting the Reagan plan. There was no unity and no continuity towards Washington.

3. The Europeans should refrain from making numerous "solemn declarations" and proposing ready-made solutions, and should rather employ discrete diplomatic methods, in order to suggest to the parties a wide range of alternatives to put an end to the crisis.

4. The Europeans ought to try to better understand the positions of the parties in a crisis. In our test-case, for example, they should have endeavored to understand the nuances of the different political forces in Israel (Likud, Alignment, Peace Now, etc.) and their attitude towards the war; and they should have tried to grasp the diversity of reactions within the PLO and among the Lebanese population. A Community reaction cannot be effective when some governments are celebrating the destruction of terrorist basis, while the others make a distinction between "moderate" and "extremist" terrorists/fighters, and yet others declare their support for the Palestinian armed struggle.

5. In order to be in a position to play the role of mediator, or to afford "good offices" for the parties in the crisis, Europe should maintain a certain proportion, a certain equilibrium between criticisms and demands made of each party, and not appear biased or unaccepting towards one of the parties.

6. The Europeans must understand that their intervention in an international crisis can never be effective if they are not ready to commit themselves, if not militarily, at least on the economic level. This implies, on the one hand, a promise of massive economic and military aid to the parties who accept the demands of the Europeans, and on the other a real threat of serious sanctions against a party who refuses. In our test case, there was a complete disagreement between the Ten regarding the utility, the types, and the eventual consequences of any sanction against Israel. 
7. Finally, it must be observed that the Community, in the Framework of Political Cooperation, is not organized to react to international crisis and does not possess the necessary institutional mechinery. This is due to a large extent to the fact that European Political Cooperation is not provided for in the Treaty of Rome, and has remained on an essentially informal basis. The Council of Ministers does not possess a "crisis think-tank" comparable to those found in the foreign ministries of prime ministers' offices of sovereign states. The Council is obliged to react "with its bare hands", without any sort of "national security council". In fact, whilst the Community displays a desire to develop its own foreign policy, it deprives itself of the means to do so. 


\title{
Votes of EC Members at the United Nations on Questions Related to Israel
}

\author{
BEATE LindeMANN
}

The United Nations is the only international forum where the industrialized nations and the developing countries confront each other in their entirety. Here the ten members of the European Community have to prove how seriously they take the co-ordination of their foreign policies and how succesful they are in "speaking with one voice" in international relations almost every day during debates or in voting. The "Agreed Diplomacy of the Ten" in New York has become a solid base of the UN policy of the EC governments and has developed into a political factor in the decision making process of the United Nations.

The framework and the machinery of European Political Cooperation (EPC) was laid down in the First Report of 27 October 1970 (Luxembourg Report) and the Second Report of the Foreign Ministers to the Heads of State and Government of the Member States of the European Community of 23 July 1973 (Copenhagen Report). In the Second Report specific reference was made to the participation of the permanent representatives of the Member States to the major international organizations in the consultation process. European Political Cooperation has been developed as another vehicle for (in addition to the EEC) and a further step in the European unification process. As such EPC is more than just an instrument for foreign policy consultations; it pursues the long-term aim of developing a common European foreign policy.

When speaking of European Political Cooperation in the UN, observations are mainly confined to the General Assembly and its seven main committees. Each of the ten West European states is represented here and enjoys the same single vote, while in all the other limited membership organs and committees of the UN only a minority of EC states have seats. Furthermore, there are many special organs such as UNDP, UNCTAD, UNRWA or UNIDO, and many inter-governmental agencies such as UNESCO, ILO, FAO or WHO, which all are part of the broader UN system; all discuss the wide variety of UN topics and, consequently, witness some kind of regional cooperation, group voting or bloc politics. 
This study on EC votes concerning Israel concentrates on the General Assembly, because the success and, at the same time, the limits of EPC are most visible here in the debates over the numerous and controversial Middle East resolutions. It is these resolutions which get a lot of international press coverage in western countries.

\section{Development of European Political Cooperation in the UN}

European cooperation in the United Nations has to be seen in the context of changes within the world organization during the last 20 years:

- The West lost its majority in the UN in the middle of the sixties with the admission of new nations to the organization.

- As the developing countries established a majority, the priorities in the work of the United Nations changed: decolonization, human rights, world economy and Middle East issues prevailed on the agenda.

- With the loss of its leading role in the UN, the West started to react to the policy of the Third World, rather than acting independantly and taking its own initiatives to strengthen its role vis-à-vis the Third World majority.

- Consequently, the West was no longer interested in having "its" concerns discussed at the UN. The major political decisions have been "regionalized" instead, and are now dealt within specialized organizations with limited membership, such as OECD, GAT'T, IMF, IEA and NATO.

It was in this political framework that the EC states were confronted with a special challenge to their cooperation. The items under discussion in the UN General Assembly did not always touch the immediate interests of the Ten, and thus the cooperation of the West Europeans in New York was not exposed to the same amount of strain and pressure as elsewhere. Moreover, regional problems tend to look less important when seen in the context of worldwide problems, while the global community helps national feelings give way to a stronger feeling for common regional interests at the same time. Finally, the possibility to influence the political process increases when an individual state joins up with other states. ${ }^{1}$

With the growing isolation and the declining interest of the United States in the UN - particularly since the 30th General Assembly in 1975 - the influence of the EC states increased and their role in the UN process was elevated. They were given the objective possibility, as well as the psychological responsibility, of being the spokesmen for the West in some situations. After West Germany joined the United Nations on 18 September 1973, all EC Member States were represented there, and from then on the UN developed into one of the most important areas for European Political Cooperation. As there was no formal Western position, the attitude of the then EC Nine was

1 Johan Kaufmann, Conference Diplomacy. An introductory analysis 149 (1970). 
taken by many Third World delegations to be representative of the West as such.

The united front of the EC states vis-à-vis the outside world was most clearly seen in the joint statements at the plenary and committee level which were delivered by the representative of the EC Presidency in the name of the member governments (38th General Assembly in 1983: ninety joint statements). Thus the Ten were able to express their attitude early enough to influence the formulation of the texts of resolutions, or at least the way other delegations vote. Furthermore, the political status of the Ten was enhanced by common voting positions the delegations took on many resolutions. Finally, there were daily informal consultations of the EC delegations, sometimes held in the conference rooms, which proved that serious efforts were being made to coordinate their positions on every agenda item (38th General Assembly: almost three hundred EPC meetings).

All these efforts had left such a strong impression on the other UN members that the EC delegations were often approached as a group by representatives of third parties, who could explain their attitudes to particular problems in order to gauge the reactions of the Europeans and, if possible, gain their support. Their views were asked and their contributions wanted. The confrontation over Israel caused by the so-called Zionism-Resolution ${ }^{2}$ in the 30th General Assembly in 1975 promoted the Nine's attempt to exert concerted influence on the behaviour of third countries. Even if the action to change the attitude of sixty-five states in Africa, Asia and Latin America towards the resolution was only partly successful, the effort demonstrated the increased importance of the EC states. All these activities of the Community members have been increasingly noticed by the UN majority.

In this context, the foreign policy positions of the EC members at the UN have clearly been acquiring greater political significance in recent years - also for the unification process and the formulation of common positions at home. Recognition of this progress in reality and in the eyes of third countries, however, should not obscure the fact that there are still gaps in the common voting at the UN, particularly on topics of real political significance. As a Third World diplomat in New York rather bluntly put it: "The EC states vote together on unimportant questions and apart on important ones, in contrast to the Third World's voting, where the reverse is true."

Even if the West European's behaviour may be more "European" in the global community than at home, there are strict limits to their freedom of action in New York. EPC at the UN, as an instrument of the joint diplomacy of the Community countries, has to be seen as a function of European cooperation in the EC capitals. As such, it can only develop its own dynamics to a certain extent. The harmonization process at the United Nations, therefore, reaches its limits and is in danger of regressing, if instructions from

2 GA Res. 3379 (XXX) of 10 November 1975. 
the ten capitals for the delegations in New York are not adequately harmonized and if the discrepancy between the progress achieved in New York and the readiness of governments to produce uniform Community positions becomes too great. Continuing progress in political cooperation in New York is, consequently, closely linked to the further development of the European Community into a political union. The tension between Community interest and national interest involves the basic question of the European commitment of the member governments. There have been cases in the past where the attempt to retain a national profile and to pursue particular political and economic interests weighted more heavily than did the commitment to Europe.

However, the organizationally advanced cooperation in recent General Assemblies has also helped strengthen the consultation mechanism internally in the capitals, i.e. in the Political Committee and at the foreign-minister level. The UN delegations have had more opportunity to exert influence on the instructions from the EC capitals in order to arrive at a common voting position in New York. ${ }^{3}$ Such success provided the incentive for the continuation of internal harmonization and the pursuit of a coordinated strategy.

But it is a rather different matter with regard to important agenda items which are significant for separate national foreign policies. There will not be a unanimous voting by the Ten in New York on these questions, as long as their foreign ministers or heads of government fail to agree on a common stance. This is particularly true for one of the major problem areas, namely the Middle East.

\section{European Political Cooperation and the Middle East Debate in the General Assembly}

In November 1970, when the foreign ministers of the then six EC States met within the framework of EPC for the first time in Munich, they agreed on two priorities for their future political cooperation: the Conference on Security and Cooperation in Europe (CSCE), and the Middle East. In contrast to the CSCE policy, the endeavour to develop a common Middle East policy created enormous problems and difficulties. These problems were rooted in the domestic policies of the Member States as well as in international conditions.

First of all, Middle East policy of the West Europeans could not build on a solid domestic and foreign policy base. The Mediterranean states had

3 Beate Lindemann, "Die Generalversammlung der Vereinten Nationen: Testfeld für die globale Neuner-Diplomatie", in: Die Europäische Politische Zusammenarbeit. Leistungsvermögen und Struktur der EPZ 223 (R. Rummeland and W. Wessels eds. 1978). 
traditions and interests in their relations to the Arab states which were very different from those of the Northern European Member States. Furthermore, the political-psychological role of Israel was not the same in all EC states. Finally, France and Great Britain, as permanent members of the Security Council and participants in the Four-Power-Talks in New York, had a special responsibility in the Middle East peace process. ${ }^{4}$

Ever since the Munich meeting of November 1970, the question of Europe's role in the Middle East has been of major concern to the EC governments. Every year the divided voting behaviour of the UN delegations on Middle East questions in the General Assembly served as an obvious proof of the non-existent Middle East policy of the West Europeans. It was not simply the inter-regional cooperation which has foundered on the Middle East problem but intra-regional cooperation as well. The cooperation of the EC states in the Euro-Arab Dialogue (since 1974) has had little influence on the shaping of Community attitudes about central questions of the Middle East conflict.

The demands of the Arab states in the UN resolutions go substantively beyond the common basic position agreed upon by the member governments in the different EPC reports or Middle East declarations. The General Assembly is, so to speak, the propaganda forum of the Arab world. Here the Arabs try hard to get majority support - even if only verbally - for their policy of further undermining the state of Israel and strengthening the international status of the PLO. The Euro-Arab dialogue and the Middle East debate in the General Assembly cover different themes and, for the Arabs, run on parallel but separate lines. The solution of the Palestinian problem and the Middle East conflict as such was denied as subject matter for the dialogue by the EC members. ${ }^{5}$ A number of Arab spokesmen who turned out to be quite moderate in the dialogue, were more radical in the Middle East debate of the UN, and effectively prevented any simple translation of the atmosphere of cooperation developed in the dialogue to the General Assembly.

Except for the Euro-Arab dialogue, the Arabs do not need support or even good-will of the EC members in the UN to pass their resolutions successfully. Here they can generally count on the support of the Third World, which guarantees them vast majorities for their anti-Israel strategy. In return, the Arabs back the opposition of black Africa to the Republic of South Africa and denounce the apartheid policy with strong rhetoric and anti-apartheid voting.

4 Günther van Well, Die Entwicklung einer gemeinsamen Nahost-Politik der Neun, in: Europa-Archiv 4/1976, p. $119 \mathrm{ff}$.

5 Udo Steinbach, Die Europäische Gemeinschaft und der Mittelmeerraum, in: Udo Steinbach (ed.), Europäisch-Arabische Zusammenarbeit. Rahmenbindungen, Probleme und Aussichten. Arbeitspapiere zur Internationalen Politik No. 11, Forschungsinstitut der Deutschen Gesellschaft für Auswärtige Politik e.V., Bonn 1979, p. $26 \mathrm{ff}$. 
However, the anti-Israel resolutions do not have real consequences outside the world organization. Many countries would not vote the way they do if these UN decisions were to acquire immediate and practical effect. ${ }^{6}$ The United States made it very clear in the debates of the last General Assemblies that they do not consider the UN to be the appropriate body for dealing with the Middle East problem. Consequently - and particularly under President Reagan - the administration followed a policy of standing back from the debates and involved themselves closely only on the key issues of Israeli credentials and US-Israeli cooperation. Israel in return followed a policy of rejecting the UN as a forum for discussing the Middle East problem.

The Middle East resolutions which in recent years have been largely condemnatory, making extreme demands of Israel but not offering realistic frameworks for solutions, get larger majorities each year. Only very few states continue to vote "No" on resolutions condemning Israel, with the result that the United States and Israel are often completely isolated. "What happens", a Western ambassador said, "is that resolutions that seemed very radical when they were first introduced become more acceptable as time goes on. Gradually, as these resolutions gain larger and larger majorities, the countries that have been voting against them begin to feel isolated, until, eventually, it is only the Americans who oppose them."7

Although they have little or no impact outside the UN, the Middle East resolutions serve group politics and regional solidarity at Israel's expense: They keep the Arabs united against Israel, although at the 38th session of the General Assembly in 1983 the Arab group appeared noticeably more divided and the PLO played a somewhat diminished role in comparison with previous sessions. For the Ten in New York, the Middle East resolutions have become some kind of a testcase for their cooperation process. Israeli expansionism, i.e. Israel's policy in the occupied territories, the continued building of new settlements, and Israel's policy in Lebanon certainly furthered the harmonization of the European position on Middle East votes.

Nevertheless, the EC states are still far from developing a common Middle East policy and a joint position on major Middle East issues under discussion at the UN. This is a fact - even more so since Greece joined the EC in 1981 which cannot be painted over by the joint statements on Middle East topics delivered by the representative of the EC Presidency in the name of the nine member governments. During the General Assembly in 1983, for instance, the Ten made a common statement on the "Question of Palestine" 8 and "The Situation in the Middle East"' in plenary, even though they only voted in

6 Richard Bernstein, "The UN versus the US", in: The New York Times Magazine, 22 January 1984.

7 Id.

8 GA Res. $38 / 58$ of 13 December 1983.

9 GA Res. 38/180 of 19 December 1983. 
common twice ${ }^{10}$, as opposed to nine times independently, on the different paragraphs of resolutions $38 / 58$ and $38 / 180$. All nine times it was a minority of one country, namely Greece, which made a Community position impossible. The Presidency delivered statements on each of the six Middle East agenda items on behalf of the Ten. Common explanations of vote were made about the majority of the resolutions, sometimes followed by national explanations of vote.

Community declarations are sometimes used to cover up differences in the position of the member countries, when the Ten did not agree on a common voting behaviour after long negotiations. That it is advisable to continue delivering joint statements without a common voting position seems questionable. Declarations of the Ten may help the internal development of European unity, but at the UN they appear to have only a minimal effect, because they represent the lowest common political denominator and the sole expression of the political will of the Ten on Middle East questions. ${ }^{11}$

\section{Voting Patterns of the Ten: Unity and its Limits}

There is a tendency for resolutions to be approved by a consensus procedure in the plenary and main committee meetings. In the plenary of the 38th General Assembly in 1983, a total of 176 votes were taken while 205 resolutions passed by consensus. ${ }^{12}$ As a rule, the West only agrees to the acceptance of resolutions by acclamation on the condition that its interests are given sufficient consideration in the process of decision-making and are reflected in the texts of the resolutions. In general, the common positions of the Ten are manifested more strongly in the general consensus resolutions, whereas votes on the controversial political issues, such as the Middle East, tend to illustrate the Ten's disunity. ${ }^{13}$

Out of the 41 Middle East votes in the plenary of the 38th General Assembly in 1983, the Ten only voted together 24 times. However, nine member states voted together on 40 of the 41 votes. Thus, the pattern of common voting remained much the same as in the 37 th General Assembly: 20 common votes out of 37 - and in the 36th General Assembly: 16 out of 34. The numbers give evidence that the basic differences in the national policies on the Middle East remained much the same.

The Community states are rejecting one-sided, unbalanced and conse-

10 GA Res. 38/58 D and GV Res. 38/180 C.

11 See Beate Lindemann, "EG Staaten und Vereinte Nationen. Die politische Zusammenarbeit der Neun in den UN-Hauptorganen. Schriften des Forschungsinstituts der Deutschen Gesellschaft für Auswärtige Politik e. V.", 42 Reihe Internationale Politik und Wirtschaft 127 (1968).

12 See table I.

13 See table II. 
quently anti-Israel resolutions, with the exception of Greece. In the last General Assembly, the Greek delegation always supported the Arab side and consistently voted with the UN majority. Sixteen times during the 38th General Assembly in 1983, it was the only state which departed from a common Community position and thus made unanimous abstention of the Ten impossible.

It can be traced back over the last years that on the crucial Middle East votes in the UN the majority of the EC states changed its position from a "No" to an abstention (otherwise known as a "polite No"), thus following the French position. Since 1967, France, in contrast to Germany and Britain, has consistently conducted a policy in the Middle East which has been dominated by traditional interests and influence in this area. After the oil embargo in 1973, France became even more convinced that Europe had to play a greater role in the Middle East, where it has its vital political and economic interests. ${ }^{14}$

During the 29th General Assembly in 1974, France was the only EC state to abstain on the resolution which granted the PLO observer status at the UN (the other eight members voted "No"). ${ }^{15}$ In the same General Assembly, France, along with Ireland and Italy, supported the resolution which invited the PLO to participate in the plenary debate on Palestine. ${ }^{16}$ The Federal Republic of Germany and Great Britain which had originally planned to vote against the resolution, finally abstained and thus prevented opposed EC votes. Italy, as a Mediterranean state, has always had special relations with the Arab states and so has Ireland which, moreover, always felt close to the developing countries.

In the following years, the EC states moved clearly in the direction of supporting the concept of the mutual recognition: recognition of Israel by the Arab neighbors within the boundaries of 1967, foundation of a Palestinian state on the territories occupied by Israel, and recognition of this state by Israel. During the 32nd General Assembly in 1977, the nine EC states abstained jointly for the first time on the resolution "The Situation in the Middle East". ${ }^{17}$ The United States and Israel remained the only UN members which rejected the resolution.

Also on the resolution "Question of Palestine" the EC states developed a common stand over the years. However, when Greece joined the EC, it did not go along with the abstention of the nine partners, but supported the Arab demands. The progress in the development of a joint balanced position on Middle East votes was made possible mainly by West German and British

14 Dominique Moisi, "Europe and the Middle East", in: The Middle East and the Western Alliance (S. L. Spiegel ed. 1982).

15 GA Res. 3237 (XXIX) of 22 November 1974.

16 GA Res. 3210 (XXIX) of 14 October 1974.

17 GA Res. 32/20 of 30 November 1977. 
politics. The Middle East Declarations by the European Council (1977 and 1980) have to be seen as the base for the harmonization process of the EC voting in the United Nations.

The Ten will continue following a balanced Middle East policy in the UN, taking the interests of all parties to the conflict into account. In the General Assemblies of 1982 and 1983 they strictly and unanimously rejected the effort of some radical Arab states under the leadership of Iran to exclude Israel from UN membership. Although only nine UN member states favoured this move in 1982, it was supported by 43 states one year later. The success of Iran's strategy has to be seen mainly as a result of Israel's policy in Lebanon, and of the building of more settlements in the occupied territories.

The two opposing poles in the EC are Greece, who most strongly supports the Arab position in the Middle East debate, and the Federal Republic of Germany, whose policy is still dominated by its particular relation to the State of Israel. The German government, therefore, is following a low-profile policy. However, European Political Cooperation certainly influenced the German Middle East policy to move more to the center. The realization of the need for European cohesion is one of the major assets of German politics.

Table I: Votes of the Ten EC States in the Plenary of the General Assembly 1975-1983 (Comparison of Common Positions)

\begin{tabular}{lcccccc}
\hline Year & Consensus & $\begin{array}{c}\text { Common } \\
\text { Voting }\end{array}$ & Total & $\%$ & $\begin{array}{c}\text { Divergent } \\
\text { Voting }\end{array}$ & $\%$ \\
\hline 1983 & 205 & 54 & 259 & 68.0 & 122 & 32.0 \\
1982 & 196 & 74 & 270 & 72.2 & 104 & 27.8 \\
1981 & 206 & 76 & 282 & 77.3 & 83 & 22.7 \\
1980 & 195 & 68 & 263 & 80.9 & 62 & 19.1 \\
1979 & 203 & 97 & 300 & 82.2 & 64 & 17.8 \\
1978 & 167 & 95 & 262 & 84.0 & 50 & 16.0 \\
1977 & 166 & 67 & 233 & 83.5 & 46 & 16.5 \\
1976 & 158 & 61 & 219 & 82.3 & 47 & 17.7 \\
1975 & 110 & 66 & 176 & 83.4 & 35 & 16.6 \\
\hline
\end{tabular}


Table II: Votes of the Ten EC States in the Plenary of the General Assembly 1975-1983 (Comparison of Divergent Voting)

\begin{tabular}{lccccc}
\hline Year & $\begin{array}{c}\text { Total } \\
\text { of Votes }\end{array}$ & $\begin{array}{c}\text { Divergent } \\
\text { Voting }\end{array}$ & $\%$ & $\begin{array}{c}\text { Common } \\
\text { Voting }\end{array}$ & $\%$ \\
\hline 1983 & 176 & 122 & 69.3 & 54 & 30.7 \\
1982 & 178 & 104 & 58.4 & 74 & 41.6 \\
1981 & 159 & 83 & 52.2 & 76 & 47.8 \\
1980 & 130 & 62 & 47.7 & 68 & 52.3 \\
1979 & 162 & 65 & 40.1 & 97 & 59.9 \\
1978 & 145 & 50 & 34.5 & 95 & 65.5 \\
1977 & 113 & 46 & 40.7 & 67 & 59.3 \\
1976 & 108 & 47 & 43.6 & 61 & 56.4 \\
1975 & 101 & 35 & 34.7 & 66 & 65.3 \\
\hline
\end{tabular}




\title{
Suppressing Terrorism: Problems of European-Israeli Cooperation
}

\author{
Noemi Gal-Or
}

Europe and Israel are closely connected through an unpleasant phenomenon of modern political violence - political terrorism. Not only are the democracies of the European States and of Israel equally threatened by this new kind of warfare; they are in part threatened by the same perpetrators of this weapon. Students may argue that such a clear case of common interests and the apparent mutual capacity of and successful experience in controlling terrorism should coincide with cooperation in the suppression of terrorism. Yet the reality is strikingly different. There is no official intergovernmental cooperation between separate European states and Israel. Nor is there any such agreement between the Council of Europe (CE), which has a workable convention for the suppression of terrorism - or the European Community (EC), which has no defined policy to fight terrorism - and Israel, aimed at overcoming the danger of this new "unconventional" warfare.

In the following paper, the situation is analysed and explained according to three frames of reference. In the first section, the European attitude towards terrorism in general is examined. The second section involves discussion of intra-European cooperation, and the third section contains analysis of the specific relations between Europe and Israel vis-à-vis terrorism. This leads to clarification of the issie of cooperation between Europe (especially the European community) and Israel in the suppression of terrorism.

\section{Europe and Terrorism}

Terrorism of all kinds, fitting into various academic and expert classifications, takes place intensively, and not without effect, on West European territory. In order to appreciate the European response to this phenomenon, an understanding of the attitude of these states toward terrorism would seem helpful.

The issue of Western Europe and the problem of terrorism may be studied from at least three aspects:

1. The typology of terrorism in Europe. 
2. Geopolitical characteristics of West European states as explaining the European attitude towards terrorism. ${ }^{1}$

3. The value of liberal democracy and European sensitivity to the issue of human rights as influencing the attitude towards the suppression of terrorism.

Examination of the issue from these angles will, I hope, help to give an overall view of the European perception of terrorism.

\section{The Typology of Terrorism in Europe and Geopolitical Characteristics of West European States}

Dennis Pluchinsky divides terrorism in Europe into four categories, according to the terrorist operational level: ${ }^{2}$

a) "indigenous" terrorism, carried out within the primary targeted country, which is usually also the country of origin of the perpetrators, but may also be against alien targets within this country;

b) "supraindigenous" terrorism, carried out on other countries territory, beside the primary target country, but restricted to a specific region;

c) "international terrorism, which is a transregional extension of the supraindigenous kind of terrorism, carried out by international terrorist groups; and

d) "state-directed" terrorism, which is not only sponsored but planned and deliberately used as either an internal or external policymaking device by governments.

This typology seems to suffice for the purpose of analysing the European attitude towards terrorism. However, this typology does not explain the actual and objective reality of terrorism in Europe. We prefer to divide the present appearances of terrorism (on European territory as well as elsewhere) into two categories:

a) indigenous terrorism, relating to terrorist activities carried out within the terrorist's country of origin and against it only;

b) international terrorism, which includes supraindigenous and international terrorism and which can be distinguished from indigenous terrorism by the following criteria:

1. nationality - the victim is of a nationality different than that of the terrorist;

2. territory - the act takes place on a third party's territory;

3. goal - the proclaimed goal of the act is to affect the international system;

1 For discussion of the definition of terrorism, see Noemi Gal-Or, International Cooperation to Suppress Terrorism, (London: Croom Helm, 1985), pp. 1-7.

2 For a more detailed description of this typology see D. Pluchinsky, "Political Terrorism in Western Europe: Some Themes and Variations", Terrorism in Europe, p. 40 (Y. Alexander and K. A. Myers, eds. 1982). 
4. cooperation - there is cooperation among different national groups of terrorists; and/or

5. the terrorist acts are state-sponsored, waged or abetted by third states.

Therefore, we actually have two ways to look at terrorism, specifically in the European region. One is the subjective approach proposed by Pluchinsky, which considers terrorism from the subjective point of view of the European region and which furthermore is restricted to particularly one aspect of this phenomenon - the operational area. Our approach, in contrast to Pluchinsky's, establishes objective criteria to evaluate the terrorist phenomenon and takes a multitude of characteristics into consideration. ${ }^{3}$

The discrepancy between this and the better accepted classification serves to explain the European attitude towards terrorism, and particularly of its achievements in controlling terrorism until now. That is, the European attitude, at least as expressed organizationally, focuses on the suppression of Pluchinsky's "indigenous" and "supraindigenous" terrorism. Its main failure lies in its reluctance to go beyond this consensus and face the objective reality, that is, that terrorism cannot be defined simply by national or regional interests, nor by ideological codes for morality. ${ }^{4}$

It is our contention that the formula for suppressing terrorism lies in the recognition that it is an indivisible phenomenon, and that indigenous terrorism may at times be a part of, or become international terrorism. Thus, in order to combat terrorism effectively, European statesmen must include in their efforts the consistent treatment of international terrorism, whenever such acts arise. Further academic or expert categorizations that separate international terrorism or terrorism in other countries and regions from those occurring closer to home may be valuable for the short-term tactic of suppressing terrorism, but not for the strategy.

\section{Geopoliticial Characteristics}

We now turn to the other salient perspective in the study of the European attitude towards terrorism, which is closely related to geopolitical characteristics of the European states.

We have argued elsewhere that it is more realistic to expect the formation of a uniform attitude towards terrorism within a regional rather than within a global context. ${ }^{5}$ States sharing a similar "Weltanschauung", close political regimes as well as political economic interests, are likely to be complementary, even if they occasionally conflict. The following analysis concentrates on those factors that distinguish between the various groups, and hinder a European uniform attitude towards terrorism.

\footnotetext{
3 See Gal-Or, supra, note 1 at 4-7.

4 Infra, pp. 14-18.

5 Gal-Or, supra, note 1 at 175.
} 
From a geopolitical point of view and regarding the phenomenon of terrorism, we can divide the West European states into three major groups: a) the EC members (the Nine) and Austria, Iceland and Switzerland;

b) the Scandinavian states and

c) the Mediterranean states, excluding Italy and France, which are members of the first group.

To better understand the varying degrees of enthusiasm with which these groups might engage in cooperative initiative to suppress terrorism, it is first necessary to consider their vulnerability and exposure to terrorism.

\section{Vulnerability}

Of the three groups, the Scandinavian states are the least vulnerable to terrorism. Domestic terrorism is practically unknown, so the main issue confronting these states is imported, that is, international terrorism. Even in this respect, since they are comparatively less important from the politicaleconomic point of view than other European members, the Scandinavian states are less attractive and less favorable targets for terrorists than others. Consequently, the scope of means needed to suppress and prevent terrorism is rather limited. Scandinavian states can adequately use existing means to combat indigenous terrorism; yet, like other states, they need cooperative devices to counter international terrorism. In this light, their reserved commitment to international cooperation in the suppression of terrorism can be understood.

The other two groups of states are, in general, seriously vulnerable to both indigenous and international terrorism. The difference between these groups lies not so much in their vulnerability to terrorism and the kind of terrorism inflicted upon them, as in their reaction to it. Both groups consist of states afflicted by ideological, sociopolitically motivated terrorism (New Left, fascists or any kind of revolutionary terrorism), as well as by nationalistic (often fascist-connected) and separatist terrorism. ${ }^{6}$ However, considering their political-economic status on the regional as well as international scenes, the frequency of international terrorism in the more important (in global terms) EC Member States is higher.

Besides its effect on the vulnerability of states to terrorism, the politicaleconomic interdependence of these states may depend their common interest in suppressing terrorism. Thus, the economically weaker states (the Mediterranean group) are dependent on the more vulnerable Western states

6 For example, in Germany, the Rote Armee Fraktion (RAF), Hoffmann Wehrsport Gruppe; in Italy, the Brigate Rosse, Movimento Sociale Italiano (MSI) and SouthTyrolians; in France, Front de Libération de la Bretagne, Noyau arme de l'autonomie proletarienne (NAPAP); in Turkey, the Nationalist Action Party (MMP); and in Northern Ireland, the Provisional Irish Republican Army (IRA). 
of the EC. Both the EC and Mediterranean groups, then, have a vested interest in suppressing terrorism and doing it cooperatively.

In spite of common interests, both groups express different attitudes towards terrorism, explained by their different political heritages and historical background. Compared with the stable democracies of the (former Nine) EC members, the Mediterranean states are rather unstable. Subject to politically uncertain conditions and instability, the maintenance of democracy there is under constant threat. This was the case in Greece when it was ruled by the Colonels ${ }^{7}$, and it has also been true of the Turkish military regime. Past unrest in Cyprus $(1974,1982)$, as well as Malta's close links with Libya (during the 1970's) also emphasize this aspect of the Mediterranean group. The differences result in divergent conceptions of the various states' responsibility towards human rights and of the due balance to be kept between the rights of the individual citizen and the needs of the Community's safety when threatened by terrorism.

\section{Reaction (Legal procedures)}

We come, then, to the second important factor distinguishing European states vis-à-vis terrorism, namely, their reaction to terrorism: the legal provisions concerning government responses to violence. The national legislations of most European states provide no measures specifically designed to respond to crimes of terrorism, nor do they define the phenomenon of terrorism. A CE questionnaire concerning legal aspects relating to terrorism revealed that states do not even provide a legal definition for political offense, and that most of them introduced acts of terrorism into the category of "very severe offenses". 8

Although there are differences between the various national legal provisions that might apply to terrorists, the gap is not very wide. All those who answered the questionnaire provide for nonextradition of a political

7 The impact of that experience still has repercussions upon EC members' confidence in the viability of common liberal cooperation within the $\mathrm{CE}$ in such delicate matters as human rights. The situation today, among the Ten, is probably similar.

8 Réponses au questionnaire relatif aux aspects juridiques des problèmes posés par le terrorisme international. Doc. DPC/CEPC (73) 28, CE, August 21, 1973, Strasbourg, 14 p. (hereafter: Questionnaire). Greece and Turkey did not reply to the questionnaire. The question was: "Quel est le taux de la paine prévue par la législation de votre Etat pour certains actes de terrorisme tels que la prise d'otage? L'envoi de lettres piégées?” The majority of the states answered that the taking of hostages and the sending of letter bombs did not constitute specific offenses within the terms of their rules. Nevertheless, these acts can generally be considered severe infractions relative to general dispositions concerning, for instance, sequestration, extortion of funds, arbitrary detention, homicide, violation of the regementation concerning the use of explosives and the like. $I d$. at 10 . 
offender and have some degree of extraterritorial jurisdictional competence (more limited when it refers to aliens than to nationals). The differences are more significant concerning the penalties for various delicts: the taking of hostages is punishable by life sentence in France, Iceland, Sweden, and the United Kingdom, while Ireland prescribes only two years. In France, the taking of hostages resulting in severe corporal damage was, until recently, a crime deserving of capital punishment, while in the Netherlands it called for only nine years imprisonment. Aerial sabotage is punishable with a life sentence in Sweden but with only six years imprisonment in Norway; the sending of letter bombs receives a life sentence in Austria, Iceland, and the United Kingdom, and only one year imprisonment in Denmark and Ireland. ${ }^{9}$

The legal provisons themselves are not the only potential obstacles to effective cooperation in the suppression of terrorism; the stability (or lack of it) of the various political regimes also poses a serious problem. The possibility that existing legal provisions that are compatible with Western liberal and democratic tradition might be suspended or replaced in the event of a new regime, renders the value of long-term commitment to cooperation questionable. Despite presently-shared negative attitudes towards political violence and sensitivity to the values of individual freedom, there is a fear that serious differences might evolve in the conception of the government's role in combatting terrorism and the due use of its power to react to it.

Specific legislation to deal with terrorist offenses has been elaborated by the following EC members: Germany, Ireland, Italy and United Kingdom, Not unexpectedly, these countries are among the European states most affected by terrorism. ${ }^{10}$ They have also provided for special police forces specializing in combatting terrorism (recently France, too, has followed this trend).

Only subsequent to the signing of the European Convention on the Suppression of Terrorism, 1977 (ECST), and after ratifying it, have most of the members of the Council of Europe (CE) taken steps to combat terrorism through legal modifications of their penal code. Indeed, although adequately equipped with legal tools to respond to indigenous or "nonfugitive" terrorists, until then they lacked the appropriate means to cooperate internationally against international terrorism. It is precisely this gap that the designers of the ECST sought to fill, at least partially.

9 Id. at $11-12$.

10 See Der Bundesminister der Justiz, BRD, Die Rechtsstellung des Verteidigers im Strafverfabren: Ein europäischer Vergleich (n.d.); Kontaktsperre: Informationen über ein $G e-$ setz zur Bekämpfung des Terrorismus (1978); and Wirksame Verbrechensbekämpfung durch recbtsstaatliche Regeln (1979). These brochures compare a number of European State legislations (Belgium, Denmark, UK, France, Italy, the Netherlands, Austria, Sweden, and Switzerland) with the German legal modifications concerning terrorism. See also, Gal-Or Supra note 1 at $229-233$. 
In addition to this divergency between the three groups of countries outlined above, there are also vast differences within each group concerning the issue of terrorism. For example, although they are very similar geopolitically, as well as in terms of their vulnerability and reactions to terrorism. ${ }^{11}$

\section{Liberal Democracy, Human Rights, and Terrorism}

In the preceding section the attitude of European states towards terrorism has been evaluated as a function of their vulnerability to it and of their specific political characteristics.

Another factor to be taken into account when considering this issue is the ideological and moral atmosphere in Europe. This is related to the direct threat of terrorism to liberal, pluralist, and democratic European states, coupled with commitment (political as well as ideological) to the liberal values involving human rights and the right of a people to self-determination.

There exists a paradox in European attitudes: on the one hand, political violence is negated when a possibility for peaceful means of opposition is given. This is based on widespread devotion and commitment to the values of liberal and representative democracy. On the other hand, the use of such violent means by people striving for self-determination - even if they are too often carried out on European territory, against its citizens, property, and interests - is considered understandable. This is explained on historical grounds such as identifying with Basque resistance during Franco's regime, the role of present French socialists in the Resistance, the century-old Irish struggle for independence and so forth.

The European formula to settle this paradox is based on the distinction between "indigenous" and "nonindigenous" terrorism. Indigenous terrorism comprises of Pluchinsky's indigenous and supraindigenous categories.

According to this approach, all other forms of terrorism need not enter the realm of European direct concern. This unrealistic and ostrich-like attitude has been well reflected during the debates concerning European cooperation in the suppression of terrorism (leading to the ECST) in the framework of the Parliamentary Assembly of the CE. It has also been voiced within its Council of Ministers.

The breakthrough in the European attitude towards international cooperation in the suppression of terrorism occured in late 1972, provoked by the terrorist assault at Lod airport and, especially, the murder of Israeli sportsmen at the 1972 Munich Olympic Games. It was, of course, Europe's own vulnerability to the threat of international (not supraindigenous) terrorism which had once more been demonstrated, at least as much as their

11 See Gal-Or, Supra note 1, at 195-199, 233-237, 298-301. 
concern or identification with the Israeli situation. Aware of the severity of the situation, the CE foreign ministers met in Rome, in September 1972, assessing the situation and stressing the need for European responsability in facing this danger. (This took place at the same time as Mr. Waldheim's initiative within the UN.) ${ }^{12}$

Debates within the CE Assembly focused on the conciliation of politicoideological divergencies. ${ }^{13}$ The first major theme was whether to refer to the causes of terrorism and approximate the UN's approach to countering terrorism. Consequently, the distinction was established between just and unjust terrorism and non-European and European terrorism respectively. ${ }^{14}$ Following this distinction, the debates digressed to arguments supporting and opposing various sides of the Middle East crisis and Third World national liberation problems. Keeping in mind the distinction made, it was not difficult to accept the attitude that "tout comprendre c'est tout pardonner", and thus exclude causes and motivations when referring to indigenous terrorism.

The European ideological stand on terrorism has been expressed in other forums, including some sectors of European public opinion. It came specifically in response to the signature of the ECST (1977) and represents European commitment to control and prevent excessive governmental enthusiasm concerning the combat of terrorism, as well as misuse of intergovernmental cooperation in the suppression of terrorism. Generally, criticism has been motivated by a fear of regression from the achievements concerning respect for human rights, as ideologically and legally developed in the West as well as globally through international agreements. The arguments are overwhelmingly concerned with the accused, their main concern being the legitimate right to political violent self-defense (for example, Liberation from oppression and tyranny), and the fundamental rights of the offender (such as, fair trial, for instance). In their preoccupation with the protection of the rights of the offender (whether political or terrorist), many critics of European terrorism policy too often forget the victim. Not so the Council of Europe which has agreed elsewhere that "the

12 Id. at $83-84$.

13 See debates surrounding recommendation 684, Id. at 208-212.

14 Mr. Judd (UK), "International Terrorism". Official Report of Debates. PA, 24th Ordinary Session, Oct. 17-24, 1972, Strasbourg, CE, 1973, p. 518 (hereafter: 24th Ordinary Session, says: "My political party in Britain has come to the said conclusion that when we find these people denied effective action by the international community to remove intolerable injustice from which they suffer then liberation movements and freedom fighting become legitimate. The Labour Party in Britain has established a fund to support the liberation movements. In the context of our own free democratic society of Western Europe these techniques are now being applied and we cannot allow them to develop and fester, and to undermine the principles on which our society is based."

15 Explanatory Report on the European Convention on Human Rights and Fundamental Freedoms of Nov. 4, 1950. 
human rights to which regard has to be had are not only the rights of those accused or convicted of acts of terrorism, but also of the victims or potential victims of those acts".

Inevitably, such discussions deal with the political character of the committed crime and consequently, with the issue of motivation, which was intentionally extracted from the ECST and considered irrelevant. Consequently there often occurs an erroneous exchange between the constituents of terrorism and those of the political offense. European proponents of suppression of terrorism define it as a political crime of an especially horrifying character within a liberal democracy, where other legal forms of opposition are available. Opponents of such policy usually see terrorism in the context of an authoritative regime, where state-terror ${ }^{16}$ is exercised, and the assaults are directed against the military organs; this is actually guerillawarfare and not terrorism. These critics often exaggerate their mistrust of Western democracies, accusing them with "counterterrorism". For example, Nagel states: "The State by its nature maintains itself partly by 'terror'. It is strikingly obvious that modern democratic nations prefer to obscure this." 17

This attitude towards terrorism is based on shaky self-confidence in connection with recent European history; it seems that its proponents' conscience is evoked by the attack of terrorist causes and tactics. Their line might be paraphrased with two major points:

a) Wasn't it the Western States which, through underground combat, fought the fascist regimes in Europe of World War II? How, then, can we judge others who use the same "underground" methods that were once adopted by us for ourselves?

b) Furthermore, how can Western democracies be certain that such suppression is not, in effect, a first step on the road to fascism? Perhaps the reason for the rise of terrorism must be sought in the model of society they have constructed in order to make solution of the problem possible. ${ }^{18}$

\section{Intra-European Cooperation}

Reviewing the various efforts undertaken towards formal intergovernmental cooperation in the suppression of terrorism, the decisive starting point for effective European cooperation in the suppression of terrorism is traced back to the terrorist assault at the Olympic Games in Munich, 1972. Two European organizations are involved in this process in a rather competitive

16 See Gal-Or, Supra note 1 at 2.

17 W. Nagel, "A Social-Legal View on the Suppression of Terrorism", Conference on the Defence of Democracy against Terrorism in Europe. Tasks and Problems (Strasbourg, Nov. $12-14,1980)$. Compendium of Documents. As/Pol/Coll/Terr (32) 19. Strasbourg, Council of Europe, 1981, p. 6 (hereinafter: Conference on Defence of Democracy).

18 See Gal-Or, Supra note 1 at 283. 
manner: the EC and CE. The composition of the CE, that is, the fact that all EC members are CE members as well, has operated as an impediment to the $\mathrm{CE}$ 's efforts in the suppression of terrorism. The EC has one major argument along which it has consistently tried to halt European cooperation in suppression of terrorism within the CE', while the CE has been perceived as a suitable forum to exchange views about a common policy concerning terrorism, the more limited framework of the Nine (the EC), providing optimal similarity of attitudes towards terrorism and mutual confidence, was deemed more appropriate for the elaboration of specific measures against terrorism. EC members were reluctant to become bound by any antiterrorism policy within a broader organizational framework, until such efforts were adopted by them in the narrow context of the EC.

However, the smaller forum of the EC is also more strictly binding from a legal point of view. In accordance with the Treaty of Rome, the precedents set by Community cooperation in other fields, and the various guidelines laid out by the European Court, an EC agreement concerning the suppression of terrorism should immediately be incorporated within the domestic law of Member States. In such a delicate matter as terrorism, this has been and is still considered as an insupportable sacrifice of national sovereignty. ${ }^{19}$ (In this light, intergovernmental cooperation with Israel is clearly even more remote.)

Description of the development of events concerning European cooperation in the suppression of terrorism leads back to the competition between the EC and the CE which deepened through the Nine's meeting of the Davignon Committee (which was then confidential and held in Frascati, 21 September 1972). The objective of the meeting was to work out a joint initiative of the Nine to be presented and defended before the UN. ${ }^{20}$ EC's alternative was cooperation on the global level of the UN on the one hand, and specific narrow Eurocentric cooperation within the framework of the Nine.

To bring the competing EC and CE closer together, in 1973 the Director of Legal Affairs of the CE suggested a relevant exchange of views: it would be advantageous to European legal cooperation if an exchange of views about the legal points concerning terrorism were to take place within the broader

19 J. Lodge and D. Freestone, "The European Community and Terrorism: Political and Legal Aspects", Terrorism in Europe (79-80) (A. Yonah and K. A. Myers, eds., 1982). J. Weiler, "Community Member States and European Integration: Is the Law Relevant?" The European Community and its Mediterranean Enlargement (39-56) (L. Tsoukalis, ekd. 1981).

20 One aim of this meeting was to reach agreement on the joint policy of defense within the UN, since the Nine's cooperation was envisaged as including provisions for exchange of information bypassing Interpol's framework, control of visas (in particular of Arab countries), etc. 
framework of the CE. He pressed for the convocation of an Ad Hoc Committee for International Terrorism, providing for the permanent participation of representatives from the Davignon Committee, that would keep the CE apprised concerning the work of the Nine.

It took more than three years to persuade the group of Nine to change their "separatist" attitude towards cooperation within the CE. During this period the CE's Parliamentary Assembly succeeded in bringing about two decisions concerning European cooperation to suppress terrorism. The Committee of Ministers replied only much later. ${ }^{21}$ This resolution can be appreciated as a first step towards a European effort to depoliticize certain acts of terrorism for the purpose of extradition. Furthermore, it has been the basis for the elaboration of a draft convention culminating in the ECST (1977). This ECST provides the procedures to be followed after the apprehension of a terrorist, yet does not deal with the prevention of the specific act (although deterrance is inevitably an accompanying effect of legal sanction). The Convention establishes a catalogue of terrorist offenses, and the parties to it are subject to the principle of primo dedere, secundo judicare: a state holding a terrorist must first consider extraditing him to the state which requests it to do so or, if it refuses to do so, try him itself. To date, the Convention has been ratified by fourteen states.

The ECST is thus the fruit of the efforts within the CE, with the "reserved blessing" of the CE as a homogeneous body; it was achieved through the active participation of some of its members, particularly West Germany and the United Kingdom. In spite of this, the obstacle to European cooperation was not overcome, even with the elaboration of the Convention. At the occasion of signature, the French government, for instance, refused to ratify the Convention until the work of the Nine on the suppression of terrorism was culminated. 22

Though the governments were reluctant to initiate any closer and binding cooperation against terrorism, the European Parliament expressed a positive opinion upon the achievement of the ECST. It unanimously adopted a resolution recommending immediate ratification of the CE Convention by EC members. ${ }^{23}$ Indeed, the members of European Parliament have been

21 Recommendation 684 (1972) on International Terrorism. PA 24th Ordinary Session, Strasbourg, Council of Europe, Oct. 23, 1972.

Recommendation 703 (1973) on International Terrorism. PA 25th Ordinary Session, Strasbourg, Council of Europe, May 16, 1973.

Resolution 74 (3) on International Terrorism. CM 53rd Session, Strasbourg, Council of Europe, January 24, 1974.

22 See France's declaration on the occasion of signature. Reservations and Declarations. France, Jur./Jr. No. 90, Decl./Res. France, Strasbourg, Council of Europe, Januąry 27, 1977, point 2.

23 EP-DOK. 513/56. Sitzungsdokumente 1976-1977, January 13, 1977. 
more active than their ministers. After the Entebbe operation in July, 1976, they urged for an EC policy on terrorism. ${ }^{24}$ They have continued since 1977 and until today, discussing, among other things, the old idea of a European prison for terrorists. ${ }^{25}$

Actually, agreement within the EC, if incompatible with the ECST, might have paralyzed the Convention, since the important members of the $\mathrm{CE}$ are the EC's Ten. However, developments within the EC tended to favor the ECST.

In 1977 it appeared that the EC Commission considered a separate convention on terrorism for its members as superfluous. ${ }^{26}$ This resulted from a working group within the EC which began work in July 1976 on measures to combat terrorism to be applied by the Nine. ${ }^{27}$ The work followed an English draft suggestion, parallel to both the ECST and a French proposal for a multilateral general extradition treaty among the Nine, relating to specifically odious acts of criminal violence. Yet, many obstacles had to be overcome before a consensus among the Nine could be achieved. While the French suggestion had been rejected temporarily, the French President (5-6 December 1977) raised the idea of a "European judicial area": ("un espace judiciaire européen") and asked to have it discussed within the Nine. ${ }^{28}$

Indeed, there already were enough alternative legal possibilities for cooperation in the suppression of terrorism (an issue not directly considered by the Treaty of Rome). First, Article 235 could be invoked. ${ }^{29}$ In case of failure of this procedure, Article 100 offers another way of bypassing treaty

24 European Working Documents, 222/76, July 6, 1976.

251977 Eur. Parl. Deb. (No. 223) 73 (Nov. 15, 1977). The idea of a "European Court for Terrorists" was raised later by the French Minister of Justice before the EC in 1982 (Economist, Nov. 6, 1982, at 73). It was rejected by his Belgian colleague who wished first to see the Dublin Agreement ratified.

European Working, 1-583/82, 1-588/82, Sept. 13, 1982 and Parliamentary Assembly's Res. 9423/82, Sept. 20, 1982.

26 T. Stein, "Die europäische Konvention zur Bekämpfung des Terrorismus", 37 Zeitschrift für ausländisches Öffentliches Recht und Völkerrecht, 682 (1977), No. 44.

27 However, they did not progress any further than formulating a statement of principles. See H. J. Bartsch, "Das europäische Übereinkommen zur Bekämpfung des Terrorismus”, 30 Neue Juristische Woche 987 (1977).

28 Mr. Poetz, Stenographisches Protokoll, p. 30/25. Mr. Tabone, Report on Terrorism in Europe, European Documents (Working Papers). Doc. 4258, Dec. 5, 1978 at 17 (hereafter: Doc. 4258).

29 "If action by the Community should prove necessary to attain, in the course of the operation of the common market, one of the objectives of the Community and this Treaty has not provided the necessary powers, the Council shall, acting unanimously on a proposal from the Commission and after consulting the Assembly, take the appropriate measures." Treaty Establishing the European Economic Community (hereinafter e.e.c.) art. 235. 
deficiencies concerning the issue of cooperation in the suppression of terrorism, although this article refers to laws concerning the functioning of the Common Market. ${ }^{30}$ Article 36 may be used for the specific requirements when confronting state-directed or sponsored terrorism. ${ }^{31}$

Yet, through the eventual establishment of a separate, specific legal framework it was hoped to bypass those restraints to cooperation in suppressing terrorism that emanate from the supranational obligation which is perceived as an impingement on national sovereignty. ${ }^{32}$ Therefore, many states were reluctant to pick up these tools provided by the Rome Treaty. The "judicial area" was meant to extricate the Nine from the legally problematic framework of the Treaty of Rome and constitute an independent system of cooperation. ${ }^{33}$

Just as the terrorist assault at the Munich Olympic Games stimulated European concern with combatting terrorism, so did Aldo Moro's kidnapping (March 1978) result in a breakthrough in the EC's attitude towards terrorism. Debates within the various bodies of the EC related to different aspects of the subject: the need to study the problem of terrorism, to increase police cooperation, to regulate acquisition of arms and so on. ${ }^{34}$

30 "The Council shall, acting unanimously on a proposal from the Commission, issue directives for the approximation of such provisions laid down by law, regulation or administrative action in Member States as directly affect the establishment of functioning of the common market. The Assembly and the Economic and Social Committee shall be consulted in the case of directives whose implementation would, in one or more Member States, involve the amendment of legislation." Article 100 e.e.c.

31 "The provision of Article 30 to 34 shall not preclude prohibitions or restrictions on imports, exports or goods in transit justified on grounds of public morality, public policy or public security; the protection of health and life of humans, animals or plants; the protection of national treasures possessing artistic, historic or archaeological value; or the protection of industrial and commercial property. Such prohibitions or restrictions shall not, however, constitute a means of arbitrary discrimination or a disguised restriction of trade between Member States." Article 136 e.e.c.

32 Lodge and Freestone, Supra note 19 at 90-91, 94.

33 Nevertheless, the idea of a "judicial area" continues to be raised by various French politicians. Recently, Foreign Minister Cheysson raised it again, following the terrorist assault in Jerusalem. Ha'aretz, (April 4, 1984) at 2. See relevant initiatives, European Working Documents, 1 -588/82, Sept. 13, 1982 and Parliamentary Assembly Resolution $9423 / 82$, Sept. 20, 1982.

A separate legal framework cannot, however, overcome the problem of states avoiding cooperation in the delicate matter of terrorism. A recent reminder is the decision of the European Parliament to investigate events in Northern Ireland. The United Kingdom argued against interference within its domestic sphere. In case such interference actually takes place, it will be a precedent for similar activity in other areas concerning South-Tyrolian activity, for example; the French Basques, etc. Ha'aretz, April 25, 1983, at 9 .

341978 Eur. Parl. Deb. (No. 223) 28 (March 1978); Id (No. 229), April 1978. 
On 11 October 1978, the EC opened in Dublin to sign a new agreement on terrorism, restricted to the Nine only. ${ }^{35}$ This convention concerns the operation of the ECST among the Nine and was meant to be ratified, if possible, without reservation. Based on the ECST, it provides (probably due to an Irish initiative $)^{36}$ for domestic courts to decide upon the eventual political character of the crime, and re-establishes the principle aut dedere, aut judicare (instead of the ECST's principle primo dedere, secundo jusicare).

Although the agreement was to come into force three months after ratification by all members, France made her ratification dependent upon acceptance by the other states of her plan for a "European judicial area" (which includes a draft convention on cooperation in criminal matters and concerns the extradition of terrorists). The Netherlands refused to agree; consequently the French refused to ratify the Dublin Agreement, which thus did not come into force. ${ }^{37}$ Besides the legal and ideological constraints (related to the issue of human rights), very specific political interests hampered cooperation and stood in the way of the control of terrorism through the EC. Such has been for example the argument of the Danish member of the European Parliament that by cooperating against terrorism, Denmark, which is not afflicted with it, would also become target for terrorist assaults, and that therefore, it is in Denmark's interest to avoid such cooperation. ${ }^{38}$ This scepticism only strengthened those forces that were reluctant to cooperate. Had the EC members adhered to the Convention, reservations would still have been expressed concerning effectivity of European cooperation in the suppression of terrorism:

It seems quite obvious that the parallel existence within the Council of Europe's legal area, of two systems of cooperation with diverse intensity, might in the long run have a detrimental influence on the further development of cooperation between Council of Europe States belonging to these different systems. ${ }^{39}$

35 Communication from the Secretary-General, Transmitting to the Assembly the Text of an Agreement Concerning the Application of the ECST Among the Member States of the European Communities. Doc. 4460, Strasbourg, December 17, 1979. The agreement was signed in Dublin on December 4, 1979.

36 Report on Terrorism in Europe (Rapporteur: Vincent Tabone). Doc. 4258, p. 19.

37 J. Lodge, "The European Community and Terrorism: Establishing the Principle of "Extradition or Try'" in Terrorism: A Cballenge of the State 165 (1981). J. Kelly, "Problems of Establishing a European Judicial Area", Conference on Defence of democracy 3 (As/Pol/Coll/Terr (32) 8, Nov. 12-14, 1980).

38 Eur. Parl. Deb. (No. 245) 172 (September 1979).

39 R. Linke, "International Cooperation in the Fight Against Terrorism", Conference on Defence of democracy (As/Pol/Coll/Terr (32) 3). An opposite opinion is Mr. Tabone's (Doc. 4258 at 19); "Sources close to the Communities indicate that enactment of that agreement does not mean the abandonment of the Council of Europe Convention, which covers a wider geographical area and which is likely to be ratified by the majority of the EEC member States." 
Another recent example of cooperation transcending the EC framework concerns the police and intelligence field as provided by the Europol plan. This model should enable the police to cooperate across the borders of the countries involved and beyond the hitherto existing information and experiences. Thus a movement was started which caused an increasing international awareness of the risks involved in terrorism and strengthened the international cooperation with a view to its suppression. ${ }^{40}$

Moreover, it has been suggested that the Wiesbaden computer be the basis for a data bank on international terrorism; it would be available to all CE members for periodic consultation for prevention as well as apprehension during a specific terrorist assault. ${ }^{41}$

\section{Europe-Israel Cooperation}

Much of the terrorism that takes place on European territory relates in one way or another to the Israel-Arab conflict. Therefore, one may wonder why there exists no formal intergovernmental cooperation between Europe and Israel which, at least as liberal democracies, should have common interest in the suppression of terrorism. Moreover, as Israel is known to have significantly controlled terrorism, cooperation with it could at least be beneficial to European states on the tactic level of cooperation. Israel's interest in such cooperation is evident; profit from such benefits are mutual.

Nevertheless, until today, official European efforts to suppress terrorism have been restricted to the European states only or expressed through their activity within the UN.

As discussed earlier, multilateral cooperation within Europe itself in the suppression of terrorism, is rather shaky and almost nonexistent. The absence of agreement for example, between France and the Netherlands, between Belgium and France, or between the United Kingdom and the Republic of Ireland logically precludes agreement between any of the European organizations and Israel, which is not a member. Second, there are specific reasons why European organization would refuse formal cooperation with

40 G. Steinhilper, "Violence and Police" The Police and the Prevention of Crime 81 (Art Collected Studies in Criminological Research, 1979). A proposal to create a European Judicial Information Center was made as early as 1970. See Council of Europe, Council of Europe Activities in the Field of Crime Problems, (1956-1976) 20 (1977).

41 Meetings of the police are already quasi-routine. What is left is to put these discussions into practice as a standard measure. Because Interpol, by its own statute, does not have the jurisdiction to deal with international terrorism, such an alternative framework is necessary. (See Doc. 4258, pp. 8, 17). See also C. Lorieux, "Un téléphone rouge contre le terrorisme", 30 jours d'Europe. (July-August 1977) at 16; "Anti-terror Maschen enger knüpfen”, Baseler Zeitung, Aug. 13, 1978, at 1; European Working Documents, 1-588/82, Sept. 13, 1982 and Parliamentary Assembly Resolution 9423/82, Sept. 20, 1981. 
Israel, even if intra-European cooperation did develop. All along the decision-making process of the cooperative European efforts to suppress terrorism, the same argument is repeated: Europe must limit its efforts to the suppression of "indigenous" European terrorism.

It has been argued that a separate common European position within the UN might be interpreted by Third World states as a "Western bloc" against movements of national liberation and freedom fighters. This would jeopardize any remaining readiness within the UN to combat international terrorism, and would damage European credibility in that organization. European fears that such an interpretation would follow an eventual European separatist attitude have been strengthened by debates within the General Assembly of the UN. These debates resulted with the well-known Arab-sponsored Resolution 3034 entitled:

Measures to prevent international terrorism which endangers or takes innocent human lives or jeopardizes fundamental freedoms, and study of the underlying causes of those forms of terrorism and acts of violence which lie in misery, frustration, grievance and despair and which cause some people to sacrifice human lives, including their own, in an attempt to effect radical change. ${ }^{42}$

Similarly, due to the dynamics of the automatic majority in the UN, a relevant Draft Convention on terrorism that was proposed by the US (1972) was rejected. ${ }^{43}$

Consequently, efforts of the major European governments (the members of the EC) were aimed at keeping the separate efforts within the Nine confidential and, at the same time, trying to achieve some kind of compromise within the UN. The European approach to the challenge of terrorism has, therefore, been to undertake cooperation measures against terrorism that would meet specific European conditions of terrorism as distinguished from so-called non-European terrorism ${ }^{44}$, and which would be closely related to the already existing European legal framework. ${ }^{45}$

42 General Assembly Resolution 3034 (XXVIII). UN GA, A/AC. 160/1, May 16, 1973.

43 R. Lagoni, "Die Vereinten Nationen und der internationale Terrorismus", Terrorismus: Untersuchungen zur Strategie und Struktur revolutionärer Gewaltpolitik 266 (M. Funke ed. 1977).

44 The distinction between kinds of terrorism by identifying a type of "indigenous terrorism" (expressed in the Ministers of Justice meeting, May 1975), is rather misleading. A Moluccan or Arab terrorist act carried out on European soil against strangers, against Europeans on alien terrority, or just as a terrorist fugitive in Europe, is neither exclusively European nor non-European in character. It is clearly international.

45 The CE Director of Legal Affairs, for example, emphasized and assured that a) an eventual undertaking of the CE must not bypass the strictly regional level and conditions, and b) that any initiatives with international character should not conflict with UN Initiative, 1973. 
The political distinction between indigenous and non-indigenous terrorism is a useful tool to avoid the necessity of applying anti-terrorism measures in uncomfortable cases. Thus, the common interest between Israel and the European states in suppression terrorism splits apart when operationalization is considered.

Besides their similar vulnerability to terrorism as liberal democracies, and their inability to control terrorism unilaterally, terrorism binds Israel and Europe through another two specific factors. One relates to the perpetrators of terrorism - to Palestinian and Arab terrorists. The other factor concerns the target terrorism is directed at - terrorism against Israel and terrorism against Jewish objects (either on European or on Israeli territory, since cooperation is also needed in the apprehension of terrorists).

\section{Europe and Palestinian/Arab Terrorism}

In most cases involving Palestinian terrorism against Israeli objects, the European attitude has been directed by its Middle-East policy, whereby anti-terrorism policy could not be separated from its political environment. The Europe - Arab Energy (balance of power, economics, transit, etc.) Palestinian connection is well known: it is unnecessary to enter into details here. The usual European argument that a terrorism policy should be guided by political neutrality, i.e., that motives of the terrorists should not be considered and that the common crime element is overriding, does not hold in the Palestinian case.

We distinguish two directions in the European policy on Palestinian and Arab terrorism. One is related to individual political terrorism, the other to state-sponsored and state-directed terrorism.

In many cases of Palestinian terrorism, European states do not even reach the stage where the dilemma of having to consider the motivation might rise. The tactic is often that of expulsion or even deliberate ignorance of the terrorists, ${ }^{46}$ enabling them espace and avoiding the need to bring them before trial.

The Abu Daoud case (January 1977) is a prime example for successful informal intelligence cooperation. Joint efforts by Franco-Israeli intelligence and police agencies resulted in the identification and arrest of the leader of the 1972 terrorist assault in Munich. Although there were extradition requests by Germany and Israel, France preferred, through a juridical manoeuvre, to free the detained terrorist and expel him.

We are interested here only in one of the pretexts, that relating to the Israel request of extradition. It was based on the argument that Israel could not obtain Abu Daoud's extradition on the basis of the Extradition Convention

46 Infra, p. 23. 
between France and Israel of 12 November 1958, since there was a problem of reciprocity. ${ }^{47}$ Under the French Extradition Law of 10 March 1927, extradition is restricted to acts committed against nationals of the requesting state outside of its territory to acts over which France would have jurisdiction had the victims been French nationals. Although a new law of 1975 vested French courts with such jurisdiction, it was argued that it could not apply retroactively. Nevertheless, the validity of this argumentation seems rather dubious since the relevant Extradition Convention does not require reciprocity of jurisdiction. Therefore, the French authorities should have at least detained Abu Daoud until receiving the formal request for extradition or until the expiration of twenty day period.

The French move then can only be understood politically - as an action meant to secure its political-economic interests in the Arab world, disregarding its political-moral obligations towards like-minded states. ${ }^{48}$

The Entebbe raid (3-4 June 1976) could have proven to be an opportunity for Israeli-European cooperation. A number of European states were involved in different ways: through terrorists' demands to free imprisoned comrades, through nationals being held hostage, through territorial passage of the aircraft or its national registration and so on. Yet even this occasion did not evoke a drive to cooperate beyond the limited consultation during this specific event.

There existed a psychological barrier of loose confidence in the IsraeliFrench relationship. French authorities kept assuring the Israeli that they were not freeing themselves from responsibility. Yet France's appeal for UN General-Secretary's intervention in Uganda aroused Israeli doubts concerning French sincerity. Their reaction was not to inform French authorities in due time about the Israeli operation and to continue consultation with the involved "victim" governments' special ad hoc group in Paris as if nothing was going on. Germany coordinated its reaction with Israel, leaving the choice whether or not to free imprisoned terrorists as ransom, to Israeli consideration. The British joined the Israeli stand during subsequent UN debates, primarily because one of the victims was a British national (loyal to its long-practiced imperial tradition of responsibility for its nationals). ${ }^{49}$

A more recent example is the Venetian legal authorities' arrest warrant against PLO chief Yassir Arafat, issued on the basis of statements by arrested Italian terrorists, that Arafat was involved in smuggling armaments to the

47 Convention d'extradition entre la France et l'Etat d'Israel J. O. of Nov. 12, 1958, Nov. 16, 1971, at 11268-11270. Entered into force on Nov. 14, 1971.

48 See R. Tophoven, "Der internationale Terrorismus - Herausforderung und Abwehr", Terrorismus 252 (Funke, ed. 19). See also Poirier, "International Terrorism: Extradition", 18 Harv. Int'l L. J. 467-470 (1977); S. Liskofsky. "The Abu Daoud Case: Law or Politics?" 7 Israel Y. B. Hum. Rts. 66-76 (1977).

49 Ha'aretr, July 5, 1976, at 4, 9; Id. July 16, 1976, at 14. 
Red Brigades organization. The order against him was cancelled by the Italian High Court of Appeals on grounds of technical lapse, ${ }^{50}$ obviously politically motivated.

Other examples of a specific European policy on Palestinian terrorism are found on the strategic level of policy making. The strategy for a policy on Palestinian terrorism can be traced both through special arrangements achieved by European states with terrorists and in various official declaration. An absurd cooperation between West Germany and the PLO is represented by the following bargain: In return for a) a PLO promise not to carry out terrorist activity on German territory and against Germany; b) assurances against economic "countermeasures" by Arab oil-exporting countries; and c) a promise to "extradite" German terrorists, the German government has agreed to ignore Palestinian terrorists, and not hinder them, even when their activity is not exactly "peaceful".

Similar agreements seem to exist between other European states, especially France and Britain, and terrorists. At the very least, journalists claim that there exists an unwritten agreement between France and "Carlos" concerning Middle-East terrorist organizations: terrorists arrested in France are expelled under the condition of not having targeted France and not operated on its territory. ${ }^{52}$ Indeed, West European states prefer to handle Palestinian terrorism with silk gloves, and this has been true for a long time. ${ }^{53}$

A well-known "formula" of European policy on Palestinian terrorism is to welcome the well known "responsibility" policy of terrorists. Terrorists seem not to belong to major terrorist organizations, but appear as ad hoc splinter groups, issued for special operations and motivated by special events. The top organization, in our case the PLO, which apparently has divorced from the violent political method and is on the way of gaining international respect and due status, is surprised, ignorant, repulsed, and so forth, by the acts of those uncontrollable and irresponsible deviants. Of course, it cannot, therefore, take responsibility.

One of many examples backing this attitude is Kreisky's reaction to the terrorist attack on the synagogue in Vienna, 29 August 1981. Kreisky expressed his conviction that it had not been the PLO that carried it out. Moreover, Israel's hostile attitude towards the Palestinians was, for Kreisky, an explanation for this kind of terrorism (which was perpetrated against

50 Yediot Acharonot, February 5, 1984, at 2.

51 Neue Zürcher Zeitung, April 19, 1979, at 3; Ha'aretz, November 14, 1979, Poirier, at 467-470.

52 Economist, May 1, 1982 at 50-51.

53 Ha'aretz, Sept. 25, 1972, p. 2. The latest example is the terrorist piracy of the Italian ship "Achille Lauro" (October 1985). The case refers to Italy's relations with the PLO. Israel was indirectly involved, however the US which was an immediate party in this affair was confronted with a most non-cooperative Italian policy impinging on the efforts to suppress terrorism. 
Jewish Austrians, not Israeli citizens). Consequently, he found no reason to change his policy towards the Palestinians. ${ }^{54}$

In this context another practical politico-journalistic typology is worth mentioning, which establishes the distinction between moderate and radical Palestinians. ${ }^{55}$ It is obvious that moderates would not dare carry out terrorist assaults; by definition, only radicals can also be terrorists. But, unfortunately, their activity is beyond European capability of intervention, they are uncontrollable (like the splinter groups), and - in face of Arab issued politicoeconomic constraints - are more a fact that Europe must live with than combat against.

Furthermore, according to Kreisky's interpretation, there are two kinds of terrorism. One kind is terrorism à la Baader-Meinhof, Red Brigades and AbuNidal, which is their raison d'être. The other kind is "Arafats" terrorism which is one way among others, of mass action and furtherance of the national cause. Yet Arafat's terrorism in Europe, unlike Palestinian terrorism on Israeli soil, threatens to undermine European sympathies with the Palestinian cause. 56

The above-mentioned European habit of dealing with Palestinian terrorism is accompanied by numerous political declarations concerning the Palestinian issue. They strengthen the attitude of inactivity adopted by European governments. As early as 1972, the French President Pompidou claimed that without a solution for the Palestinian problem there would be no end to Palestinian terrorism. ${ }^{57}$ Although this sounds plausible, it should not be interpreted by a fatalistic specific rejection of an anti-Palestinian-terrorism policy. Yet this attitude seems to continue to prevail today, in spite of the fact that in the meantime London and Paris have become major scenes of rival Arab terrorism (not Palestinian only). ${ }^{58}$ Although Scotland Yard has warned that many of the Arab embassies have become logistic bases for terrorists and has required appropriate reaction, the government's reaction in this matter has not been decisive. Indeed, as long as the "account-settling" between Arab factors on European soil neither harms European human life or property, nor interrupts or complicates European international relations, there are no obvious reasons for a relevant European anti-terrorism policy. ${ }^{59}$

54 Ma'ariv, Aug. 30, 1981, at 5, 22; Aug. 31, 1981, at 1; Sept. 2, 1982 at 2.

55 See Curtis, Michael, "The Myth of PLO Moderation", Middle East Focus, July 1978, at $18-19$.

56 Ma'ariv, Sept. 2, 1981, at 2.

57 Ha'aretz, Sept. 22, 1972, at 2.

58 Consider the events concerning the Lybian Embassy in London, April 1984.

59 Students of terrorism should seriously face the question: is such terrorism actually "terrorism"? Does it terrify the "innocent" masses, does it shatter the foundations of the State, government, etc.? Isn't it rather not terrorist, but another kind of international political violence? This must be thoroughly checked up against the characteristic criteria 
It is important to mention in this context also the shift in Israeli image in European eyes. Under the Likud government led by Begin (1977-1984) Israel had to take a severe regression of its reputation. The Likud policy in the Occupied Territories, dictated by nationalist considerations as well as its inconsistencies in the practicing of liberal democratic principles respectively, definitely brought about the decline in Israel's moral standing in the West. This, no doubt, served as an additional reason for not engaging in close, at least not open an institutionalised cooperation in the suppression of terrorism between Europe and Israel.

A recent example of this European attitude, in spite of changes in the Israeli political structure and politics (in particular the withdrawal out of Lebanon and policy changes in the Occupied Territories) was EC's reaction to the Israeli raid in Tunis (October 1985). Palestinian terrorism which stroke shortly after indeed served immediately to reverse this attitude. Yet it rather demonstrated European indeterminacy in matters of terrorism related to the Israel-Arab conflict."

This leads us to the issue of state-sponsored terrorism. Merari argues against deliberate European ignorance of state-directed terrorism, where the "long Soviet arm" operates on European territory through surrogates terrorists sent from Arab states. ${ }^{60}$ Perhaps this European lack of response should be understood as a silent commitment of the European governments to engage in a new kind of unconventional international warfare, which serves to reduce the level of other alternative kinds of international violence (conventional and nuclear warfare). If this is the case, the phenomenon of terrorism must undergo a new evaluation. For Israel this means a new consideration of its anti-terrorism policy as well. Notwithstanding this possibility, it is clear that the issue of Europe-Israel cooperation in the suppression of terrorism must be considered in the global context and not only with regard to Palestinian terrorism. It is possible that a revision of the perception about the role of terrorism in global terms (not only bilateral or regional) in international relations is approaching. Israel like Europe, cannot evade this development.

Israeli politicians expected a change in the European attitude towards Palestinian terrorism subsequent to the multitude of revelations concerning terrorism by Arabs as well as other nationals that were found in Lebanon. Evidence of the PLO's role as USSR's surrogate, with connections with various governments (but not as a center) has not inspired any moves in the direction of formal intergovernmental cooperation between Israel and

of individual political terrorism. See also Proposition of Resolution, European Working Documents, Doc. 1-602/82, Sept. 13, 1982 calling the Council to condition any of its Middle East conflict settlement policy with the renouncement of terrorism.

60 A. Merari, "Weltweite Zusammenhänge des Terrorismus und weltweite Zusammenarbeit bei der Bekämpfung des Terrorismus”. Memo. 
European states. ${ }^{61}$ The European Parliament has sufficed with a Proposition of Resolution concerning state-sponsored terrorism on Community's and Associated States' territory, referring, among others, to "Eastern" states' connections with terrorists. ${ }^{62}$

For the meantime, the basis of Europe-Israel cooperation in matters of state-sponsored terrorism also seem to be lacking. Israel is vulnerable to such terrorism, directed by states with which she is in a state of belligerency. Europe maintains peaceful relations with the states sponsoring terrorism, trying to expand its economic relations with them (with the Soviet Union as well as with Arab states). This state of affairs commands different kinds of terrorism policy. The points of departure of Israel and Europe being thus contradictory in this respect, due cooperation should not be expected.

\section{Terrorism against Israeli / Jews in Europe}

The second factor determining prospects of official intergovernmental cooperation between Europe and Israel evolves around the target of terrorism. Are the targets Israeli or Jewish? In both cases Israel and Europe disagree regarding prevention and control of terrorism and responsability including all duties emanating from it.

When the target of terrorist attack has been Israeli, i. e., an Israeli embassy, an El-Al office, or the like, European states have preferred to handle the issue themselves, without transferring functions to Israel, and thus avoiding the necessity to extradite the terrorists. Territorial jurisdiction has been preferred over extraterritorial jurisdiction. The reasons are obvious. In most cases Palestinian terrorism has been the origin of the assaults. Procedures of control against terrorism, apprehension of terrorists, and bringing to trial have been guided by relevant international rules. ${ }^{63}$ Israeli requests to defend

61 West European reaction to the revelations of the Lebanon War on international terrorist connections has been limited to such as Italy's appeal to Israel through Interpol for information about the identity of some detainees in Lebanese Prison camps who could have been related to the Red Brigades (Ma'ariv, June 16, 1982, p. 3). Turkey (member of $\mathrm{CE}$ ) considered the possibility of requesting extradition for terrorists held by Israel in Lebanon who carried out assaults on 'Turkish territory ( $M a^{\prime}$ ariv, June 27, 1982, p. 3).

62 European Working Documents, Doc. 1-361/83, May 26, 1983.

63 Among them are the three international conventions adopted in this matter: The Vienna Convention on Diplomatic Relations (1961), stipulating the inviolability of diplomatic agents and extending the category to include the family, members of the administrative and technical staffs of the mission, members of their families, as well as diplomatic agents in transit through a third state: the Vienna Convention on Consular Relations (1963); and the New York Convention of Special Missions (1969). All three conventions reaffirm the duty incumbent upon the receiving states to provide special protection to the persons. The conventions do not renew anything, but rather resume what has already been constituted in numerous domestic, bilateral, and multilateral agreements. 
itself, i.e., to place its own guards to protect Israeli personnel, property interests, and the like are met with rejection. The reasons given are various and range from legal to political considerations. ${ }^{64}$

When the target of the terrorist assault is Jewish, disparity between Israeli and European attitudes is even greater, as it involves, in addition to legal considerations, historical reminiscences. The terrorist attack at the rue Copernic, Paris, 4 October 1980, may serve such an example. It struck sensitive nerves in the French public opinion, resulting in an expression of solidarity with the Jewish compatriots, in a demonstration of 200,000 people. Still, guilt feelings, forty years after the discrimination against and deportation of French Jews under the Vichy Regime, did not help the Paris police to apprehend the terrorist, nor perhaps did they contribute to a stronger motivation to do so. ${ }^{65}$ On the other hand, in the Israel Knesset, then-Prime Minister Begin accused the anti-Israeli attitude of the French President as creating a fertile soil for violent anti-Semitism. ${ }^{66}$

Ideologically, Israel's stand is that the affairs of the Jewish communities constitute a part of Israeli affairs. Israel perceives itself as responsible for Jewish existence everywhere around the globe. Moroever, Israeli basic law includes as its national pillar the Law of Return, postulating that every Jew in the Diaspora be perceived as a potential Israeli citizen.

In contrast, European states (probably as any other states) legally claim that assaults against their natural citizens, whatever their religious faith, are part of their internal domestic sphere, not to be penetrated and influenced by interests of any foreign state. Action against leftist or rightist elements that target Jewish objectives is the sole responsibility of the territorial state, and as such depends on its sensitivity to its Jewish citizen's interests and to terrorism, on its ideology and its historical memory.

\section{Concluding Remarks}

Finally, cooperation between Europe and Israel in the suppression of terrorism remains subject to all the range of problems that appear whenever cooperation in a delicate matter is considered. In part I, reference has been made to differences among states in terms of their vulnerability and reaction to terrorism.

The threat terrorism poses to Israel is acute. Terrorism against Israel is conducted in view of the final goal; it is directed at the annihilation of the

This is not the place to review the attitudes of the various states to the issue of legalizing existence of foreign armed elements on their territory.

65 Economist, October 25, 1980. Raymond Barre made a slip-of-the-tongue, defining three of the victims (excluding the Israeli victim) as "innocent".

66 Ma'ariv, October 14, 1980, p. 3. 
State of Israel. ${ }^{67}$ Therefore, the entire Jewish population, at least, is bound by the consensus that suppression of terrorism is vital for its survival. Although sensibility concerning the methods used with regard to the respect of human rights exists, the border separating the allowed from the forbidden is much higher than for European states. For the latter, terrorism threatens either the existence of the state in its present geopolitical form (separatists or unionist as in Ireland) or the kind of regime - liberal parliamentary democracy (as the $\mathrm{RAF}$ in Germany). In neither case is the threat directed at the physical survival of the state. This difference in the way terrorism is sensed in Europe and in Israel explains the difference in the respective attitudes towards the means used to control terrorism.

This situation raises questions as to ideological divergencies expressed through legal means. ${ }^{68}$ Does Israel fit into the concept of a state respecting human rights according to European measures? The impression is that, especially during the last few years, some European governments were not convinced that this has been the case. Fear of the potential abuse of extensive international cooperation in order to handle the problem of terrorism, and deviation from European standards has even been voiced against members of the CE. ${ }^{69}$

Recently, Israel failed to fulfill its obligation to the Red Cross Organization when exchanging Israeli prisoners of war with Palestinian terrorists. ${ }^{70}$ The circumstances of the death of two among the four terrorists who hijacked an Israeli bus and held it hostage in Gaza serves another example. ${ }^{71}$ Israel is not an outstanding example here. As a reminder, there was, for instance, the Irish claim before the European Court of Human Right concerning British inhumane and degrading treatment and torture. ${ }^{72} \mathrm{~A}$ further development in. the Israeli terrorist scene has been the unravelling of the so called "Jewish Underground" terrorist group. Israeli society has been confronted for the first time with a phenomenon close to the type of European indigenous terrorism and is until today torn between by the well-known polemic of just and unjust terrorism.

67 See the Palestinian National Covenant (November 1969) Y. Harkabi. Palestinians and Israel 49-69 (1974); and Curtis, Supra note 55.

68 Even supposing that politico-ideological barriers have been overcome, legal obstacles should be too complicated to solve, as well.

69 During the decision-making process of the ECST. See Gal-Or, Supra note 1, at 244, no. 32, concerning members' attitude towards Greece of the Colonels. Later the establishment of the military regime in Turkey evoked the same hesitations concerning European cooperation.

70 Ha'aretz, Dec. 7, 1983, p. 1.

71 Ibid., April 24, 1984, p. 1; August 28, 1985, p. 7.

72 European Court of Human Rights: Judgment in Ireland v. United Kingdom (Inhumane and Degrading Treatment and Torture), Jan. 18, 1978. 27 Int'l Legal Materials 680 (1978). 
Yet such incidents could serve as barriers to the encouragement of mutual confidence among Israel and its potential European partners in the suppression of terrorism. In the face of extensive criticism on grounds of the guarantees against persecution and the issue of political asylum as handled by the ECST, such cooperation with Israel still seems remote. Israel has no constitution guaranteeing human rights, and although it is party to the European Extradition Convention ${ }^{73}$, and has generally been faithful to liberal democratic guidelines of human and civic rights, formal cooperation with European organizations in suppression terrorism seems for the time unrealistic.

Contacts with Israel relating to the management and formation of an antiterrorist strategy remains, therefore, to the discretion of each member, to be settled on a bilateral basis. Israeli participation in a formal intergovernmental cooperation is limited to bilateral cooperation between the executive branches of the government: the cooperation between the intelligence and police in the case of Abu-Daoub is one example of this.

In fact, such cooperation is often more effective than regulated cooperation according to a severe code of rules. It leaves more freedom of manoeuvre which would be limited by the legal measures that would certainly evolve out of the process of establishing formal cooperation.

Israeli participation in nongovernmental cooperation concentrates on the kind of exchange of knowledge and opinion in specialist and academic forums, such as conferences on the subject of terrorism. Moreover, most of these conferences are international, transcend the European region, and include other members such as the USA, Canada, Japan, and Australia.

73 European Convention on Extradition. No. 24, Paris, December 13, 1957. 


\title{
Science and Politics: The Links Between Israel and the European Community
}

\author{
Gerald M. Steinberg
}

\section{Introduction}

In politics, as in economics and trade, the relationship between Israel and Europe is very uneven and asymmetric. For Europe, Israel is a small market, and liberalized trade with Israel is of little economic significance. Politically, links with Israel are awkward and often embarrassing in the context of Arab pressures and European responses.

In contrast, in the spheres of science and technology, Israel represents a real potential asset to the European Community. The flow of research and development programs between Israel and Europe is in the interest of both sides and could be mutually beneficial. While Israel is geographically small and relatively distant, Israeli scientists and engineers are disproportionately productive in both basic and applied research across a number of fields. These scientists are often ranked among the best in the world, and on a per capita basis, Israel has the largest number of individuals engaged in research and development in the world ${ }^{1}$.

From the Israeli perspective, scientific and technological cooperation and links with Europe are exceedingly important. A small state with limited resources and great ambitions, Israel is scientifically, economically, culturally, and most importantly, politically isolated from the Middle East. In addition, although politically (and geographically) isolated from Europe, scientific and technical cooperation provide a "back door" to the Community. By becoming active in European research and development activities, as well as cultural and sports programs, Israel hopes to be drawn closer to Europe, and, eventually, to be accepted within the European political and economic framework.

The full potential of Israeli-European scientific cooperation, however, has remained largely unrealized as Europe has consistently, and in some cases

1 See Scientific Research in Israel, 1982, Jerusalem, National Council for Research and Development (NCRD), 1982. 
gratuitiously rejected or even ignored Israeli capabilities. Although many of the scientific activities have a low political visibility and are relegated to the realm of "low politics", the European Community has been unwilling to accept even this low level of functional Israeli integration in Europe. Those few small joint projects which do take place are of marginal interest. As a result, even those limited ties, which do exist, are coming under greater scrutiny within Israel.

\section{The Structure of Science and Technology in Europe}

The integration of European research and development activities reflects, to a large extent, the level and limitations of political and cultural integration. The European Economic Community established a separate Directorate (DG-12) for Research, Science and Education which has the task of integration and coordination of research and development activities among the Member States. DG-12 has succeeded in establishing and funding some joint projects, but, like the rest of the EEC establishment, the scope of these activities is limited.

In addition, a number of multilateral European research and development organizations, some linked with the EEC and others outside its framework, have been created over the past thirty years. Those with membership limited to Western Europe include EURATOM, the European Space Agency (ESA), and CERN (a large particle physics complex and laboratory located in Geneva which includes some of the world's most advanced particle accelerators). Other groups, with broader membership, include the European Science Foundation (ESF), (which includes Yugoslavia), the Conference on European Molecular Biology (CEMB), and the European Division of UNESCO (including North America and Eastern Europa). Some organizations, such as CEMB, CERN, and UNESCO are formally composed of representatives of the member governments, while others, such as ESF and EMBO (European Molecular Biology Organization) are formed by unofficial groups such as the national academies of science or individual scientists.

Whether taken individually or together, these multilateral or "European" organizations are not insignificant. While the activities of Euratom and UNESCO have decreased in importance during the past decade, those of ESA and CERN are of growing significance.

Nevertheless, the preponderance of R \& D activity in Europe takes place within the context of the individual states. For France, Britain, West Germany and Italy, unilateral scientific and technological research activities in most areas are of much greater importance than the multilateral frameworks. For example, while ESA is currently involved in a number of significant projects, including Spacelab (in cooperation with the US National Aeronautics and Space Administration), the French national space effort is 
much larger, encompassing an independent launcher (Arianne) and a variety of payloads.

For many of the smaller states, such as Norway, Holland, Spain, Portugal and Greece, however, the multilateral regional (European) scientific and technical organizations and facilities are important. CERN, and the European Molecular Biology Laboratory (EMBL), for example, provide these states with access to facilities that they could not afford to duplicate independently. These groups also provide professional interactions for those scientists in narrow fields who have few colleagues in their home countries ${ }^{2}$.

\section{Israeli Science and Technology}

Science and technology occupy a central position in Israel. Research and development are of fundamental importance in Israel's economic development, in both the industrial and agricultural sectors, in Israel's defense and national security strategy, and in her cultural and intellectual life. The role of science and technology and the resources which are invested are reflected in the quality and breadth of activities in this sector, including agriculture, hydrology, astrophysics, particle physics, engineering and electronics.

Since 1976, Israeli investments in research and development have grown from $2.24 \%$ of the GNP to $2.76 \%$ in $1982 / 83$, or $\$ 600$ million, distributed approximately equally across civil and military sectors. This percentage of GNP is greater than that of the US, Japan, and all European nations, and can be compared with $1.85 \%$ for France, $2.2 \%$ for the UK, and $0.86 \%$ for Italy. Even in absolute R \& D budgets, Israeli investments in this area are comparable to those of Norway and Belgium, and far exceed those of Denmark, Portugal, Spain, and Ireland. Similarly, with over 11,000 full-time $\mathrm{R} \& \mathrm{D}$ personnel, the Israeli effort is comparable to that of Norway and far exceeds that of the smaller European states.

\section{Israeli Objectives}

Given Israel's small size and extent of research activities and needs, however, this state is dependent on collaboration with foreign partners to sustain the breadth and depth of its scientific and technological activities ${ }^{3}$. Like their colleagues in other small states such as Holland, Switzerland, Belgium, and Canada, Israeli scientists and engineers spend much of their time abroad, and invite large numbers of foreign scientists to come to Israel research labs. There are numerous international seminars, symposia, workshops, and conferences in which Israelis participate.

2 M. Carmi, The Research and Development System in Small States with a Particular Focus-on Israel, (Jerusalem, NCRD, 1979), Hebrew).

3 Id. 
To a very large extent, Israeli bilateral and multilateral research and development activities focus on the US, Canada, and Western Europe. Israeli scientists publish in journals from these areas, visit laboratories and universities in these regions, and are, in a very broad sense, part of the OECD scientific and technological network.

In the 1950s, links with Europe were strongest, as a result of both geography and the number of scientists and engineers who had emigrated from Europe. By the 1960s, the focus on Israeli scientific activity had shifted to the US, as the Americans dominated research, development, and innovation. In the past decade, however, the situation has changed again. American dominance has abated as the quality and the breadth of European scientific activities has grown. Large scale projects include Spacelab, Arianne, EMBL, and the French nuclear breeder program known as SuperPhoenix. Geographic proximity to Israel as well as the cost of travel are again proving to be important factors in Israeli international scientific activities. For the cost of sending one scientist to the US, Israel can send at least two to Europe, and annual (or even bi-annual) trips to conferences in Europe are logistically less taxing than to the US.

In addition, in a broad sense, Israeli scientific interests and resources are more closely matched with those of some of the European efforts than with the US. For example, while active in the areas of laser and particle beam research, neither Israel nor Europe is particularly interested in space-based BMD (ballistic missile defense) systems, as currently under development in the US. Similarly, while computer R \& D is of central importance, the large scale systems using VHSIC technology, which are the focus of current American research (for code breaking and other defense related applications), do not receive the highest priority in Europe and Israel.

Another factor stems from the fact that Israel is a small state, like Norway, Sweden, Holland, and in some respects, Italy. Resources for research and development activities, and in particular, for the construction of facilities, are limited. Like their European colleagues, Israeli particle physicists are dependent on access to the accelerators and other equipment at CERN.

\section{European Interest and Objectives}

Despite its small size and geopolitical isolation, Israel has the highest per capita concentration of scientists and engineers in the world ${ }^{4}$. This quantitative standing is complemented by the quality of Israeli contributions to science and technology. In fields ranging from theoretical solid-state physics and astrophysics to molecular biology, and medical technology and water management, Israeli scientists and engineers have made fundamental contributions. The Weizmann Institute of Science and the other advanced research and educational institutions in Israel are recognized as among the

4 See reference No. 1. 
best in the world. The quality of Israeli research and development potential is widely recognized in Europe. Twelve of the original 120 founders of the European Molecular Biology Organization came from Israel.

In the area of research projects, Israel also provides relatively inexpensive manpower. Until recently (and perhaps again in the light of the current Israeli recession) Israeli scientists and engineers were paid significantly less than their European colleagues.

\section{The Nature of the Relationship}

Formally, Israel has signed scientific cooperation agreements with a number of countries in Europe (including Greece) and while some are dormant, agreements with France, West Germany, and Holland have provided a framework for very active interchanges (see below).

In addition, Israel participates in many of the European regional scientific and technological organizations and structures. Israel's associate status with the EEC, for example, has led to agreements between DG-12 and Israel to promote scientific interchange. Since 1971, scientific delegations have met with representatives of DG-12 and Israeli delegations have visited EEC scientific establishments in Italy, Belgium, and Holland. In 1977, following the overall agreement between Israel and the EEC establishing Israel's acceptance as an associate member, a protocol was signed creating a framework for scientific cooperation between Israel and the EEC. Mechanisms for specific exchanges, joint research symposia, and research projects were established ${ }^{5}$.

Similarly, while Israeli efforts to join ESF and ESA have been unsuccessful, and full membership in CERN proved too costly, Israelis are active in all these groups. Finally, as full members in EMBO, CEMB, EMBL, and the European Division of UNESCO, Israel participates actively in these organizations.

The relative importance of each such relationship as well as the IsraeliEuropean relationship in research and development as a whole can be measured in terms of three types of interactions:

1. Joint seminars, conferences, symposia, and workshops;

2. The exchange of scientists, and technical experts; and

3. Joint research projects.

In general, these rank in increasing significance, particularly for small states such as Israel. Participation in international seminars and meetings requires perhaps the minimum investment and costs and benefits are relatively evenly distributed among the participants. Such seminars give the

5 Memorandum: Scientific and Technological Cooperation between Israel and the European Economic Community, (Jerusalem, NCRD, November 1983). 
participants in narrow areas of specialization professional contact and perhaps increased professional qualifications that might be lacking in any individual small country.

The exchange of scientists on the other hand, allows for the in-depth transfer of new knowledge and is potentially the more significant. A scientist who spends months or even years visiting a laboratory overseas can return to his native country with the knowledge to create a similar facility. New areas of specialization can be introduced as the result of such a visit. Similarly, a foreign visitor can introduce new knowledge while a guest in another institution.

Finally, joint research projects can, potentially, provide resources to allow undertakings that one of the partners alone would find difficult or could not support. Such resources could be financial as well as technical, and in many cases, one of the parties provides the former in exchange for the latter.

A qualitative survey of the relationship between Israel and Europe in the area of science and technology demonstrates the overwhelming importance of the bilateral agreements. Of the over one thousand scientific exchanges that took place between 1977 and 1982 only 4\% took place within the framework of the EEC, and a few more within the framework of EMBO. The overwhelming majority of such exchanges took place within the bilateral framework (40\% with France, $12 \%$ Italy, etc.). ${ }^{6}$

In addition, the bilateral framework provides support for the bulk of international scientific seminars and workshops in which Israel participates. Between 1977 and 1982, fifteen such seminars took place in conjunction with France, and seven more in other bilateral frameworks ${ }^{7}$.

Some seminars and joint research projects are, in fact funded by and take place within the larger multi-lateral frameworks. The 1977 protocol between the EEC's Directorate General for Science, Research and Development and the Israeli National Research and Development Council calls for an annual symposium or research seminar on subjects of mutual interest to take place alternately in Europe and Israel.

The agreement also called for Israeli participation in European research projects sponsored by DG-12. Until recently, this provision was dormant (although Israel had submitted a number of requests and proposals). More recently, however, two research projects were approved and funded under this framework (in the areas of agriculture and water recycling). The EEC funded $55 \%$ of the costs of this research $(\$ 120,000$ out of $\$ 220,000)$, which was undertaken entirely in Israel although with the participation of European partners. This should be compared with bilateral joint research projects with Holland (in the area of electro-chemistry, budgeted at $\$ 100,000$ per year) and

6 Information supplied by the NCRD, Jerusalem.

7 Id.

8 See reference No. 5 . 
Germany (including seventy-seven projects covering nine basic areas and budgeted at over $\$ 1,000,000)$. Furthermore, these bilateral links are expanding, and in 1984, an agreement calling for cooperative industrial research between France and Israel was signed. Thus, in the area of joint research, the ties between Israel and the European Community, as distinct from a few of the individual states, are very weak.

In 1984, Israel and the EEC negotiated a new agreement under which the EEC is to fund $70 \%$ of the costs of joint research projects. A water management workshop scheduled for December 1984 is designed to create a framework for new projects to be undertaken during 1985 and 1986. In addition, Israel was invited to participate in two large multilateral research projects dealing with tropical medicine and agriculture9. While both are welcomed by Israel, it should be noted that both projects are part of the EEC's "Developing Countries Research Program" and are not central to the scientific or technological interests of either the EEC or Israel. In general, this is part of a larger pattern in which Israel is included in marginal, noncommercial research and development (both basic and applied). Israeli applications to participate in more commercial industrial or electronic research within the framework of EEC projects such as the ESPRIT information technology project have been rejected. In addition, it should be noted that Israel is, in most cases, invited to participate in areas such as water management and agriculture, in which Israeli knowledge is outstanding and perhaps the best in the world. This had led some Israeli policy analysts to ask whether the benefits are evenly distributed. Israel, like other states, benefits most from the new knowledge that is developed or transferred in international exchanges. To the extent that the flow is largely outward, the benefits are limited.

\section{Political Aspects}

To fully understand the nature of the relationship between Israel and Europe in the areas of science and technology, the political importance and role of these links must be analyzed. For Israel, such links are conceived as a means of increasing Israeli "functional" 10 and, ultimately, political integration into Europe. Not coincidentially, political factors external to scientific activities and issues have had a fundamental influence on the nature of these activities.

In a broad sense, Israel has made a very broad attempt to participate in most European regional scientific organizations and programs, including the

9 Minutes of the Summing-up Meeting, The Commission of the EEC and the NCRD, NCRD, Jerusalem, January 1984.

10 For a detailed analysis of the functionalist theory of international integration, see D. Mitrany, A Working Peace System, (Chicago, Quadrangle Books, 1966); E. Haas, The Uniting of Europe, (Stanford University Press, 1958); and C. Pentland, International Theory and European Integration, (London: Faber and Faber, 1973), Chapters 3 and 4. 
EEC, and in particular, DG-12, the European section of UNESCO, CEMB, EMBO, EMBL, the European Space Agency (ESA), CERN, and the European Science Foundation (ESF). Most of these efforts have been of limited success. In many cases, Israel has been refused membership, despite strenuous and repeated attempts. Nevertheless, as noted above, Israeli scientists are very active in these groups through various formal as well as informal agreements. Thus, it is apparent that the formal status of Israel in these groups is not the result of any scientific or technical factor, but is fundamentally the result of political considerations.

\section{EEC}

As a result of its status as an associate member of the EEC, Israel has participated in the activities of DG-12 under the terms of protocols signed in 1974, 1977 and 1984. As noted above, these protocols called for annual conferences, scientific exchanges, and joint research projects.

Despite the protocols and the resulting activity, the relationship was clearly limited to those scientific and technical activities of low visibility and marginal economic or political significance. In general, it should be noted, DG-12 and the EEC framework is active primarily in such "low-profile" activities. In contrast, space and nuclear research, which are far more politically visible and important, are confined to specialized organizations (EURATOM, ESA, CERN, etc.) and unilateral programs. However, even within the EEC framework, Israeli participation has been confined to projects in the areas of water quality and agriculture. While important in themselves, they are far from the current focus of scientific activity either in Israel or in Europe. Thus, despite the protocols, Israel has been kept in the outlying regions of the EEC's scientific activities.

In 1982, in the wake of the Lebanese War, the earlier agreement was suspended unilaterally by the EEC. This suspension, which was part of a broader European response to the war, illustrated the degree to which science and technology, like any other area of international contact, is not immune to the ebb and flow of political tides. While Israeli scientific contacts with the EEC are limited, even this limited interaction is highly sensitive to largely political events.

\section{$C E M B, E M B O, E M B L$}

In contrast to most of the regional organizations listed above, Israel is a full member of the Conference on European Molecular Biology and its affiliated organs, the European Molecular Biology Organization and the European Molecular Biology Laboratory. At first glance, it would appear that this case presents a contrast to the others, in that Israeli membership could be seen as the result of a strength of Israeli scientists in this area. However, the history of this affiliation demonstrates the role of political factors here as well. 
EMBO was founded by 120 individual scientists in 1974 as a private (nongovernmental), professional organization, and twelve Israeli scientists were among the founding members. EMBO's original activities were limited to workshops, seminars, and scientific exchanges, funded initially by the Volkswagen Foundation. Towards the end of the five-year period during which this initial grant was available, the Israeli government, among some (but not all) other governments, contributed additional funds. for these activities.

When the initial grand expired, the scientists turned to their respective governments for financial support, and the CEMB was founded. In contrast to the EMBO, the CEMB is a formal association of governments, whose representatives set policy, fund activities, and decide on questions of membership.

During the initial discussions concerning the creation of CEMB, some states, (including France, Spain and Greece) objected to Israeli membership, and threatened to veto the application. After strenuous efforts by Israeli representatives, and by the scientists who had themselves founded EMBO and welcomed the participation of their Israeli colleagues, the by-laws were modified to allow "founding members" of EMBO such as Israel who had contributed to activities in the past to join CEMB.

At a somewhat later date, CEMB created the EMBL, and after the familiar discussion over the location of large multi-national facilities, experimental facilities were built in Heidelberg. Israel, as a member of CEMB, is also member of EMBL, and pays annual dues of $\$ 100,000$ for access to this facility. Among both government and scientific analysts, there is a general agreement that the $\$ 100,000$ for micro-biological research could be better spent in Israel. Proposals to leave the EMBL, however, have been opposed on political grounds. Israeli ties with the European governmental scientific organizations are tenuous enough, and the political importance of participation in the EMBL itself justifies the cost. Instead of leaving this organization, the Israeli National Research and Development Council is attempting to encourage greater exploitation of the EMBL by Israeli scientists.

\section{UNESCO}

In addition to the CEMB and its affiliated organizations, Israel is also a member of the "European" division of UNESCO. Although a member of UNESCO since 1949, Israel was expelled from the Asian division after the 1973 War, and applied for and was accepted in the European Division, which also includes the US, Canada, as well as Eastern Europe and the USSR.

Israel is a member and full participant in this group's five working committees, (biophysics, biomaterials, electrochemistry, systems analysis, and the chemistry of natural compounds). In addition, UNESCO has 
sponsored seminars in the areas of magneto-hydrodynamics (MHD), Solar Energy, and hydrology in Israel.

In the case of UNESCO, the political factors of interest concern the relationship between Israel and the USSR and Eastern Europe. Periodically, the UNESCO committees and working groups have held sessions in the USSR and Eastern Europe. On occasion, the USSR has resisted inviting Israeli delegates to these sessions and has fought to prevent meetings in Israel. In most cases, however, visas were eventually issued for Israeli representatives to attend meetings (e.g. a Committee on Biomaterials meeting in Leningrad in 1979). While Poles, Romanians, and East Germans attend conferences and meetings in Israel, the delegates from the USSR are usually absent.

\section{European Science Foundation}

The ESF consists of sixteen national Academies of Science representing countries in Northern, Western, and Southern Europe, including Yugoslavia and Greece. Although the charter of the ESF specifies that membership is open only to European states, in the mid-1970s, Israel applied for membership, citing the UNESCO and CEMB precedents. This effort, as well as the response, was also largely political in nature, as individual Israelis participate in ESF activities without benefit of formal affiliation. The response of the ESF members was also political, and despite the campaign waged by Israel for membership, the largely symbolic change in Israel's status was denied.

\section{CERN and ESA}

The most politically and perhaps scientifically visible activities in Europe currently take place in the areas of atomic and space research. Both areas are very expensive, and while individual states would prefer national programs, the cost of facilities has led to the creation of regional organizations in both areas.

For both scientific and political reasons, Israel has sought to join both groups. Not only would Israeli scientists like to increase their participation in the ESA, (including the possibility of launching an Israeli satellite), but the government would not object to participating in ESA meetings and placing the Israeli flag on the ESA Spacelab. In addition, contracts and facilities for ESA projects could conceivably be won by Israeli firms if Israel became a member. In both cases, however, Israel was denied membership. (In the case of CERN, the question of Israeli membership was re-opened by European members recently, but the high costs of memberships led the Israeli government to decide against resubmitting its application.) In the case of the ESA, however, recent Israeli attempts to gain membership reached an 
impasse in the wake of the 1982 Lebanese War. In the opinion of the Israelis who were involved in talks with ESA, there was a direct connection between the failure of this effort and the political consequences of the war.

\section{Conclusions}

Relative to the economic and political relationships between Israel and Europe, the scientific and technological relationship has the potential for being mutually beneficial. However, the benefits of this relationship are not fully recognized in Europe, and various frameworks to realize these benefits remain underdeveloped. In the past, the bilateral agreements have been of greatest significance overall, reflecting the limited degree to which European science and technology has expanded into a regional framework.

The relatively limited formal Israeli participation in those regional scientific organizations which do exist also demonstrates the degree to which science is inextricably linked with politics. Israeli efforts to gain formal acceptance into European scientific organizations are largely political in nature, as are the frequent rejections of these applications. As European regional research and development efforts and cooperative projects expand, and the extent and importance of competition with the US and Japan grow, the potential mutual benefits of Israeli-European scientific and technological cooperation increased. Although the framework for this cooperation has been created, it remains generally unused. 


\section{Index}

of Key Words, Names and Concepts

Abbasids, the 11

Abu Daoud Case, the 329, 337

Abu-Nidal 332

Adenauer, K. 270

AFL-CIO 54

Alawis 258

Algeria 200

Algerian War, the 14

American Culture, Values 2, 12, 13 (see also United States)

American GSP scheme, the 59

American Parameter in the Middle East 262

Anglo-French Intervention, the 258

Anti-Semitism 12, 14

Apartheid 307

Arab Boycott, the 74

Arab-Israeli Conflict, the 3, 20, 25, 26, 30, $38,256,260$

Arab League 255, 261, 288

Arab Oil Embargo, the 26, 260, 271

Arab Oil Power 36

Arab States 260 (see also Euro-Arab Dialogue; Trade Deficit betw. France and Arab States)

Arab Summit of Fez, the 26, 297, 298

Arafat-Hussein Negotiations, the 300

Arafat, Y. 38, 272, 280, 295, 298, 300, 330, 332

Argentina-Economic Sanctions 248, 277 (see also Falkland Crisis)

Ariane 340

Article 113 EEC 217, 239, 249

Article 238 EEC 217, 218

Article 224 EEC 248

Article 115 EEC 201

Article 228 EEC 240

Article 30 EEC 224

Article 36 EEC 224

Attlee, C. 35

Australia 337
Austria 75, 76, 316, 318

Avnery, U. 295

Baader-Meinhof Group 332

Balassa, B. 179

Basque Resistance, the 319

Begin, M. 21, 37, 38, 263, 273, 287, 293, 297, 333, 335

Belgium 66, 67, 76, 83, 272, 279, 288, 327, 340

Ben-Gurion, D. 35, 36, 57

Benelux 273, 280

Bevin, E. 35

Bouhelier Case 225

Brazil 50

Bresciani Case 223

Bulk Oil v Sun Oil International Case 220

Byzantinum 11

Camp David Agreement, the 20, 26, 28, $37,263,274,279,280,286$

Canada 337, 340, 341

Canary Islands, the 187

Carrington Lord 263, 294

Cayrol v Rivoira Case 224

CEMB 345

CERN 339, 347

Chad 23

Cheysson, Cl. 30, 292, 294, 298

Commonwealth, the 50

Completion of the Internal Market, the 47

Conference on European Molecular Biology 339 (see also European Molecular Biology Organization)

COREPER, the 246

Council of Europe, the 313

Craxi, B. 272

CSCE 259

Cultural Revolution-late 1960s, the 17

Cyprus 201, 202, 203, 317

Darwin, Ch. 12

Davignon Committee, the 322 
De Gaulle, Ch. 14, 36, 261, 288

Denmark $13,74,75,83,116,159,249$, $253,272,273,288,297,318,326,340$

Diversion of Trade 116

Douglas-Home Sir, A. 265

Dreyfus Affair, the 34

Druze, the 258

Eastern Europe 11, 14, 49, 52

Eban, A. 278

EEC-Israel-Commercial Agreement-1964 57

EEC-Israel-Cooperation Protocol-1977 216

EEC-Israel-Cooperation Protocol-First Protocol concerning the Financial Cooperation 216

EEC-Israel-Cooperation Protocol-Second Protocol relating to Financial Cooperation 216

EC Agreement on the Industrial Sphere, the 79

EC Aid and Cooperation Policies, the $\mathbf{1 8 5}$

EC Common Agricultural Policy, the 44, $167,170,174$

EC Common Commercial Policy, the 3, 217

EC Common External Tariff, the 74

EC Currencies, the 88

EC Members at the UN 303

EC External Relations 237

EC-Israel-Commercial Diplomacy 56

EC-Spain Agreement-1970 164

EC Treaty-Making Powers 216

Economic Sanctions against Israel, the 291

Eden, A. 36

EFTA, the 46, 171, 173, 174, 183, 186, 195, 222

Egypt 121, 123, 201 (see also Europ. position towards the Israeli-Egyptian rapprochement; US-Egypt-Israel Investment Deals)

Einstein, A. 12

EL-AL 334

Embargo on Military Shipments to Israel 291

EMBL 345

EMBO 345

Entebbe Raid, the 324,330

ERTA Case, the 216

ESPRIT Project, the 47, 344

\section{EURATOM 339}

Euro-Arab Dialogue, the 3, 22, 255, 307

European Attitude towards Terrosism, the 313

European Bank for Investments, the 75

European Civilization 2

European Convention on the Suppression of Terrosism 318, 323

European Court of Human Rights, the 336

European Court of Justice, the 220, 239

European Culture, the 11

European Industrial Space, the 48

European Molecular Biology Organization, the 339 (see also Conference on Europ. Molecul. Biology)

European Monetary System, the 48, 167

European Parliament, the 290, 323, 326, 334

European Political Cooperation 23, 258, 268, 270, 275, 303, 306

European Political Cooperation and the EEC 247

European Political Cooperation-Copenhagen Report 243, 303

European Political Cooperation-Framework, the $3,5,238,241,256,283$, 302

European Political Cooperation-Group of Correspondents 246

European Political Cooperation in the UN 303

European Political Cooperation-London Report-1981 246, 247

European Political Cooperation-Luxembourg Report-1970 242

European Position towards the IsraeliEgyptian Rapprochement 279

European Public Opinion 2

European Science Foundation, the 339, 347

European Space Agency, the 339, 347

European Strategic Programme on Information Technologies 47

Export Similarity 141

Extradition Convention between France and Israel 329

Falkland Crisis, the $16,248,277,286,287$, 292 (see also Argentina)

Fanfani, A. 272 
Fascism 15, 321

Federal Foreign Policy 236

Federalism 252

Federal State, the 233

Federations 234

Fifth Soviet Escadra, the 259

Final Solution, the 18 (see also Holocaust)

Finland 75,76

FLN, the 36

France $12,13,15,23,27,28,36,49,50$, $65,67,76,83,186,202,208,257,258$, $260,261,265,270,271,280,288,287$, $290,292,294,296,310,316,318,323$, 326, 327, 330, 339 (see also AmericanFrench Intervent.; Extradition Convention; Trade Deficit betw. France and Arab States)

France-French Policy towards the United States and PLO, the 292

France-French Revolution, the 36

Franco 14, 160, 319

Free Trade Agreement of 1975 between the EEC and Israel 29, 31 53, 58, 73, 113, 215

FTA-Additional Protocol 215

FTA-Direct Foreign Investments 121

FTA-Effects on Imports 116

FTA-Effects on Exports 114

FTA-Impact on Israeli Exports 136

Free Trade Agreement of 1972 between the EEC and Portugal 174

Freud, S. 12

GATT 161, 164, 195, 197, 222, 304 (see also Non-Discrimination Principle)

Gaza Strip, the 271, 297, 336

Generalized System of Preferences, the 196

Genscher, H. D. 288, 296

Germany $13,14,15,23,24,27,35,49$, $50,66,67,83,202,203,208,234,253$, $270,271,273,278,280,287,297,304$, $310,311,318,323,331,336,339,342$

Germany-German Social Democrats, the 27

Giscard D’Estaing, V. 268, 288

Global Mediterranean Policy, the 23, 261, 164

Golan Heights, the 271

Great Britain $12,13,23,34,35,36,58$, $65,66,83,159,184,202,208,210,248$,
$253,257,258,265,272,280,287,294$, $310,318,323,327,330,339$

Great Britain-Labour Party, the 35

Greece 4, 14, 25, 57, 76, 78, 89, 116, 159, $164,173,177,179,184,186,273,280$, $286,288,290,291,300,308,311,317$, 340,342

Group of 77, the 196, 197

GSP 200 (see also American GSP)

Guerilla-Warfare 321 (see also Terrosism)

Gulf, the 24, 25, 31, 32, 267

Habib, Ph. 280, 287

Haegeman v Belgian State Case 220

Hague Summit-1969, the 4, 242, 251

Haig, A. 290

Hallstein, W. 57

Hama Massacres, the 21

Hauptzollamt Mainz v Kupferberg Case 220

Herzl, Th. 34

Hess, M. 33

Hindu 14

Hitler, A. 11, 12, 13, 14, 17, 18, 28, 38 (see also Nazism; Holocaust)

Holocaust, the 1, 2, 3, 18, 19, 34, 38 (see also Final Solution)

Hostages in Teheran, the 292

Human Rights 319, 320

Hussein King 37, 264, 300 (see also ArafatHussein Negotiations)

Hussein, Saddam 35

Hussein, Sherif of Mecca 258

Iceland 316,318

IEA 304

IMF 151, 304

Industrial Revolution, the Third 43, 45

Institutional Capacity for Trade Management, the 52

International Fruit Company Case 221

International Trade Theory 138

Intra-European Mercantilism 46

Iran 24, 263, 311 (see also Hostages in Teheran; Khomeini; Shah of Iran)

Iraq 23, 35

Iraqi-Iranian War, the 26

Ireland $75,76,83,116,159,184,272,280$, $288,318,327,340$

Islam 14, 24, 31

Israel-Agricultural and Industrial Exports 137 
Israel's Comparative Advantage in EC Markets 178

Israel's Balance of Payments 173

Israel's Economy-Agriculture $\mathbf{7 6}$

Israeli Action in Lebanon, the 283 (see also Lebanon War)

Israeli Attitudes to America, the 2

Istaeli Demicracy 297

Israeli Foreign Currency-Liberalization 122

Israeli Investments in Research and Development 340

Israeli Manufactured Exports 62

Israeli National Research and Development Council 343

Israeli Raid in Tunis 333

Italy $15,23,66,74,75,76,83,184,186$, $258,272,287,288,316,330,339,340$, 341

Japan $24,48,49,52,65,66,67,195,337$, 340

Jarring UN Mission, the 262

Jerusalem-Reunification, the 272

Jewish Influence on Western Europe, the 12

Jewish Settlements 274

Jobert, M. 264

Jordan 28

Judaic Culture 2

Judea and Samaria 21

Kaddoumi, F. 295, 298

Kalischer Hirsch, Z. 33

Keynes, J. M. 12

Khomeini 26, 32

Kibbutzim Movement, the 78

Kissinger, H. 264, 274, 279

Knesset, the 335

Koestler, A. 11

Kreisky, B. 331

Kundera, M. 2

Latin America 186

Law of Return, the 335

League of Nations, the 257 (see also United Nations)

Lebanon 21, 22, 23, 26, 28, 36, 257, 283, 333

Lebanon War, the 21, 38, 39, 285

Lesser Developed Countries (LDCs) 50 Libya 23
Likud, the $20,28,78,286,333$

Lomé Convention, the $75,166 / 67,169$, $170,196,200,223$

Luxembourg 83, 116, 270, 272, 279, 288, 297

Luxembourg Accord, the 242

MacMahon Sir, H. 258

Maghreb, the 23, 58

Malta 145, 200, 201, 203, 317

Marx, K. 12, 33

McKloskey Document, the 295

Meir, G. 36

MFO, the 286

Mitterand, F. 19, 268, 288, 292, 294

Mixed Agreements 233

Mollet, G. 36

Morgenthau, H. 277

Moro, A. 272, 325

Morocco 24, 202, 203, 208

Moshavim Movement, the 78

Multifibre Agreement, the 54, 201, 203 (see Textile Exports to the EEC)

Munich Olympic Games-1972 319

Mutual Recognition Concept, the 310

Nasser, G. 20, 25, 36

NATO $18,24,36,171,237,280,304$

Nazism 14, 34, 35, 278, 288 (see also Third Reich; Hitler; Holocaust; Fascism; World War II; Vichy Regime)

Nazism-Equation of PLO with 38

Neo-Mercantilist Community 45

Netherlands, the $13,26,65,66,67,74,76$, $83,253,270,271,288,297,318,326$, $327,340,341,342$

New Left 316

New Zealand 76

Newly Industrialized Countries, the 52, 168, 195, 196, 200

Non-Discrimination Principle (GATT) 59, 195

North-South Relations 53

Norway $75,76,318,340,341$

Occupied Territories, the 267, 333

OECD, the $144,161,304,341$

OEEC 161

OPEC $22,26,50$

Opinion 1/78 218

Opinion 1/76 217 
Pabst \& Richarz v Hauptzollamt Oldenburg Case 221

Palestinian National Council, the 299

Palestinian Rights 19, 20, 26, 260, 271, 274, 279, 297

Palestinian Terrorism 329, 331, 333 (see also PLO)

Palestinians-Right of Self-Determination, the $4,36,271,277$

Palestinians, the 19, 25, 265

Papandreou, A. 288

Parliamentary Control of Foreign Policy 234

PASOK 273, 286

Pertini, S. 272

Pescatore, P. 252

Pinsker, L. 33

PLO 4, 14, 20, 21, 37, 38, 264, 268, 271, $272,275,278,280,281,285,286,287$, $288,289,290,291,293,294,297,298$, 308, 310, 330, 331, 333 (see also Arafat; French Policy towards U.S. and PLO; Munich Olympic Games; Nazism-Equation with PLO)

Polydor v Harlequin Case 221

Pompidou, G. 261, 265, 288, 332

Portugal 4, 28, 36, 75, 76, 78, 79, 89, 159, 173, 174, 224, 225, 340 (see also Free Trade Agreement of 1972; Second Enlargement)

Portuguese Revolution, the 27

Preferential Trade Agreement-1970 57, 74, 115

Protectionism - the Geography of 50

Proust, M. 13

Puerto Rico 76

Pym, F. 291

Racism 14, 15, 16

Reagan, R. 28, 59

Reagan's Peace Plan 297, 298, 299

Red Brigades, the 331, 332

Red Cross Organization, the 336

Renaissance 16

Revealed Comparative Advantage (Economic Theory of) 178

Rogers Plan, the 262, 263

Rogers, W. 262

Roosevelt, F. D. 160

Rote Armee Fraktion 336
Sabra and Shatila 38, 296, 297 (see also Lebanon War)

Sadat, A. 26, 37, 279, 286

San Remo Conference, the 257

Saudi Arabia 23

Scheel, W. 278

Schlüter v Hauptzollamt Lörrach Case 222

Schumann, M. 261

Science and Politics 338

Scotland Yard 332

Second Enlargement, the 4, 5, 157, 173, 195

Self-Determination 19, 34, 319 (see also Palestinians-Right of Self-Determination)

Sephardic Jews, the 20

Shah of Iran, the 32 (see also Iran)

Shamir, I. 294, 299

Shiite 26, 258

Sikh 14

Sinai, the 23

Six Day War, the 4, 20, 25, 271

Sixth American Fleet, the 259

Solemn Declaration on European Union, the 244

South Africa 66, 67, 307

South Korea 51

Soviet Union, the 12, 24, 27, 28, 34, 259, $261,265,277,290,333$

Spain 4, 12, 14, 28, 58, 74, 76, 78, 79, 83, $89,145,159,173,340$ (see also EC-Spain Agreement)

Spain-Economic Links to EEC Countries 160

Suez-1956 24, 36, 258

Sunnis 258

Supranationalism 2, 240

Sweden 76, 318, 341

Switzerland $22,65,66,67,75,76,234$, 316,340

Sykes-Picot Agreement, the 257

Syria 21, 26, 257

Technological Mercantilism 46

Tel Aviv 22

Terrorism 20, 21, 38, 313 (see also BaaderMeinhof; Europ. Attitude tow. Terrorism; Europ. Convention on Suppr. of Terrorism; Extradition Convention; $\mathrm{Pa}$ lest. Terrorism; PLO; Red Brigades; 
Rote Armee Fraktion; US Draft Convent. on Terrorism;

Terrorism - extraterritorial jurisdictional 318

Terrorism - just and unjust 320

Terrorism - legal procedures 317

Textile Exports to the EEC 206 (see also Multifibre Agreement)

Third Reich, the 279

Third World, the 328

Tindeman, L. 298

Trade Creation 183

Trade Deficit between France and the Arab States 260

Trade Diversion 180

Trade in the High-Technology Field 47

Trade Policies in Manufactures 195

Trollope, A. 13

Tunisia 201, 203, 208, 333

Turkey 23, 25, 202, 203, 208, 257, 317

Uganda 330

Unemployment 43

UNESCO 339, 342, 346

UNIFIL 281

United Nations, the 161, 246, 278, 281, 303, 328 (see also EC Members at the UN; Europ. Pol. Coop. in the UN; League of Nations)

UN General Assembly, the 306, 307, 328

UN General Assembly - the Middle East Debate 306

UN Resolution 3034 of the General Assembly 328

UN Resolutions 508 and 509 of the General Assembly 288

UN Resolution 242 of the Security Council 262, 265, 274, 278, 297

UN Secretary General, the 330

UN Voting Patterns of the Ten 309 (see also European Political Cooperation)

United States, the $12,13,25,26,27,28$, $29,48,49,59,65,66,88,121,144,161$,
195, 197, 234, 259, 261, 263, 276, 277, $280,290,292,293,310,337,340,341$

(see also American GSP, etc.; French Policy tow. the US and PLO; Israeli Attit. to US)

US Civil War, the 12

US Draft Convention on Terrorism, the 328

US-Egypt-Israel Tripartite Investment Deals 121

US General System of Preferences 121, 122

US-Israel Free Trade Agreement, the 54

US National Aeronautics and Space Administration 339

US Trade Act-1974 59

UNRWA 281

Van der Klaauw, Ch. 270

Venice Declaration, the $2,28,37,263,268$, $274,275,277,285,289,293,294,298$

Vichy Regime, the 335

Waldheim, K. 320

War of Independence 12

Weizmann Institute of Science, the 341

Welfare State, the $\mathbf{4 5}$

West Bank, the 20, 25, 26, 28, 30, 37, 271, 272, 297 (see also Occupied Territories)

Western Culture, the 24

World Bank, the 53

World War II 3, 34, 35, 160, 259, 321

World War I 34

Yalta Conference, the 259

Yaoundé Convention-1969 223

Yom Kippur War, the 26, 119, 243, 264, 269, 276

Yugoslavia 247, 339

Zionism 18, 33 




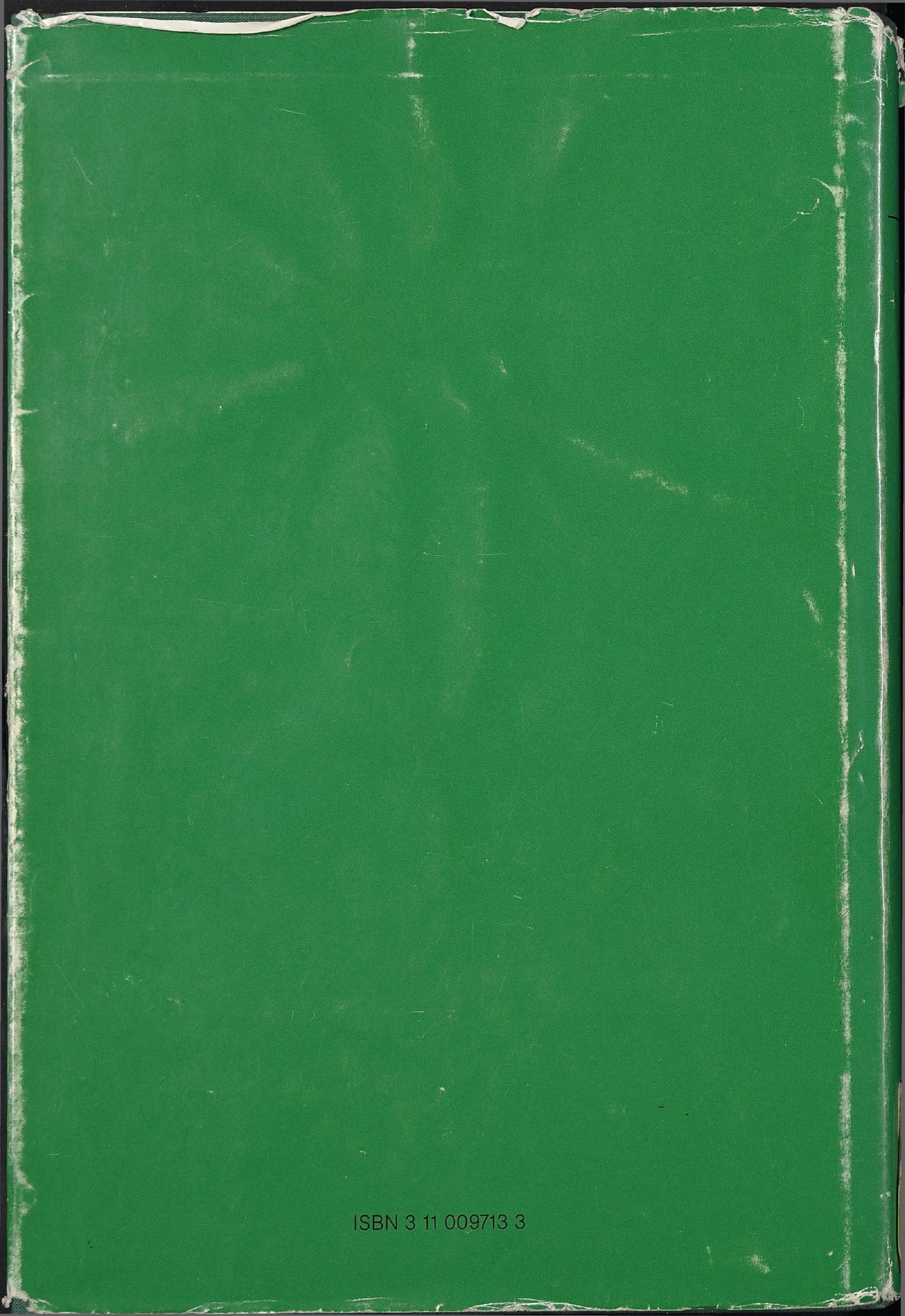


EUI

ए马

+ है

(1)

5

$\frac{\pi}{2}$

$\frac{2}{0}$

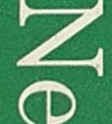

$\stackrel{0}{10}$

00

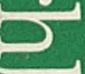

2

ह

हृ

MAG1

327

405694

\section{GRE}

